\title{
ENVIRONMENTAL POLICY
}

\section{CLIMATE CHANGE AND CONFLICT}

CAN CLIMATE CHANGE IMPACTS INCREASE CONFLICT POTENTIALS? WHAT IS THE RELEVANCE OF THIS ISSUE FOR THE INTERNATIONAL PROCESS ON CLIMATE CHANGE? 


\title{
Climate Change and Conflict
}

\author{
Can climate change impacts increase conflict \\ potentials? \\ What is the relevance of this issue for the \\ international process on climate change?
}

Contents

Introduction 1

Part I: $\quad$ Report of the „Special Event“ Climate Change and Conflict 3 Prevention on June the $12^{\text {th }}$ in Bonn by Dennis Tänzler, Alexander Carius (Adelphi Research) and Sebastian Oberthür (Ecologic)

Part II: $\quad$ Study on „Climate Change, Environmental Stress and Conflict" by Hans Günter Brauch (AFES-PRESS)

Part III: $\quad$ Study on „Climate Change and Conflict Prevention: The Relevance for the International Process on Climate Change by Sebastian Oberthür (Ecologic), Dennis Tänzler and Alexander Carius (Adelphi Research) 


\section{Imprint:}

\section{Published by:}

Federal Ministry for the Environment, Nature Conservation and Nuclear Safety

Public Relations Division, Alexanderplatz 6, 11055 Berlin

E-Mail: service@bmu.bund.de

Internet: www.bmu.de

Editor: The Federal Ministry for the Environment, Division G II 3

Part I - III of this brochure were prepared within the framework of the "Environmental Research Programme" 2001 of the Federal Ministry for the Environment, Project "Evaluation and Development of Strategic Initiatives on Environment and Security Issues" (FKZ 90119 101). The Federal Ministry for the Environment thanks Adelphi Research for its technical support.

Status: November 2002

1. Edition 500 Copies 
"As we look ahead, we can see real risks that resource depletion, especially fresh water scarcities, as well as severe forms of environmental degradation, may increase social and political tensions in unpredictable but potentially dangerous ways.

These new security challenges require us to think creatively, and to adapt our traditional approaches to better meet the needs of our new era" (Kofi A. Annan, Millenium Report 2000).

\section{Introduction}

Throughout the world we are witnessing the growing frequency of climatic anomalies such as flooding, storms, droughts or persistent forest and bush fires. They can have dramatic consequences for those affected, entailing loss of property and livelihood, famine and life threatening situations. Not least the floods in the Elbe river basin district in summer 2002, as well as those in the Russian Black Sea region, Bengal, southern China and south-east Asia, led many people to realize, even without definitive scientific proof, that there must be some truth in the theory of a man-made, measurable warming and that therefore climate protection must be given greater priority in future.

The Federal Government has accepted climate protection as the key challenge of the coming decades. Our energy supply will gradually be made viable for the future. Germany is making progress in its implementation of the necessary climate protection measures and hopes to take on a frontrunner role. But one country alone cannot protect the world's climate. In an international context, the breakthrough for the Kyoto Protocol on international climate protection was achieved at the 2001 Conferences on Climate Change held in Bonn and Marrakech. Nevertheless, this success is only a first step towards effectively combating the dangers of climate change.

In addition to the direct ecological impacts, other significant political and social consequences of climate change also take centre stage. Throughout the world the number of so-called environmental refugees is on the increase. These are people who, as a result of soil erosion, desertification, water shortages or the rise in sea level, now face such desperate living conditions that they can no longer continue in their original homes. Moreover, millions of people are fleeing temporarily from weather-related 
catastrophes such as droughts, floods and devastating storms. Their number is already estimated at 25 million per year, and given the continued population growth in the developing world - from the current 6 billion to 9.5 billion by 2050 - this figure will probably continue to rise. Environmental refugees will look for other places to live, in the mega-cities of developing countries, in the already overpopulated, still fertile areas of their own or neighbouring lands. Alternatively, they will try to reach the rich industrialised countries. This situation creates a very serious potential for conflict. In some regions and conflict situations there could even be violent clashes over habitable land and natural resources such as freshwater.

This brochure aims to shed more light on the empirical evidence and perspectives of "Climate Change and Conflicts" and thus contribute to the international and national debate on climate protection. Crisis prevention and crisis management are given top priority on the international political agenda and provide additional supportive arguments in favour of a precautionary and ambitious climate protection policy.

Part I of this brochure summarises the results of a "Special Event" on "Climate Change and Conflicts" which took place on 10 June 2002 in the framework of the UN climate protection process. It was organised by the Federal Environment Ministry in cooperation with Finland, United Kingdom and Mexico. Part II is a study by Hans Günter Brauch (AFES-PRESS) on current knowledge regarding the connections between climate change, environmental stress and conflicts, taking a detailed look the situation in the small island states, Mexico, Bangladesh, Egypt and the Mediterranean region. Finally, in Part III, Sebastian Oberthür (Ecologic), Dennis Tänzler and Alexander Carius (Adelphi Research) investigate whether there are any starting points for linking the topic of "climate change and conflicts" with the Framework Convention on Climate Change and the Kyoto Protocol 


\section{Climate Change and Conflict Prevention}

\section{Special Event at the 16th Meeting of the}

Subsidiary Bodies to the UNFCCC, Bonn, 10 June 2002

Dennis Tänzler and Alexander Carius, (Adelphi Research) Sebastian Oberthür (Ecologic)

Report on behalf of the German Federal Ministry for the Environment, Nature Conservation and Nuclear Safety

Berlin, July 17, 2002 


\section{Background}

Since the 1980s, a growing body of research has dealt with the relationship between environmental stress (environmental degradation and resource scarcity) and conflict. More specifically, evidence is mounting that the adverse effects of climate change can, particularly by interacting with a number of other socio-economic factors, contribute to an increasing potential for conflict. On the other hand, effective climate and environmental policies hold the promise to lessen such potential and serve as a tool for conflict prevention and conflict avoidance. Despite the significance of the issue, however, conflict prevention and avoidance has not yet been established as a topic in the international process on climate change.

Filling this gap and the further improvement of the issue's understanding were the objective of the side event "Climate Change and Conflict Prevention" which was held during the 16th meeting of the Subsidiaries Bodies to the United Nations Framework Convention on Climate Change (UNFCCC) in Bonn on June 10, 2002. This event was initiated by the German Federal Ministry for the Environment, Nature Conservation and Nuclear Safety (BMU) in co-operation with the Finnish Ministry for Foreign Affairs, the Mexican Ministry of Environment and Natural Resources and the Foreign and Commonwealth Office of the United Kingdom. Some 40-50 participants from various countries attended the side event and actively participated in the debate.

\section{Introduction}

As the chairman Mr. Gylvan Meira Filho (Director General from the Brazilian Ministry of the Environment) emphasised in his opening remarks, this side event offers the possibility to introduce and discuss a new issue within the climate change community. It should be assessed, he stated, whether there is an "added value" of introducing the conflict or security dimension to climate change negotiators. To this end, the event focussed on two questions. First, it should be answered whether climate change impacts are likely to increase conflict potentials. Second, it should be discussed in which way these findings affect the international process on climate change for example with respect to possible options to include this topic in the future work of the climate regime.

Dr. Karsten Sach of the German Federal Ministry for the Environment, Nature Conservation and Nuclear Safety and Ms. Anu Pärnänen-Landtman of the Finish Ministry for Foreign Affairs pointed out the added value of considering respective findings on the linkages between a changing climate and an increasing conflict potential during the international negotiations. Such consideration could increase the awareness for this specific problem among the international climate change community.

They noted that the concept of security has expanded during the last decade and that issues such as human security or collective well-being have become more and more crucial. In this context, the long lasting nature and the scope of the problem also need 
to be taken into account. Pointing to the linkage between environmental stress, scarcity of natural resources, poverty, and conflict potential Ms. Pärnänen-Landtman stressed the relevance of those areas for both the security and the sustainable development agendas. As a precondition to sustaining the environment a coherent strategy is needed. Such a strategy should both recognise the intersectoral nature of the issue of environmental security and climate change and be reflected in the institutional structures. She stressed that prevention, mitigation and rehabilitation have an obvious environmental dimension. Both speakers also emphasised the possible contribution of multilateral environmental agreements (MEAs) to conflict prevention either in terms of substance or through the negotiation processes as such. In this regard, the issues of compliance, capacity building and the involvement of the civil society are of central importance. Ms. Pärnänen-Landtman referred to an international workshop on "Environment and Security: Sustainable Development and Durable Peace" that was held in Helsinki in January 2002 and in which decision-makers from environment ministries and foreign offices of EU member states participated. At the workshop, participants concluded e.g. the following:

- The complexity of issues calls for comprehensive, coherent policy responses which should be reflected in the organisation of governments;

- Dealing with the linkage between environment and security requires the organisation of the issue area. A recent study by the NATO Committee on the Challenges of Modern Society (CCMS) includes a typology based on conflict intensity and time span of environmental degradation, complemented with e.g. the geographical dimension;

- More conceptual clarity is needed in the discussion;

- The issue of sovereignty and the related issue of failed states have become globally shared concerns;

- However, we should avoid to consider to everything in security terms, since e.g. the MEAs contribute significantly to security through their own substances and processes. By fulfilling their specific purpose, the MEAs contribute to sustainable development and thus also to security. Therefore, compliance with MEAs is crucial. This requires capacity building efforts by developed countries ultimately aiming at security and stability;

- Multi-stakeholder participation was considered as indispensable. Concrete examples of confidence-building have proven their value as catalysts for conflict prevention and wider regional co-operation through spill-over effect;

- Concrete tools must be developed taking into account the specific needs of conflict prevention (stressing the bottom-up approach), governance (better integration of MEAs), disarmament purposes as well as conflict and post conflict situations. Instead of reforming environmental institutions we better seek to improve their efficiency.;

- International response capability in environment-related conflicts must be improved: the need is obvious, ways and means have to be developed. 


\section{Scientific Findings: Pressures and Responses}

Addressing key questions on climate change, environmental stress, and conflict, Hans Günter Brauch, chairman of Peace Research and European Security Studies (AFESPRESS) presented the available scientific evidence on the linkages between climate change, environmental stress, and conflict. He focussed on six causes of Global Environmental Change that contribute to both environmental degradation (e.g. of soil and water) and scarcity (e.g. of water and food) and in turn add to environmental stress. Taking the specific global and national conditions into account, these causes may lead to several groups of outcomes: a) distress migration, b) natural hazards and disaster, c) domestic crises, and d) internal or international conflicts.

Among the six structural factors of Global Environmental Change, Mr. Brauch distinguished between primarily nature-induced factors that are reinforced by anthropogenic consumption patterns (climate change, water scarcity and soil erosion) and human-induced factors (population growth, urbanisation, food security). Based on the findings of the IPCC's Third Assessment Report (TAR) on the projected consequences of global climate change with regard to increases in temperature and sea level rise, he examined the factors' interactions with the projected population increases based on the most recent UN data.

The impact of the afore mentioned six key factors on the conflict dimension was illustrated in three case studies on the Mediterranean region, Bangladesh, and Egypt. The first case study discussed the impact of supply declines (of water and food) and an increased demand for food imports in the Middle East and North Africa (MENA) region. The analysis suggested that this region would experience a high potential for food crises in the $21^{\text {st }}$ century due to an increasing population (rising demand) and declining yield supplies. The case study on Bangladesh showed that this country has already been a primary victim of extreme weather events (cyclones, floods and droughts) that forced people to migrate. Since environmental stress will intensify due to climate change impacts, the conflict potential may also rise and might eventually lead to international tensions and regional instability. Based on the first National Communication on Climate Change of Egypt and on an integrated climate modelling, Mr. Brauch pointed to the severe consequences of sea-level rise for Egypt and in particular for agricultural yields in the Nile Delta that will also be affected negatively by temperature increases. The case study suggested that Egypt would face severe environmentally induced security challenges due to the competition for the Nile's water in the decades to come. In the light of these findings, Mr. Brauch concluded that there are alarming signals that climate change impacts and population growth in connection with several other structural factors may contribute to regional non-violent or violent conflicts. Bilateral and multilateral international co-operation to strengthen the adaptive capabilities in those regions and to launch global mitigation efforts would therefore be required.

John Pearson, former head of the Environmental Security Team in the United Kingdom's Foreign and Commonwealth Office and currently at King's College, London, focussed on the relevance of the conflict dimension for the future process on climate change. He first pointed out that the conflict dimension provides an additional rationale for implementing and strengthening mitigation efforts by industrialised countries. The possible impact of climate change on existing conflict situations may cause additional 
costs. In particular, ensuing conflicts may result in loss of life, social and economic instability and a general reduction of economic activity and international trade. Mr. Pearson added that the conflict dimension provides an additional rational for taking mitigation action in developing countries, as these states would be most affected by any instability. He stressed that climate policies can contribute to conflict prevention, for example through the promotion of domestic energy sources. This aspect of energy security is of particular importance in areas like the Middle East.

Mr. Pearson also addressed how the conflict dimension might be considered within the international process on climate change. In this regard, he emphasised the prominent role of the Intergovernmental Panel on Climate Change (IPCC) in providing the scientific basis for international climate politics and proposed that the links between climate change and conflict prevention should be addressed by the IPCC. The conflict dimension would be particularly relevant to the adaptation and vulnerability sections of the IPCC Assessment Reports. Special emphasis should be put on how climate change might exacerbate environmental stresses. Mr. Pearson pointed out that the existing literature on environment and security would already provide a sound basis for such an assessment. In addition, a special workshop on climate change and conflict prevention sponsored by the IPCC would provide the opportunity to improve understanding of the issue and to identify how the IPCC could further address and take up the issue in its work. Mr. Pearson concluded that, in a wider interpretation, the UNFCCC could be considered a security treaty, in particular from the perspective of Small Island States that are in danger of losing their territory. Moreover, climate change may have security consequences in other areas such as refugee flows, health or disaster relief. Therefore, there is a strong linkage to early warning systems. At the same time, promoting appropriate mitigation and adaptation measures (e.g. by building upon existing approaches to co-operative freshwater management and capacity building) could reduce conflict potential. Regions that are vulnerable to climate change impacts and which possess a high conflict potential could be prioritised in funding for adaptation and other relevant programmes. In addition, links to other organisations and processes could be strengthened.

\section{Discussion}

In the discussion, various aspects of the issue of "climate change and conflict prevention" were addressed, in particular the related assessment challenges; the question to what extent the international climate change community already deals sufficiently with aspects of adaptation; and the question how appropriate policy responses for this problem area could be developed and implemented.

It was stressed that there is a need to go beyond a quantitative assessment of potential conflict hot spots. To do so would imply to combine quantitative analysis on climate change impacts with case study oriented qualitative analysis. Since it is hardly possible to predict specific future conflicts, it was held that such case studies could offer important insights on the probability of certain types of conflicts and crises due to increased environmental degradation and political instability.

Furthermore, some participants highlighted the need for both mitigation and adaptation measures. Both climate policy approaches are tools for increasing conflict prevention 
capacities. The UNFCCC deals with adaptation in Articles 4.8 and 4.9 from the very beginning. In order to implement both the substance of these articles and the ultimate objective of stabilising atmospheric greenhouse gas concentrations at a level that would prevent dangerous anthropogenic interference with the climate system, comprehensive efforts would be required to enhance and improve capacities in developing countries. In this context, socio-economic development and poverty eradication were stressed as the most effective ways to increase conflict prevention capacities.

Finally, participants highlighted the importance of an enforceable legal framework within the international climate change regime to ensure that those nations most affected by climate change impacts and in need of improved coping capacities receive sufficient assistance from the international community. Establishing appropriate legal structures for technology transfer is an important issue of the international negotiations and future legal instruments could, for example, establish a compensation mechanism to provide for appropriate adaptation. It was pointed out, however, that the area of resource transfer and assistance for adaptation is ultimately primarily a matter of political will. Moreover, the involvement of private actors in relevant activities, the importance of solidarity in the international fight against climate change and in disaster relief as well as the need for further technological innovations were raised in the debate.

\section{Conclusions and Follow -up}

Both the presentations and the subsequent discussion stressed that climate change impacts will not be the single or main causes of future conflicts or crises. Nevertheless, in combination with other factors climate change impacts are likely to contribute to environmental stress and thus could become a potential cause of future conflicts. This finding suggests that in order to take appropriate policy measures, comprehensive assessment procedures are needed which should include the conflict dimension. So far, the IPCC has not dealt with the linkages between climate change impacts and the potential for conflict. However, having in mind that sufficient scientific research on this issue exists, an expert workshop on this topic could facilitate a common understanding of future climate change impacts by focusing on the conflict and crisis dimension of climate change.

In practical terms, three points were raised for a first follow-up:

- $\quad$ a documentation of this event will be prepared by the German Federal Ministry for the Environment, Nature Conservation and Nuclear Safety and will be sent to all participants;

- $\quad$ a list of participants that can be used as a first step towards further "networking" will be circulated; and

- the German Federal Ministry for the Environment, Nature Conservation and Nuclear Safety will provide each participant with a copy of two studies on the pressure and response side of "Climate Change and Conflict Prevention". 
Hans Günter Brauch

\title{
Climate Change, \\ Environmental Stress and Conflict
}

\author{
AFES-PRESS Report \\ for the
}

Federal Ministry for the Environment, Nature Conservation and Nuclear Safety 



\section{Contents}

List of Tables $\quad 13$

List of Figures $\quad 14$

List of Abbreviations $\quad 15$

Acknowledgements and Permissions $\quad 17$

Executive Summary 19

1 Long-term Societal and Political Implications of Climate Change 25

1.1 Introduction: Climate Impact Studies of the IPCC 25

1.2 Purpose: Scientific Agenda-setting of Linkages and Strategies 28

1.3 Structure of the Report 30

2 Climate Change Impacts: Results of IPCC Studies 31

2.1 Results on the Scientific Basis of Climate Change (WG I) 31

2.2 Results of WG II of the TAR on Climate Change Impacts 33

2.3 IPCC Study on Regional Impacts of Climate Change 35

2.4 Interactions Among Climate Change and Patterns of Environmental Stress:
Concept of a "Survival Hexagon"

2.5 Linkages Between Global Climate Change, Possible Conflict Constellations and $\begin{array}{ll}\text { Human, National and Global Security Issues } & 37\end{array}$

2.5.1 Linkages Between Climate Change and Water 38

2.5.2 Linkages Between Climate Change and Soil 38

2.5.3 Linkages Between Climate Change and Agriculture $\quad 39$

2.5.4 Linkages Between Climate Change and Population Growth 40

2.5.5 Linkages Between Climate Change and Urbanisation, Pollution, Human Health 43

3 Patterns of Environmental Stress 45

3.1 Environmental Vulnerabilities and Risks $\quad 46$

3.1.1 Environmental Vulnerabilities $\quad 46$

$\begin{array}{ll}\text { 3.1.2 Environmental Risks } & 47\end{array}$

3.2 Social Science Research and Considerations in International Organisations on

$\begin{array}{ll}\text { Environment and Security } & 48\end{array}$

3.2.1 Four Phases of Research $\quad 48$

3.2.2 Considerations in International Organisations 53

3.3 Environmental Stress and Outcomes: Disasters, Crises, Conflicts and their
Resolution, Prevention and Avoidance

3.3.1 Environmental Stress and Environmental Hazards and Disasters 55

3.3.2 Environmental Stress and Environmental Refugees 58

$\begin{array}{ll}\text { 3.3.3 Environmental Stress and Political Crises } & 60\end{array}$ 
3.3.4 Environmental Stress and Environmental Conflict 61

3.3.5 Environmental Conflict Prevention Through Cooperation 63

3.3.6 From Environmental Conflict Prevention to Avoidance 63

3.4 Previous IPCC-Assessments in Dealing with Outcomes 64

4 Case Studies on Impacts of Climate Change 66

4.1 Common Criteria for the Country Studies 66

4.2 Climate Change Impacts for the Small Island States 69

4.3 Projected Climate Change Impacts for Mexico 72

$\begin{array}{lll}\text { 4.3.1 Basic Facts on Mexico } & 72\end{array}$

4.3.2 Climate and GHG Emissions in Mexico 72

4.3.3 Projected Regional Climate Change Impacts in Mexico 74

4.3.4 Projected Sectoral Climate Change Impacts in Mexico 75

4.3.5 Climate Change Impacts and Environmental Stress 75

4.3.6 Urbanisation, Migration Flows and Conflict Potentials in Mexico 76

4.4 Projected Climate Change Impacts for Bangladesh 77

4.4.1 IPCC Assessments on Climate Change Impacts for Bangladesh 77

$\begin{array}{lll}\text { 4.4.2 Basic Facts on Bangladesh } & 77\end{array}$

4.4.3 Climate and Climate Change Impacts in Bangladesh 79

4.4.4 Urbanisation and Migration in Bangladesh 81

4.4.5 Prospective Climate Change Impacts: A View from Bangladesh 81

4.4.6 Environmental Stress and Conflict Potentials in Bangladesh 82

4.5 Projected Climate Change Impacts for Egypt 83

$\begin{array}{lll}\text { 4.5.1 Basic Facts on Egypt } & 83\end{array}$

4.5.2 Environmental Challenges and Climate Change Impacts in Egypt 84

$\begin{array}{ll}\text { 4.5.3 Climate Protection Activities in Egypt } & 87\end{array}$

4.5.4 Environmental Stress in Egypt 89

4.5.5 Conflict Potentials in the Nile Basin 90

4.6 Projected Climate Change Impacts for the Mediterranean 92

4.6.1 The Mediterranean: Common Ecological Space - Divided Region 92

4.6.2 The Mediterranean: Climate Change Studies and Obligations 92

4.6.3 Environmental Challenges for the Mediterranean 95

4.6.4 Environmental Stress and Conflict Potentials in the MENA 97

4.7 Conclusions: Most Likely Outcomes of Climate Change 99

5 From Conflict Prevention to Conflict Avoidance: Conceptual Suggestions 100

5.1 Need for Problem Recognition and Anticipatory Learning 100

5.2 Partnership Building to Counter Climate Change Impacts 101

$\begin{array}{ll}5.3 \text { Conflict Avoidance with Adaptation and Mitigation } & 101\end{array}$

5.4 Conflict Avoidance and the Survival Hexagon 102

$\begin{array}{ll}\text { References } & 104\end{array}$

\section{List of Tables}


Table 1.1: Assumptions in Climate Scenarios of the $21^{\text {st }}$ Century

Table 3.1: Total and Average Number of People Reported Killed and Affected by Disasters, by Country between 1981-1990, 1991-2000, and in 2001

Table 3.2: Stock of Foreign-born Population in the USA, 1970, 1980, 1990

Table 3.3: Survey of IPCC Analyses of Environmental Stress and Outcomes

Table 4.1: Impacts of Climate Change on National Security and Survival

Table 4.2: Population Growth Estimates and Projections in Million, 1950-2050

Table 4.3: Comparison of Regional Climate Change Impacts for Temperature and Precipitation

Table 4.4: Land Area and Population Data $(1995,2050)$ for Selected Small Island States and Tourists as \% of Population (1997)

Table 4.5: National Statistics of Bangladesh (1981-1995)

91

Table 4.6: Population Development of the Ten Nile Basin Countries (1950-2050)

Table 4.8: Population Growth of Germany, five Southern European EU and 12 Mediterranean Dialogue Countries (plus Libya) in million 


\section{List of Figures}

Figure 1.1: Scope of the IPCC's WG II Assessment of Climate Change Impacts 26

Figure 2.1: Global Climate of the $21^{\text {st }}$ Century: Temperature Increase 32

Figure 2.2: Global Climate of the $21^{\text {st }}$ Century: Sea Level Rise 32

Figure 2.3: Estimates of Extreme Weather Events in the $21^{\text {st }}$ Century 33

Figure 2.4: Interactions Among Climate and Other Factors of a Survival Hexagon 36

Figure 3.1: Causes and Outcomes of Environmental Stress and Potential Outcomes 45

Figure 3.2: The Roads to Conflict $\quad 50$

Figure 3.3: Costs of Catastrophic Weather Events (1950-1999) 56

Figure 3.4: Regional Insurance Coverage of Natural Disasters (1985-1999) 58

Figure 3.5: Climate Change Impacts: Pentagon of Conflict Constellations 62

Figure 4.1: Projected Changes in Temperature by Region (1990-2100) 68

Figure 4.2: Projected Changes in Precipitation by Region (1990-2100) 68

Figure 4.3: Administrative Districts and Population Density in Mexico (1990) 73

Figure 4.4: Sea Level Transgression Scenarios for Bangladesh 80

Figure 4.5: Sea-Level Rise in the Nile Delta by $50 \mathrm{~cm}$ and $1 \mathrm{~m} \quad 85$

Figure 4.6: The Nile Basin 91

Figure 4.7: Countries around the Mediterranean $\quad 92$

Figure 4.8: Summer Scenario Maps for Temperature Changes in 2080s 94

Figure 4.9: Summer Scenario Maps for Precipitation Changes 94 


\section{List of Abbreviations}

\begin{tabular}{|c|c|}
\hline AOGCMs & Atmosphere-Ocean General Circulation Model \\
\hline CAM & Central America \\
\hline CAS & Central Asia \\
\hline $\mathrm{CHT}$ & Chittagong Hill Tract \\
\hline CNA & Central North America \\
\hline $\mathrm{CO}_{2}$ & Carbon Dioxide \\
\hline EAS & Eastern Asia \\
\hline ECLAT-2 & $\begin{array}{l}\text { A Concerted Action Towards the Improved Understanding and Application of } \\
\text { Results from Climate Model Experiments in European Climate Change Im- } \\
\text { pacts Research }\end{array}$ \\
\hline ECOMAN & $\begin{array}{l}\text { Environmental Change, Consensus Building and Resource Management in the } \\
\text { Horn of Africa }\end{array}$ \\
\hline ECONILE & Environment and Cooperation in the Nile Basin \\
\hline EEAA & Egyptian Environmental Affairs Agency \\
\hline EIB & European Investment Bank \\
\hline ENA & Eastern North America \\
\hline ENCOP & Environmental Cooperation and Peace Project \\
\hline ENSO & \\
\hline $\mathrm{EU}$ & European Union \\
\hline GCM & Global Circulation Models \\
\hline GDP & Gross Domestic Product \\
\hline GECHS & Global Environmental Change and Human Security \\
\hline $\mathrm{GEF}$ & Global Environment Facility \\
\hline GHG & Greenhouse gases \\
\hline GLASS & Global Assessment of Environment and Security project \\
\hline GNP & Gross National Product \\
\hline $\begin{array}{l}\text { HABITAT } \\
\mathrm{I}=\mathrm{PAT}\end{array}$ & United Nations Conference on Human Settlements \\
\hline $\begin{array}{l}\text { I=PAI } \\
\text { IFRC }\end{array}$ & impact of population, affluence and technology \\
\hline IFRC & International Federation of Red Cross \\
\hline IHDP & International Human Development Programme \\
\hline IMF & International Monetary Fund \\
\hline IOM & International Organisation on Migration \\
\hline IPCC & Intergovernmental Panel on Climate Change \\
\hline LDCs & Least Developed Countries \\
\hline MDCs & More Developed Countries \\
\hline MED & Mediterranean \\
\hline MENA & Middle East and North Africa \\
\hline MESP & Mediterranean Environmental Security and Peace \\
\hline MÉXICO & Fist National Communication of Mexico to UNFCCC \\
\hline NAFTA & North Atlantic Free Trade Agreement \\
\hline NATO & North Atlantic Treaty Organisation \\
\hline NAU & North Australia \\
\hline NBI & Nile Basin Initiative \\
\hline
\end{tabular}




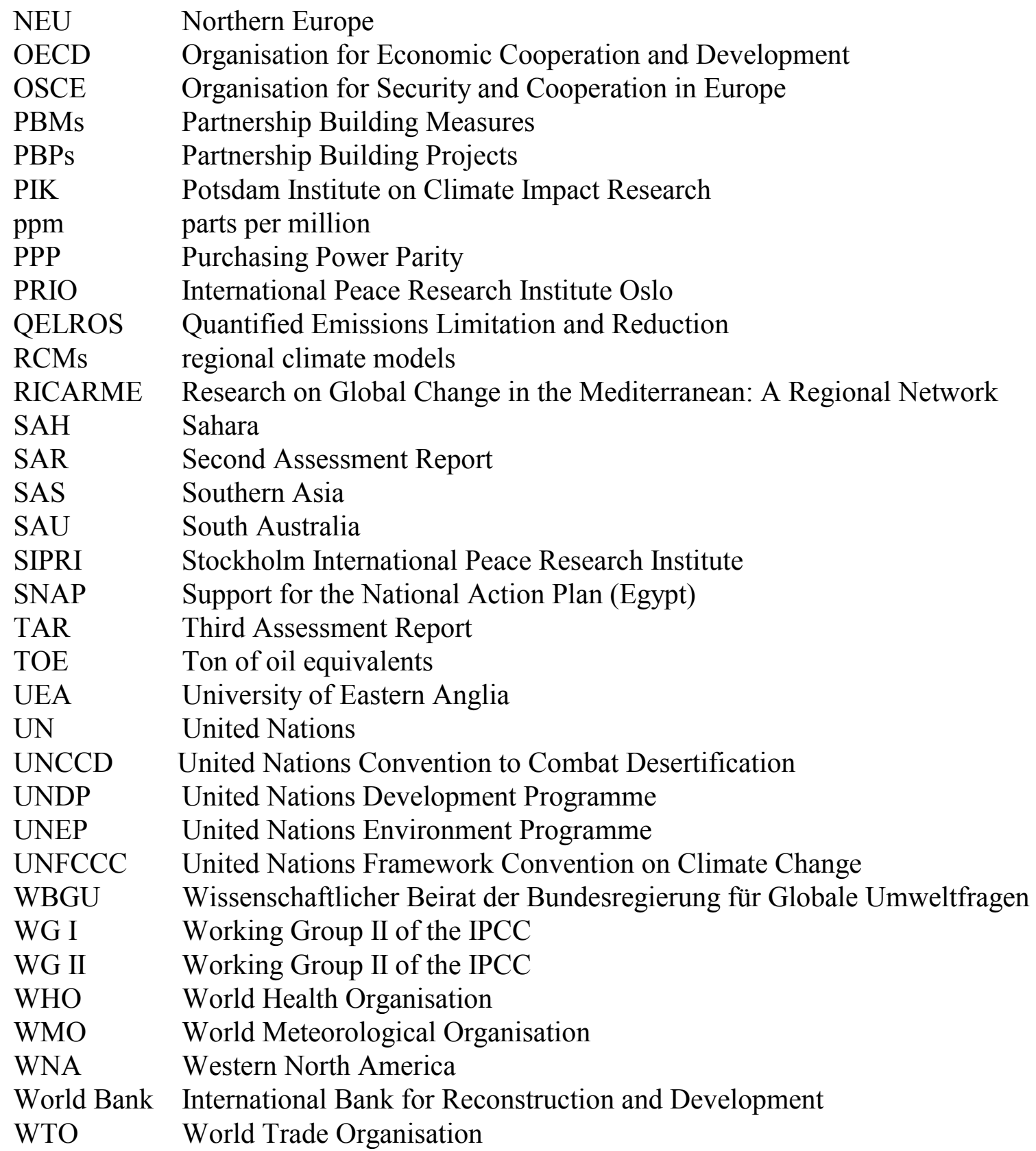




\section{Acknowledgements and Permissions}

The author is grateful for detailed comments on this report to Harald Neitzel, Federal Ministry for the Environment, Nature Conservation and Nuclear Safety, Berlin, and to his project colleagues: Alexander Carius and Dennis Tänzler, Adelphi Research, Berlin, and Sebastian Oberthür, Ecologic, Berlin for good cooperation. The author appreciates the suggestions for improving the language and the substantial comments he received from John Pearson (London).

The author is grateful for the permission to reproduce figures and quotes with the permission of the copyright-holders.

- Linda Nicol, the Permissions Controller of Cambridge University Press, on 24 May 2002 granted permission to reproduce the following figures from IPCC reports in this report in English (and for a German translation) for free distribution of the following figures:

Figure 1.1: Scope of the IPCC's WG II Assessment of Climate Change Impacts (IPCC 2001a: 22) Figure 2.1: Global Climate of the $21^{\text {st }}$ Century: Temperature Increase (IPCC 2001: 14)

Figure 2.2: Global Climate of the $21^{\text {st }}$ Century: Sea Level Rise (IPCC 2001: 14))

Figure 2.3: Estimates of Extreme Weather Events in the $21^{\text {st }}$ Century (IPCC 2001: 3

Figure 4.1: Projected Changes in Temperature by Region, 1990-2100 (IPCC 2001: 596)

Figure 4.2: Projected Changes in Precipitation by Region, 1990-2100 (IPCC 2001: 598)

Figure 4.9: Summer Scenario Maps for Temperature Changes in 2080s (IPCC 2001a: 651)

Figure 4.10: Summer Scenario Maps for Precipitation Changes (IPCC 2001a: 652)

Figure 4.11: Costs of Catastrophic Weather Events (1950-1999) (IPCC 2001: 422)

Figure 4.12: Regional Insurance Coverage of Natural Disasters (1985-1999) (IPCC 2001: 433)

Table 1.1: Assumptions in Climate Scenarios of the $21^{\text {st }}$ Century (IPCC 2001a: 27)

This table and these figures and related quotes were published in:

IPPC [Intergovernmental Panel on Climate Change], 2001: Climate Change 2001. The Scientific Basis (Cam-bridge - New York: Cambridge University Press).

IPPC [Intergovernmental Panel on Climate Change], 2001a: Climate Change 2001. Impacts, Adaptation and Vulnerability. Mitigation (Cambridge - New York: Cambridge University Press).

Figure 4.5: Sea Level Transgression Scenarios for Bangladesh (Broadus 1993: 267) from:

Broadhus, J.M. 1993: "Possible Impacts, and adjustments to sea level rise: the cases of Bangladesh and Egypt”, in: Warrick, R.A.; Barrow, E.M.; Wigley, T.M.L. (Eds.): Climate and Sea Level Change: Observations, Projections and Implications (Cambridge: Cambridge University Press): 263-275.

- Ms. R. Christ, Deputy Secretary of the IPCC, c/o World Meteorological Organization in Geneva, granted the permission on behalf of the IPCC on 28 May 2002.

- Lesley Griffin, Permissions Department, John Wiley \& Sons, on 23 May 2002 granted permission to reproduce:

Figure 3.2: The Roads to Conflict (Schwartz 2002, V: 143), and the quote published in: Schwartz, Daniel M., 2002: "The Environment and Violent Conflict", in Ted Munn (Ed.): Encyclopedia of Global Environmental Change, vol. 5, Timmerman, Peter (Ed.): Social and Economic Dimensions of Global Environmental Change (Chichester: John Wiley): 137-149.

- Dr. Kurt Fedra, Environmental Software \& Services GmbH, Kalkgewerk 1, PO Box 100, A-2352 Gumpoldskirchen, Austria, on 22 May 2002 granted the permission to reproduce:

Figure 4.7: Sea-Level Rise in the Nile Delta by 50 and $1 \mathrm{~m}$ (El Raey, Alexandria) and the quotes from: M. El-Raey: "Egypt: Coastal Zone Development and Climate Change Impact of Climate Change on Egypt", at: < http://www.ess.co.at/GAIA/CASES/EGY/impact.htm>. 
- According to the OECD copyright policies, at: http://www.oecd. org/oecd/ pages/> two figures may be reproduced free of charge and extracts totalling less than 800 words.

Figure 4.3: Administrative Districts and Population Density in Mexico, 1990 (OECD, 1998b: 38) OECD, 1998b: Environmental Performance Reviews Mexico (Paris: OECD).

Figure 4.4: $\mathrm{CO}_{2}$-Emissions by Mexico According to Sector, 1975 - 1995 (OECD 1997a: 224-225).

OECD, 1997a: $\mathrm{CO}_{2}$ Emissions from Fuel Combustion. A New Basis for Comparing Emissions of a Major Greenhouse Gas 1972 - 1995. 1997 Edition (Paris: OECD).

- AFES-PRESS, Mosbach, Germany permitted to reproduce the following figures:

Figure 2.4: Interactions Among Climate and Other Factors of a Survival Hexagon Figure 2.5: Complex Interaction: Input Factors, Political Process and Outcomes Figure 3.1: Causes and Outcomes of Environmental Stress and Potential Outcomes Figure 3.6: Climate Change Impacts: Pentagon of Conflict Constellations

All these figures were designed by the author and produced by Thomas Bast, AFES-PRESS.

The author is solely responsibility for any error in this report. The scientific assessments and opinions contained in this report are solely those of the author and do not necessarily reflect the official views of the German Federal Ministry for the Environment, Nature Conservation and Nuclear Safety, Berlin.

Mosbach, August 2002

Hans Günter Brauch 


\section{Executive Summary}

This report analyses the conflict dimension of societal and political implications of climate change in interaction with five other primarily nature-induced (soil erosion, hydrological cycle and water scarcity) and human-induced (population growth, urbanisation, agriculture and food) factors. The nature- and human-induced effects of climate change may lead to environmental degradation (e.g. of soil and agriculture) and environmental scarcity (of water and food) that may result in environmental stress. Given the specific global context and the country specific socio-economic, ethnic and religious context and the history of conflict in selected regions, environmental stress may contribute to five probable outcomes:

a) natural and manmade hazards and disasters,

b) to distress migration, internally displaced persons and environmental refugees,

c) to severe societal, economic and political crises; some of them may either escalate to

d) violent conflicts, that may be avoided by efforts for

e) conflict resolution, and prevention by the initiation of a process of de-escalation.

The report is structured in five chapters. In the introductory chapter (1) the long-term societal and political implications of climate change and the political responsibilities are outlined. Afterwards the projections of climate change and the complex interactions with other drivers of global environmental change are introduced in a concept, which is defined as a "survival hexagon". The previous work of the IPCC on the impacts of climate change on natural, economic systems and on major macro regions is summarised in the framework of this model (chapter 2). The environmental factors that contribute to environmental stress as a driver that may cause or trigger a conflict are reviewed as well as the debate on environmental security since the early 1990s (chapter 3). The potential conflictual or cooperative outcomes of environmental stress and the results of these considerations are analysed in five cases studies that focus on the small island states, on the Mediterranean region and in three country studies on Mexico, Bangladesh and Egypt. These regions and countries have been selected because they will be affected by different natural and societal impacts of climate change, e.g. by sea-level rise, increase of extreme weather events, increasing temperature and changes in precipitation that may result in both long periods of drought and irreversible desertification but also in heavy storms and flooding as well as distress migration and in-country or transboundary refugee flows (chapter 4). The final chapter 5 draws conceptual conclusions for scientific considerations and strategies aiming at both conflict prevention - to avoid an escalation of environmentally induced crises - and conflict avoidance.

Among the major results of the report are:

- Based on a systematic review of the work of working group II of the Intergovernmental Panel on Climate Change (IPCC) in its first (1990/1992), second (1995/1996) and third assessment reports (2001) on the impacts of climate change on geographic and ecological systems (e.g. coasts, wetlands etc.) and on economic sectors (e.g. agriculture, industry, insurance companies) it is stated that the conflict dimension of climate change has not yet been addressed appropriately.

- A gap was identified between the primarily natural science and economic oriented work of the IPCC and the nearly exclusive social science orientation of the environmental security debate in terms of conceptual linkages and areas of systematic cooperation. The report ad- 
dresses potential linkage points between the work of natural scientists and economists on symptoms of global environmental change and that of social scientists that have focused on the impact of environmental stress resulting from environmental degradation and scarcity on domestic and international crises that may even escalate into violent conflicts.

- After some references to the results of the scientific basis of climate change (WG I), to the results of WG II of the Third Assessment Report (TAR of 2001) on climate change impacts and to an IPCC study on Regional Impacts of Climate Change, the linkages between global climate change, possible conflict constellations and human, national and global insecurity are analysed between:

a) climate change and water,

b) climate change and soil,

c) climate change and agriculture,

d) climate change and population growth,

e) climate change and urbanisation, pollution, human health, and

f) between climate change and the possible impacts on security policy (from the global, international, to the regional, national, societal to the human level) are being analysed (chapter 2).

- The results of the intensive social science debate on the concept of environment and security and of the empirical studies on the linkages between environmental change and societal outcomes on crises or even violent conflicts are assessed with a focus on the patterns of environmental stress. It can be concluded that environmentally induced vulnerabilities and risks caused by natural processes (global environmental change) and human behaviour are considered as inappropriate within the concepts of threats and challenges that focus primarily on "hard" political and military security issues (3.1).

- The report reviews the social science research on linkages between the environmental and security areas, discusses achievements and shortcomings of available case studies, and notes ongoing projects. Furthermore, the manifold activities and initiatives by international organisations on security and environmental linkages are summarised (3.2).

- Afterwards the report reviews and assesses the linkages between environmental stress and several probable outcomes: a) natural and manmade hazards and disasters, b) distress migration and environmental refugees, and c) potential political crises. The latter are described as turning points where political action may either succeed in crises prevention or management by containing the sources of distress by fast and efficient relief operations in cooperation with international organisations and humanitarian NGOs, or fail. In case of failure different non-violent and violent conflict constellations are foreseeable at the national, bilateral and international level. Thus, an environmentally induced national crisis may gain a regional dimension that affects adjacent regions by rapidly increasing flows of distress migration.

- It is emphasised that Working Group II of the IPCC seems to have not yet assessed the socio-economic, societal and human impacts of climate change for highly vulnerable countries and regions sufficiently. Few references to "environmental refuges" may be considered as a beginning of future work of the IPCC to cover the crisis and conflict dimension of climate change as well. Furthermore, the small island states have been systematically analysed by the IPCC in a report on regional impacts of 1998 and in the TAR of 2001. 
- The country related case studies on Mexico, Bangladesh and Egypt and the regional study on the Mediterranean focus on different climate zones, eco-regions or biomes (tropical, subtropical, semi-arid and arid). They are affected by different impacts of sea-level rise, temperature increases and extreme weather events, storms, flooding, forest fires and drought. The probable consequences of the environmental impacts on the conflict dimension may affect different levels from the global, international, and regional to national, societal and to the human level (human security). The five case studies apply the same criteria and they include the most recent UN data of projections of population growth until 2050, urbanisation until 2030 and for specific cities until 2015.

- The first case study on the Small Island States in the Atlantic, Indian and Pacific Oceans and the Caribbean Sea and in the Mediterranean (Malta and Cyprus) summarises the results of the IPCC report on the specific vulnerabilities of these countries taking into account population projections until 2050 (chapter 4.2). The projected sea-level rise by the IPCC and the projected population growth by the UN Population Division offer clear early warning signals for countries that have already been severely affected by extreme weather events, e.g. Dominican Republic, Haiti and Jamaica in the Caribbean, or the Comoros, Maldives, Seychelles and Mauritius in the Indian Ocean in combination with a high population density.

- The second case study on Mexico distinguishes - based on the national communication to the UNFCCC and analyses conducted by Mexican experts - the impacts for the northern, the central and the southern region of Mexico on desertification, on the declining precipitation and the increasing demand for water due to population growth and urbanisation (chapter 4.3). Included in this analysis is the projected decline in the areas suitable for the production of maize without irrigation and on the decline in the yield of some agricultural products. It is argued that due to these projected trends and the impact of the severe weather events that have caused severe damages in Central America during the 1990s, the pressure for (trans)migration from Central America to Mexico and from there to the United States and Canada will increase in the decades to come.

- The third case study on Bangladesh focuses on one of the poorest, very densely populated countries of the world that has become the major victim (in terms of human casualties) of extreme weather events: of cyclones, floods and drought (chapter 4.4). A one metre increase in the sea-level could inundate about $17 \%$ of Bangladesh, and destroy agricultural land due to progressing intrusion of seawater (salination). Based on studies by scientists from Bangladesh and on data by the International Federation of Red Cross and Red Crescent Societies the vulnerabilities have been analysed in detail:

o During the 1980s, each year about 22.9 million, during the 1990s, about 9 million, and in 2000, close to 3 million people were affected by extreme weather events.

o Since 1960, about 600,000 persons have died in Bangladesh due to cyclones, storm surges and floods and probably around a million between 1945 and 2001. The human and economic loss for the poorest in Bangladesh has been most severe.

o There have been violent events both within Bangladesh and between emigrating Bangladeshi and tribal people in Northern India (especially in Assam) where several thousand people died. 
o In Bangladesh the struggle for survival against the impacts of global environmental change has been real for decades. Without more intensive efforts to address the causes at their roots a major human catastrophe may be possible that will not only affect the neighbouring states (India, Myanmar) but the OECD countries as well.

- Egypt is affected both by the effects of temperature increases and sea-level rises (chapter 4.5). The first will increase the evapotranspiration and the water needs of agriculture and has been projected to result in declining yields for all major agricultural food products. Thus, climate change may also intensify the process of desertification and make it irreversible in some cases. The sea-level rise in the Nile Delta will inundate some of the most fertile agricultural land and most densely populated regions. At the same time the population growth in Egypt and in the other nine riparian countries of the Nile will increase the demand for scarce water. In the framework of the Nile Basin Initiative the international community, with major support from the World Bank, has been active to avoid future water conflicts from arising. Egypt has become both a country of emigration (so far primarily to other Arab countries) but also of increasing immigration (of refugees and asylum seekers) from countries in Sub-Saharan Africa.

- Based on IPCC assessments of regional climate models, the Mediterranean region will be severely affected by both increases in temperature and in the sea level during the $21^{\text {st }}$ century (chapter 4.6). In the MENA countries and Turkey it is estimated that between 2000 and 2050 about 181 million additional persons must be fed. This is more than presently live in the five South European EU countries (Greece, Italy, France, Spain, Portugal, 2000: 177 million). The clash between declining supply of water and food and increasing demand will become extremely severe in the Maghreb and in the Mashriq countries, especially in Jordan, Israel, Palestine and Syria where the UN projects a population increase by 40 million between 2000 and 2050. The most likely outcome of the impact of climate change for Europe will be a dramatic increase of distress migration to all South European countries that will affect all EU countries.

- Catastrophic weather events have increased dramatically since 1945, especially since 1985, as have the incurred and uninsured economic damages and the resulting economic losses that have been estimated by the insurance industry from 1985 to 1999 at US\$ 707 billion (chapter 4.7). In its World Disaster Report 2001 the International Red Cross noted significant increases of the number of people that were either killed or affected by these likely impacts of global climate change. The emigration from the highly affected countries has also increased significantly, e.g. from the Caribbean states to North America.

- In the final chapter 5, the need for problem recognition and anticipatory learning is stressed, the concept of partnership building to counter climate change impacts is introduced and the concept of conflict avoidance is outlined and linked to policies and measures of adaptation and mitigation to counter the effects of climate change. Finally, the challenges identified by the six factors of the "survival hexagon" and the need for a strategy of conflict avoidance by policies of environmental cooperation on sustainable development are stressed by some general remarks.

This report summarises the linkages between climate change impacts, environmental stress and the conflict dimensions with the following hypotheses: 
a) There is no mono-causal linkage between climate change and conflicts.

b) Climate change impacts do not pose a military threat nor can they be solved with the traditional mindsets nor by the means of military services.

c) Climate change impacts - in relation with other factors - will contribute to environmental stress and thus become a potential cause of conflict constellations.

d) Climate change impacts - in relation with other factors - may challenge the survival of human beings and thus are a major challenge to human security.

e) Climate change impacts - in relation with the other factors - persuade or force human beings to leave their rural home for the next major city (urbanisation) or to take refuge in a neighbouring country or overseas.

f) Climate change impacts - in relation with the other factors - will pose severe challenges for countries that will be confronted with the most severe effects of sea level rise in delta areas but also by the complex interactions of increasing temperature and declining precipitation in arid- and semi-arid regions.

g) Climate change impacts - in relation with the other factors - may contribute to an escalation of social, ethnic or religious tension that may erupt in violent temporal riots or result in a long-lasting domestic civil strife or civil war.

h) Climate change impacts in combination with disputes on scarce resources - access to water in river basins or country-crossing aquifers - may contribute to bilateral or regional non-violent or violent conflicts.

i) Climate change impacts in combination with international environmental refugees may lead to international North-South tensions on migration issues on the admission of refugees in neighbouring or in industrialised countries and on the domestic treatment of immigrant communities.

j) The mitigation of challenges posed by the impact of climate change requires bilateral or multilateral international cooperation, support for adaptive capabilities and a massive technology transfer.

The main thesis of this study is that cooperative climate mitigation strategies are needed that must be linked with policies to assist those countries that will be affected most by these effects. This requires policies that contain the manifold causes of insecurity and instability and that aim at a regional peace based on equity and strategies of sustainable development that may also be associated with the concept of a "sustainable peace". These policies should assist these countries to adapt to and to cope with these projected effects of extreme weather events and long-term climate change impacts. 



\section{Long-term Implications of Climate Change}

\subsection{Introduction: Climate Impact Studies of the IPCC}

The analysis of impacts of climate change has been a major focus of the Intergovernmental Panel on Climate Change (IPCC), of the national communications to the Secretariat of the United Nations Framework Convention on Climate Change (UNFCCC), of many scientific analyses and of a new segment of interdisciplinary scientific analysis as pursued, e.g. by the Potsdam Institute on Climate Impact Research (PIK). The IPCC was established by UNEP and WMO in 1988 to assess the scientific, technical and socio-economic information relevant for the understanding of human induced climate change, its potential impacts and options for mitigation and adaptation. The IPCC has three working groups and a task force that deal with: I: The Science of Climate Change; II: Impacts, Adaptation and Vulnerability; III: Mitigation of Climate Change; and a Task Force on Greenhouse Gas Inventories.

The major activity of the IPCC is to prepare, approximately every 5 years, a comprehensive and up-to-date assessment of the policy-relevant peer-reviewed scientific, technical and socio-economic dimensions of climate change. The first assessment was completed in 1990, the Second Assessment Report (SAR) in 1995/96, and the three Working Groups contributions to the Third Assessment Report have been accepted by the IPCC in April 2001 and the Synthesis report in September 2001 (IPCC 1990, 1995, 2001). ${ }^{1}$

Climate change impacts, adaptation and vulnerability have been analysed by the second IPCC working group (1990; 1996a; 2001a: 21) whose mandate is "to assess the vulnerability of ecological systems, socio-economic sectors, and human health to climate change, positive and negative, on these systems. This assessment also examines the feasibility to adaptation to enhance the positive effects of climate change and ameliorate negative effects." According to the Third Assessment Report (TAR) of the IPCC:

Impacts can be expected in ocean circulation; sea level; the water cycle; carbon and nutrient cycles; air quality; the productivity and structure of natural ecosystems; the productivity of agricultural, grazing, and timber lands; and the geographic distribution, behaviour, abundance, and survival of plant and animal species, including vectors and hosts of human disease. Changes in these systems in response to climate change, as well as direct effects of climate change on humans, would affect human welfare, positively or negatively (IPCC 2001a: 21).

The TAR noted that the economic sector, especially human welfare, would be affected:

by changes in supplies of and demands for water, food energy, and other tangible goods that are derived from these systems; changes in opportunities for non-consumptive uses of the environment for recreation and tourism; changes in non-use values of the environment such as cultural and preservation values, changes in income; changes in loss of property and lives from extreme climate phenomena; and changes in human health. Climate change impacts will affect the prospects for sustainable development in different parts of the world and may further widen existing inequalities. Impacts will vary in distribution across people, places, and times, raising very important questions of equity (IPCC 2001a: 21).

The IPCC also distinguishes between sensitivity ("the degree to which a system is affected ... by climate-related stimuli"), adaptive capacity ("ability of a system to adjust

\footnotetext{
${ }^{1}$ This text is based on: <http://www.ipcc.ch/activity/act.htm>.
} 
to climate change") and vulnerability ("the degree to which a system is susceptible to, or unable to cope with, adverse effects of climate change, including climate variability and extremes"). The IPCC (2001a: 22) also refers to possible impacts ("that threaten substantial and irreversible damage to or loss of some systems within the next century"), modest impacts ("to which systems may readily adapt" and impacts that would be beneficial for some systems. The WG II's TAR examines "climate change impacts, adaptations and vulnerabilities of systems and regions and to provide a global synthesis of cross-system and cross-regional issues" and to the extent possible "in the context of sustainable development and equity". The WG II's TAR is based on an "interdisciplinary process that combines, interprets, and communicates knowledge from diverse scientific disciplines from the natural to the social sciences to investigate and to understand causal relationships within and between complicated systems". WG II's TAR admits that progress has been made primarily with regard to mitigation strategies but less with regard to the assessment of vulnerabilities (IPCC 2001a: 25).

Figure 1.1: Scope of the IPCC's WG II Assessment of Climate Change Impacts (IPCC 2001a: 22)

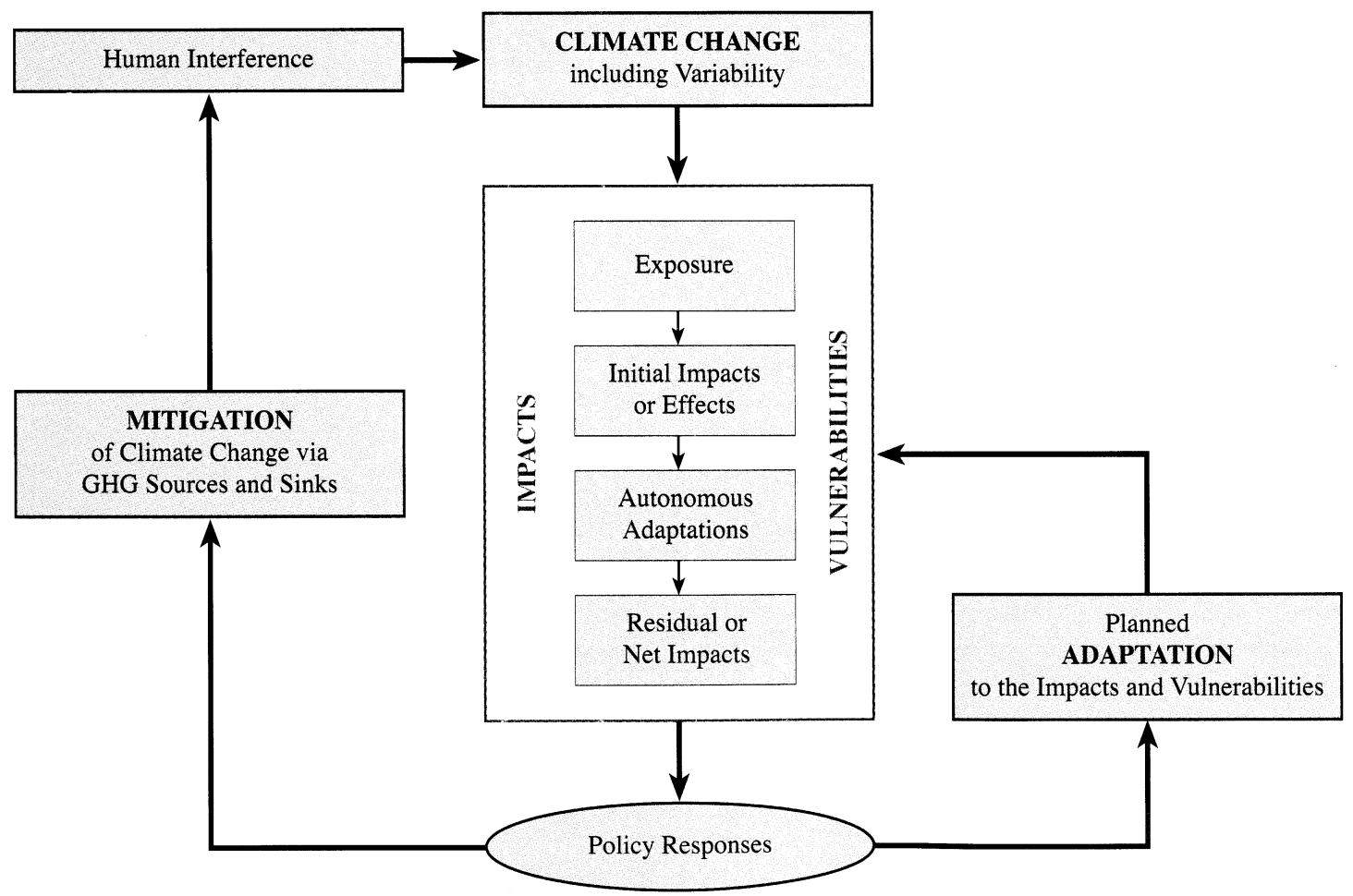

The analysis of the climate change impacts (sensitivity, adaptive capacity and vulnerability) during the $21^{\text {st }}$ century are based on several scenarios for the years 1990 and 2100 that include a range of socio-economic assumptions. The WG's II TAR analysed in detail the projected impacts of the different climate change scenarios on hydrology and water resources, on ecosystems, on coastal zones and marine ecosystems, on human settlements, energy and industry, on the insurance and other financial services as well as on human health both at the global and eight regional levels for the five continents as well as for the polar regions and for the small island states. In its assumptions, the WG II includes as input factors: population and economic factors (GDP per capita income) and three output factors: $\mathrm{CO}_{2}$ concentration in the atmosphere, global temperature change and global sea-level rise (table 1.1). 
Table 1.1: Assumptions in Climate Scenarios of the $21^{\text {st }}$ Century (IPCC 2001a: 27)

\begin{tabular}{|l|c|c|c|c|c|c|c|}
\hline Date & $\begin{array}{c}\text { Population } \\
\text { (in billion) }\end{array}$ & $\begin{array}{c}\text { Global } \\
\text { GDP } \\
\left(10^{12}\right. \\
\text { US\$/a) }\end{array}$ & $\begin{array}{c}\text { Per capita } \\
\text { income } \\
\text { ratio }\end{array}$ & $\begin{array}{c}\text { Ground le- } \\
\text { vel } \mathrm{O}_{3} \text { con- } \\
\text { centration }\end{array}$ & $\begin{array}{c}\mathrm{CO}_{2} \text { con- } \\
\text { centration } \\
(\mathrm{ppm})\end{array}$ & $\begin{array}{c}\text { Global } \\
\text { tem- } \\
\text { perature } \\
\text { change } \\
\left({ }^{\circ} \mathrm{C}\right)\end{array}$ & $\begin{array}{c}\text { Global } \\
\text { sea-level } \\
\text { rise }(\mathrm{cm})\end{array}$ \\
\hline 1990 & 5.3 & 21 & 16.1 & - & 354 & 0 & 0 \\
\hline 2000 & $6.1-6.2$ & $25-28$ & $\begin{array}{c}12.3- \\
14.2\end{array}$ & 40 & 367 & 0.2 & 2 \\
\hline 2050 & $8.4-11.3$ & $59-187$ & $2.4-8.2$ & 60 & $463-623$ & $0.8-2.6$ & $5-32$ \\
\hline 2100 & $7.0-15.1$ & $197-550$ & $1.4-6.3$ & 70 & $478-1009$ & $1.4-5.8$ & $9-88$ \\
\hline
\end{tabular}

In 1998, the IPCC released a special report on The Regional Impacts of Climate Change: An Assessment of Vulnerability that explores potential consequences of climate change for ten continental - or macro regions based on "assessing sensitivities and vulnerabilities of each region, rather than attempting to provide quantitative predictions of the impacts of climate change", i.e. to assess "the extent to which climate change may damage or harm a system" taking into account the sensitivity of the region to climate and the adaptive ability. The report tries to explain:

how projected changes in climate could interact with other environmental changes (e.g. biodiversity loss, land degradation, stratospheric ozone depletion, and degradation of water resources) and social trends (e.g. population growth, economic development and technological progress) (IPCC 1998: ix).

The special IPCC report calls for additional research "into the interlinkages among environmental issues", and it notes that climate change represents an:

important additional stress on those systems already affected by increasing resource demands, unsustainable management practices, and pollution, which in many cases may be equal to or greater than those of climate change. These stresses will interact in different ways across regions but can be expected to reduce the ability of some environmental systems to provide, on a sustained basis, key goods and services needed for successful economic and social development, including adequate food, clean air and water, energy, safe shelter, low levels of disease, and employment opportunities (IPCC 1998: 3).

It assessed the vulnerability of natural and social systems of major regions to climate change with primarily qualitative methods rather than "assessing quantitatively the expected impacts of climate change". The IPCC cautions on the status of our knowledge:

The estimates are best interpreted as illustrative of the potential character and approximate magnitudes of impacts that may result from specific scenarios of climate change. They serve as indicators of sensitivities and possible vulnerabilities. ... They are not predictions that climate will change by specific magnitudes in particular countries or regions (IPCC 1998: 4).

These regional assessments focus on: a) ecosystems, b) hydrology and water resources, c) food and fibre production, d) coastal systems, human settlements, human health, and other sectors or systems including the climate system of relevance for the 10 regions analysed. The report suggests an "anticipatory adaptation in the context of current policies and conditions" and so-called "win-win" or "no-regrets" options that would have positive effects, even without climate change impacts. The report suggests: 
Adaptation and better incorporation of the long-term environmental consequences of resource use can be brought about through a range of approaches, including strengthening legal and institutional frameworks, removing pre-existing market distortions ..., correcting market failures ..., and promoting public participation and education. These types of actions would adjust resource-use patterns to current environmental conditions and better prepare systems for potential future changes. The challenge is to identify opportunities that facilitate sustainable development by making use of existing technologies and developing policies that make climate-sensitive sectors resilient to today's climate variability. This strategy will require many regions of the world to have more access to appropriate technologies, information, and adequate financing. In addition, the regional assessments suggest that adaptation will require anticipation and planning; failure to prepare systems for projected changes in climate means, variability, and extremes could lead to capital-intensive development or infrastructure or technologies that are ill-suited to future conditions, as well as missed opportunities to lower the costs of adaptation. Additional analysis of current vulnerability to today's climate fluctuations and existing coping mechanisms is needed and will offer lessons for the design of effective options for adapting future changes in climate (IPCC 1998: 8).

So far the conflict dimension of environmental stress due to the impacts of climate change on human insecurity and survival has not yet been addressed by the IPCC appropriately. In its future endeavours, the IPCC may consider to include the need for political mitigation and adaptation strategies to cope with these socio-political impacts.

These issues have been analysed since the early 1990s in the social sciences in research focusing on linkages between environmental causes and socio-economic and political outcomes that may result in man-made disasters, severe domestic crises or conflict constellations that may either be prevented from breaking out or escalating, or avoided by addressing i.a. its longer-term environmental root causes by multilateral policies of sustainable co-development.

This body of research - primarily conducted by environmental, peace, security specialists in the North - on environmental "refugees", "security" and "conflicts" has not yet been assessed by the IPCC while most social science analyses focused primarily on the demand (poverty and consumption) driven "environmental scarcity" (primarily human induced) and less on the supply driven factors of "environmental degradation" (both anthropogenic and nature-induced).

\subsection{Purpose: Scientific Agenda-setting of Linkages and Strategies}

The purpose of this report is a twofold agenda-setting addressing two communities:

- the scientific community: to focus at the socio-economic and political impacts of climate change (in relation with other related input factors) that may be conducive to environmental stress and that may result in several types of probable outcomes: manmade disasters, distress migration, crises and conflicts; and

- the international political community: to recognise the long-term potential root causes for human catastrophes, domestic instability, conflicts and to aim at longer-term cooperative multilateral and national strategies to address these challenges by strategies of conflict avoidance by cooperative sustainable co-development.

Within the scientific community at this early stage of analysing linkages between the results of natural science research on the symptoms of global change (both in the geosphere and in the biosphere) and social science research on conflictual human outcomes statements on causation patterns are not yet possible. A major international inter- and 
multidisciplinary analysis involving researchers from North and South is needed with a plurality of scientific approaches combining both inductive national and regional case studies on past experience and future-oriented integrative modelling. In addition to the global climate modelling approach of the IPCC, a regional and nationally focused environmental, socio-economic and political approach to climate change impacts is needed to develop solid integrated interdisciplinary knowledge.

In the political realm, several international organisations (UN, EU, OECD, World Bank, EIB, GEF), programmes (UNDP, UNEP) and regimes (UNFCCC, UNCCD etc.) have translated scientific knowledge into political declarations, action plans and political strategies. International organisations and national governments have done a lot of work on climate change, but this has mainly focused on science, with little consideration of the link to security or conflict. On climate change, the IPCC has become the major international epistemic community and translator of sound scientific knowledge into political action. It may be worthwhile for the IPCC to consider whether the results of the social science research - including the work of the Global Environmental Change and Human Security (GECHS) project conducted in the framework of the International Human Dimensions of Global Change Program (IHDP) - might be included in its scientific agenda for the fourth assessment report. This social science research has dealt with the:

- linkages between environmental degradation and scarcity (input factors),

- the impact of both on environmental stress that will produce - in interaction with specific socio-economic factors for different national, regional and global economic and political contexts - certain types of conflictual and cooperative outcomes;

- the impact of environmental stress on manmade hazards, internal displacements and distress migration, on domestic instability and crises situations that may escalate to violent domestic conflicts and international wars.

The goal of this dual scientific and political agenda setting its three-fold:

- to contribute to an early recognition of potential root causes for conflict constellations, e.g. by addressing these issues in the curricula of the most affected countries;

- to stimulate scientific research and conceptual thinking on strategies for environmental conflict avoidance that address the structural drivers of global environmental change that may be conducive to conflictual constellations;

- to motivate national and international co-operative action to contain and counter the root causes by sustainable energy, transportation and agricultural policies, by cooperative efforts focusing on reproductive health and sustainable urbanisation, especially in developing countries.

This approach differs from social science approaches focusing on political efforts of conflict prevention relying on short-term early warning indicators. ${ }^{2}$ Instead, this report addresses both longer-term causes of nature-induced global and regional environmental change that contribute to environmental degradation and primarily human induced factors that contribute to environmental scarcity. Both contribute to environmental stress that could become one crucial driver of conflict. To avoid conflicts these causes must be addressed by both researchers and national and international policy makers. ${ }^{3}$

\footnotetext{
${ }^{2}$ For a survey of the comprehensive literature on conflict prevention see Lund 2003 (forthcoming).

${ }^{3}$ Many concepts referred to above have been developed and documented in Brauch 2003 (forthcoming).
} 


\subsection{Structure of the Report}

This report is structured in five chapters that focus on:

- The causes of climate change and on the complex interactions of climate change with other drivers of global environmental change that will be introduced in a model of a survival hexagon (chapter 2, figure 2.4);

- The environmental factors that contribute to environmental stress as a driver that may cause or trigger a conflict (chapter 3);

- Potential conflictual or cooperative outcomes of environmental stress and discussion of the results of these considerations for five cases studies (chapter 4);

- Draw conceptual conclusions for scientific considerations and strategies aiming at conflict prevention (chapter 5). 


\section{Climate Change Impacts: Results of IPCC Studies}

The IPCC Working Group I (WG I) is to assess available information on the science of climate change, in particular arising from human activities. WG I is concerned with: a) developments in the scientific understanding of past and present climate, of climate variability, of climate predictability and of climate change including feedbacks from climate impacts; b) progress in the modelling and projection of global and regional climate and sea level change; c) observations of climate, including past climates, and assessment of trends and anomalies; and d) gaps and uncertainties in current knowledge. ${ }^{4}$

\subsection{Results on the Scientific Basis of Climate Change (WG I)}

Its first report (1990) served as the basis for negotiating the UNFCC. The Second Assessment Report (SAR) of 1995 (IPCC 1996) included technical issues on economic aspects of climate change. WG I covered the state of knowledge on the physical climate system, the factors that drive climate change, analyses of past climate and projections of future climate change, and the role of human influence on recent climate. In January 2001 WG I accepted the "Scientific Basis" of climate change of the Third Assessment Report (TAR) that concluded "the global average surface temperature has increased over the $20^{\text {th }}$ century by about $0.6^{\circ} \mathrm{C}$. . This value is about $0.14^{\circ} \mathrm{C}$ larger than estimated by the SAR." The TAR further found that the temperatures have risen during the past four decades in the lowest $8 \mathrm{~km}$ of the atmosphere, the snow cover and ice have decreased by $10 \%$ since the 1960 s, the global average sea level has risen by 0.1 and 0.2 metres during the $20^{\text {th }}$ century and ocean heat content has increased. With regard to drought the IPCC (2001: 4-5) noted that from 1900 to 1995:

There were relatively small increases in global land areas experiencing severe drought or severe wetness. In many regions, these changes are dominated by inter-decadal and multidecadal climate variability, such as the shift of ENSO towards more warm events. In some regions, such as parts of Asia and Africa, the frequency and intensity of droughts have been observed to increase in recent decades.

The IPCC (2001: 7) noted that emissions of greenhouse gases have increased due to human activity, e.g. for $\mathrm{CO}_{2}$ by $31 \%$ since 1970 which was unprecedented during at least the past 20,000 years. While the SAR saw a "discernible human influence on global climate", the TAR found that "there is new and stronger evidence that most of the warming observed over the last 50 years is attributable to human activities". With regard to the $21^{\text {st }}$ century, the IPCC, based on its Special Report on Emission Scenarios (IPCC 2000) noted that "human influence will continue to change atmospheric composition" and that "emissions of $\mathrm{CO}_{2}$ due to fossil fuel burning are virtually certain to be the dominant influence on the trends in atmospheric $\mathrm{CO}_{2}$ concentration."

In its projections from 1990-2100, the IPCC (2001: 13) stated:

- The globally averaged surface temperature is projected to increase by 1.4 to $5.8^{\circ} \mathrm{C}$ over the period 1990 to 2100 . The results are for the full range of 35 SRES scenarios, based on a number of climate models.

- Temperature increases are projected to be greater than those of the SAR, which were about 1.0 to $3.5^{\circ} \mathrm{C}$ based on six IS 92 scenarios.

\footnotetext{
${ }^{4}$ This text is based on the website of the IPCC, at: $<$ http://www.ipcc.ch/activity/act.htm>.
} 
- The projected rate of warming is much larger than the observed changes during the $20^{\text {th }}$ century and is very likely to be without precedent during at least the last 10.000 years, based on palaeoclimate data. ...

Figure 2.1: Global Climate of the $21^{\text {st }}$ Century: Temperature Increase (IPCC 2001: 14)

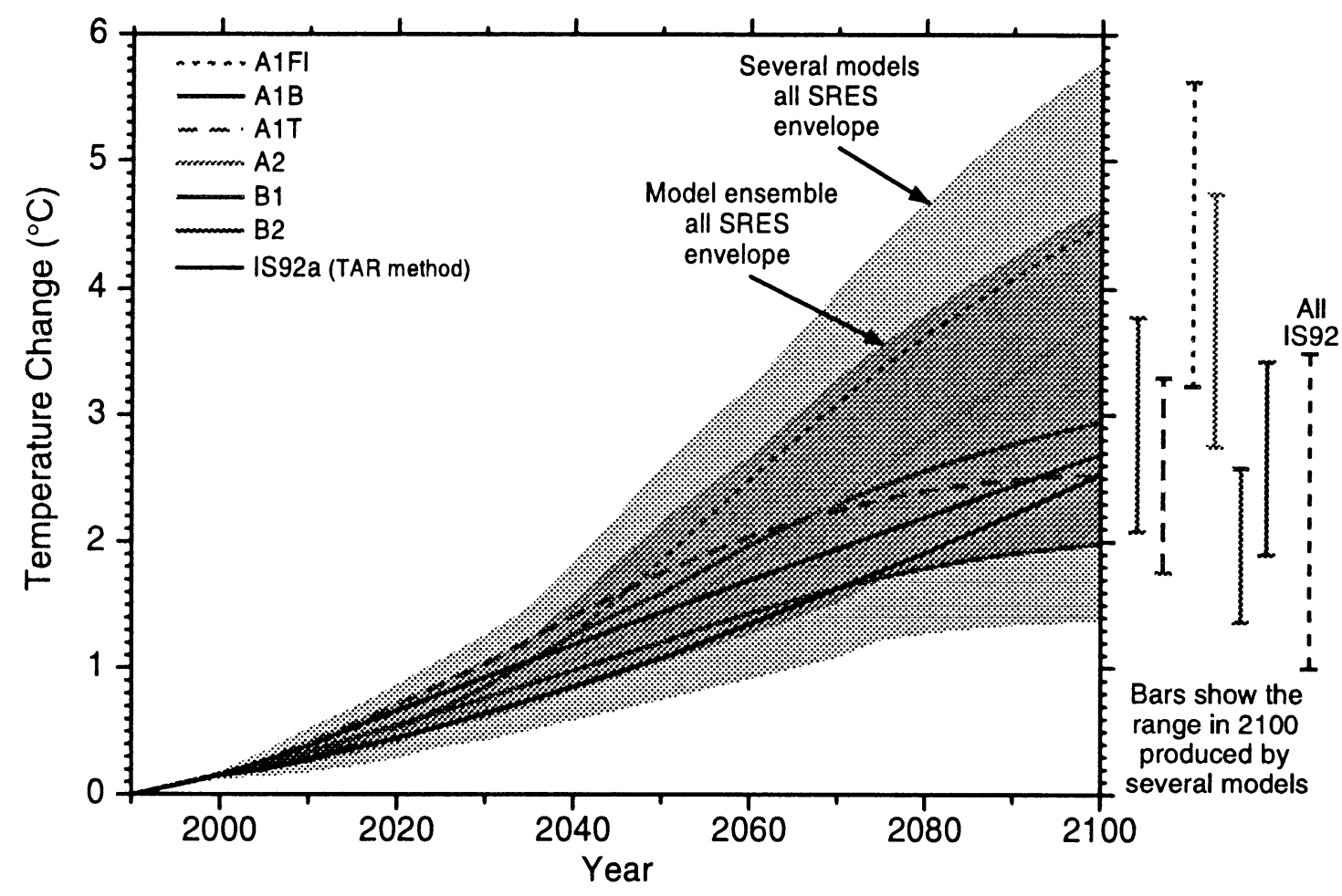

Figure 2.2: Global Climate of the $21^{\text {st }}$ Century: Sea Level Rise (IPCC 2001: 14)

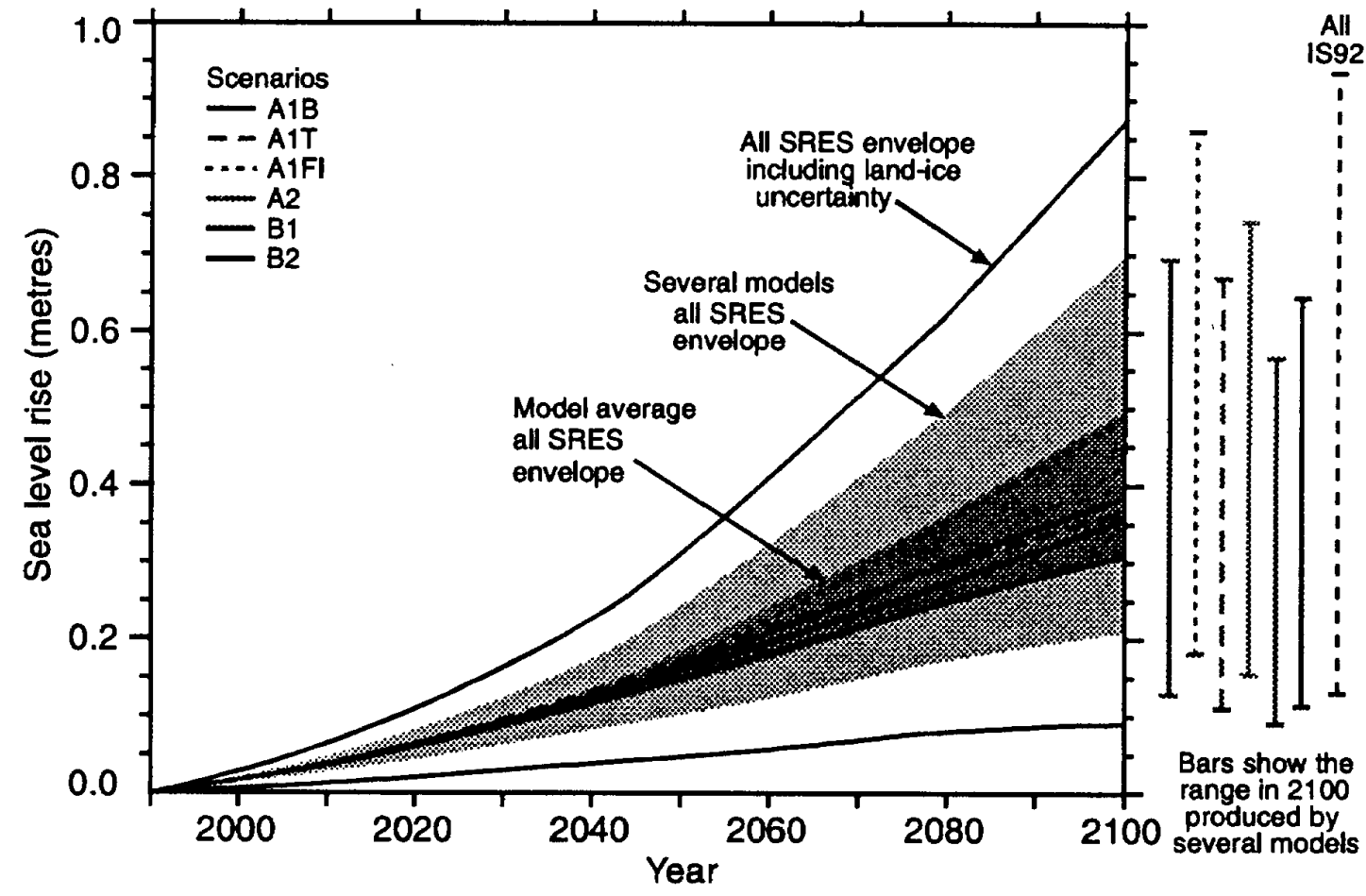

Figures 2.1-2.3 are reproduced with permission of Cambridge University Press and the IPCC. 
The TAR offered a summary of its assessment of extreme events it projects based on observed changes in the latter part of the $20^{\text {th }}$ century and modelling studies (figure 2.3). The TAR projected the mean sea level to rise by 0.09 to 0.88 metres between 1990 and 2100 compared with projections of sea level rises in the SAR of 0.13 and 0.94 metres.

Figure 2.3: Estimates of Extreme Weather Events in the $21^{\text {st }}$ Century (IPCC 2001: 3)

\begin{tabular}{|c|c|c|}
\hline $\begin{array}{l}\text { Confidence in observed changes } \\
\text { (latter half of the 20th century) }\end{array}$ & Changes in Phenomenon & $\begin{array}{l}\text { Confidence in projected changes } \\
\text { (during the } 21 \text { st century) }\end{array}$ \\
\hline Likely ${ }^{7}$ & $\begin{array}{l}\text { Higher maximum temperatures and more } \\
\text { hot days over nearly all land areas }\end{array}$ & Very likely ${ }^{7}$ \\
\hline Very likely ${ }^{7}$ & $\begin{array}{l}\text { Higher minimum temperatures, fewer } \\
\text { cold days and frost days over nearly } \\
\text { all land areas }\end{array}$ & Very likely ${ }^{7}$ \\
\hline Very likely ${ }^{7}$ & $\begin{array}{l}\text { Reduced diurnal temperature range over } \\
\text { most land areas }\end{array}$ & Very likely ${ }^{7}$ \\
\hline Likely ${ }^{7}$, over many areas & Increase of heat index ${ }^{12}$ over land areas & Very likely ${ }^{7}$, over most areas \\
\hline $\begin{array}{l}\text { Likely }{ }^{7} \text { over many Northern Hemisphere } \\
\text { mid- to high latitude land areas }\end{array}$ & More intense precipitation events ${ }^{b}$ & Very likely ${ }^{7}$, over many areas \\
\hline Likely ${ }^{7}$, in a few areas & $\begin{array}{l}\text { Increased summer continental drying } \\
\text { and associated risk of drought }\end{array}$ & $\begin{array}{l}\text { Likely }{ }^{7} \text {, over most mid-latitude continental } \\
\text { interiors. (Lack of consistent projections } \\
\text { in other areas) }\end{array}$ \\
\hline $\begin{array}{l}\text { Not observed in the few analyses } \\
\text { available }\end{array}$ & $\begin{array}{l}\text { Increase in tropical cyclone peak wind } \\
\text { intensities }^{c}\end{array}$ & Likely $^{7}$, over some areas \\
\hline Insufficient data for assessment & $\begin{array}{l}\text { Increase in tropical cyclone mean and } \\
\text { peak precipitation intensities }^{c}\end{array}$ & Likely $^{7}$, over some areas \\
\hline
\end{tabular}

Regional climate information "has been substantially improved since the SAR" relying on three categories: a) coarse resolution AOGCMs, b) regional climate models (RCMs) and c) empirical/statistical and statistical/dynamic methods "that exhibit different strengths and weaknesses and their use at the continental scale strongly depends on the needs of specific application" (IPCC 2001: 53). Such work "indicates at finer scales that the changes can be substantially different in magnitude or sign from the large area-average results." The TAR includes for the first time a chapter on regional climate information with evaluations and projections (IPCC 2001: 583-638) and new information on changes in sea level (639-694).

\subsection{Results of WG II of the TAR on Climate Change Impacts}

WG II of the first assessment of 1990 dealt only with impacts on agriculture and forestry, natural terrestrial ecosystems, hydrology and water resources, on human settlements and oceans and coastal zones. The WG II report for the SAR dealt with "Impacts, Adaptations and Mitigation of Climate Change: Scientific-Technical Analyses" (IPCC 1996a). WG II of TAR focused on "Impacts, Adaptation, and Vulnerability". 5 Depending on climate change scenarios WG II foresees large-scale and irreversible impacts:

\footnotetext{
5 The TAR distinguished between sector (hydrology and water resources, ecosystems and their goods and services, coastal systems and marine ecosystems, human settlements, energy, and industry, insurance and other financial services) and regional impacts for Africa, Asia, Australia and New Zealand, Europe, Latin and North America, the polar regions and the small Island States as well as with the adaptation to climate change in the context of sustainable development and equity and the vulnerability to climate change and reasons for concern. Among the major findings of WG II of TAR were that regional climate changes have already affected many physical and biological systems in many parts of the world.
} 
Examples include significant slowing of the ocean circulation that transport warm water to the north Atlantic, large reductions in the Greenland and West Antarctic Ice Sheets, accelerated global warming due to carbon cycle feedbacks in the terrestrial biosphere, and releases of terrestrial carbon from permafrost regions and methane from hydrates in coastal sediments. ... If these changes in Earth systems were to occur, their impacts would be widespread and sustained (IPCC 2001a: 6).

While adaptation is a necessary strategy at all scales to complement the climate change mitigation efforts, those countries with the least resources may be affected in terms of loss of life and relative effects on investments and the economy. But most affected developing countries have the least capacity to adapt and are thus the most vulnerable. ${ }^{6}$ Climate change will affect hydrology and water resources (IPCC 2001a: 9; 191-234), and thus also agriculture and food security (IPCC 2001a: 235-342). ${ }^{7}$ WG II addressed in detail the climate change impacts on human health. ${ }^{8}$ The IPCC report claims that most climate scenarios assume "a net increase in the geographic range of potential transmission of malaria and dengue-two vector born infections each of which currently impinge on $40-50 \%$ of the world population" (IPCC 2001a: 12). Projected climate change would also be associated by increases in heat waves, what will often be exacerbated by increased humidity and urban air pollution.

The increase in flooding: "will increase the risk of drowning, diarrhoeal and respiratory diseases, and in developing countries, hunger and malnutrition". Declining crop yields and food production "will predispose food insecure populations to malnutrition, leading to impaired child development and decreased adult activity. Socio-economic disruptions could occur in some regions, impairing both livelihoods and health" (IPCC 2001a: 12). Climate change will also impact upon human settlements, and thus worsen existing trends further due to: "flooding and landslides, driven by projected increases in rainfall intensity and, in costal areas, sea-level rise". This will affect many urban centres in the South.

In such areas, squatter and other informal urban settlements with high population density, poor shelter, little or no access to resources such as safe water and public health services, and low adaptive capacity are highly vulnerable. Human settlements currently experience other

\footnotetext{
6 "Many communities and regions that are vulnerable to climate change are also under pressure from forces such as population growth, resource depletion, and poverty. Policies that lessen pressure on resources, improve management of environmental risks, and increase the welfare of the poorest members of society can simultaneously advance sustainable development and equity, enhance adaptive capacity, and reduce vulnerability to climate and other stresses" (IPCC 2001a: 8).

7 "Approximately 1,7 billion people, one third of the world's population, presently live in countries that are water-stressed (defined as using more than $20 \%$ of their renewable water supply). This number is projected to increase to around 5 billion by 2025 , depending on the rate of population growth. The projected climate change could further decrease the streamflow and groundwater recharge in many of these water-stressed countries - for example in central Asia, southern Africa, and countries around the Mediterranean Sea - but may increase it in some others. ... Crop yield responses to climate change vary widely. ... Most studies indicate that global mean annual temperature increases of a few ${ }^{\circ} \mathrm{C}$ or greater would prompt food prices to increase due to growth in global food demand. ... It is established, though incompletely, that climate change, mainly through increased extremes and temporal/spatial shifts, will worsen food security in Africa" (IPCC 2001a: 9-10).

8 "The impacts of short-term weather events on human health have been further elucidated since the SAR, particularly in periods of thermal stress, the modulation of air pollution impacts, the impacts of storms and floods, and the impacts of seasonal and inter-annual climatic variability on infectious diseases. There has been increased understanding of the determinants of population vulnerability to adverse health impacts and the possibilities for adaptive responses" (IPCC 2001a: 12; 451-486).
} 
significant environmental problems which could be exacerbated under high water and energy resources and infrastructure, waste treatment, and transportation. ... Model-based projections of the mean number of people who would be flooded by coastal storms surges increase several fold (by 75 to 200 million people depending on adaptive responses) for mid-range scenarios of a $40-\mathrm{cm}$ sea-level rise by the 2080 s relative to scenarios with no sea-level rise. Potential damages to infrastructure in coastal areas from sea-level rise have been projected to tens of billions US\$ for individual countries (IPCC 2001a: 13).

Due to regional climate differences "expected climate change give rise to different exposures to climate stimuli across regions". Some regions are severely vulnerable.

Most less-developed regions are especially vulnerable because a larger share of their economy are in climate sensitive sectors and their adaptive capacity is low due to low levels of human, financial, and natural resources, as well as limited institutional and technological capability. ... Adverse changes in seasonal river flows, floods and droughts, food security, fisheries, health effects, and loss of biodiversity are among the major regional vulnerabilities and concerns of Africa, Latin America, and Asia where adaptation opportunities are generally low. ... In Europe, vulnerability is significantly greater in the south (IPCC 2001a: 15).

WG II pointed to several gaps in current knowledge and needs of policymakers (IPCC 2001a: 17). These future research needs require a strengthened international cooperation and coordination "for regional assessment of impacts, vulnerability, and adaptations, including capacity building and training for monitoring, assessment, and data-gathering, especially in and for developing countries" (IPCC 2001a: 17).

\subsection{IPCC Study on Regional Impacts of Climate Change}

In the special report on The Regional Impacts of Climate Change: An Assessment of Vulnerability, the IPCC (1998) explores potential consequences of climate change for ten macro regions. The report notes that climate change represents an "important additional stress on those systems already affected by increasing resource demands, unsustainable management practices, and pollution, which in many cases may be equal to or greater than those of climate change." The report assessed the vulnerability of natural and social systems of major regions to climate change with primarily qualitative methods. These regional assessments focus on: a) ecosystems, b) hydrology and water resources, c) food and fibre production, d) coastal systems, human settlements, human health, and other sectors or systems including the climate system of relevance for the 10 regions analysed (table 3.2). For the case studies, the regional impact assessments in the WG's II TAR (2001a) will also be reviewed for Latin America, Tropical Asia and the Middle East and Arid Asia with regard to the relevant regional features that directly influence the impacts of climate change for Mexico, Bangladesh and Egypt. Due to a lack of a regional assessment of the Mediterranean the references in the regional reports for Europe, Africa and the Middle East and Arid Asia (IPCC 2001a) will be reviewed below. ${ }^{9}$

\subsection{Interactions Among Climate Change and Patterns of Environmental Stress: Concept of a "Survival Hexagon"}

To illustrate the complex linkages among nature- and human-induced factors or symptoms of global change, this author has introduced the concept of a survival hexagon (Brauch 2000, 2000a: 305). Among its six factors two were described as root causes for

\footnotetext{
${ }^{9}$ For more details see the quotes above, p. 3-4.
} 
different natural and socio-economic effects: climate change and population growth. This survival hexagon tries to illustrate manifold direct and indirect impacts and interactions of the six structural causes that may pose a survival dilemma (Brauch 2000a: 284286) for the countries in the South (figure 2.4).

Figure 2.4: Interactions Among Climate and Other Factors of a Survival Hexagon

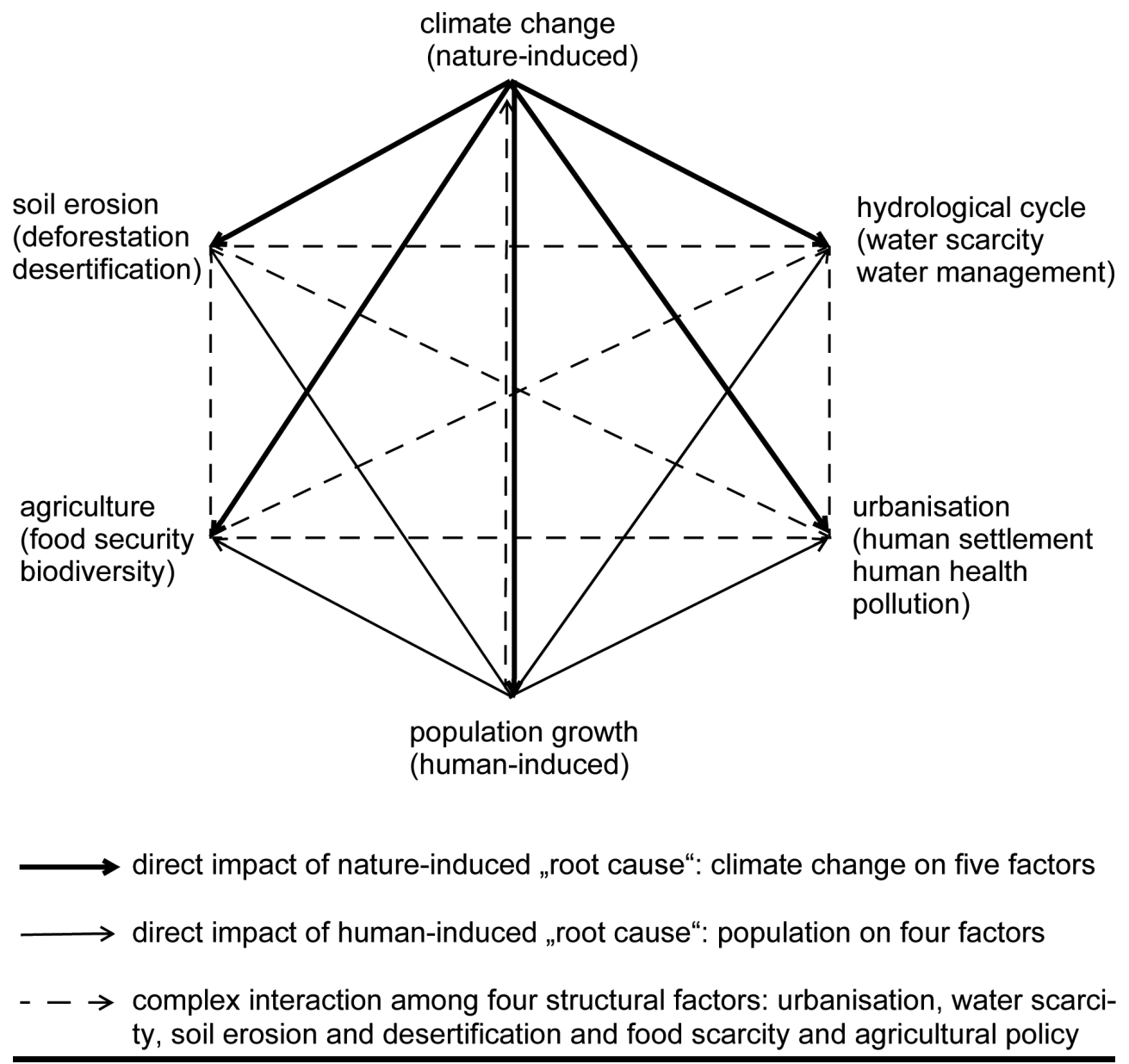

The author argued that these six structural causes are instrumental for medium-term (2000-2020) and long-term (2020-2050) socio-economic effects that can be projected as general possible outcomes without any specification as to when and how they will occur because no methodology exists for foreseeing singular events. While these effects have occurred and can be observed internally for many years it is their external manifestations in terms of conflicts that makes them a primary concern for international politics. The domestic socio-economic effects of both root causes could be observed for many years, such as the rapid process of urbanisation. The droughts resulted in some countries in food riots and both were partly responsible for migration flows. Once domestic violence crosses national boundaries and leads to border clashes and conflicts over scarce resources and results in large streams of refugees, asylum seekers, and undocumented migrants, these effects will be observed as severe „crises“ by the media and governments in the North that require a speedy response to contain follow-on costs.

These linkages will differ according to climate zones (Köppen) or between temperate, subtropical, tropical and arid regions of the globe. Arid and semi-arid regions around the globe may experience a greater communality of climate change effects while the macro regions are relatively insensitive to these specific climatic conditions. Among the 
three national case studies analysed below, Mexico has the greatest variety of climate contexts that produce different impacts in the affected sub-regions of the country.

These complex linkages between climate change and other symptoms of global environmental change have been illustrated in the concept of a survival hexagon that focuses on six structural factors that produce the nature and human induced input factors for environmental degradation and scarcity that may lead to severe environmental stress that may result - under certain socio-economic conditions and specific national and international contexts - in conflictual outcomes that may be resolved, prevented or avoided by cooperative diplomatic efforts (figure 2.4 and 3.4).

This political process on the inter- and transnational level between state, economic and societal actors among four system components (state, society, economics, knowledge) produces at least five outcomes: 1) affluence (in the North) or poverty (in the South) produce two different inputs for 2) human mobility and migration (due to pull or push factors) that may result in 3) tensions and crises that may result either in 4) a successful resolution by cooperation or 5) in conflict at the internal (protest, skirmishes, civil strife, civil war) or international level (bilateral, regional, interregional or global) that may be but need not be caused by the complex interaction of structural inputs, political processes and constellations of mobility, conflict and cooperation (figure 3.1).

At least four different socio-economic effects of the complex interplay of the above six structural causes have occurred: a) domestic societal conflicts; b) resource and border conflicts, c) regional violence with implications for the security perception of the North and d) militarisation of non-military causes of conflicts. None of the violent domestic and international conflicts have been caused primarily by factors associated with environmental degradation and population growth. However, the six factors that have already put the survival of many countries in the Sahel zone at risk during the 1980s may pose a survival dilemma for highly vulnerable countries in the Third World (figure 2.4).

The linkages between climate change and the other five factors of the survival hexagon will be reviewed next primarily on the basis of the work that has already been assessed by the IPCC in its first three assessment reports.

\subsection{Linkages Between Global Climate Change, Possible Conflict Constellations and Human, National and Global Insecurity}

The IPCC impact analyses have addressed both at the global and also at regional level the potential interaction of several other factors, especially between climate change and water (hydrological cycle, 2.5.1), climate change and soil (including the impacts of deforestation, soil erosion, desertification (2.5.2), climate change and agriculture (including food, 2.5.3). So far the linkages between climate change and population growth (2.5.4) and urbanisation (2.5.5) have already been addressed by the UN Populations Division (UN 2001a) and by IIASA (O’Neill/Mac Kellar/Lutz 2001), but they have not yet systematically been assessed by the IPCC for all regions.

So far, the IPCC has also not yet assessed the potential linkages between climate change impacting on environmental stress and thus becoming a potential cause for conflict constellations that have often been solved peacefully on the national or regional level, but in some cases the victims of severe environmental stress situations have been a cause or more often an object of violence by individuals or ethnic and religious groups that feel 
threatened by people that have been displaced by severe weather events or that fled across borders for their own survival and those of their families.

\subsubsection{Linkages Between Climate Change and Water}

The WG II (IPCC 2001a: 191-234) devoted one chapter on "hydrology and water resources" to the state of our knowledge on the known linkages at the global level:

- There are apparent trends in streamflow volume ... in many regions. These trends cannot be definitely attributed to changes in regional temperature or precipitation. ...

- The effect of climate change on streamflow and groundwater recharge varies regionally.

- Peak streamflow is likely to move from spring to winter in many areas. ....

- Glacier retreat is likely to continue, and many small glaciers may disappear.

- Water quality is likely to be degraded by higher water temperature, but this may be offset regionally by increased flows. ...

- Flood magnitude and frequency are likely to increase in most regions, and low flows are likely to decrease in many regions.

- Demand for water generally is increasing as a result of population growth and economic development, but it is falling in some countries.

- The impact of climate change on water resources depends not only on changes in the volume, timing, and quality of streamflow and recharge but also on system characteristics.

- Unmanaged systems are likely to be most vulnerable to climate change.

- Climate change challenges existing water resources management practices by adding additional uncertainty (IPCC 2001a: 193).

With regard to water availability, the IPCC (2001a: 193) stated that change "has the potential to induce conflict between different users" within the same area or between different parts of the river basin.

Where there are disputes, the threat of climate change is likely to exacerbate, rather than ameliorate, matters because of uncertainty about the amount of future resources that it engenders. One major impact of climate change for agreements between competing users (within a region or upstream versus downstream) is that allocating rights in absolute terms may lead to further disputes in years to come.

The impact of climate change for water resources, requires according to the TAR more research with a focus on: a) creation of credible climate change scenarios; b) characterisation of natural and hydrological variability, c) improved hydrological models, d) characterisation of uncertainty, e) impacts on real world water systems and f) effects of adaptation. Effective adaptation to climate change in the water sector requires, according to the IPCC, efforts in five main areas: a) data for monitoring; b) understanding patterns of variability; c) analytical tools; d) decision tools and e) management techniques. Many scientific studies have addressed the climate-ocean interaction, the implications of climate and sea level change and the impact of climate change on coastal areas. More research is needed, at the regional and national level on the likely impact of climate change on the availability of water resources, on precipitation and evaporation levels.

\subsubsection{Linkages Between Climate Change and Soil}

WG II (IPCC 1996a: 95-324) assessed in detail the implications of climate change impacts on forests, rangeland, deserts, land degradation and desertification, mountain regions, non-tidal wetlands and on coastal zones and small islands. On the impact of climate change on deserts, the IPCC (1996b: 161) stated with certainty: 
- Most deserts are likely to become even more extreme if climate changes as projected by current scenarios; most desert regions are expected to become hotter and most will probably not become significantly wetter.

- If changes in the frequency or intensity of the rainfall events occur, they are likely to cause changes in the flora and fauna. ... Any reduction in the intensity of rainfall, however, could also be detrimental to this set of organisms due to false starts in their life cycles.

- In a few places (e.g. central Australia) conditions may improve, but any net change in rainfall will depend on the human management of these regions.

- Opportunities to mitigate greenhouse gas emissions in desert regions are few.

- Human-induced desertification has the potential to counteract any ameliorating effect of climate change on most deserts unless appropriate management actions are taken.

On the interactions between climate change, land degradation and desertification, the IPCC (1996a: 173) argued that both processes must be considered in parallel. Often it would be impossible to separate the impact of unsustainable land-management and climate change but often they interact and produce negative cumulative effects on soil.

- Fundamental soil properties and processes ... will be influenced by changes in climate.

- Desertification arises both from human abuse of the land and from adverse climate conditions. Climate related factors such as increased drought can lead to an increase $\mathrm{n}$ the vulnerability of land to desertification and to the escalation of the desertification process.

- Reversing the effects of desertification is not always possible and is more difficult for drier environments with shallower soils.

- Changes in the frequency and intensity of precipitation will have the greatest direct effect on soils via erosion by water. ... Future erosion risk is likely to be related more to increases in population density, intensive cultivation of marginal lands, and the use of resource-based and subsistence farming techniques than to changes in precipitation regimes. ...

- Where conditions become more arid, salinization and alkalisation are likely to increase because evapotransporation and capillary rise will be enhanced. ...

- Predicted warming may give rise to higher evaporation rates, leading to drier soils and more frequent episodes of severe wind erosion.

- Because arid and semi-arid land ecosystems have little ability to buffer the effects of climate variability ... they are particularly vulnerable to climate change. ...

- Adaptation to desertification will rely on conventional strategies.

These projected effects are relevant for all MENA countries on the Southern and Eastern shores of the Mediterranean, especially for Egypt and but also for parts of Mexico while Bangladesh will be affected most by the effects for coastal zones due to sea-level rise. The interactions between desertification and climate change have been analysed in detail by Williams and Ballings (1996) and they have been mentioned in the extensive literature on desertification (Mainguet 1994; Portnov/Hare 1999; Babaev 1999) as had the impact of desertification on migration (Puigdefabregas/Mendizabal 1995).

\subsubsection{Linkages Between Climate Change and Agriculture}

The impacts of climate change on agriculture (Parry 1990; Bazzaz/Sombroek 1996; FAO 1997) and biodiversity have been widely studied. In 1992, a German parliamentary study pointed to these regions that would be particularly sensitive to climate change effects on agricultural production: "in Africa: Maghreb, West Africa, the Horn of Africa, southern Africa; in Asia: western Arabia, southeast Asia; in America: Mexico, Central America, eastern Brazil, Peru” (Enquête Commission 1992: 130).

WG II (IPCC 1996a: 427-468) noted on the impacts of climate change on agriculture "that regional effects will vary widely" but it also pointed to a lack of information "to 
distinguish reliably and precisely those areas that will benefit and those that will lose" (IPCC 1996a: 429). While increased $\mathrm{CO}_{2}$ concentrations may have a positive effect on crop yield, changes in soil are a likely consequence of climate change for some soils in some climate zones. Livestock production is more problematic in pastoral systems where production is sensitive to climate change. The risk of losses is likely to increase due to weeds, insects and diseases. The impact will be uneven in different regions:

Vulnerability to climate change depends on physical and biological response but also on socio-economic characteristics. Low-income populations depending on isolated agricultural systems, particularly dryland systems in semi-arid and arid regions, are particularly vulnerable to hunger and severe hardship. Many of these at-risk populations are found in SubSaharan Africa, South and Southeast Asia, as well as some Pacific islands and tropical Latin America (IPCC 1996a: 430).

The IPCC notes a high degree of uncertainty with regard to the ability of agricultural systems to adapt to climate change due to future changes in population, technology and resource availability. While adaptation would be likely, the extent will depend "on the affordability of adaptive measures. Country studies pointed to "incremental additional costs of agricultural production under climate change which could create a serious burden for some developing countries" (IPCC 1996a: 430). In the TAR, the IPCC (2001a: 235-342) notes the different projections on future food security between more optimistic projections of the US Department of Agriculture (1999) and a more sceptical assessment by FAO (1999) that pointed to a variation in food security challenges for low-income countries where there is a lack of access to food. According to Alexandratos (1995) some extrapolations of yield increases may be overoptimistic.

Degradation of natural resources - taken here as soil, forests, marine fisheries, air, and water - diminishes agricultural production capacity. Soil degradation emerges as one of the major challenges for global agriculture. ... Degradation of natural resources is likely to hinder increase in agricultural productivities and could dim optimistic assessments of the prospects of satisfying growing world food demand at acceptable environmental cost (IPCC 2001a: 253).

The TAR pointed to the close interaction of climate change with other global changes "including population growth and migration, economic growth, urbanization, and changes in land use and resource degradation" (IPCC 2001a: 254). The IPCC agreed that there is a need for further research in many areas: "for future assessments of the impact of climate change on goods and services provided by ecosystems, adaptation options, or identification of vulnerable systems or regions" (IPCC 2001a: 314).

\subsubsection{Linkages Between Climate Change and Population Growth}

All climate change models are based on different assumptions (table 1.1) on population growth that primarily rely on the biannual revisions of global population projections until 2050 by the UN Population Division. Population growth is a major anthropogenic factor. It determines the demand for water and food but through the level of economic growth it also contributes to land degradation and pollution, especially in the fast growing population centres of the world. In its 2000 Revision, the UN Population Division pointed to these key findings:

1. World population reached 6.1 billion in mid-2000 and is currently growing at an annual rate of 1.2 percent, or 77 million people per year. ... By 2050, world population is expected to be between 7.9 billion (low variant) and 10.9 billion (high variant), with the medium variant producing 9.3 billion. 
2. The population of more developed regions as a whole, currently 1.2 billion, is anticipated to change little during the next 50 years because fertility levels are expected to remain below the replacement level. ....

3. The population of the less developed regions is projected to rise steadily from 4.9 billion in 2000 to 8.2 billion in 2050 ....

4. International migration is projected to remain high during the $21^{\text {st }}$ century (UN 2001: $\mathrm{v}$-vii).

Based on UN long-term projections, the world population will continue to grow for the next 200 years. According to the medium variant, the UN considers as most likely, "global population is projected at 8.9 billion people in 2050, 9.7 billion in 2150 , and nearly stabilize at just above 10 billion after 2200". The UN's World Population Monitoring 2001 report on population, environment and development (UN 2001a: 13) noted:

Because the different regions ... find themselves at different dates of the demographic transition from high to low mortality and fertility, their growth paths differ considerably, resulting in significant shifts in the geographical distribution of world population. In $1950,68 \%$ of the world population resided in the less developed regions. This proportion has grown to $80 \%$ at present, and it is projected to be nearly $90 \%$ in 2150 . Of the 78 million people being added to the world each year, $95 \%$ live in the less developed regions.

The regional population projections are a crucial element of any regional or national climate impact projection up to 2100 and beyond. The drastic increase of $\mathrm{CO}_{2}$ emissions is due to the enormous expansion of global production since 1950. Between 1950 and 2000, world GDP at constant prices increased about eight-fold (IMF 2000; UN 2001a: $15)$ and due to technological progress, "output growth has increasingly surpassed population growth". But this growth has been uneven, in the wealthiest quarter of the world GDP per capita climbed almost six-fold over the $20^{\text {th }}$ century, the per capita income of the poorest quarter grew les than three-fold (IMF 2000: UN 2001a: 16). At the end of the $20^{\text {th }}$ century, $20 \%$ of the world population in OECD countries consumed $60 \%$ of the world's primary energy. Since 1751, an estimated 265 billion tonnes of carbon have been released to the atmosphere, one half of these emissions since the mid 1970s (UN 2001: 18; Marland et al. 1999). The UN population report noted:

The magnitude of future carbon emissions depends on a number of factors, including global energy demand, the pace of economic development, the introduction of energy-saving technologies and the degree of shift away from fossil fuels. ... Current models suggest that immediate stabilization of atmospheric carbon dioxide concentrations at present levels can only be achieved if emissions are immediately slashed by some 50 to 70 per cent and further reduced thereafter (UNEP, 1999). Because of the inertia associated with climate systems, even if stabilization of emissions is achieved, global warming could continue for decades and sea levels rise for centuries (UN 2001: 19).

With regard to the integration of population and environmental policies, the UN report pointed to the efforts that were launched at the Rio conference (1992) and at the population and development conference in Cairo (1994) that have so far produced little success due to administrative problems that made the coordination in many countries difficult. The UN Population Monitoring 2001 report (2001a: 38) suggested several ways "in which population size, growth and distribution may be related to environmental issues".

In the 1940s and 1950s, Malthusian concerns prevailed and hardly any attention was devoted to the environment. During the 1960s and 1970s, projections on the limits of growth (Meadows et al, 1972) pointed to the collapse of environmental systems and widespread famine due to population growth. Since the 1980s, new environmental challenges emerged (UN 2001a: 39). 
While much theoretical and empirical work was influenced by Malthusian ideas "that production of food would not be able to keep pace with population growth. Increasingly this question has been joined by concern about the environmental costs of producing that food" (UN 2001a: 44). The UN report stated that most assessments of the food situation conclude "that slower growth and earlier stabilization of population size would reduce the pressure to expand agricultural land" while increase in food production has "aggravated numerous environmental problems" (UN 2001a: 47). There are not only impacts of population growth on the environment but also environmental trends that have a direct impact on population issues, including health, mortality and migration.

Since the 1970s, the relationship between demographic impact on the environment has been expressed with the I=PAT formula (impact of population, affluence and technology) that was introduced by Ehrlich and Holdren (1971). There is no linear relation between population growth and environmental outcomes, "because some environmental outcomes (per capita greenhouse gas emissions, for instance) are lowest where population growth is highest" (UN 2001a: 51). O’Neill, MacKellar and Lutz (2001) argued:

Considering only global averages, and holding $\mathrm{CO}_{2}$ emissions constant at their then current level, population growth alone would be projected to increase global $\mathrm{CO}_{2}$ emissions by 86 per cent in 60 years. But if the calculations were done separately for each region (with regional $\mathrm{CO}_{2}$ emissions held constant) and then added up, the effect of population growth would be to increase global emissions by only 20 per cent. In general, higher per capita GNP is associated with both lower population growth, and lower levels of pollution, as richer countries tend to use less polluting techniques. Because of this, applications of the I=PAT framework at the global level can produce seriously misleading results (UN 2001a: 51).

Brown, Gardner and Halweil (1999: 76) have also pointed to the non-linear relationship between population growth and greenhouse gas emissions:

The effects of population growth are most profound in countries were people are heavy emitters. For example, the 115 million people added to the population of the United States between 1950 and 1998 - an increase of nearly 75 percent in just 45 years - account for more than one tenth of current global emissions, And the carbon emissions of the 71 million people who will be added to the US population in the next 50 years roughly equal the emissions of the 1 billion people who will be added to Africa during that period.

More recently O'Neill, MacKellar and Lutz (2001) have analysed the manifold linkages between population and climate change and concluded that

in the near-term future, alternative plausible assumptions about the course of the 'affluence' and, especially, 'technology' factors have a much larger impact on projected emissions trends than do alternative assumptions about population trends. However, they also suggest that the greater the concern with long-range futures, the more important should be population policies in the array of concern with long-range futures, the more important should be population policies in the array of strategies for enhancing the environmental condition. In the case of greenhouse gas emissions, for instance, a common conclusion is that policies to accelerate demographic transition would reduce emissions significantly only in the long run (after the second half of this century). In the near to medium term, policies impinging on per capita emissions would have a far greater effect on emission reductions (UN 2001a: 52).

Some researchers estimated "that over a human lifetime it would cost less than half as much to reduce emissions indirectly through support for family planning than through implementing a carbon tax" (UN 2001a: 53). O’Neill, MacKellar and Lutz (2001: 205) concluded: 
- Slowing population growth in either LDCs or MDCs is likely to reduce GHG emissions in the long term and ease the measures necessary to stabilize GHG concentrations. Because of the inertia of population growth, GHG emission reductions can be achieved over the next few decades only by reductions in per capita emissions, whether through reductions in consumption, a shift in consumption patterns, or improvements in technology. ...

- Policies to slow population growth in LDCs are likely to improve the resilience of vulnerable populations to climate-related impacts....

- MDCs characterized by sub- or nearly sub-replacement fertility are unlikely to display much enthusiasm for policies that would further slow the growth of their populations. However, not just equity, but global efficiency logic, as well, suggests that population policies in LDCs should receive financial support from MDCs.

This study does not imply "that population policies are the most effective or equitable policies for addressing climate change" but it suggests "that policies related to population should be part of a broad range of policies to mitigate and adapt to climate change, and to global environmental change in general", thus contributing to win-win strategies.

\subsubsection{Linkages Between Climate Change and Urbanisation, Pollution, Human Health}

The linkages between climate change, urbanisation, pollution and human health have been addressed by the IPCC in the SAR and TAR of WG II but also by WHO, WMO and UNEP (1996). According to the UN's Population Monitoring 2001 the urbanisation trends have also been projected to grow which will have serious repercussions as an additional factor contributing to environmental stress:

Whereas in 1950, 30\% of the world population lived in urban areas, by 2000 the proportion of urban dwellers has risen to $47 \%$ and it is expected to reach $60 \%$ by 2030 ... Between 1950 and 2030 , the urban share is expected to increase from $55 \%$ to $84 \%$ in the more developed regions, and from $18 \%$ to $56 \%$ in the less developed regions. In $2000,68 \%$ of the world's urban population lived in the less developed regions. By 2030, 79\% will. With the increasing levels of urbanization, giant urban agglomerations have become both, more numerous and considerably larger in size. The number of mega cities of 10 million or more persons has grown from 1 to 19 since 1950, and is expected to increase to 23 by 2015 . The large majorities of the more inhabitants are found in the less developed regions.

Potential climate change impacts on human settlements, including urban centres (IPCC 1996a: 399-426; 2001a: 381-416), pollution and human health (IPCC 1996a: 561-586; 2001a: 451-486) have been analysed by WG II in the SAR and TAR. The SAR summarised the outcome of climate change on human settlements (IPCC 1996a: 401):

- Impacts on human settlements from climate change may be indirect as well as direct....

- Thresholds beyond which impacts escalate quickly are unique to individual local situation and tend to depend on the degree of adaptive response. ...

- Non-climate effects may be more important than climate change. ...

- A significant potential for non-coastal flooding (river basin and local urban flooding) is expected if precipitation intensity increases as a result of climate change. ...

- Health risks are potentially very large ...

In the TAR, WG II (2001a: 383-385) found that the impacts of climate change on human settlements "are expected to be among the sectors that could be most easily adapted to climate change, given appropriate planning and foresight and appropriate technical, institutional and political capacity". TAR pointed to several major effects:

- Infrastructure would have increased vulnerability to urban flooding and landslides.... 
- Water supplies for human settlements would be vulnerable to increased warming, dryness, and flooding....

- Fire dangers in settlements could increase with climate change. ...

- Hail and windstorm could cause more damage to settlements. ...

- Heat waves would have more serious effects on human health and productivity. ...

- Sea-level rises increases the cost/vulnerability of infrastructure and coastal ...industry.

- There will be increased air and water pollution impacts....

- Infrastructure in permafrost regions is vulnerable to warming.

- Heat island effects could increase heat stress, increase summer energy demand, and reduce winter energy demand (IPCC 2001a: 383-385).

The World Population Monitoring 2001 report (UN 2001a: 95-103) discussed the linkages among population, environment and development in urban settings, stating that

virtually all the population growth during 2000-2030 will be concentrated in the urban areas of the World (UN 2000). Growth will be particularly rapid in the urban areas of the less developed regions, averaging $2.3 \%$ per annum during 2000-2030, consistent with a doubling time in 30 years. ... Population growth influences the spatial concentration of people, industry, commerce, vehicles, energy consumption, water use, waste generation, and other environmental stresses.

The UN report referred to the complex relationship between urbanisation and environmental degradation due to manifold interactions between the natural and the built environment and many economic, societal and political factors on which climate change will impact as an additional factor that often strengthens existing negative trends of water pollution, sanitation problems, solid waste and air pollution. While climate change will have negative impacts on human health (Mc Michael/Haines/Sloof/Kovats 1996), urbanisation produces additional environmental impacts on urban health, often linked with water, such as waterborne diseases, water hygiene, water vector diseases:

In most cases, the poorer residents of the world's large cities bear the human costs of the most debilitating impacts of environmental degradation. In many large cities, environmental pollution affects the poor more severely in part because many of them live at the periphery where manufacturing, processing, and distilling plants are often built (IPCC 2001a: 101).

The UN (21001a: 107) study concluded that "population pressures are contributing factors to environmental stress" while population and development policies "are necessary and vital components of the constellation of actions to ensure sustainable development and to safeguard the environment during the twenty-first century and beyond". The SAR (IPCC 1996a: 565) summarised the knowledge how climate change can affect human health with adverse effects. The TAR (IPCC 2001a: 451-486) analysed the health effects of thermal stress (heat waves, cold spells), of extreme weather events, such as floods, storms, tropical cyclones and droughts, air pollution, infectious diseases (malaria, dengue et al.), coastal water issues, food yields and nutrition, and demographic and economic disruption, but also adaptation options and secondary health benefits of mitigation policies. People who had to leave their home due to wars, deforestation or extreme weather events associated with climate change may often experience health impacts from the new ecological environment and from living conditions in refugee camps. 


\section{Patterns of Environmental Stress}

Based on the social science and the climate literature we conclude that climate change is only one of several global challenges (see survival hexagon in figure 2.4) that contribute to environmental degradation (of soil, water) by reducing the supply of water, food thereby contributing to environmental scarcity. Population growth has increased the demand for water, food, housing and jobs and has been a major determinant of urbanisation. Both the supply-driven environmental degradation and the demand-driven environmental scarcity contribute to environmental stress, and thus may become a cause of conflict constellations that may be solved locally by the migration of the victims of climate stress (causing potential conflicts in recipient countries) but they may also become an additional contributing factor to domestic conflicts that may erupt on ethnic, religious or other identity issues or along class divisions. Some resource conflicts, e.g. on water in multinational river basins have been solved by diplomacy and functional cooperation. Thus, based on the state of our knowledge in the social sciences, no monocausal relationship could be found between environmental stress and violent conflict (figure 3.1).

Figure 3.1: Causes and Outcomes of Environmental Stress and Potential Outcomes

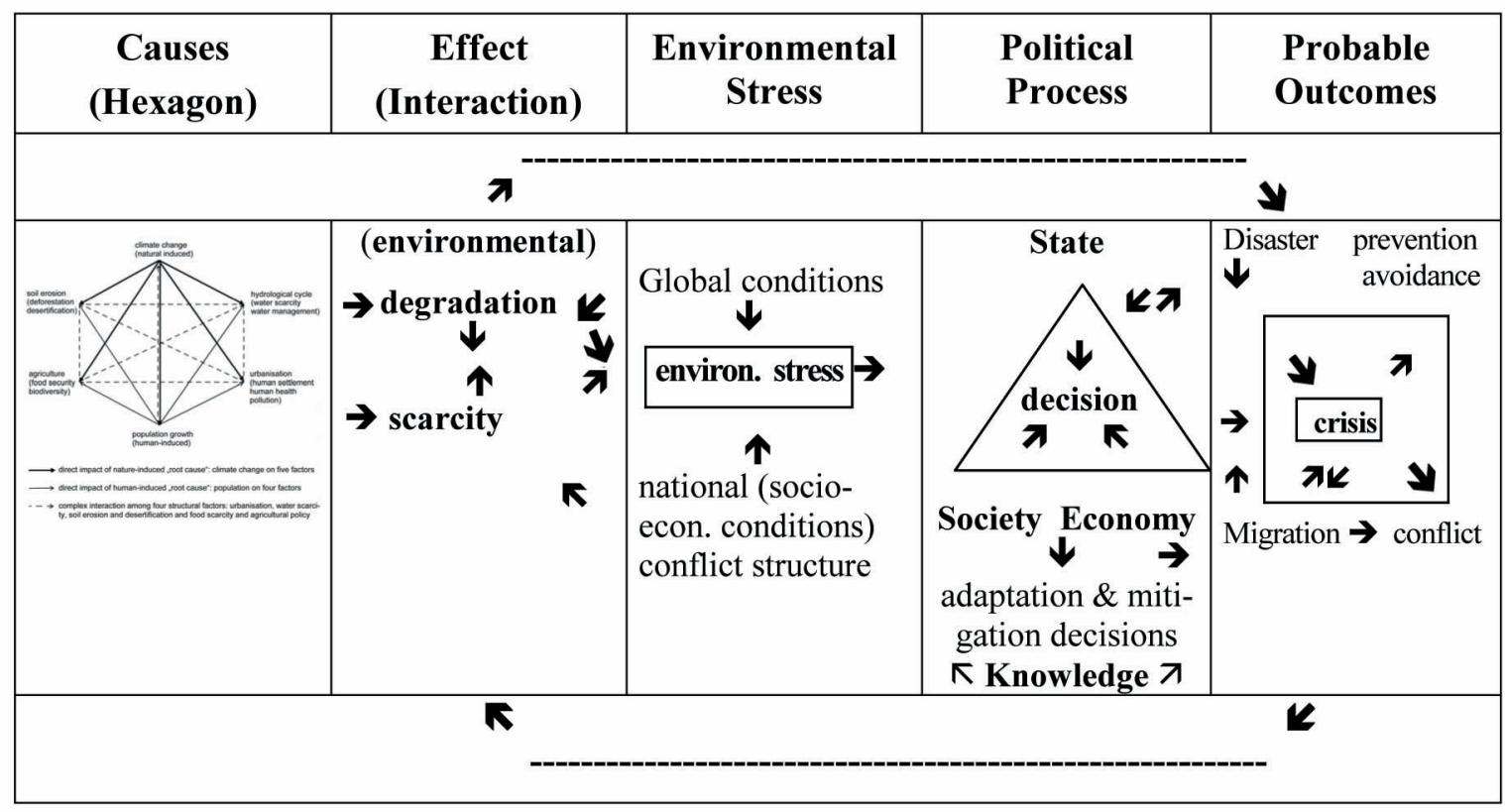

Figure 3.1 illustrates the complex interactions between the six causes of the symptoms of global and regional environmental change of the survival hexagon (figure 2.4, 2.5), its effects on human beings and societies as both environmental degradation and scarcity. Environmental degradation may lead to or intensify environmental scarcity (especially of water and food). Both result in an enhanced level of environmental stress that will also be influenced by global political, economic and environmental but also by national socio-economic conditions and by the specific conflict-proneness and structure. Environmental stress requires political decisions that will reflect the dominating economic and societal interests. Based on the political will and available resources they may lead to policy decisions to adapt to and mitigate against this environmental stress or to a postponement of decisions. Environmental degradation and stress may result in unforeseen repeated extreme weather events resulting in disasters that may contribute to national crises situations that may escalate to violent conflicts or may be avoided. 
For the analysis of the sensitivity of regions, nations and societies to environmental stress, two basic social science concepts will be introduced: environmental vulnerabilities and risks (3.1). Then, the results of social science research on environmental security will be reviewed and assessed in detail (3.2.). In a third step, five possible outcomes of environmental stress (3.3) will be distinguished: a) environmental hazards and disasters; b) environmental refugees; c) environmental crises; d) environmental conflicts and e) environmental conflict resolution, prevention and avoidance. Finally, existing deficits in the climate change impact analysis of WG II of the IPCC will be listed that should be addressed in the fourth assessment report of the IPCC in 2007 (3.4)

\subsection{Environmental Vulnerabilities and Risks}

In the political and social science literature on environmental security (Brauch 2003) four concepts have been used to describe the objects of this body of research and to qualify the likely outcomes: threats, challenges, vulnerabilities and risks that have often been used without clear definitions and sometimes even synonymously. While threats and challenges are closely related with "hard" political and security issues, vulnerabilities and risks refer more to a "soft" human security perspective (from the vantage point of the affected victims). Only the latter two concepts will be reviewed more closely.

\subsubsection{Environmental Vulnerability}

In the research on hazards (Hewitt 2002, V: 297-303) and disasters (Abramovitz 2001) in global environmental change the concept of vulnerability assessment was used that refers:

to the evaluation of the sensitivity of a particular ecosystem, resource or activity to a broad range of environmental and socio-economic stresses. Depending on the particular case, the assessment could be conducted through determining critical thresholds of different stresses and risks associated with those thresholds. Stochastic downscaling is a suitable method for evaluating the risks associated with climatic thresholds (Bass 2002, 1: 346-347).

In the context of the precautionary principle O'Riordan (2002, IV: 369) defined vulnerability at the societal level as:

the incapacity to avoid danger, or to be uninformed of impending threat, or to be so politically powerless and poor as to be forced to live in conditions of danger. On a personal level, vulnerability relates to such a physical condition as to be unable to withstand stress to a weakened immune system. In essence, precaution carries with it both the principle of playing safe, and paying due attention to the physically weak and the politically powerless.

According to Hewitt (2002, V: 299) a vulnerability perspective "considers especially how communities are exposed to dangers, the ways in which they are readily harmed, and the protection that they lack". Vulnerability to a hazard is to a large extent created by the respective social order, on the division of labour, cultural values and on legal rights (O'Riordan 1986). Thus, according to Hewitt (2002, V: 300) vulnerability is a "relative condition, and can only be defined and assessed in relation to the safety which others actually enjoy".

Thus, environmental stress depends on the relative vulnerability of the country or society on which environmental degradation and scarcity impact on, and thus also on the available resources to adapt to the increasing "stress" and to mitigate against its impacts. 


\subsubsection{Environmental Risks}

The concept of risk has been used in the social sciences with a special reference to environmental issues. ${ }^{10}$ Ulrich Beck (1999: 55-57) distinguished between predictable risks and unpredictable threats and offered a typology of three types of global threats: 1) wealth-driven ecological destruction and technological-industrial dangers (ozone hole, global warming, regional water shortage) and the unpredictable risk of genetic engineering; 2) risks related to poverty (environmental destruction); and 3) weapons of mass destruction. Zürn (1995: 51) saw an essential difference between environmental destruction as a result of well-being and poverty.

Kasperson and Kasperson (2001: 1) distinguish between systemic risks (e.g. of global warming) and cumulative environmental change that may cause both short- and longterm consequences. For them global environmental risks "threaten international security and peaceful relations among states" contributing to differentiation of wealth and "increasing competition, tensions, and conflict. These issues are also being stressed in "the Science Plan for the Global Environmental Change and Human Security Planning Committee ... of the IHDP" (Kasperson/Kasperson/Dow 2001: 47). They differentiate "criticality" from lesser degrees of environmental threats such as environmental endangerment, impoverishment and sustainability. Such regions are characterised by environmental degradation (water, air, soil, biomass productivity), wealth (GNP, income p.c., savings), well-being (longevity, mortality rates, infant mortality, nutrition, environmentally induced disease) and economic and technological substitutability (degree of cashcrop dependency, technological monocultures, innovation, economic diversity). Before a region reaches a status of environmental criticality, there are many warning signals that alert experts and the society to impending or recurring damage. The degree of response depends to a large extent on the political and societal sensitivity but also on the resources available to governmental and individual actors to cope with these challenges.

In their comparative synthesis they distinguished among these key driving forces: a) population growth, b) technological capacity, c) affluence/poverty, d) political-economic forces and e) beliefs and attitudes. Based on nine case studies the research team concluded that external factors were more important than internal ones and they criticised overstressing affluence and neglecting poverty. In most third world cases "poverty rather than affluence has driven unsustainable resource use" (Turner/Kasperson/Kasperson/Dow/Meyer 1995: 556).

On the regional level, they pointed to "three aspects of environmental and socioeconomic conditions [that] suggest an increasing potential for higher or catastrophic losses: 1. Vulnerability and overshoot ... 2. market conditions and overcapitalisation... [and] 3. loss of options and safety nets." (560) They discussed the different societal responses and among the generic patterns, the specificity and context, the relationship between environmental degradation and improved regional well-being, the symptoms of emerging criticality, spatial and temporal categories and among the categories of environmental change: a) peripheral or marginal situations and b) agglomerated environmental stressors. With regard to causality for the nine case studies they noted a rich variety of human causation and that no single dominant human driving force can explain "the historical emergence of environmental degradation or that captures the com-

\footnotetext{
${ }^{10}$ Smith (2001: 6) noted that risk is often used synonymously with hazards whereby "risk has the additional implication of the chance of a particular hazard actually occurring. ... Risk is the actual exposure of something of human value to a hazard and is often regarded as the product of probability and loss."
} 
plexity of change", nor could the grand theories offer satisfying interpretations what makes them conclude:

What we term the regional dynamics of change - the interplay among the trends of environmental change, vulnerabilities and fragility, human driving forces, and societal responses - must be examined within their cultural, economic, and ecological contexts. And the most satisfying interpretations invariably recognize the shifting complexes of driving forces and responses over time, tap diverse social science theory, and are firmly grounded in careful empirical work (Turner et al.: 580).

The regional trajectories of change and associated regional dynamics must be analysed in the broader framework of extra-regional linkages, such as processes of economic globalisation, including trade policies in the WTO framework that have a major environmental impact.

\subsection{Social Science Research and Considerations in Inter- national Organisations on Environment and Security}

The social science research on linkages between environmental causes and societal political impacts has been associated with political, conceptual, empirical and theoretical debates on "environmental security" that has been put on the political and research agenda by the Brundtland Report of the World Commission on Environment and Development (1987). Since the 1990s, environmental security concerns - both from national political-military to global or local human security perspectives - have gained operational relevance for governments and international organisations (e.g. NATO, OSZE, OECD). Since the 1980s, UNEP has been instrumental in initiating and supporting research on the environmental impacts of wars: a) first of the war in Vietnam (until 1975), b) later on the second Gulf War (1991), c) on the wars in the Balkans (19992001), and d) in Afghanistan (2001-2002), and possibly e) on the conflict between Israel and the Palestinians (Westing 2003, Haavisto 2003).

The social science research has focused so far primarily on two different linkages: 1) on the manifold impacts of wars on the environment and on legal efforts to protect the environment during conflicts (2001); and 2) on environmental degradation and scarcity as causes for environmental conflicts and on efforts to resolve, prevent and to address the structural root causes of these catastrophic and conflictual outcomes by both adaptation and mitigation strategies and by political efforts at conflict avoidance.

\subsubsection{Four Phases of Research}

The political and scientific claims on causal linkages between environmental stress and conflict outcomes have stimulated individual and collaborative research projects. Environmental stress factors in connection with socio-economic and political contextual factors may be either structural, conflict escalating or stimulating factors that must not necessarily result in conflict. Four phases of research have been distinguished:

- Phase I: The early research resulting from cooperation between UNEP and SIPRI and PRIO on the environmental impact of wars is linked to the pioneering work of Arthur H. Westing (1976, 1980, 1984, 1985, 1986, 1988, 1988a, 1989, 1997);

- Phase II: Two empirical environmental conflict research projects of the Toronto Group (Homer-Dixon 1991, 1994, 1996, 1999, 2000; Homer-Dixon/Blitt 1999) and of the Bern-Zuerich Group (Bächler 1990, 1994a, 1995, 1999, 1999a, 1999b, 1999c; Bächler/Spillmann 1996a, 1996b; Bächler/Böge/Klötzli/Libiszewski/Spillmann 1996); 
- Phase III: Comparative studies and conceptual deepening by many different research teams (IHDP, GECHS), partly relying on modelling (GLASS), on management efforts (ECONILE, 2001; ECOMAN, 1999) and focusing on the conflict potential of resource use (PRIO), on state failures (Esty et al. 1998, 1998a), and on syndromes (WBGU 1996);

- Phase IV: The efforts to combine the structural factors from both natural (climate change, water, soil) and the human dimensions (population growth, urbanisation/ pollution, agriculture/food) based on expertise from the natural and social sciences with conjunctural conflict constellations (Brauch 2000, 2000a, 2001, 2002, 2003).

While the first two research phases are completed ${ }^{11}$, many projects in the third are still continuing, and the fourth phase has just started. During second research phase, besides, many political, conceptual and theoretical contributions on the concept of "environmental security", two project teams have analysed the linkages between environmental scarcity and conflict (Toronto group) and between environmental degradation and scarcity and environmental conflicts and conflict resolution (Zuerich-Bern group) for a total of more then 30 both theory guided and purely descriptive case studies.

Homer-Dixon (1999: 5-6) pursued the linkages between environment, scarcity, and violence further by looking at five future types of likely violent conflicts that third world countries will be less able to prevent: 1) Disputes arising from local environmental degradation; 2) Ethnic clashes arising from population migration and deepened social cleavages due to environmental scarcity; 3) Civil strife caused by environmental scarcity that affects economic productivity and people's livelihoods. 4) Scarcity-induced interstate war, e.g. over water. 5) North-South conflicts (i.e., conflicts between the developed and developing worlds) over mitigation of, adaptation to, and compensation for global environmental problems like global warming, ozone depletion, and threats to biodiversity. He focused on the scarcity's causal role:

\section{Environmental Scarcity $\rightarrow$ Social Effects $\rightarrow$ Violent Conflict}

After a decade of research based on three major projects, Homer-Dixon (1999: 177) concluded: "that scarcity of renewable resources ... can contribute to civil violence, including insurgencies and ethnic clashes" and he predicted that in the future "such violence will probably increase as scarcities of cropland, freshwater, and forests worsen in many parts of the developing world", where the role of scarcity will be "often obscure and indirect", interacting with political, economic and many other factors. He further predicts that continued population growth and rising resource demand and persistent inequalities will affect environmentally sensitive regions, as in the Mediterranean.

The Environment and Conflicts Project (ENCOP), co-directed by Günther Bächler and Kurt R. Spillmann (Swiss group) started from the premise that environmental transformation does not directly result in conflicts but that it impacts on existing socioeconomic conflict potentials that violently escalate. The project concluded that the effects of resource degradation did not directly result in conflicts but that other contextual factors were decisive. ${ }^{12}$ The ENCOP project focused on environmental degradation as a cause of war, on the environment as a topic of conflict research, on environmental degradation through over-development (wealth-driven) and underdevelopment (poverty-

\footnotetext{
${ }^{11}$ For an overview by GECHS at: $<$ http://www.uni-bonn.de/ihdp/gechssp.htm $>$ and for a comprehensive online bibliography at: $<$ http://www. gechs.org/INES/ inespubs.shtml $>$.

${ }^{12}$ See for a review in the GECHS Science plan at: $<$ http://www.uni-bonn.de/ihdp/gechssp.htm>: 13-4 of 44 .
} 
driven) focusing on actors, and the key environmental factors of soil, rivers, mining and by offering a synthesis on environmental degradation as a cause of war and how environmental conflicts can be solved peacefully.

The GECHS Science Plan (1999) referred to several related research projects that concluded that some environmental challenges have resulted in certain forms of violence: ${ }^{13}$

The U.S. National Academy of Science (1991) and Myers (1993) suggest that atmospheric change ... has the potential to cause significant societal disruption. Land degradation ... may directly affect society's ability to provide food resources for a growing population, or may indirectly affect other changes, such as global warming. ... The evidence for a direct causal link between environmental degradation and violent conflict remains speculative. ... Lipschutz (1995), Gurr (1993, 1995), and Libiszewski (1992) argue that [Homer-Dixon, 1994] overstates the importance of resources and the environment as contributors to conflict.

The GECHS report notes "an increasing acceptance that environmental degradation is at least a contributor to conflict and insecurity". For the GECHS report the debate has also shown: "how various factors or relations of inequality and impoverishment structure threats. ... Environmental change ... is related to insecurity through conditions of inequality, institutional weakening, and impoverishment." According to the GECHS Science Plan "there is a continued need for further conceptual and theoretical discussions on ... the relationship between environment and security", and they suggest "to build upon the early empirical work ... and to provide additional empirical studies on environmental change and its relationship to a broader conception of security".

Figure 3.2: The Roads to Conflict (Schwartz 2002, V: 143)

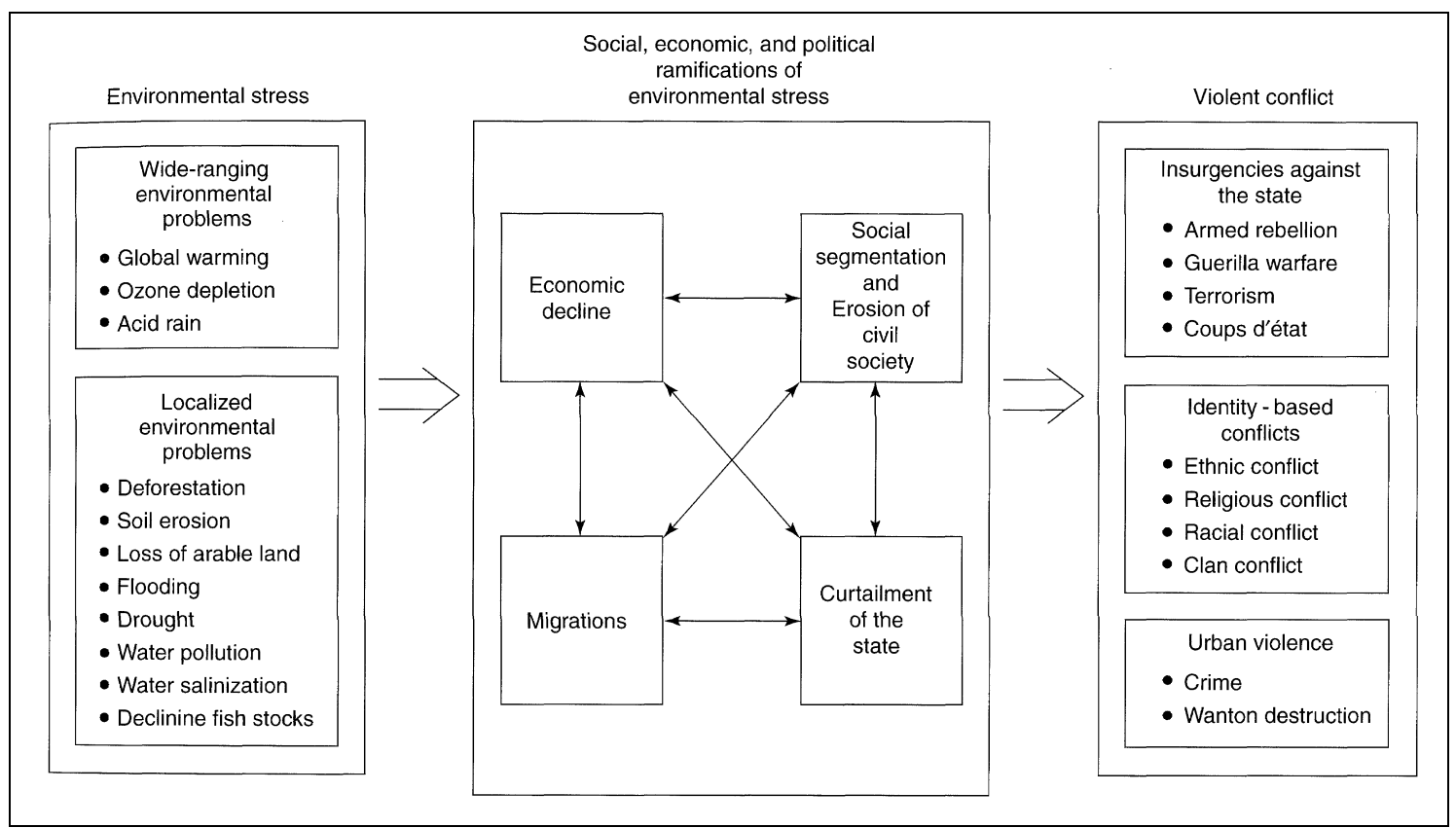

However, why the critical socio-economic constellation escalated into violent conflict and when and why they could be avoided by bilateral and multilateral cooperation of the states, experts and representatives of civil society could not yet be explained by these studies. After a decade of research a consensus emerged that "environmental stress is rarely considered to be the sole factor in precipitating conflict" both within and between nations. In his review of the state of the art, Schwartz (2002, V: 137) stated:

\footnotetext{
${ }^{13}$ For a review in the GECHS Science plan see at: < http://www.uni-bonn.de/ihdp/gechssp.htm>: 15 of 44 .
} 
In many cases environmental stress is a relatively distant factor, acting in combination with other economic and social factors such as poverty and weak governments. In other cases, conflict breaks out when rival nations, or rival groups within a nation, battle for diminishing supplies of environmental resources. Although environmental stress is usually only one cause of conflict among many, the evidence suggests that it can play an important role, and that violence may be avoided by addressing environmental problems.

Schwartz (figure 3.2) considers population growth to be closely linked with environmental stress. Among the wide-ranging environmental factors he includes ozone depletion and global warming and among the localised ones those environmental factors that affect small areas at different times (desertification, water pollution). He points to "five pathways to indirect internal conflict that involve environmental stress: economic decline, migrations, social fragmentation, erosion of civil society and curtailment of the state" (139).

A major effect of several types of environmental stress is economic decline that will effect the poor more than the rich strata of society and countries (Myers 1993; Homer Dixon 1999). A second pathway from environmental stress to conflict is through migration that are sometimes caused by floods, droughts or locusts, by a lack of arable land that again is often the result of environmental stress, but also by water and air pollution, a shortage of fuel wood.

Global and localised environmental stress has in some cases - e.g. in the Sahel - contributed to international conflicts. While Lipschutz and Holdren (1990: 126-129) have doubted this connection, Gleick (1989: 338, 1989a) has noted that global warming could affect freshwater availability and food productivity what will have severe impacts on poorer nations. Some have argued that environmental stress coupled with rapid population growth could induce large-scale migration pressures from the South to the North, e.g. across the Mediterranean (Brauch 1997b, 1997c, 2000), what could increase domestic tensions between citizens of host countries and immigrants in the North.

Direct international conflicts may result from the increasing competition over access to water resources (Starr 1991; Gleick 1993, 1993a, 1994, 1998) while others (Hamner/ Wolf 2000: 123 -148) counted only few minor skirmishes over international waters partly due to increasing international cooperation (Homer-Dixon 1999: 139; Schwartz 2002: 147). Direct internal conflict, especially in developing countries, has also occurred as a result of environmental stress. Schwartz (148) argues that causal linkages between environmental stress and conflict could be shown in individual case studies, but that future research is needed "to estimate the causal effects of environmental stress." In a review of the state of the art on resource and environmental conflict, Gleditsch (2002: 56) suggested that resource and environmental aspects of conflict "should be examined within the context of a broader view of armed conflict" with a special focus at politics, economics, cultural factors and the conflict history. In Gleditsch's (2002: 62) view, "the term 'environmental insecurity' should be reserved for situations where environmental degradation seriously impairs or threatens to impair human life".

In May 2002 at least nine ongoing research projects in the third research phase may be distinguished. A difference between the second and third phase was leaving the outcome (dependent variable) - violent conflict or cooperation - open. The second phase chose cases studies where there was a violent outcome, while the third phase also looks at cooperative managed scarcity problems (Brauch 2003). 
- Within the International Human Dimensions of Global Change Program (IHDP) the Global Environmental Change and Human Security (GECHS) project was launched that offered a framework for research cooperation and coordination and suggested an index human insecurity (Lonergan/Gustavson/Carter 2000).

- The research projects ECOMAN, ECONILE and "Environmental Change and Conflict Transformation", in Zuerich and in Berne, continue the case study approach and focus on peaceful and cooperative management of renewable resource use in the Horn of Africa, the Nile region and other areas.

- The analytical and conflict theoretical syndrome approach of the Scientific Advisory Council on Global Environment Issues of the German government focuses on the patterned interaction of symptoms of global change with socio-economic processes.

- A policy oriented Swiss project on "Research Partnerships for Mitigating Syndromes of Global Change" that has started in late 2001 and is projected for 10 years.

- The US State Failure Task Force Project classified 175 cases of state failure between 1956 and 1996 which found only peripheral linkages between environmental phenomena as causes of state failure. The research was funded primarily by the CIA and conducted by social scientists at American universities.

- Research teams by Klaus-Jürgen Gantzel (Hamburg), Frank Pfetsch (Heidelberg), Peter Wallensteen (Uppsala) and Nils-Petter Gleditsch (Oslo) have analysed causes and intensity of violent conflicts. However, so far in all four databases environmental causes were not systematically analysed.

- Several PRIO projects focused on environment and conflict linkages, especially on civil wars, including poverty, democracy and good governance as crucial variables. In a projected new centre on civil wars within PRIO environmental factors are planned to be analysed systematically. The Conflict Prevention and Reconstruction team of the World Bank has become a funder of policy relevant peace research projects.

- The Transboundary Freshwater Dispute Database at the Oregon State University Department of Geosciences has compiled data on water disputes and their efforts at resolution (Wolf).

- The Global Assessment of Environment and Security (GLASS) project at Kassel university models future threat intensity of environmental changes for human security with a special focus on the linkages between water and food scarcity (Alcamo/ Endejan 2002) ${ }^{14}$.

This author has proposed a fourth phase of environmental security debate with a focus on the Mediterranean (Brauch 2002, 2003).

So far the scientific debate on "environmental security" has involved primarily peace researchers, security and environmental specialists from Europe and North America while there was hardly any debate in the South where these implications will occur (Se$\lim$ 2003; Brauch 2003). The debate took place primarily among social scientists while the physical-human nexus that would require the expertise of both natural and social scientists has been missing. From a Southern perspective, the Egyptian diplomat, S. Saad worried: "that wealthy countries in the North can afford to care about the environment and will undermine the international legal principle of sovereignty in the name of a higher goal called environmental security" (Lonergan $2002 \mathrm{~V}$ : 275). This concern indicates that Northern states may try to dictate the patterns of natural resource usage,

\footnotetext{
${ }^{14}$ GLASS: "Global Assessment of Environment and Security”, in: < http://www.usf.uni-kassel.de/usf/forschung/ projekte/glass.de.htm>.
} 
development priorities and population policies to the South. The elite in some countries may find change of social bargains for environmental reasons as a larger threat to state security than environmental destruction. This concern was not shared by Rajendra Pachauri who was elected in spring 2002 as the new chairman of the IPCC. Pachauri ${ }^{15}$ defined environmental security from an Indian perspective as:

the minimization of environmental damage and the promotion of sustainable development, with a focus on transboundary dimensions. 'Environmental stress' - an important factor in this equation - is caused both by environmental resource scarcity (deforestation) and also by environmental resource degradation (polluted water). Economic vulnerability and resource dependency play key roles in the link between environmental change and the potential for violence and insecurity in the developing world. Developing countries also usually lack the infrastructure and institutions to respond to crises, thereby increasing the chance of violence. The majority of such disputes thus far have been solved amicably, but Pachauri stressed that this might not be the case in the future.

He pointed to five linkages between poverty and natural resource stress:

First, the continuing struggle to provide food and basic needs is increasing land degradation in the developing world. ... Second, worsening pollution increasingly impacts air quality, with vehicular traffic and industrial expansion the key contributors. Acid rain resulting from such pollution has become a critical issue in the South Asia region. Third, world climate change that has led to a rise in both temperature and sea level holds dire consequences for South Asia coastal regions. In Bangladesh, for example, hundreds of people are killed every year by a monsoon and flood cycle, which has become more severe due to changes in sealevel and climate changes. Fourth, both water quality and quantity are at risk due to land-use changes, deforestation, and polluted waters both locally and across national borders.

For Pachauri poverty refers to the people's lack of ability to retain control over their living conditions. Many other factors, such as lacking property rights, unsustainable resource exploitation, restricted access to resources such as fuel, the impact of science and technology, global economic factors, and national economic policies strengthen the cycle between environmental degradation and poverty.

\subsubsection{Considerations in International Organisations}

Several high-level Commissions of the 1980s (Brandt, Palme, Brundtland), and the analyses by social scientists have concluded that issues of environmental stress have reached policy makers in national governments and in international organisations more in the North than the South, which has already been affected by these factors and whose countries may become the primary victims. In the following the activities of several international organisations (NATO, UN, OSCE, OECD, EU) will be reviewed on the background of changes in the political agenda of the sole superpower where environmental security concerns have been taken from the agenda.

Since the mid-1990s, the Science Committee of NATO has supported several Advanced Research Workshops on issues of environmental security and environmental conflict that have facilitated the scientific communication between security specialists, peace

\footnotetext{
${ }^{15}$ See: R.K. Pachauri: "Environmental Security: A Developing Country Perspective", meeting report of the Wilson Center, Environmental Change and Security Project, Current Events, 17 October 2000, at: $<$ http://ecsp.si.edu/archive/rk-pauchari.htm>.
} 
researchers and environmental experts. ${ }^{16}$ The final report of the NATO-CCMS (1999: 84) pilot study on "Environment and Security in an International Context" stated:

that non-traditional threats to security such as economic decline; social and political instability; ethnic rivalries and territorial disputes; international terrorism, money laundering and drug trafficking; and environmental stress are redefining the traditional missions of security organisations such as the North Atlantic Treaty Organisation (NATO). NATO ... has begun to address non-traditional threats to security in order to meet the looming domestic and international risks defining the security context in the post-Cold War world.

The pilot study pointed to the needed adaptations of institutions both in the environmental and security policy area. Among the future challenges, the pilot study pointed to the "unfavourable consequences of local, regional, and global environmental stress" that may emerge from regions other than the "Euro-Atlantic region, such as developing countries and countries in transition" (NATO/CCMS 1999: 88). The pilot study assesses the links between environment and security, examines the consequences of economic stress and their potential impact on conflict escalation, offers a typology of environmental conflict cases, provides an integrated risk assessment, deals with indicators, data and decision support systems and presents an integrated approach of policy responses for environmental, development, foreign and security policy (Lietzmann 1999: 35) that deal i.e. with early warning, preventive diplomacy, permanent mechanisms for dispute settlement, crisis and post-crisis management (NATO/CCMS 1999: 164-167). ${ }^{17}$

Since the publication of the Brundtland Report (1987), several international organisations have addressed the linkages between environmental stress and its potential for conflicts. They have been referred to in the UN Agenda for Peace (Boutros Ghali 1992) and Developments (UN 1992) and in the Millennium Report of the Secretary General (Kofi Annan 2000). In 1998, the UN Task Force on Environment and Human Settlement developed a planned contribution to the prevention of environmental conflicts further (Schwartz/Singh 1999).

The Organisation for Security and Cooperation in Europe (OSCE) has dealt with security risks resulting from environmental stress. ${ }^{18}$ Among the non-traditional security risks confronting some OSCE countries are trans-boundary pollution, shortage of drinking water, disposal of radioactive waste, reduction of human losses in man-made disasters and natural catastrophes.

The Organisation for Economic Co-operation and Development (OECD) has addressed the linkages between development, environment and conflicts in several policy statements, such as "Development Assistance, Peace and Development Co-operation of the $21^{\text {st }}$ Century" (OECD/DAC 1997) and in a scooping paper on the economic dimension of the environmental security problem that have been reflected in the new "Guidelines on Conflict, Peace and Development Co-operation" (OECD 2001).

\footnotetext{
${ }^{16}$ NATO's scientific and Environmental Affairs Division financed several Advanced Research Workshops (ARWs) including: "Conflict and the Environment" (Gleditsch 1997); "Environmental Change, Adaptation and Security" (Lonergan 1999); "Responding to Environmental Conflicts: Implications for Theory and Practice" (Petzold-Bradley/Carius/Vincze 2002); "The Caspian Sea: a Quest for Environmental Security" (Asher/Mirovitskaya 2000); "Soil Quality, Sustainable Agriculture and Environmental Security in Central and Eastern Europe (Wilson/Maliszewska-Kordybach 2000).

${ }^{17}$ See the Background Paper by Petzold-Bradley/Carius for the OSCE seminar in July 2001.

18 OSCE: Background Paper "Environment and Security: the Role and Work of the OSCE" for the International Seminar: Strengthening the OSCE's Role in the Realm of Environment and Security", Berlin 3-4 July 2001.
} 
The European Council at Nice (2000) and Göteborg (2001) adopted conceptual papers on conflict prevention and conflict management that are of relevance for the security and environment linkage. Within the European Commission this nexus has been addressed by the DG External Relations in the framework of its conceptual efforts at conflict prevention that was supported by the establishment of the Conflict Prevention Network and since 1996 by several seminars on "European security and the European Union's External Economic Policies" that looked at new security threats including environmental challenges for European security. In implementation of the Amsterdam Treaty and of the Cardiff decision (1998) the DG for Environment prepared a document on the integration of environmental concerns in foreign relations and also into the common strategies, e.g. for the Mediterranean that was adopted at the European Council in Feria (2000).

Within the European Parliament, the Committee on Foreign Affairs and Defence Policy adopted the Theorin-Report that dealt both with the ecological consequences of military activities and with the security implications of environmental degradation. On the operational level linkages between environment and security have already been addressed in the framework of the Stability Pact of the Balkan Regional Environmental Reconstruction Programme (RERP), and they have been funded by the TACIS - Programme for the Newly Independent States and by other "Cross Border Projects".

In the Millennium Declaration of September 2000, the role of the UN in conflict prevention was stressed. ${ }^{19}$ The World Summit on Sustainable Development in Johannesburg in 2002 may offer a new opportunity to address this linkage in the context of efforts for "environmental policy and sustainable peace". A German official cautioned that "no general agreement has been reached on the topic of environment and security and little progress has been made to develop workable schemes on how to proceed with this issue to make practical progress though everybody seems to agree that it is a highly important question." International organisations should move from discussions "to negotiate practical solutions for troublesome zones of the globe" (Szelinski 2001: 1).

\subsection{Environmental Stress and Outcomes: Disasters, Crises, Conflicts and their Resolution, Prevention and Avoidance}

Environmental security studies focus on vulnerabilities and risks that may produce different outcomes. Five potential outcomes of the environmental - societal linkages with an impact on security and survival will be reviewed next: a) environmental hazards and disasters (3.3.1), b) environmental refugees (3.3.2), c) environmental crises (3.3.3), d) environmental conflicts (3.4.4) and e) efforts to resolve, prevent and avoid violent outcomes (3.4.5).

\subsubsection{Environmental Stress and Environmental Hazards and Disasters}

A hazard may be the result of a naturally occurring event or of a human induced process that can be increased or reduced by human actions. In its Third Assessment Report (TAR) the IPCC (2001) estimated that extreme weather events (heat waves, storms, cyclones) are likely to very likely to increase during the $21^{\text {st }}$ century (figure 2.3 ). Thus, climate change may become a direct cause for increased hazards (e.g. floods, drought).

19 See the sections: „Peace, Security and Disarmament” and "Protecting the Vulnerable”. 
Keith Smith (2001: 8) distinguished among hazards to people (death, injury, diseases); to goods (property damage, economic loss); and c) to the environment (loss of flora and fauna, pollution, loss of amenity). Environmental hazards may be natural or man-made with different effects. Natural environmental hazards or events are caused by external forces. Human sensitivity to these hazards is a combination of physical exposure and human vulnerability. Technological disasters are created by the spread and failure of high-risk technologies.

Smith distinguished between five potentially hazardous environmental events of an a) atmospheric (rain, hail, storm, hurricane, tornado); b) hydrologic (floods, drought); c) geologic (landslides, earthquake, volcanic eruption, rapid erosion); d) biologic (epidemic, forest fires); and e) technologic (air crash; industrial explosion, nuclear power plant failure, collapse of buildings, germ, nuclear warfare) nature. Environmental disasters are often defined as the result of human factors and physical triggers (environmental events), such as earthquakes, volcanic eruptions, floods or storms. While accidents are localised events, disasters affect large parts of the infrastructure and of the community's social systems (Aptekar 1994). Many of the natural disasters are the result of "ecologically destructive practices and from putting ourselves in harm's way" (Abramovitz 2001: 6).

Figure 3.3: Costs of Catastrophic Weather Events (1950-1999) (IPCC 2001: 422)

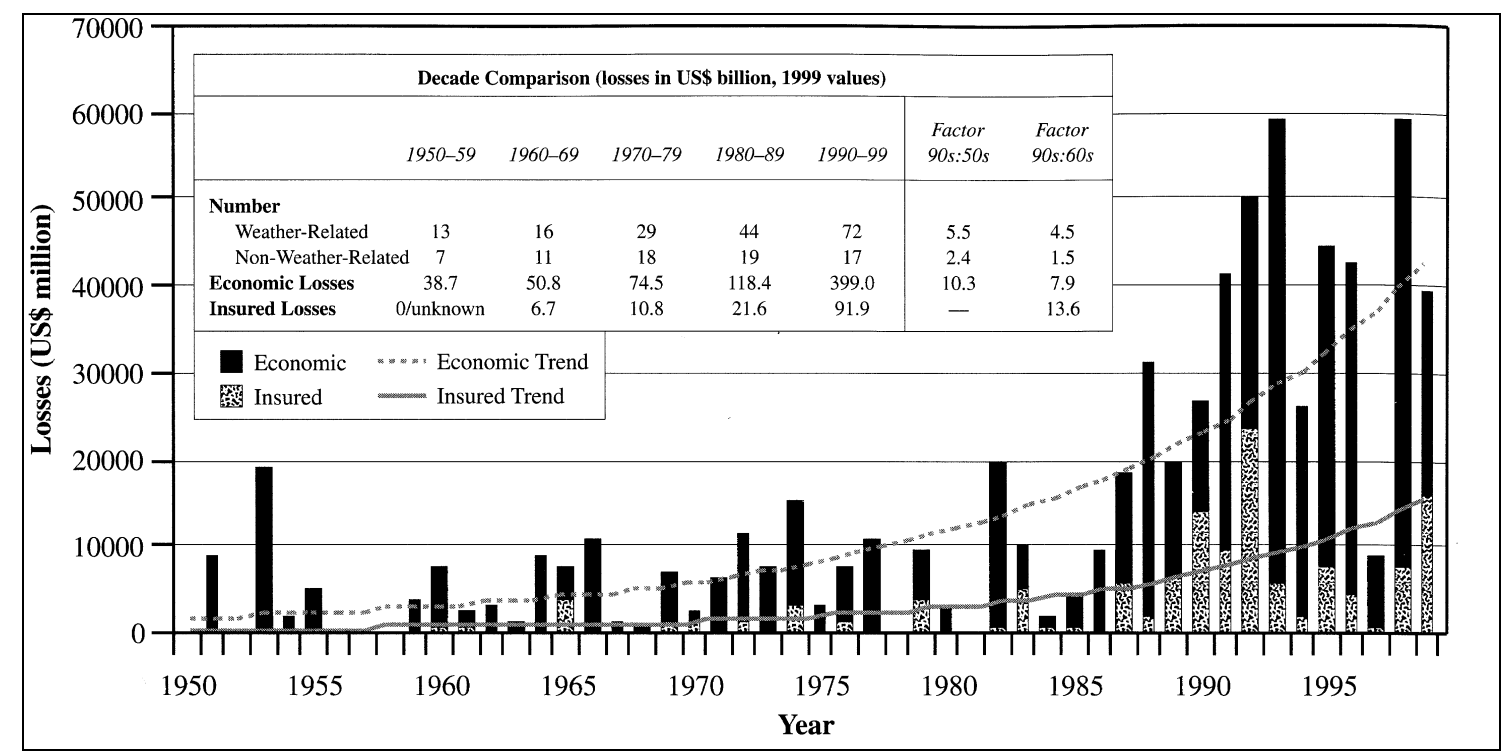

Since the 1950s both the number of major catastrophes and the economic losses have increased. Between 1985 and 1999 77\% of the death were in Asia, 4\% in Africa and 1\% each in Europe and North America that were caused by floods (49\%), earthquakes and volcanoes $(30 \%)$, windstorms $(15 \%)$ and others $(6 \%)$, but of the economic losses $45 \%$ occurred in Asia, 33\% in North America, 12\% in Europe but only 1\% in Africa. National efforts and international activities to side-step environmental conflicts by an improved assessment and mitigation of natural hazards have intensified (IFRC 2001). ${ }^{20}$

\footnotetext{
${ }^{20}$ See: United Nations, Office for the Coordination of Humanitarian Affairs: "Risk Assessment Tools for Diagnosis of Urban Areas against Seismic Disasters", at: < http://www.unisdr.org/unisdr/>; See: International Decade for Natural Disaster Reduction 1990-2000, at: $<\underline{\mathrm{http}} / / /$ www.unisdr.org/ $>$; and a sitemap of UN activities at: <http://www.unisdr.org/sitemap.htm>; for other activities at: http://www. oneworld.org/idndr/ about. html; See also: UN International Strategy for Disaster Reduction: "Natural Disasters and Sustainable Development: understanding the links between development, environment and
} 
The IPCC (2001: 422) noted a rapid upward trend in the costs of catastrophic weather events since 1950, especially since 1988, most of them weather-related (figure 3.3):

Weather-related events of all magnitudes resulted in US\$ 707 billion in insured and uninsured losses between 1985 and 1999. A longer term comparison of large catastrophic events over the past 50 years reveals that economic losses (adjusted for inflation) increased by a factor of 10.3. Over this period population grew by a factor of 2.4 (IPCC 2001: 422)

Table 3.1: Total and Average Number of People Reported Killed and Affected by Disasters, by Country between 1981-1990, 1991-2000, and in 2001

\begin{tabular}{|c|c|c|c|c|c|c|c|c|c|c|}
\hline \multirow[t]{3}{*}{ Countries } & \multicolumn{4}{|c|}{ 1981-1990 } & \multicolumn{4}{|c|}{ 1991-2000 } & \multirow{2}{*}{\multicolumn{2}{|c|}{\begin{tabular}{c|}
2001 \\
no. of people
\end{tabular}}} \\
\hline & \multicolumn{2}{|c|}{ number of people } & \multicolumn{2}{|c|}{ annual average } & \multicolumn{2}{|c|}{ numb. of people } & \multicolumn{2}{|c|}{ annual average } & & \\
\hline & killed & affected & killed & affected & killed & affected & killed & affected & killed & affected \\
\hline & \multicolumn{10}{|c|}{ Three country case studies } \\
\hline Mexico & 11,961 & 753,887 & 1,196 & 75,389 & 4,902 & $2,851,231$ & 490 & 285,123 & 43 & 6,400 \\
\hline Bangladesh & 27,903 & $228,794,460$ & 2,790 & $22,879,446$ & 147,753 & $90,473,239$ & 14,775 & $9,047,324$ & 469 & 729,033 \\
\hline \multirow[t]{2}{*}{ Egypt } & 1,054 & 163 & 105 & 16 & 2,696 & 204,096 & 270 & 20,410 & 147 & 510 \\
\hline & \multicolumn{10}{|c|}{ Selected Mediterranean States (MENA) } \\
\hline Algeria & 402 & 52,006 & 40 & 5,201 & 511 & 94,904 & 51 & 9,490 & 921 & 50,423 \\
\hline Morocco & 136 & 12,216 & 14 & 1,222 & 1,423 & 99,685 & 142 & 9,969 & 26 & 200 \\
\hline Tunisia & 441 & 163,549 & 44 & 16,355 & 34 & 89 & 3 & 9 & & \\
\hline Israe & 62 & 398 & 6 & 40 & 115 & 1,912 & 12 & 191 & 15 & 247 \\
\hline Lebano & 65 & 1,500 & 7 & 150 & 35 & 104,102 & 4 & 10,410 & & \\
\hline Syria & 0 & 0 & 0 & 0 & 155 & 658,097 & 16 & 65,810 & 54 & 191 \\
\hline \multirow[t]{2}{*}{ Turkey } & 1,800 & 94,287 & 180 & 9,429 & 20,815 & $2,054,419$ & 2,082 & 205,442 & 154 & 3,696 \\
\hline & \multicolumn{10}{|c|}{ Selected Mediterranean States (EU) } \\
\hline France & 768 & 507,279 & 77 & 50,728 & 808 & $3,844,907$ & 81 & 384,491 & 46 & 34,292 \\
\hline Greece & 1,418 & 126,148 & 142 & 2,615 & 504 & 214,789 & 50 & 21,479 & 11 & 1,350 \\
\hline Italy & 785 & 58,983 & 79 & 898 & 837 & 244,519 & 84 & 24,452 & 139 & \\
\hline \multirow[t]{2}{*}{ Spain } & 1,297 & 816,681 & 130 & 81,668 & 520 & $6,069,334$ & 52 & 606,933 & 66 & 28 \\
\hline & \multicolumn{10}{|c|}{ Selected Small Island States } \\
\hline Cap Verde & 64 & 119,722 & 6 & 11,972 & 18 & \begin{tabular}{|l|}
16,306 \\
\end{tabular} & 2 & 1,631 & - & \\
\hline Mauı & 161 & 37,358 & 16 & 736 & 5 & 10,800 & 1 & 1,080 & - & \\
\hline Seychelles & 0 & $1,218,000$ & 0 & 121,800 & 5 & 1,237 & 1 & 124 & - & \\
\hline Antigua & 2 & 83,030 & 0 & 8,303 & 5 & 76,684 & 1 & 7,668 & - & \\
\hline Cuba & 289 & 815,680 & 29 & ,568 & 813 & $2,306,172$ & 81 & 230,617 & 5 & $5,900,012$ \\
\hline $\begin{array}{l}\text { Dominican } \\
\text { Republic }\end{array}$ & 245 & $1,343,190$ & 25 & 134,319 & 782 & $1,024,425$ & 78 & 102,443 & & \\
\hline Hai & 475 & $1,165,491$ & 48 & 549 & 4,110 & $2,605,670$ & 411 & 260,567 & 71 & 5.091 \\
\hline Jamaic: & 166 & 882.703 & 17 & 88,270 & 13 & 556,512 & 1 & 55,651 & 1 & 200 \\
\hline Maldives & 0 & 300 & 0 & 30 & 10 & 23,849 & 1 & 2,385 & & \\
\hline Fiji & 79 & 606,201 & 8 & 60,620 & 80 & 430,730 & 8 & 43,073 & 1 & \\
\hline Micronesia & 5 & 203 & 1 & 20 & 0 & 84,000 & 0 & 8,400 & - & \\
\hline Salomon I. & 8 & 197,000 & 1 & 19,700 & 2,724 & $1,637,506$ & 272 & 163,751 & & \\
\hline Tonga & 0 & 1,832 & 0 & 183 & 37 & 88,904 & 4 & 8,890 & - & 16,450 \\
\hline Tuvalu & 8 & 149,617 & 1 & 14,962 & 0 & 6,571 & 0 & 657 & & \\
\hline
\end{tabular}

In the World Disaster Report 2001, the International Federation of the Red Cross listed among the countries and regions covered here for 1981 to 2000 the number of people killed and affected by disaster (Table 3.1). The total number of reported disasters increased from 454 in 1991 to 752 in 2000 reaching a total of 4,703 events from 1991 to 
2000. In 1991 a total of 170,093 persons were killed (most in Bangladesh) and over the decade until 2000 a total of 752,521 died and 2,108,025 were affected by disasters causing damages amounting to US\$ $809,785.8$ million (in 2000 prices).

Figure 3.4: Regional Insurance Coverage of Natural Disasters (1985-1999) (433)

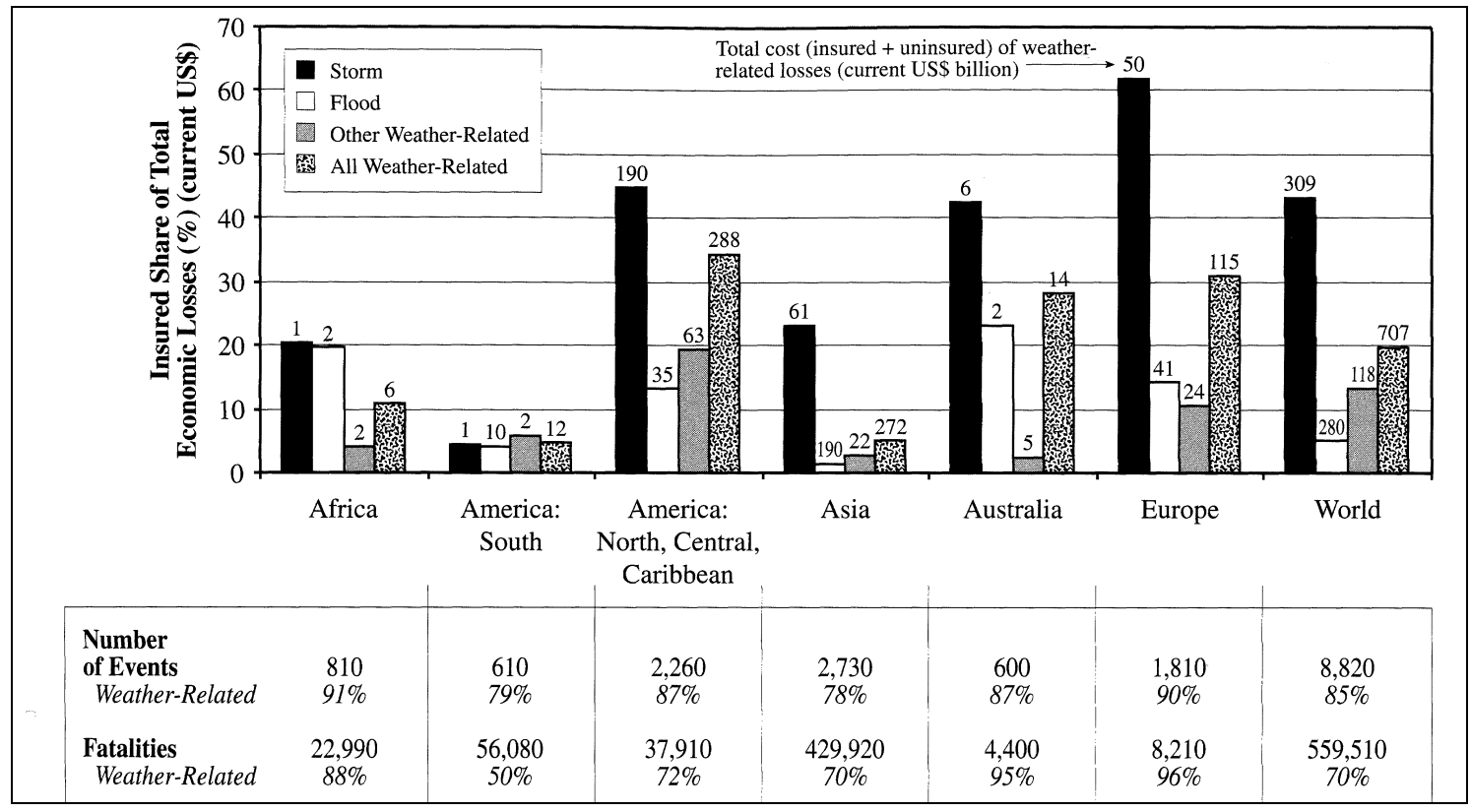

\subsubsection{Environmental Stress and Environmental Refugees}

Since the mid 1980s, many studies stated that environmental stress caused by both natural factors (climate change and extreme weather, soil erosion, deforestation and desertification, drought and floods) and human factors (population growth, urbanisation, food scarcity and agricultural exploitation of marginal lands) have forced people to migrate from their territory (push factors) and to look for better living conditions in urban centres or abroad (pull factors). In the literature labour migrants are often distinguished from environmental refugees or distress migrants that have left their homeland due to drought (Sahel), floods and storms (Bangladesh) that are consequences of climate change and of overexploitation of the soil. Depending on the specific contexts, such refugees have either been absorbed or provoked violent clashes (Suhrke 1993, 1996, 1997). ${ }^{21}$

While during the $20^{\text {th }}$ century environmental causes may have played a minor role, many authors (El-Hinnawi 1985; Jacobson 1988; Myers 1993, 1995; Williams 1998), and international organisations (IOM 1996) and regimes (IPCC 1996, 2001) have pointed to environmental refugees as a new challenge while others doubted the scientific plausibility and lacking empirical evidence (Black 1993, 1998, 2001). Myers (2002; IV: 214218) estimated that of the 25 million environmental refugees in 1995, 5 of 10 million were in the Sahel, and 4 of 11 million in the Horn of Africa.

Poverty serves as an additional push factor associated with the environmental problems displacing people. Other factors include population pressures, malnutrition, landlessness, unemployment, over-rapid urbanisation, pandemic diseases and government shortcomings, together with ethnic strife and conventional conflicts. In particular it is sometimes difficult to differentiate between refugees driven by environmental factors and those impelled by economic problems (218).

\footnotetext{
${ }^{21}$ El Hinnawi 1985; Jacobson 1988; Myers 1993, 1995, 2002; Bächler 1994; Brauch 2000/2001.
} 
Myers admits the statistical problems of identifying environmental refugees, because there is no institutionalised mode for dealing with them. In 1994, a UN symposium on Desertification and Migration addressed these linkages (Puigdefabricas/Mendizabal 1995; Westing 1994, 1994a) and its participants adopted "The Almeria Statement". Environmental migrants and refugees are often difficult to quantify because both in the emigration and immigration statistics of the sending and recipient countries and in the migration statistics of international organisations (UN, OECD, IOM) environmental causes are not included.

However, as the concept of "refugees" has a specific meaning in international legal instruments and entitles to specific protection, the concept "environmental refugee" has been confusing because environmental causes do not entitle the victim to be protected with a refugee status. Thus, in national and international migration statistics environmental push factors are not listed. It may be more appropriate to use the concept of distress migration instead. In their struggle for survival distress migrants require both short-term catastrophe relief (food aid, water supply etc.) at the family or clan level and complex and interrelated counter strategies of climate change and reproductive health.

Natural disasters have already become a major push for distress migrants in Bangladesh to leave their homes and to migrate elsewhere within the country or abroad. According to the US Committee of Refugees, the number of refugees and asylum seekers from Bangladesh were 48,300 in 1994, about 53,000 in 1996 and 40,000 in 1997. In 1998 and 1999 Bangladesh reported 50,000 internally displaced persons and in 2000 about 60,000. In 1994, Bangladesh hosted 116,200 refugees and asylum seekers, in 1996 about 40,000 and in 2000 about 121,600. From Egypt this source lists only 3,000 refugees and asylum seekers for 1999 while the number of refugees and asylum seekers in Egypt increased from 10,700 in 1994 to 47,000 in 1999 and slightly declined to 45,000 in 2000. In Mexico the number of refugees declined from 47,700 in 1994 to 6,500 in 2000 (IFRC 2001).

Table 3.2: Stock of Foreign-born Population in the USA, 1970, 1980, $1990(1,000)$

\begin{tabular}{|l|r|r|r|r|r|r|}
\hline Country of Birth & \multicolumn{1}{|c|}{1970} & \multicolumn{1}{|c|}{1980} & \multicolumn{1}{|c|}{1990} & \multicolumn{3}{|c|}{ inflow of perm. settlers } \\
\hline & & & & 1991 & \multicolumn{1}{c|}{1995} & \multicolumn{1}{c|}{1998} \\
\hline Mexico & 759.7 & $2,199.2$ & 4.298 .0 & 946.2 & 89.9 & 253.0 \\
\hline Cuba & 439.0 & 607.8 & 737.0 & 10.3 & 17.9 & 20.4 \\
\hline Dominican Republic & & 169.1 & 347.9 & 41.4 & 38.5 & 131.6 \\
\hline Jamaica & & 196.8 & 334.1 & 23.8 & 16.4 & 15.1 \\
\hline Haiti & & & & 47.5 & 14.0 & 13.4 \\
\hline Total & $9,619.3$ & 14,079 & $19,767.3$ & $1,827.2$ & 720.5 & 660.5 \\
\hline
\end{tabular}

Migration has become a major outcome of environmental stress. But it is difficult to provide statistical evidence that people left their home country for environmental reasons. In the census based migration statistics to the United States of the foreign born population from 1970 to 1990 significant increases can be observed from several countries that have been affected by natural disasters and that may become victims of the impacts of climate change in the coming decades (OECD 1998, 2001: 300, 317; table 3.2). 


\subsubsection{Environmental Stress and Political Crises}

While environmental hazards and disasters may be a direct outcome of an increase of climate-induced extreme weather events, environmental refugees or distress migration may be caused by environmental degradation and scarcity that it is often triggered or intensified by severe environmental hazards (e.g. drought in the Sahel, cyclones, floods in Bangladesh). Environmental stress can also become an additional cause that may contribute to severe domestic political instability and crises. In European history, between 1783 and 1789 extreme weather events and bad harvests in France in six consecutive years may have triggered the discontent that erupted in the French revolution of 1789. Between 1840 and 1850 cold and wet summers in Central Europe and bad harvests in several countries caused famine (e.g. in Ireland after 1846) and provoked severe discontent that triggered a second wave of revolutions in Central Europe (Stock 1996: 38).

The term crisis refers to a turning point - in medicine between recovery and death - in international politics between war and peace. Charles Hermann (1993: 205) distinguished between systemic crises, international confrontation crises, and governmental decision-making. "A systemic crisis threatens the stability of the international system and creates the possibility of system transformations". But systemic crises may also be resolved if the decision makers have the capability to adapt and to learn from the shocks. Domestic, governmental or decision-making crises "involve an event or other stimulus that poses a severe problem for the policymakers and possibly their constituents". Hermann referred to three properties "high threat, short time, and surprise". ${ }^{22}$

Environmentally-induced social and political crises include domestic natural events that often lead to unrest, (hunger) revolts that may threaten a government or regime. Prescriptive studies focus at means to avoid such crises or to manage them without severe consequences and to avoid escalation into violent confrontations or civil strife.

Environmental stress may lead to severe humanitarian crises that are distinct from international crises and thus, the international crisis research is only of peripheral relevance. This is supported by a study by de Soysa and Gleditsch (1999) who counted between 1989-1997 103 armed conflicts of which 88 were purely domestic and nine were classified as "intra-state with foreign intervention" and only 5 were interstate conflicts.

Uwe Kracht (2000: 133-148) analysed the linkages between humanitarian crises, food security and conflict prevention focusing on the consequences of domestic conflicts on food insecurity and hunger but he notes that "food insecurity can act as a trigger to conflict" (145). Buckland, Eele and Mugwara (2000: 181-195) analysed the relationship between drought, natural disasters and humanitarian crises in southern Africa with a special focus on the link between poverty and drought.

So far no research has been conducted on domestic and international environmental crisis decision-making on the countries that have been or will be challenged by severe environmental stress. While there is a huge body of research on adaptation and mitigation measures to counter the impact of climate change (especially by WG III of the IPCC) these technical measures have not been linked with political strategies to cope with the impacts of environmental stress that may erupt into violence and that may escalate into civil strife or international conflicts.

\footnotetext{
${ }^{22}$ Hermann, Charles, 1993: "Crisis", in: Krieger, Joel (Ed.): The Oxford Companion to Politics of the World (New York - Oxford: Oxford University Press): 205-206.
} 


\subsubsection{Environmental Stress and Environmental Conflict}

Since the 1990s, much conceptual and theoretical debate has focused on the assumed violent outcome of environmental stress (Gleditsch 1997; Diehl/Gleditsch 2001). Especially the case studies of the second phase by the Toronto and Zürich-Bern groups produced many empirical insights on the linkages between:

environmental scarcity $\rightarrow$ environmental stress $\rightarrow$ environmental conflict.

Homer-Dixon (1999: 5) distinguished above among five risk sources. Schwartz (figure 3.2) grouped the violent outcomes as a) insurgencies against the state, b) identity-based conflicts and c) urban violence. Below five likely outcomes of environmental stress were grouped in a pentagon of possible conflict constellations primarily on the domestic level: 1) situational hunger riots, 2) struggle on access to scarce resources: water and agricultural land, 3) enduring and structural urban violence and crime, 4) domestic instability, radicalisation of social classes, political, ethnic and religious groups that may also contribute to terrorism, and 5) civil wars (figure 3.5).

On the international or inter-state level environmental stress may trigger international disputes related to a) mass migration across national boundaries (e.g. in the Sahel, Bangladesh to India), b) violent clashes between migrants and natives on access to wells and agricultural land (between nomads from the Sahel and pastorals in Ghana and Nigeria), c) transborder conflicts on access and control of water from rivers (Nile, Jordan), d) resource conflicts on control over minerals and hydrocarbons (oil and gas), e.g. on oil during the second gulf war (1990), and e) on international obligations under multilateral environmental regimes (e.g. under the Kyoto Protocol of the UNFCC). So far no systematic research exists on the probability that environmental stress may lead to violent outcomes on the national or on the international level and which of the ten outcomes of the two conflict pentagons are most likely (figure 3.5).

Carius and Imbusch (1999: 18-23) saw no direct causal linkages between environmental change and violent conflict. They pointed to the "triggering and accelerating effect" of environmental degradation and resource depletion on conflict. Whether environmental stress leads to violence depends on several context variables that have been identified in the NATO Pilot Study (1999: 104-108) as a) patterns of perception, b) economic vulnerability and resource dependency, c) institutional, socio-economic and technological capacity and d) cultural and ethno-political factors, that are based on e) the violence potential and internal security structures, f) political stability, participation rights and the rule of law, g) political and economic interdependence and h) on the knowledge on conflict resolution mechanisms. These variables may explain whether and when "a conflict over environmental degradation and resource scarcity escalates to a violent conflict, or can instead be settled or solved by peaceful means".

In a critique of the literature on armed conflict and the environment, Nils-Petter Gleditsch (1998: 381-400, 2001) pointed to many weaknesses and he concluded that "systematic cross-national study by social scientists of any aspect of the environment is its infancy". In linking research on the environmental performance of nations to regime characteristics (Gleditsch/Sverdrup 1995: Midlarsky 1998) he called for major improvements in systematic data collection" in future research linking both fields. 


\section{Figure 3.5: Climate Change Impacts: Pentagon of Conflict Constellations}

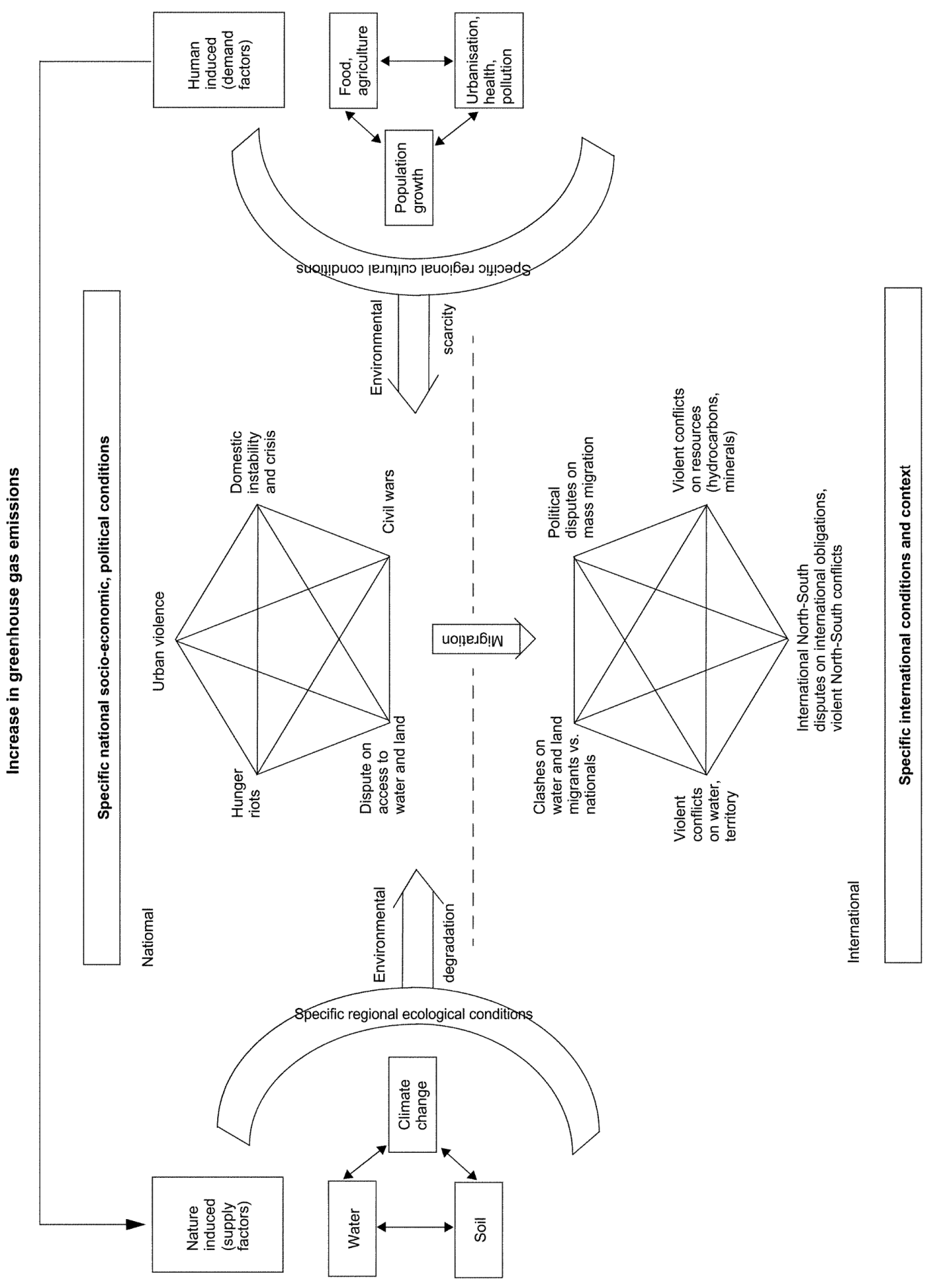

Diehl/Gleditsch (2001: 1-9) criticised a) the insights without evidence in the environmental security field and addressed empirical and theoretical shortcomings with a special focus on environmental factors as sources of conflict, b) the management of environmental conflict and c) on the future of environmental security research. Schwartz/ Delingiannis/Homer-Dixon (2001: 273-294) replied: "We need to explore how causation works at the interface between the physical/ecological and social worlds" (290) 
where "systems are characterised by huge numbers of components, causal interactions, feedback loops, and non-linearity".

\subsubsection{Environmental Conflict Prevention Through Cooperation}

A major goal of research and decision-making is to search for strategies, policies and measures to intervene in the domestic crises decision making process to address those causes that contribute to environmental stress and to develop routines for resolving domestic crises before they escalate into violent strife (environmental conflict resolution and prevention). On the longer-term structural level, strategies for sustainable development must deal with both root causes: anthropogenic climate change with policies and measures, and population growth with effective policies of reproductive health in line with the religious and cultural value systems of the respective countries.

So far adaptation and mitigating measures have been conceived as purely technical measures detached from their potential contribution to avoid environmental stresses from arising. For the development of a strategy of environmental conflict avoidance a better understanding of the linkages among the factors of the survival hexagon that contribute to environmental degradation and scarcity is needed both at the regional but also at the national level.

Among the six factors of the survival hexagon most research and political activity has focused on potential conflicts that may arise from water scarcity among countries that share the water of a river on control of these resources and on sharing arrangements. With the increasing water scarcity in semi-arid and arid regions, the division of access to scarce waters has been closely linked with several existing conflicts, especially in the Middle East conflict between Israel and the Palestinians (Lowi 1993; Lonergan 1999; Feitelson/Haddad 2001).

So far many conflicts on competing claims for transboundary water resources (both rivers and aquifers) have been solved by negotiations (hydro-diplomacy) and international agreements, (Barandat/Kaplan 1998; Schiffler 1998; Peichert 2003) e.g. in the Mediterranean for the Nile (Schiffler 1998) by both bilateral and multilateral agreements, for the Jordan (Wolf 1995; Dombrowsky 1998, 2003; Libiszewski 1995, 1997; Lonergan 1997; Beaumont 1997) and the Euphrates and Tigris (Scheumann 1998, 2003) that have contributed to dispute resolution (Beach/Hammer/Hewitt/Kaufman/Kurki/Oppenheimer /Wolf 2000). To decrease the probability of future potential conflicts over the water of the Nile the Nile Basin Initiative was launched with a major contribution by the World Bank and other international financial institutions (Waterbury 2002).

\subsubsection{From Environmental Conflict Prevention to Avoidance}

Sebastian Oberthür $(1999,2002)$ has analysed the many multilateral international efforts by environmental regimes and international organisations (UN, UNEP, UNDP) and international financial organisations and funds (World Bank, GEF) to prevent environmentally induced conflicts that may "have a general effect of civilizing and stabilizing cooperation" (2002: 243). Oberthür claimed that international environmental regimes may "contribute to the emergence of an international framework that supports a peaceful settlement of conflicts. Countries that have 'practiced' cooperation in a number of issue areas should be able to resolve problems peacefully in other areas as well (Zürn 1997)". But he also cautioned that international environmental policy "has only in the rarest cases arrived at a sustained solution of the underlying environmental problems" due to its structural limits, including the degree of effectiveness and the lack of effective sanctions 
to counter non-compliance. More effective international environment policies depend less on the specific organisational arrangements and primarily on the political will of the countries to grant sovereignty to international bodies and to fully implement the agreements they adhere to domestically.

So far, the literature on conflict prevention has focused primarily on short-term situational factors and less on medium- and longer-term structural factors that may but must not necessarily lead or contribute to conflict-prone situations in the future. Thus, this author suggested to use the concept of conflict avoidance for dealing with these longerterm structural factors (see chapter 5 below).

\subsection{Previous IPCC-Assessments of Socio-Economic Outcomes}

In the Third Assessment Report (2001) the Working Group II of the IPCC has assessed so far the factors contributing to climate change, including the increasing socio-economic vulnerabilities. Among the socio-economic and political outcomes of environmental stress, the IPCC has already systematically assessed the cost of disasters in a chapter on "insurance and other financial services" (2001a: 417-450) and has made occasional references to migration but it has not yet assessed the research dealing with environmentally induced crises, conflicts and with efforts for conflict prevention and avoidance (table 3.3).

Table 3.3: Survey of IPCC Analyses of Environmental Stress and Outcomes

\begin{tabular}{|c|c|c|c|c|c|}
\hline & \multirow[t]{2}{*}{\begin{tabular}{|c|} 
IPCC \\
Assessments
\end{tabular}} & \multirow[t]{2}{*}{$\begin{array}{l}\text { Objects of Analysis } \\
\text { (Causes) }\end{array}$} & \multirow[t]{2}{*}{$\begin{array}{c}\text { Environmental stress } \\
\text { (Impacts) }\end{array}$} & \multicolumn{2}{|c|}{$\begin{array}{c}\text { Outcomes of Environ- } \\
\text { mental Stress }\end{array}$} \\
\hline & & & & $\begin{array}{l}\text { hazard, } \\
\text { disaster }\end{array}$ & migration \\
\hline 1 & WG II (1990) & $\begin{array}{l}\text { Agriculture, forestry, } \\
\text { terrestrial ecosystems, } \\
\text { hydrology settlements } \\
\text { oceans, snow \& ice }\end{array}$ & $\begin{array}{l}\text { Impact on water/food: } \\
\text { (yields) food security, } \\
\text { regions at risk water short. } \\
\text { human health }\end{array}$ & $\begin{array}{l}\text { Drought, } \\
\text { fire, soil } \\
\text { diseases } \\
\text { flood }\end{array}$ & $\begin{array}{l}\text { Migration and } \\
\text { resettlement } \\
(5.9-5.10)\end{array}$ \\
\hline 2 & WG II (1996) & $\begin{array}{l}\text { Forests, rangelands, de- } \\
\text { serts, mountains wet- } \\
\text { lands oceans, coastal } \\
\text { zone hydrology, indus- } \\
\text { try, settlements, } \\
\text { agriculture, water, } \\
\text { wood, fisheries, health, } \\
\text { financial services }\end{array}$ & $\begin{array}{l}\text { Industry, energy, transpor- } \\
\text { tation, settlements, insur- } \\
\text { ance and financial services, } \\
\text { human infrastructure } \\
\text { health, tourism, agroindus- } \\
\text { try, biomass, renewables }\end{array}$ & $\begin{array}{l}\text { Drought, } \\
\text { deserti- } \\
\text { fication }\end{array}$ & $\begin{array}{l}\text { Human migra- } \\
\text { tion, urbanisa- } \\
\text { tion }\end{array}$ \\
\hline 3 & $\begin{array}{l}\text { Regional } \\
\text { Study (1998) }\end{array}$ & $\begin{array}{l}\text { Africa; Arctic/Antarctic, } \\
\text { Australasia, Europe, } \\
\text { Latin America, North } \\
\text { America, Small Island } \\
\text { States, Temperate Asia, } \\
\text { Tropical Asia }\end{array}$ & $\begin{array}{l}\text { Terrestrial ecosystem, hy- } \\
\text { drology, agriculture, coast } \\
\text { zone settlement, energy, } \\
\text { industry, transportation, } \\
\text { tourism health }\end{array}$ & & \\
\hline 4 & WG II (2001) & $\begin{array}{l}\text { Hydrology ecosystems } \\
\text { coastal zones human } \\
\text { settlements, energy, } \\
\text { industry insurance \& fi- } \\
\text { nancial Services health }\end{array}$ & $\begin{array}{l}\text { Africa, Australasia, Europe } \\
\text { Latin America, North Ame- } \\
\text { rica, Small Island States, } \\
\text { Temperate Asia, Tropical } \\
\text { Asia }\end{array}$ & $\begin{array}{l}\text { Extreme } \\
\text { weather } \\
\text { events }\end{array}$ & \\
\hline
\end{tabular}

The first three assessments focused on the impact of climate change upon specific ecosystems (forests, rangelands, deserts etc.), on water, soil, human settlements and human health as well as on economic sectors: agriculture, industry, energy, transportation, in- 
surance and financial services and tourism. While the IPCC assessed the impact of climate change on environmental degradation and with regard to food and water also on potential scarcities, it has not yet addressed issues associated with environmental stress and their outcomes, except a few brief remarks on environmental hazards and disasters due to extreme weather events. The IPCC has not yet assessed the impact climate change had on distress migration during the past century nor has it offered simulations of migrations until 2100.

The regional impact analysis in the regional study of 1998 and in the TAR (2001) was limited to macro-regions such as continents (Africa, Europe, Australasia), on temperate and tropical Asia, on Latin and North America and on Arctic, Antarctic and the most affected Small Island States. It drew on available country case studies on climate change impacts but it did not yet offer an assessment of the research on these issues. Only the impact of climate change on the Small Island States was discussed in the Regional Study (1998) and in the TAR (2001). Chapter 4 reviews the available evidence of the observed and likely climate change impacts for three vulnerable countries: Mexico, Bangladesh and Egypt and the arid and semiarid Mediterranean region. 


\section{Case Studies on Impacts of Climate Change}

The impact of climate change on (national) security and survival will be briefly noted for the highly vulnerable small island states based on IPCC assessments (4.2), and on three countries (4.3.-4.5) and on the Mediterranean space (4.6) based on national communications (Mexico, Egypt) and on country-specific climate studies with an emphases on analyses conducted by regional specialists. The cases were selected based on a) their relevance for national, regional and global security; and b) the urgency of the environmental challenges and their consequences for national and regional security policy.

\subsection{Common Criteria for the Country Studies}

The selected national case studies are situated in different climate zones or eco-regions (from arid to sup-tropical) that will be directly affected by the sea-level rise and by the increase of the average temperature but also by extreme weather events. All three countries share a high population growth that may negatively interact with the projected climate change impacts by increasing the demand for water, food and human settlements.

Table 4.1: Impacts of Climate Change on National Security and Survival

\begin{tabular}{|l|l|l|l|l|}
\hline & I: Mexico & II: Bangladesh & III: Egypt & IV: Mediterranean \\
\hline $\begin{array}{l}\text { Climate zone, bi- } \\
\text { omes, eco-regions }\end{array}$ & $\begin{array}{l}\text { Several clima- } \\
\text { te zones }\end{array}$ & Tropical zone & $\begin{array}{l}\text { Semi-arid, } \\
\text { arid zone }\end{array}$ & $\begin{array}{l}\text { Semi-arid, } \\
\text { arid zone }\end{array}$ \\
\hline Impacts & $\begin{array}{l}\text { Sea level and } \\
\text { temperature } \\
\text { rise, storms }\end{array}$ & $\begin{array}{l}\text { Sea level rise, } \\
\text { flooding, wa- } \\
\text { ter scarcity }\end{array}$ & $\begin{array}{l}\text { Sea level and } \\
\text { temperature } \\
\text { rise, drought }\end{array}$ & $\begin{array}{l}\text { Sea level, tempera- } \\
\text { ture rise, dryness, } \\
\text { floods, forest fires }\end{array}$ \\
\hline $\begin{array}{l}\text { Impacts on soil, } \\
\text { water, agriculture, } \\
\text { settlements, health }\end{array}$ & $\begin{array}{l}\text { Salination, } \\
\text { irreversible } \\
\text { soil erosion, } \\
\text { crop yield } \\
\text { decline } \\
\text { malaria }\end{array}$ & $\begin{array}{l}\text { Loss by sea- } \\
\text { level rise, } \\
\text { monsoon, } \\
\text { storms, water } \\
\text { diseases }\end{array}$ & $\begin{array}{l}\text { Loss of best } \\
\text { land, yield de- } \\
\text { cline, heat } \\
\text { waves, diseases }\end{array}$ & $\begin{array}{l}\text { Interaction with } \\
\text { other five factors } \\
\text { of survival hexa- } \\
\text { gon, Malaria, heat } \\
\text { waves }\end{array}$ \\
\hline $\begin{array}{l}\text { Consequences for } \\
\text { security policy }\end{array}$ & $\begin{array}{l}\text { National } \\
\text { level, land } \\
\text { conflicts, ur- } \\
\text { banisation }\end{array}$ & $\begin{array}{l}\text { All 5 levels } \\
\text { (human to } \\
\text { global secu- } \\
\text { rity) }\end{array}$ & $\begin{array}{l}\text { National and } \\
\text { regional level } \\
\text { water con- } \\
\text { flicts? }\end{array}$ & $\begin{array}{l}\text { Regional level } \\
\text { (North - South) }\end{array}$ \\
\hline $\begin{array}{l}\text { International secu- } \\
\text { rity }\end{array}$ & $\begin{array}{l}\text { security of the } \\
\text { USA: migra- } \\
\text { tion }\end{array}$ & $\begin{array}{l}\text { security of } \\
\text { India, OECD } \\
\text { migration }\end{array}$ & $\begin{array}{l}\text { conflicts with } \\
\text { neighbours, di- } \\
\text { stress migration }\end{array}$ & $\begin{array}{l}\text { for MENA-states } \\
\text { and Europe (EU) }\end{array}$ \\
\hline
\end{tabular}

In the three countries and on the Southern and Eastern Shore of the Mediterranean environmental stress will be caused by both population growth and by the manifold impacts of climate change that will reinforce each other at the local level (table 4.2). Compared with their neighbours there is a tremendous gap in key socio-economic indicators between Mexico and the USA but also between Bangladesh and India or between Egypt and Germany. 
Table 4.2: Population Growth Estimates and Projections in Million, 1950-2050 (UN 2001)

\begin{tabular}{|l|c|c|c|c|c|c|c|c|c|c|}
\hline Years $\rightarrow$ & \multicolumn{3}{|c|}{ Real population growth (million) } & \multicolumn{3}{c|}{ Projected population growth } \\
\hline Countries & $\mathbf{1 8 5 0}$ & $\mathbf{1 9 0 0}$ & $\mathbf{1 9 5 0}$ & $\mathbf{1 9 6 5}$ & $\mathbf{1 9 8 0}$ & $\mathbf{2 0 0 0}$ & Variant & $\mathbf{2 0 1 5}$ & $\mathbf{2 0 2 5}$ & $\mathbf{2 0 5 0}$ \\
\hline Mexico & & & & & & & Low (96) & & 121.079 & 127.135 \\
\hline Real/likely & 7.75 & 13.6 & 27.737 & 43.148 & 67.570 & 98.872 & Medium & 119.175 & 130.194 & 146.651 \\
\hline & & & & & & & High(96) & & 143.353 & 192.658 \\
\hline Bangladesh & & & & & & & Low (96) & & 166.535 & 178.188 \\
\hline Real/likely & 23.0 & 29.0 & 41.783 & 58.312 & 88.221 & 137.439 & Medium & 183.159 & 210.823 & 265.432 \\
\hline & & & & & & & High(96) & & 193.782 & 264.681 \\
\hline Egypt & & & & & & & Low (96) & & 87.577 & 92.596 \\
\hline Real/likely & 5.5 & 10.0 & 21.834 & 31.563 & 43.749 & 67.884 & Medium & 84.425 & 94.777 & 113.840 \\
\hline & & & & & & & High(96) & & 103.979 & 141.702 \\
\hline Germany & & & & & & & Low (96) & & 77.628 & 59.406 \\
\hline Real/likely & 35.0 & 57.0 & 68.376 & 76.031 & 78.304 & 82.017 & Medium & 80.963 & 78.897 & 70.805 \\
\hline & & & & & & & High(96) & & 84.513 & 80.094 \\
\hline
\end{tabular}

Sources: For historical data: McEvedy/Jones 1978; for growth data: 1950, 1965, 1989: Heilig 1998; for 1950, 2000 and medium variant: 2015, 2025, 2050: UN 2001; and for low and high variants, data of 1996 revision 2025, 2050: UN 1997.

While Mexico (1.52\%), Bangladesh (0.08\%) and Egypt $(0.44 \%)$ contributed in 1990 about $2.04 \%$ of the global $\mathrm{CO}_{2}$ emissions, the USA alone contributed $24.01 \%$, Japan $5.17 \%$ and Germany $4.14 \%$ or the three economically leading OECD countries accounted for one third of all $\mathrm{CO}_{2}$ emissions. In 2000, about 283 million Americans produced 12 times as much $\mathrm{CO}_{2}$ emissions as 304 million Mexicans, Bangladeshis and Egyptians or about 82 million people living in Germany contributed twice as much to global warming as 304 million persons living in Mexico, Bangladesh and Egypt. How will the impacts of climate change affect the latter three countries during the $21^{\text {st }}$ century that have contributed so far very little to global warming?

In its Third Assessment Report (TAR), the IPCC (2001) provided an overview on different regional impacts of climate change based on the best available scientific knowledge relying on a comparison of the projections of several global circulation models. WG I of the IPCC (2001: 593), in its overview of regional climate information, distinguished among 23 regions. For the analysis of the four case studies, the following are of special relevance: CAM (Central America), WNA (Western North America), CNA (Central North America). ENA (Eastern North America), NEU (Northern Europe), MED (Mediterranean), SAH (Sahara), CAS (Central Asia) and SAS (Southern Asia), EAS (Eastern Asia). In the regional projection of increases in temperature (figure 4.1) the IPCC analysed the inter-model consistency in regional warming to each model's global warming. In the regional projection of increases in precipitation (figure 4.2) the IPCC analysed the inter-model consistency in regional warming to each model's global warming. The projected changes in regional temperature (figure 4.1) and precipitation (figure 4.2) are summarised for 12 of the 23 regions that were used by the IPCC in table 4.3.

Among these 12 regions, Central Asia and the Sahara will experience much greater or greater than average warming. Only for South Asia less than one half of the model runs projected greater than average and the other half less than average warming. With regard to precipitation, Central America may experience large or small decreases of rain, only South Asia and Central Asia may experience small increases. However, Northern Europe may face large increases in precipitation and most other regions of the OECD 
(USA and eastern Asia) may have small increases while North Australia (NAU) and South Australia (SAU) varied between small and large decreases in precipitation.

Figure 4.1: Projected Changes in Temperature by Region (1990-2100)(IPCC 2001: 596)

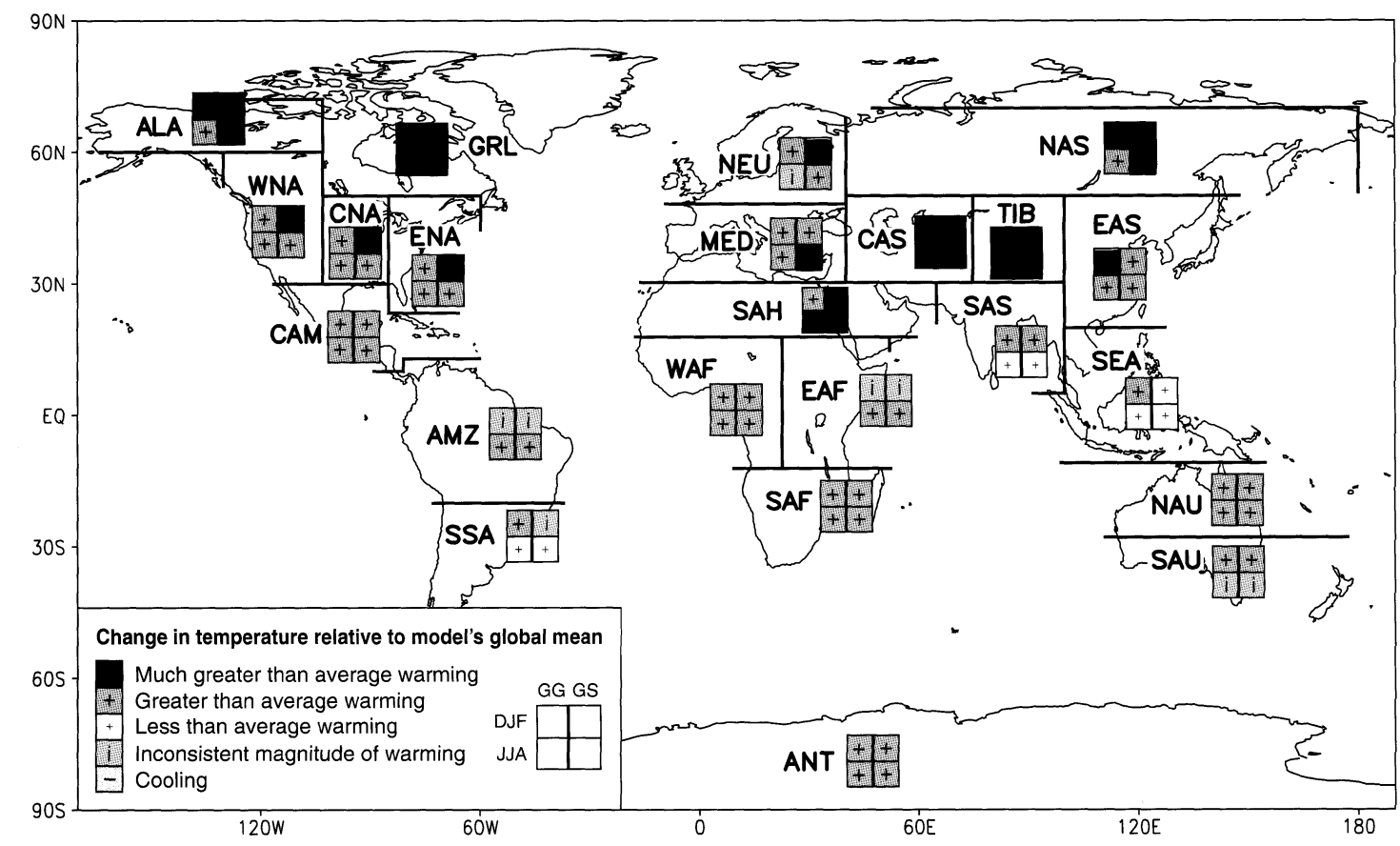

Figure 4.2: Projected Changes in Precipitation by Region (1990-2100)(IPCC 2001: 598)

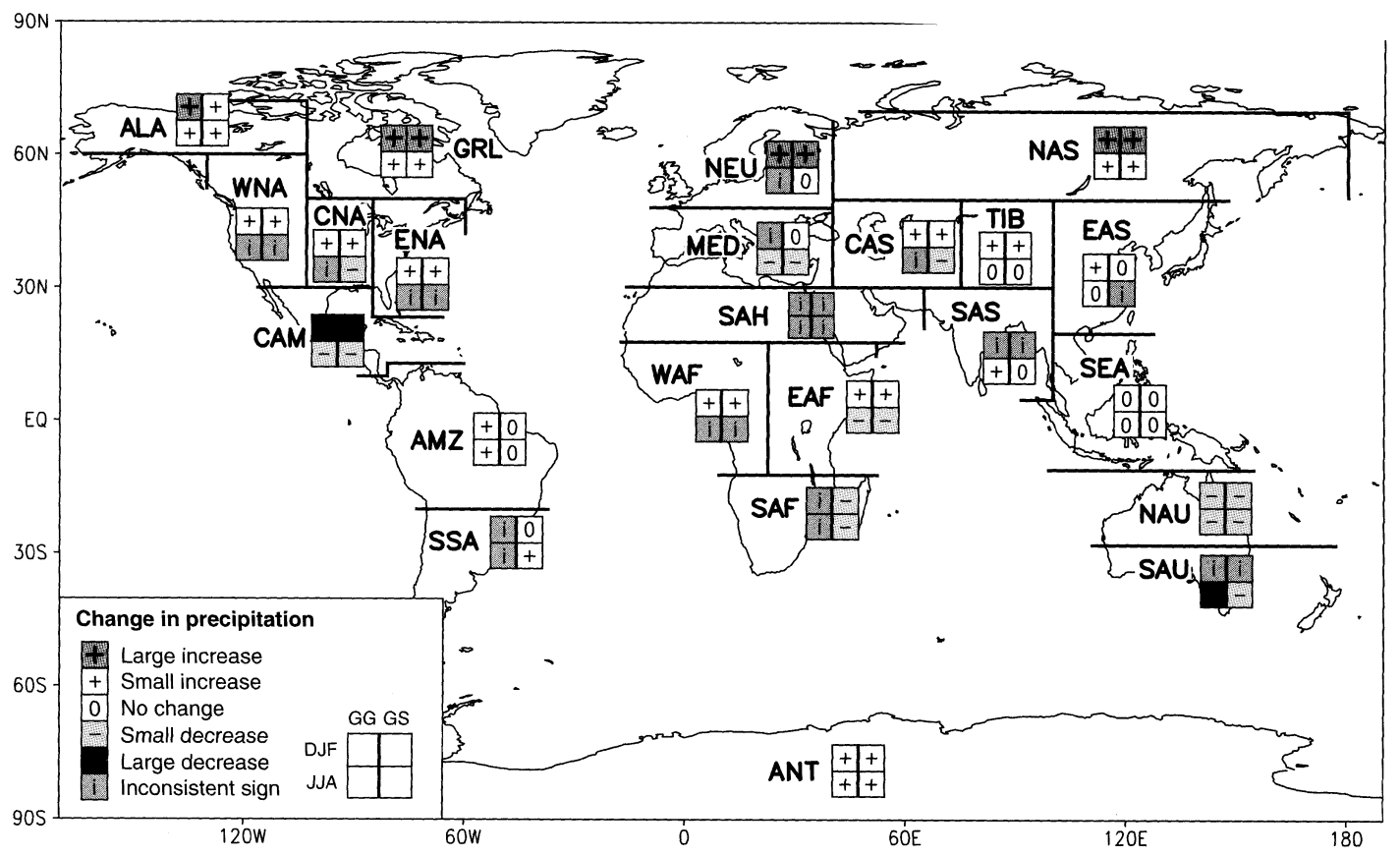

Thus, the countries with the highest GDP both in absolute and in per capital terms that have contributed most to global warming may be affected much less by the impacts of climate change than those countries that have contributed least to the cause whose affects will hurt them most. 
Table 4.3: Comparison of Regional Climate Change Impacts for Temperature and Precipitation

\begin{tabular}{|l|c|c|c|c|c|c|c|c|c|c|c|}
\hline & \multicolumn{9}{|c|}{ Change in regional temperature } & \multicolumn{6}{|c|}{ Change in regional precipitation } \\
\hline & ++ & + & - & incon & cooling & ++ & + & $\mathbf{0}$ & - & - & incon \\
\hline CAM & & 4 & & & & & & & 2 & 2 & \\
\hline MED & 1 & 3 & & & & & & 1 & 2 & & 1 \\
\hline SAH & 3 & 1 & & & & & & & & & 4 \\
\hline CAS & 4 & & & & & & 2 & & 1 & & 1 \\
\hline SAS & & 2 & 2 & & & & 1 & 1 & & & 2 \\
\hline WNA & 1 & 3 & & & & & 2 & & & & 2 \\
\hline CNA & 1 & 3 & & & & & 2 & & 1 & & 1 \\
\hline WNA & 1 & 3 & & & & & 2 & & & & 2 \\
\hline NEU & 1 & 2 & & 1 & & 2 & & 1 & & & 1 \\
\hline EAS & 1 & 3 & & & & & 1 & 2 & & & 1 \\
\hline NAU & & 4 & & & & & & & 4 & & \\
\hline SAU & & 2 & & 2 & & & & & 1 & 1 & 2 \\
\hline
\end{tabular}

What will be the consequences of these impacts of climate change for the security of the three countries on the level of human, national, regional and global security? From a global perspective, none of these countries may be expected to become a military challenge for OECD countries, given the military and technological superiority of the North. However, the potential distress and human catastrophes that may be expected especially in Bangladesh, and to a lesser extent in Egypt and Mexico will have humanitarian repercussions for the countries in the North. However, none of these challenges will be of a military nature nor can its consequences be dealt with by military means. The impacts of climate change in close interaction with the five other factors of the survival hexagon will make the struggle for survival of the affected peoples in these countries more difficult.

\subsection{Climate Change Impacts for the Small Island States}

With the exception of Malta and Cyprus all small island states are located in the tropics and subtopics in the Ocean regions of the Pacific, Indian, and Atlantic Oceans, as well as in the Caribbean and Mediterranean Seas. They share the following features that makes them highly vulnerable to the impacts of climate change:

These characteristics include their small physical size and the fact that they are surrounded by large expanses of ocean; limited natural resources; proneness to natural disasters and extreme events; relative isolation; extreme openness of their economies, which are highly sensitive to external shocks; large populations with high growth rates and densities; poorly developed infrastructure; and limited funds, human resources, and skills. These characteristics limit the capacity of small island states to mitigate and adapt to future climate and sea-level change (IPCC 2001: 845, 847; Leatherman 1997: 2).

In its third Assessment Report (TAR), WG II of the IPCC pointed to these vulnerabilities:

The most significant and immediate consequences for small island states are likely to be related to changes in sea levels, infall regimes, soil moisture budgets, and prevailing winds (speed and direction) and short-term variations in regional and local patterns of wave action. Owing to their coastal location, the majority of socio-economic activities and infrastructure and the population are likely to be highly vulnerable to the impacts of climate change and sea-level rise (IPCC 2001: 845). 
They contribute less than $1 \%$ of global greenhouse gas emissions but they are most vulnerable to the adverse effects of sea-level rise. Due to high level of poverty they have only limited resources to adapt to and to mitigate against the projected climate change impacts. The IPCC projected "that sea level will rise by as much as $5 \mathrm{~mm} \mathrm{yr}^{-1}$ over the next 100 years as a result of GHG-induced global warming" which will have serious consequences for their social and economic development.

The IPCC projected very serious impacts of climate change for beaches due to a high degree of vulnerability of coastal environments, for biological systems (coral reefs, mangroves, seagrass beds), biodiversity, for water resources, agriculture and fisheries as well as for human health, settlements and infrastructure and on tourism. They will suffer disproportionately from the effects of sea-level rise. But for them climate change is one of several challenges they will be confronted with in the $21^{\text {st }}$ century: poverty alleviation, high unemployment, improvement of housing, education and health care facilities that will compete for scarce resources. The IPCC suggested that adaptation to climate change should be integrated into risk reduction strategies for sectoral policies such as "sustainable development planning, disaster prevention and management, integrated coastal management, and health care planning" (IPCC 2001: 846).

The IPCC (1998: 333, 339-340; 2001: 847-849) referred to these observed climate trends for the years 1900-1995: For the Caribbean islands temperature rose by $0.5^{\circ} \mathrm{C}$ while mean annual rainfall decreased by $250 \mathrm{~mm}$. For the Pacific islands the temperature rise was below $0.5^{\circ} \mathrm{C}$ and rainfall records did not indicate a clear trend. In 2001, the IPCC pointed to observed temperature increases in the South Pacific between 0.3 to $0.8^{\circ} \mathrm{C}$. Since the mid 1970s western Kiribati, the northern Cook Islands, Tokela and the northern French Caledonia became wetter, whereas New Caledonia, Fiji and Tonga became drier. Rainfall has increased in the northeast Pacific but declined in the southwest Pacific region (IPCC 2001: 848). While there is still some uncertainty on the full extent of climate change impacts in the small island states, the IPCC has pointed to:

The combined effect of GHG-induced climate change and sea-level rise can contribute to coastal erosion and land loss, flooding, soil salinization, and intrusion of salt water into groundwater aquifers. The quantity and quality of available water supplies can affect agricultural production and human health. Similarly, changes in SST, ocean circulation, and upwelling could affect marine organisms such as corals, seagrasses, and fish stocks. Tourism which is a very important economic activity in many island states - could be affected through beach erosion, loss of land, and degraded reef ecosystems, as well as changes in seasonal patterns of rainfall (IPCC 2001: 848-849).

The IPCC listed among the key regional concerns of the small island sates the high vulnerability and the low adaptive capacity to climate change. Sea-level rise is expected to have disproportionately great effects on many of the small island states that may be further worsened due to increasing storm surges and flood risks. In some areas beach erosion will increase, coral reefs may be weakened, many mangroves will be put under additional stress. Water supply is very vulnerable in the atoll states of the Pacific and in the low limestone islands of the eastern Caribbean, but also in Cyprus and Malta that already experience water shortages and some islands already rely on desalination of sea water (Cyprus, Malta, Barbados, Antigua, St. Kitts, Grenada).

Climate change will have direct and indirect effects on tourism due to a loss of beaches, degradation of coastal ecosystems, saline intrusion and damage to infrastructure. This will be very important given their high dependence on tourism for their economic survival (table 4.4). Sea-level rise would also directly affect the agriculture in the low is- 
lands and atolls of the Pacific. In many island states a majority of the population lives close to the coastline and thus many settlements will be directly threatened by sea-level rises. The impacts of climate change on human health have been reported due to heat waves, drought and floods and the increase in malaria and dengue has been projected for some island states. With the increasing damage due to extreme weather events, e.g. in the Caribbean due to hurricanes and storms, the insurance costs already rose significantly.

Table 4.4: Land Area and Population Data (1995, 2050) for Selected Small Island States (IPCC 1998: 338, UN 2001) and Tourists as \% of Population (1997)

\begin{tabular}{|c|c|c|c|c|c|c|c|}
\hline \multirow[t]{2}{*}{ Country } & \multirow{2}{*}{$\begin{array}{l}\text { Land } \\
\text { area } \\
\mathrm{km}^{2}\end{array}$} & \multicolumn{2}{|c|}{ Population (1995) } & \multicolumn{2}{|c|}{ Population (2050) } & \multirow{2}{*}{$\begin{array}{c}\text { Coastline } \\
\text { length } \\
(\mathbf{k m})\end{array}$} & \multirow{2}{*}{\begin{tabular}{|c|} 
Tourists \\
$\%$ of \\
populat.
\end{tabular}} \\
\hline & & in ${ }^{\prime} 000$ & $\begin{array}{c}\text { Density } \\
\text { pers. } / \mathrm{km}^{2}\end{array}$ & in 000 & $\begin{array}{c}\text { Density } \\
\text { pers. } / \mathrm{km}^{2}\end{array}$ & & \\
\hline \multicolumn{8}{|l|}{ Atlantic Ocean } \\
\hline Cap Verde & 4,033 & 392 & 97 & 807 & & 965 & 11.4 \\
\hline Sao Tome \& Principe & 960 & 133 & 139 & 294 & & 209 & \\
\hline \multicolumn{8}{|l|}{ Caribbean Sea } \\
\hline Antigua \& Barbuda & 280 & 66 & 236 & 73 & & 153 & 364.2 \\
\hline Bahamas & 13,935 & 276 & 20 & 449 & & 3,542 & 586.4 \\
\hline Barbados & 431 & 262 & 607 & 263 & & 97 & 182.4 \\
\hline Cuba & 110,861 & 11,041 & 100 & 10,764 & & 6,073 & 10.5 \\
\hline Dominica & 750 & 71 & 95 & 72 & & 148 & 97.6 \\
\hline Dominican Republic & 48,442 & 7,823 & 161 & 11,959 & 246 & 940 & 28.1 \\
\hline Grenada & 312 & 92 & 295 & 105 & & 121 & 116.2 \\
\hline Haiti & 27,750 & 7,180 & 259 & 13,982 & 503 & 370 & 2.2 \\
\hline Jamaica & 10,991 & 2,447 & 223 & 3,815 & 347 & 1,022 & 45.6 \\
\hline St. Kitts \& Nevis & 269 & 41 & 152 & 34 & & 135 & 210.5 \\
\hline St. Lucia & 616 & 150 & 244 & 189 & & 158 & 164.7 \\
\hline St. Vicent\&Grenadines & 389 & 112 & 288 & 138 & & 84 & 54.6 \\
\hline Trinidad \& Tobago & 5,128 & 1,306 & 255 & 1,378 & & 3,760 & 28.7 \\
\hline \multicolumn{8}{|l|}{ Indian Ocean } \\
\hline Comoros & 2,171 & 653 & 292 & 1,900 & 875 & 340 & 4.9 \\
\hline Maldives & 300 & 254 & 854 & 868 & 2,893 & 644 & 130.7 \\
\hline Mauritius & 1,850 & 1,117 & 547 & 1,426 & 770 & 177 & 46.4 \\
\hline Seychelles & 280 & 73 & 261 & 145 & 517 & 491 & 166.7 \\
\hline \multicolumn{8}{|l|}{ Mediterranean Sea } \\
\hline Cyprus & 9,251 & 742 & 80 & 910 & & $\mathrm{x}$ & 280.7 \\
\hline Malta & 316 & 366 & 1,159 & 400 & 1,266 & $\mathrm{x}$ & 294.7 \\
\hline \multicolumn{8}{|l|}{ Pacific Ocean } \\
\hline Cook Islands & 236 & $(20)$ & $\mathrm{x}$ & 27 & & 120 & \\
\hline Fed. St. of Micronesia & 720 & (123) & $\mathrm{X}$ & 269 & & 6,112 & \\
\hline Fiji & 18,272 & 784 & 43 & 916 & & 1,129 & 45.3 \\
\hline Kiribati & 728 & 79 & 109 & 138 & & 1,143 & \\
\hline Marshall Islands & 181 & $(383)$ & $\mathrm{x}$ & 413 & & 370 & \\
\hline Nauru & 21 & 11 & 523 & 26 & 1,238 & 30 & \\
\hline Palau & 497 & (19) & $\mathrm{x}$ & 39 & & $\mathrm{x}$ & \\
\hline Samoa & 2,842 & 171 & 61 & 223 & & 403 & 31.1 \\
\hline Solomon Islands & 28,446 & 378 & 13 & 1,458 & & 5,313 & 3.7 \\
\hline Tonga & 697 & 98 & 141 & 125 & & 419 & \\
\hline Tuvalu & 26 & 10 & 385 & 16 & 615 & 24 & \\
\hline Vanuatu & 14,763 & 169 & 14 & 462 & & 2,5287 & 27.1 \\
\hline
\end{tabular}


In its TAR, the IPCC (2001: 869) admits many uncertainties and risks to accurately assess the effects of climate change on small island states:

Forecasting of likely outcomes will be more complex than may have been expected initially. Thus, planning of appropriate responses in regions of low adaptive capacity, such as small island states, presents an even greater challenge. One of the likely outcomes of climate change and sea-level rise in natural systems is their collapse.

The IPCC (2001: 869-870) noted "critical information gaps and uncertainties" and suggested the following research needs:

- The GCM are of inadequate resolution to provide adequate information for these states.

- Integrated climate impact studies are needed for small island states.

- Besides having many characteristics in common, the heterogeneity factor is high.

- Due to their wide geographic dispersion a coordinated monitoring programme is needed.

- As the vulnerability varies, vulnerability indices for small island states are needed.

- A balanced approach is needed that "combines the outputs of downscaled models with analyses from empirical research and observation in these countries".

The two IPCC reports that devoted a chapter on the impacts of climate change on the small island states did not include in their discussion the available island specific population projections that will increase the severe environmental stress even further. In the Caribbean the population will increase significantly in Haiti and in the Dominican Republic while it will increase slightly in Cuba. In all small island states in the Indian Ocean the projected population growth and the high reliance on tourism may increase the environmental stress even without climate change impacts. In the South Pacific projected population growth rates may become additional problems for Nauru and Tuvala that may be solved by emigration to Australia and New Zealand. The IPCC excluded a discussion of the likely impact of climate change on international relations. It is highly likely that the emigration pressure from Haiti and the Dominican Republic to North America will increase significantly in the decades to come.

\subsection{Projected Climate Change Impacts for Mexico}

\subsubsection{Basic Facts on Mexico}

Mexico is bordering the Caribbean Sea and the Gulf of Mexico, between Belize and the US, and the North Pacific Ocean, between Guatemala and the US. In 1993 Mexico joined the North Atlantic Free Trade Agreement (NAFTA) and in 1994 it became a member of the OECD. The Mexican population grew much faster than its GDP, e.g. by 36\% (GDP: 29.06\%, GDP/capita: -5.15\%), over 1980-95 (OECD 1998b: 118). In 2000, Mexico's population was 98.872 million (UN 2001), of which $27 \%$ were below poverty line. In 1999, Mexico had a labour force of 38.6 million: $24 \%$ in agriculture, $21 \%$ in industry, and 55\% in services. The GDP was composed of agriculture: $5 \%$, industry: $29 \%$, and services: $66 \%$. The major agricultural products are: maize, corn, wheat, soybeans, rice, beans, cotton, coffee, fruit, tomatoes; beef, poultry, dairy and wood products.

\subsubsection{Climate and GHG Emissions in Mexico}

Mexico's climate varies from tropical to desert and its terrain from high, rugged mountains; to low coastal plains; from high plateaus to deserts. 
23 per cent of the country has a warm-sub humid climate, 21 per cent is temperate-sub humid, 28 per cent is dry and 21 per cent very dry. Mexico also has a very wide rage of vegetation zones; in permanently snow covered areas there is almost no vegetation, while regions such as the Lacandon rain forest in the state of Chiapas are rich in flora (e.g. mahogany, red cedar) and fauna (e.g. jaguar). Between these two extremes are a large variety of shrub and chaparral communities, forming extensive, varied bush land; grassland; conifer and holm oak forests in almost all mountain systems; palm groves and jungles with varying degrees of foliage life; highly developed mangroves in the southern parts of both coasts; and pioneer plant communities in coastal dune areas, among many other. Mexico is one of the few countries in the world with mega-biodiversity (OECD 1998b: 37, 39).

Among the natural hazards are tsunamis along the Pacific coast, volcanoes and destructive earthquakes in the centre and south, and hurricanes on the Gulf of Mexico and Caribbean coasts that contribute to floods, droughts and volcanic eruptions (OECD 1998b: 37). Mexico signed the United Nations Framework Convention on Climate Change (UNFCCC) in Rio in June 1992 and ratified it in March 1993 as a non-Annex-1 country without quantified emissions reduction obligations.

Figure 4.3: Administrative Districts and Population Density in Mexico (1990), (OECD, 1998b: 38)

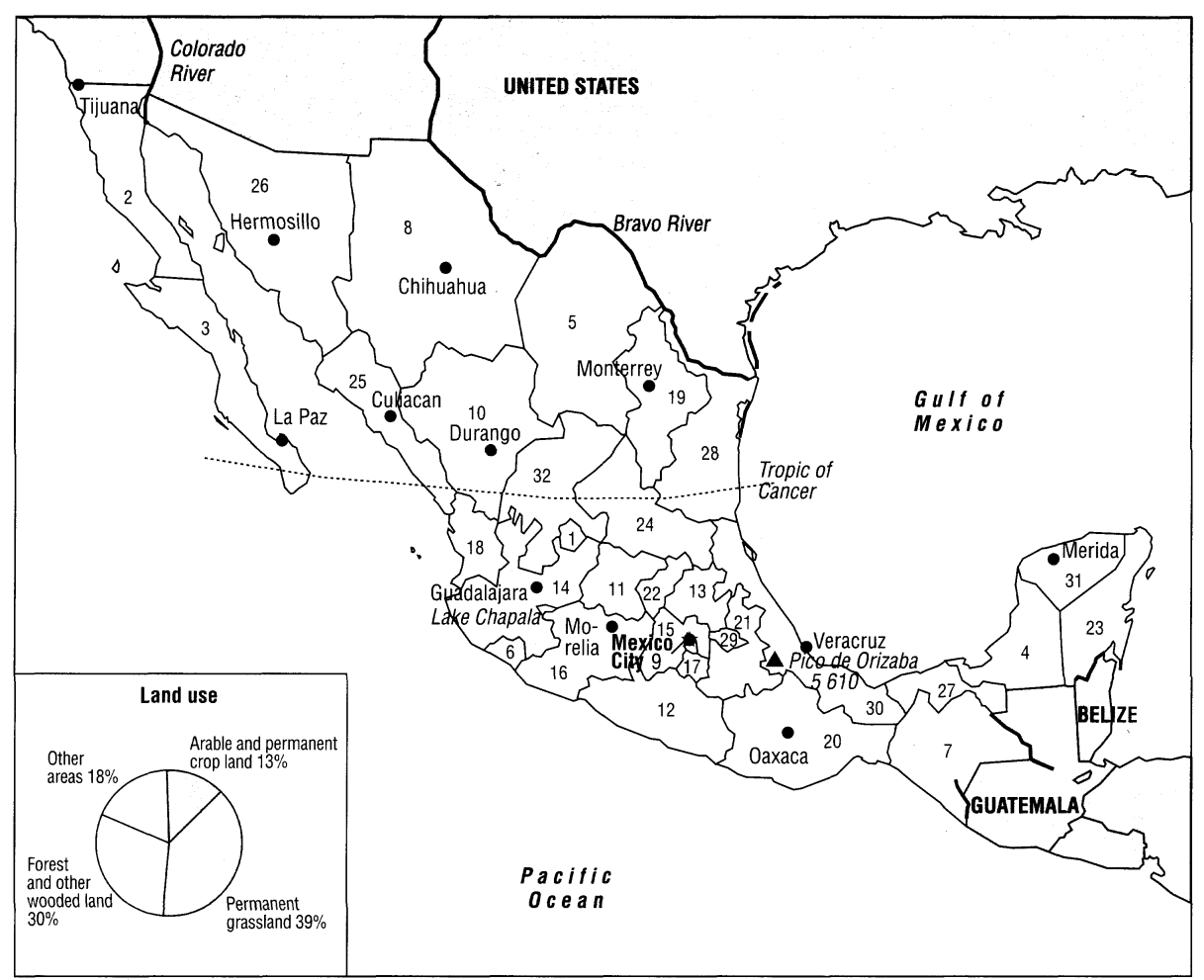

$$
\begin{aligned}
& \text { List of States: } \\
& \text { 1. Aguascalientes } \\
& \text { 2. Baja California Norte } \\
& \text { 3. Baja California Sur } \\
& \text { 4. Campeche } \\
& \text { 5. Coahuila } \\
& \text { 6. Colima } \\
& \text { 7. Chiapas } \\
& \text { 8. Chihuahua } \\
& \text { 9. Distrito Federal } \\
& \text { 10. Durango } \\
& \text { 11. Guanajuato } \\
& \text { 12. Guerrero } \\
& \text { 13. Hidalgo } \\
& \text { 14. Jalisco } \\
& \text { 15. México } \\
& \text { 16. Michoacán } \\
& \text { 17. Morelos } \\
& \text { 18. Nayarit } \\
& \text { 19. Nuevo León } \\
& \text { 20. Oaxaca } \\
& \text { 21. Puebla } \\
& \text { 22. Querétaro } \\
& \text { 23. Quintana Roo } \\
& \text { 24. San Luis Potosí } \\
& \text { 25. Sinaloa } \\
& \text { 26. Sonora } \\
& \text { 27. Tabasco } \\
& \text { 28. Tamaulipas } \\
& \text { 29. Tlaxcala } \\
& \text { 30. Veracruz } \\
& \text { 31. Yucatán } \\
& \text { 32. Zacatecas }
\end{aligned}
$$

The total $\mathrm{CO}_{2}$ emissions of Mexico doubled between 1975 and 1990 and thus grew much faster than the population, especially in transportation, followed by industry and construction, with electricity and heating contributing the third largest portion. Due to population growth and economic progress, a significant increase in global warming gases can be expected and additional rises from deforestation of tropical rain forests. Some energy projections foresee a doubling of the energy consumption until 2015 and at least a tripling until 2025. 


\subsubsection{Projected Regional Climate Change Impacts in Mexico}

In November 1997, Mexico submitted its First National Communication for the UNFCC in which the government stated:

Our country ranks among the 15 most important $\mathrm{CO}_{2}$ emitters and among the top 20 nations in terms of per capita $\mathrm{CO}_{2}$ emissions. However, in terms of the volume, Mexico contributes less than $2 \%$ of global emissions. ... Mexico's natural resources and environment suffer from chronic degradation, as is reflected in its high rates of loss of biodiversity, deforestation, soil erosion, desertification, the severe pollution of the country's major water resources, not to mention the air of its principal cities. ... The countries population and economic activities are not distributed in accordance with the availability of water, which is more plentiful in the south-eastern region of Mexico. Mexico's population ... is concentrated in the central, northern and north-eastern region ..., where water is scarce (MÉXICO 1997: 13-14).

The vulnerability studies were based on analyses of both present and changed regional climate scenarios for the northern, central and southern zone (MÉXICO 1997: 30-33). In Mexico's northern zone a dry and arid climate prevails. The National Communication projected these climate changes for he northern zone:

Under conditions of a doubling in $\mathrm{CO}_{2}$ concentrations, the arid and semi-arid climates would increase in surface area, extending southward, while the semi-cold would disappear. ... In this zone the most serious indices of drought were found, ranging from strong to very severe. ... The results of a possible rise in sea level of 0 to $2 \mathrm{~m}$ reveal that the coast of Gulf of Mexico would be affected at the Pánuco delta, and ... the Rio Grande delta (MÉXICO 1997: 30-31).

The National Communication foresaw that industry, agriculture, the energy sector and human settlement would be affected. This region will experience severe changes in its ecosystems: "Nearly $10 \%$ of all types of vegetation in forest ecosystems would be affected by the warm, dry conditions. ... Extensive grazing areas and temperate forests ... would face hotter climates, which leads one to believe that the areas with dry and very dry tropical forests, as well as the areas of desert scrub, would increase." Climate change would have severe impact on the agriculture where most of the area is unsuitable for non-irrigated maize. Climate change will also affect human settlements most (70\%) in urban centres (MÉXICO 1997: 31-32).

Mexico's central zone has the highest concentration of population and industry $(60 \%$ urban rate), and a high demand for water, energy and food. In the central zone

the consequences of a possible climate change would be extremely negative. The climates in this area are: the warm, sub-wet one of the coasts, ... the semi-warm and temperate ones of the high, mountainous areas; and the dry ones of the center. According to the general circulation models the wet and sub-wet, temperate climates would disappear ..., with the dry, warm ones increasing and arid ones appearing in small areas .... Drought ... would increase in severity. ... Michoacán ... would also have a high degree of vulnerability to desertification over more than $50 \%$ of its surface, together with Jalisco, Colima, Nayarit, Queretaro, Hidalgo and Guanajuato (MÉXICO 1997: 32).

The whole central region has already severe water supply problems, and this would worsen under the conditions of climate change.

The lands for growing non-irrigated maize in Jalisco, Nayarit, Guanajuato, Aguascalientes, Mexico, Colima and northern Michoacán would change from moderately suitable and suitable to unsuitable, reducing the agricultural potential of these states. ... This zone has most of the country's population, and with rapid growth rates. ... By the year 2050, several of these states will have more than eight million inhabitants, which would imply heavy demands for water and services that the area would not be in conditions to provide, so that its degrees of 
vulnerability are among the highest. ... The coasts of Veracruz, especially in the Alvaredo Lagoon, are considered vulnerable to the rise in sea level, taken as being two meters in height above the average level of the high tide (MÉXICO 1997: 32).

In southern Mexico, Oaxaca and Chiapas would be affected most by climate change.

Most of the surface of Chiapas would display increasing levels of drought. This situation would also be found in Quintana Roo and in the eastern part of the Yucatan peninsula, where it would increase from slight to strong. ... On the coasts of the Gulf of Mexico and Caribbean Sea, there are regions that are sensitive to the rise in sea level, specifically in the delta of the Grijalva-Usumacinta Rivers in Tabasco, on the coasts of north-eastern Campeche, and in the Sian Ka' an region, which is considered a biosphere reserve (MÉXICO 1997: 33).

The heavy, light or processing industries in the Southeast would be affected to different degrees by climate change, as would be the energy sector, the oil-producing zones and the extraction platforms in Campeche Sound that would be vulnerable to sea-level rises. As a result of climate change the suitable land for growing maize would partly disappear. Furthermore, the temperate and cold, wet forest ecosystems in Oaxaca and Chiapas would be most affected and could even disappear.

\subsubsection{Projected Sectoral Climate Change Impacts in Mexico}

Based on different climate models and models focusing on maize production, the first national communication concluded that between $59.6 \%$ and $75 \%$ of the land would become unsuitable for maize production under the conditions of climate change (MÉXICO 1997: 101). While negative trends prevail, positive change were found in the higher regions in the centre of Mexico. The vulnerability of human settlements to climate change impacts (changing sea level, precipitation, temperature) would also be a function of non-climatic factors, such as population growth, urbanisation, industrialisation and the presence of illnesses. Thus, the definition of vulnerable areas is directly related to the rapid pace of growth and the percentage of the urban population.

Climate change directly affects the mortality rate through heat-waves or floods or indirectly through infectious illnesses (e.g. malaria, dengue, cholera, typhoid fever, etc.). The growing urban centres imply a growth in demand for water, and those in arid and semi-arid areas will be most affected by water shortage. The vulnerability analysis deals with the impact of sea-level rise at the Gulf of Mexico and of the Caribbean, with the interaction of desertification and meteorological drought, the impact of climate change on forest ecosystems, on water resources and on the energy and industry sectors.

\subsubsection{Climate Change Impacts and Environmental Stress}

Both root causes of environmental stress, climate change and population growth, are highly relevant for Mexico as are the four other factors of the survival hexagon. Population growth has and will increasingly contribute to a higher demand for water for drinking and irrigation, for home-grown and imported food products that will increase the stress on arid and semi-arid soils and also contribute to deforestation. Due to projected urbanisation trends competitive land-uses will increase for agriculture, industry and human settlements. The impacts of regional climate change on the regional hydrological cycle and desertification processes may reinforce many of these trends and thus heighten the environmental stress in Mexico during the $21^{\text {st }}$ century. These factors will increase the pressures on human beings in the search for their own survival. 


\subsubsection{Urbanisation, Migration Flows and Conflict Potentials in Mexico}

What consequences of these highly complex interactions among the six factors of the survival hexagon can be foreseen for the security policy of Mexico? Norman Myers (1989: 35-38, 1994, 1995: 86-92, 1996: 139-148) has dealt with environmental stress in Mexico and its consequences that resulted in progressing desertification, the loss of tropical and other forests that were partly due to the expansion of agriculture to marginal lands and population growth but also due to unequal land ownership. This agricultural debacle and high rural unemployment rates contributed to a massive migration from rural areas to the cities that have grown at 5\% annually since the 1960s. Myers pointed to several implications of these trends on instability and insecurity that could contribute to an additional "outflow of Mexicans who now are seeking economic survival in the United States" (Myers 1989: 38). He foresaw a profound change in the US: "Hispanics would constitute one in five of all residents; they would have become more numerous than blacks and hence the largest minority within less then two decades, by 2010" (Myers 1996: 145). He remained sceptical on Mexico's future pointing at the vicious circle of environmental degradation, soil erosion and dropping agricultural yields.

In Environmental Exodus Myers (1995: 86-92) analysed the severe environmental crisis due to a development that "involved rapid industrialization, agricultural emphasis on export crops, extreme metamorphosis of cities, rapid changes in the labour force and basic shifts in the society." Since 1986, Mexico became a food net importer and in 1992 it purchased cereals to meet the food needs of 28 million people. Besides progressing desertification, the salinization of the irrigated land has become a new challenge. Declining environmental and social conditions in the rural areas, pushed many people into the rapidly growing cities. The UN's World Urbanization Prospects (UN 2000) has projected that urbanisation in Mexico will increase from $74.4 \%$ in 2000 to $81.9 \%$ in 2030 . The Mexican population is projected to grow by 31.5 million people until 2025 . The urban population has been projected to grow even faster from 73.553 million in 2000 to 110.488 million in 2030 , by about 37 million.

Most studies on migration from Mexico to the US do not include environmental stress as a factor for Mexican emigration. Many campesinos and workers went to the US to work on farms to sustain the survival of their families back home. The projected impacts of climate change on water and agriculture will increase the pressure of the rural population to move to the next major urban centre or to the US in search for jobs and for the survival of their family. Thus, urbanisation and migration will be two major socioeconomic challenges confronting Mexico and US-Mexican relations in the $21^{\text {st }}$ century.

How may climate change affect the national security of Mexico in the $21^{\text {st }}$ century? The impacts of climate change for Mexico on (in)security until 2050 (UN population projections) or 2100 (IPCC climate models) must remain purely speculative. They depend on both endogenous factors (e.g. population growth, urbanisation and related demand for food, water and impact on soil) but also on exogenous global factors of climate change and their impact on the regional hydrological cycle and on desertification processes. Given the complex interactions among the factors of the survival hexagon, it is impossible to draw conclusions on the security policy implications of climate change.

Whether the impact of climate change on environmental stress and human survival or the survival of indigenous people could become a spark for future social tension and strife (as in Chiapas since 1994) may not be predicted. But climate change as one of several factors contributing to environmental stress in the past - and even more so in the 
future - may contribute to domestic societal and political instability. Much will depend on the performance of Mexico's economy. Thus, the development and implementation for national strategies of sustainable development becomes a major task to mitigate against the climate change impacts and to reduce the environmental stress. This will require major foreign investments and a higher administrative efficiency in implementing and enforcing environmental standards.

Given the many environmental and socio-economic challenges Mexico will be confronted with in this century, increased social tensions in Mexico may be expected and both non-violent protests and violent strife may not be excluded. Whatever, the domestic consequences of increased environmental stress in Mexico may be, they will affect the security perception of the US and its future political relations with and security policy towards Mexico. One crucial factor will be how NAFTA will impact on the economic and job situation in Mexico.

To summarise, climate change has already become a factor contributing to environmental stress, during the $21^{\text {st }}$ century the impacts of climate change will become more severe due to a continuing high population growth leading to an increasing demand on water and agricultural land. There is no military solution to these new and enhanced challenges for environmental stress. In the long-run, effective and stringent climate policies with higher and legally binding obligations may be the most cost-effective solution.

\subsection{Projected Climate Change Impacts for Bangladesh}

\subsubsection{IPCC Assessments on Climate Change Impacts for Bangladesh}

In its first impact assessment, the IPCC (1990: 6.2) estimated that a $1 \mathrm{~m}$ rise in sea level could inundate $17 \%$ of Bangladesh and 12-15\% of Egypt's arable land, and that this could "decrease the agricultural productivity of many delta countries that can least afford losses." The IPCC concluded for tropical Asia that "projected climate changes ... include strengthening of monsoon circulation, increases in surface temperature, and increases in the magnitude and frequency of extreme rainfall events. ... These changes could result in major impacts on the region's ecosystems and biodiversity; hydrology and water resources; agriculture, forestry, and fisheries; mountains and coastal lands; and human settlements and human health" (IPCC 1998: 385) and that "individual countries, regions, resources, sectors, and systems will be affected by climate change not in isolation but in interaction with one another" (IPCC 1998: 403). For a better integration of impacts and adaptations the study suggests several measures including country-specific studies, a sectoral and trade integration and comprehensive monetary estimates. Later the IPCC (2001a: 343-380; 533-590; 843-876) noted that deltas will be exposed to potential inundation both due to climate change and to human-induced stresses. In its regional analysis for Asia, the TAR (IPCC 2001a: 533-590) stated that Bangladesh would be affected most by a sea-level rise between $45 \mathrm{~cm}$ and $1 \mathrm{~m}$ where the mangroves will be highly vulnerable (IPCC 2000a: 579) resulting in the loss of plant species and wildlife and in economic loss, exacerbated insecurity and loss of employment but also on food demand due to high population growth (IPCC 2001a: 580).

\subsubsection{Basic Facts on Bangladesh}

Bangladesh borders the Bay of Bengal as well as Burma and India. In 1971 Bangladesh seceded from Pakistan and declared its independence. A third of this poor country annually floods during the monsoon rainy season, hampering normal economic development. 
Bangladesh comprises a territory of $144,000 \mathrm{sq} \mathrm{km}$. The three major landscapes are: floodplain $(80 \%)$, terraces $(8 \%)$, and hills $(12 \%)$.

Its key resources are: natural gas, timber and arable land that constitutes 8.74 million ha or about $60 \%$ of the total area, thereof $33.3 \%$ is single cropped, $45.0 \%$ is double cropped, $11.5 \%$ is triple cropped, and $10.2 \%$ is cultivable waste and fallow (Ahmed/Rahman; 2001: 51). The contributions to the GDP were agriculture (30\%), industry $(17 \%)$ and services (53\%). In 1995-96 the labour force was 56 million whereof $35.2 \%$ were unemployed and $35.6 \%$ below poverty line. The labour force worked in agriculture $(63 \%)$, services $(26 \%)$, and industry $(11 \%)$. The major agricultural products are rice, jute, tea, wheat, sugarcane, potatoes; beef, milk, poultry, tobacco, pulses, oilseeds, spices, and fruit. The major industries are: cotton textiles, jute, garments, tea processing, paper newsprint, cement, chemical fertilizer, light engineering, and sugar. In 1999, the real GDP growth rate was 5.2\%, and in 1997, the industrial growth was $2.5 \%$. In 1998, exports amounted to $\$ 5.1$ billion consisting of garments, jute and jute goods, leather, frozen fish and seafood.

Table 4.5: National Statistics of Bangladesh (1981-1995), (Ahmed/Rahman 2001: 52)

\begin{tabular}{|l|r|r|r|}
\hline Indicators & $\mathbf{1 9 8 1}$ & $\mathbf{1 9 9 1}$ & $\mathbf{1 9 9 5}$ \\
\hline Population (million) & 89.9 & 111.45 & 119.80 \\
\hline Land Area (square kilometres) & 144,000 & 147,570 & 147,570 \\
\hline Forest (\%) & 15.00 & 12.80 & 12.74 \\
\hline Agricultural (\%) & 60.52 & 55.08 & 52.06 \\
\hline Cultivable wasteland (\%) & 1.62 & 3.93 & 4.28 \\
\hline Current Fallow (\%) & 3.39 & 6.49 & 2.98 \\
\hline GDP (1995 US\$ in million) in 1989-90 con. price & & 26.500 & 32,060 \\
\hline Industrial GDP (\%) & & 22.1 & 24.18 \\
\hline Services GDP (\%) & & 49.45 & 50.98 \\
\hline Agricultural GDP (\%) & & 28.13 & 24.83 \\
\hline GDP per capita (1995 US\$) & & 241 & 336 \\
\hline PPP per capita of GNP (Int'l 1995 US\$) & 15.20 & 17.20 & 22.00 \\
\hline Urban population as \% of total population & & 22.5 & \\
\hline Livestock population (Bovine) in million & 73 & 47 & 45.8 \\
\hline Population in below poverty level (\%) & 55 & 56 & 58 \\
\hline Life expectancy at birth (years) & 29.2 & 38.8 & 43.2 \\
\hline Literacy rate & & & \\
\hline
\end{tabular}

In 1995, Bangladesh had a population density of 812 persons $/ \mathrm{km}^{2}$ compared with 369 for the Netherlands. The population of Bangladesh has been projected to rise from 137.439 million in the year 2000 according to the medium variant until 2025 to 210.823 million and to 265.432 million until 2050 (figure 4.2, UN 2001: 28). The urbanisation rate has increased from $4.2 \%$ in 1950 to $24 \%$ in 1999 and it has been projected to rise to $43.9 \%$ by 2030 (UN 2000: 31). The population of Dhaka has grown from 420,000 people in 1950 to 12.3 million (2000) and may grow until 2015 to 21.1 million. The population of Bangladesh consisted of Bengali $98 \%$, Biharis 250,000, and less than 1 million of tribal people. The large majority are Muslim $88.3 \%$ and a minority are Hindu $10.5 \%$, and $1.2 \%$ are Buddhists and of other denominations. 


\subsubsection{Climate and Climate Change Impacts in Bangladesh}

The climate in Bangladesh is tropical with a cool and dry winter (October to March) and a hot and humid summer (March to June) and a cool and rainy monsoon period (June to October). Bangladesh is confronted with severe natural hazards and four natural events:

- Cyclones, floods, riverbank erosion, and salinity problems which occur mostly in the costal zone ....

- Droughts, floods, and riverbank erosion combine in the mid-western zone, reaching north-west from the districts of Narail and Gopalganj in the south through Magura, Jessore, Raijbari, Faridpur and Pabna to Sirajganj, Natore, and Rajshahi in the north.

- Flooding and riverbank erosion combine in a scattered, linear pattern through the length of the country, which may be called the river-margins zone.

- Major cities and their life-line systems are exposed to one type or more of severe natural events (Ericksen/Ahmad/Chowdhury 1996: 266)..

The tragic surge of November 1970 killed over 250,000 people, the storm of May 1985 over 5,000 people, and that of April 1991 more than 138,000. Over 600,000 people have died in Bangladesh by cyclones and storm surges since 1960. Only the north-eastern margins and part of the north-west were free from severe natural events. Among its major environmental problems are that many people are forced to cultivate flood-prone land and have limited access to potable water. Bangladesh suffers intermittent water shortages due to falling water tables in the northern and central parts, soil degradation, deforestation, and overpopulation. Water-borne diseases are prevalent.

Between 1870 and 1990, Bangladesh was warmed by about $0.5^{\circ} \mathrm{C}$ but in the late $1990 \mathrm{~s}$ it contributed only 0.2 to $0.3 \%$ to global warming gas emissions. Since signing the UNFCC in 1992, the government of Bangladesh with support from international organisations, initiated several steps to assess the possible impact of climate change and sealevel rise, and its contribution to global warming for the base year 1990, and to identify possible options to abate national GHG emissions and specific stakes that would help to curb GHG emissions (Ahmed/Rahman, 2001). In 1996 the Ministry of Environment and Forestry submitted a funding proposal for its national communication to the GEF and the US Country Study Program. The preparation of its national communication started in late 2000. Ahmed and Rahman (2001: 67) noted a lack of foresight from key leaders due to their short-term horizon. For them, poverty eradication and food security are more urgent than the probable adverse impacts of climate change in a distant future.

Whether global warming will produce more severe tropical cyclones and storm surges in the Bay of Bengal is uncertain (Ahmad/Warrick/Ericksen/Mirza 1996: 12). But sealevel rise could have potentially severe effects on Bangladesh's water, agricultural, forestry, fisheries and livestock resources that are the very backbone of its economy. In most years during the monsoon season about one quarter of Bangladesh is flooded by rain and river water and in years with high floods up to $60 \%$ of the land is submerged (figure 4.4). Due to climate change by 2030 monsoon rainfall could rise by $10-15 \%$ and in winter by $5-10 \%$. This could reduce the frequency of drought and could counteract salinity penetration in coastal areas but it could also increase the frequency and severity of floods. Due to population growth, between the 1990s and 2030, a doubling of the food demand will require "further intensification and security of production, but will have to be obtained from a shrinking cropped area as urban and other land uses expand. Some crops (jute) would benefit from temperature increases while others (wheat, potato) would suffer and increase the damage by insects and plant diseases. In the coming 
decades, the climate change impact will depend on the future technological, demographic and socio-economic trends and how they influence Bangladesh's ability to adapt. On major factor is rapid urbanisation that "could increase the risk of catastrophe from rare climatic events and is likely to create additional risks of climate impacts more akin to other urbanised countries, such as heat stress, urban flooding and urban drought. Overall, the trend of high population growth in Bangladesh should increase vulnerability to climate and sea-level change" (Ahmad/Warrick/Ericksen/Mirza 1996: 18).

Figure 4.4: Sea Level Transgression Scenarios for Bangladesh (Broadus 1993: 267)

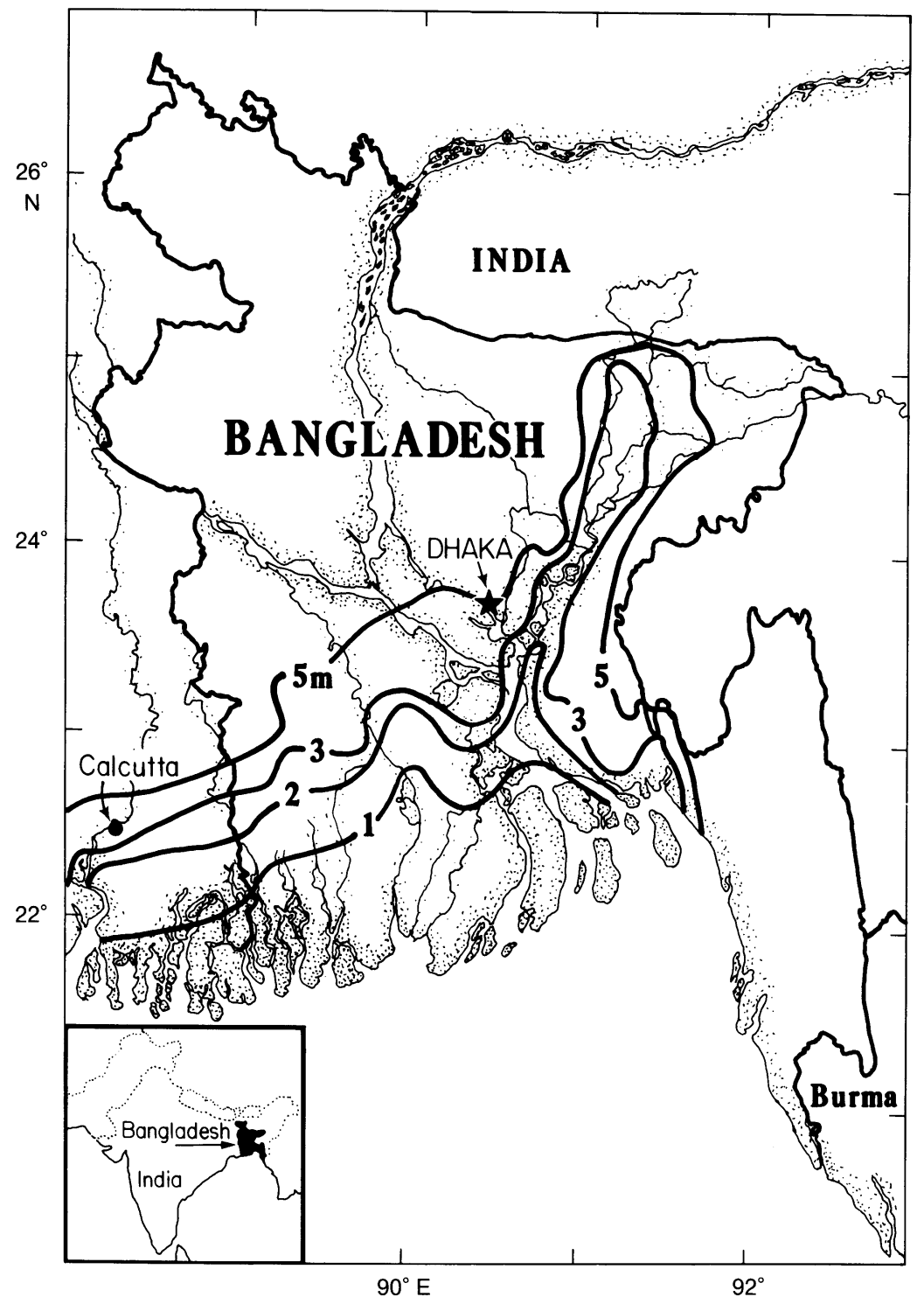

The loss of land and employment will be an additional factor for forcing people to move to areas at risk from climate change and from adverse social and environmental conditions and thus "a continuation of high migration rates is likely to aggravate the potential socio-economic impacts of climate and sea-level changes in the future". They also pointed to the interaction with humaninduced factors such as "population migration, changes in settlement patterns and health effects, particularly from possible changes in the supplies of potable water and the incidence of water-borne disease and malaria. It is not yet possible to predict such effects" (Ahmad/Warrick/ Ericksen/Mirza 1996: 19-20, 27-28).

Ericksen, Ahmad and Chowdhury (1996: 205-288, 240) foresee that more people will move into flood- and cyclone-prone char land, that settlements will spread in to lower and flood-protected lands and that the expanding urban population will spread on floodplain agricultural land. "All groups could become more vulnerable with climate and sealevel change. It is certain that, over the next 40 to 60 years, the density of rural settlements in Bangladesh will markedly increase. This will increase the absolute number of people at risk from climatic variations and extremes." 


\subsubsection{Urbanisation and Migration in Bangladesh}

Four population movements may be distinguished: from core to periphery, rural recycling, urban magnet and international movements. People left from the densely populated mid-eastern districts and from districts affected by flooding. Rural unemployment of $35 \%$ was a major reason for migrating to less populated rural districts. The urban immigration amounted to about 2 million people per year primarily to Dhaka, Chittagong and Khulna what has contributed to a pool of under-employed urban poor. In the late 1980s, international migration from rural Bangladesh was $17 \%$, primarily to the Middle East (1976-1989: 650,000) and the UK (Ericksen/Ahmad/Chowdhury 1996: 246). The growing population will increase migration which will reinforce existing severe health problems of the poor and malnourished living in sandy towns without adequate water supply and waste disposal.

With regard to the future vulnerability of Bangladesh to climate change, in the absence of effective countermeasures they foresee these outcomes over the next 40-60 years:

- The multi-hazard areas [figure 4.4] would, at a minimum, continue as such.

- Severe events and processes (cyclone, flooding, riverbank erosion, and salinity) in the coastal zone may intensify and become more frequent and spatially extended. A slowly rising sea level would exacerbate these effects along the coastal margin by: alerting erosion rates; causing saline waters to intrude further inland; 'shrinking' protective barriers; and increasing flooding by cyclone storm surges.

- Severe events (flooding and riverbank erosion) in the river-margins zone, may intensify and become more frequent. The design levels of existing protective barriers would, in effect 'shrink'.

- Drought in the mid-western zone may reduce in frequency and intensity, although severe flooding and riverbank erosion would be maintained and may even increase.

- Outside the multi-hazard core zones, severe events may become more frequent and intense, except perhaps for drought (Ericksen/Ahmad/Chowdhury 1996: 267).

These climatic change impacts will affect a socio-economic context that will have changed by 2050: population will have doubled; settlements and migration from high to low density rural areas to cities will have intensified; urban expansion in major centres will have greatly increased; service sectors of the economy will have increased further, manufacturing may have become a more important component of the GDP; human development may or may not have made significant progress depending on economic growth; the wealthy and middle class may form a larger proportion of the population; traditional rural attitudes and adaptive methods for coping with severe natural hazards should have undergone some change; the number of landless would have increased and agricultural transformation might displace significant numbers of farmers and labourers; a large number of landless will have been absorbed into non-agricultural sectors but their productivity will remain low; there will be a large number of under-employed; and the education and health care will have improved. The urban rich would be least at risk, while the poor would be the most affected: "marginal farmers, rural landless, urban squatters and migrants, the children suffering from malnutrition diseases; and women left to look after the household" (Ericksen/Ahmad/Chowdhury 1996: 270).

\subsubsection{Prospective Climate Change Impacts: A View from Bangladesh}

Saleemul Huq, the former Chairman of the Bangladesh Center for Advanced Studies in Dhaka, summarised the climate change impacts for Bangladesh: 
- Sea Level Rise: Different studies have estimated that a 1 meter rise in sea level will permanently inundate $17 \%$ of Bangladesh's total land area. There are some 20 million people living in this low-lying coastal area. ... Local level land subsidence must be added to the global mean sea level rises, which will make the impact much worse by enhancing the rates of coastal inundation. ... The impact ... of rising salinity in the coastal lands and waters will be felt much earlier and will start affecting agriculture and fresh water availability. The coastal town of Khulna is already facing such problems, and the Sundarbans mangrove forests ... is showing signs of stress from rising salinity.

- Increased temperatures: The IPCC report shows a probable rise in global temperatures of between 2 to $5^{\circ} \mathrm{C}$ over the next 100 years. ... Such an increase in mean global temperatures will also cause an increase in extreme temperatures which will lead to more frequent and more severe droughts in the future. In fact, it is quite likely that ... Bangladesh may be hit more severely by droughts than by floods....

- More intense cyclones: Different models ... differ on whether tropical cyclones will become more frequent. ... Nevertheless, the intensity and destructive power of cyclones in the future are likely to be greater as the sea surface temperature ... is likely to be higher with global warming. ...

- Greater flood intensity: Although the exact impact of elevated global temperatures on the South Asian monsoon rains are as yet difficult to predict, the consensus in scientific opinion is that the monsoon is likely to become more erratic with climate change. Therefore, the possibility of more frequent and more intense floods are likely in Bangladesh, particularly through combination of monsoon rainfall with increased snow melt from the Himalayan mountain range. Thus, the change in global climate will ... cause both more flooding (in the wet season) and more droughts (in the dry season) in Bangladesh.

- Health impacts: The impact of climate change on health still remains uncertain. However, the IPCC report states that increased incidence of vector borne as well as water borne pathogens are likely with climate change. ... The recent outbreak of Dengue fever in Bangladesh may be a harbinger of things to come. ${ }^{23}$

To what extent did the interaction of extreme poverty and environmental stress result in violent conflicts in Bangladesh and what may be the prospects of the interaction among the six challenges of the survival hexagon for future insecurity and conflicts?

\subsubsection{Environmental Stress and Conflict Potentials in Bangladesh}

Abdul Hafiz and Nahid Islam (1996: 1-108) have analysed the linkages between environmental degradation and intra/interstate conflicts in Bangladesh evolving both from global challenges but also by environmental degradation in India due to "uncoordinated economic activities" in the Himalayan drainage system. They analysed three cases where ecological degradation produced social effects that resulted in conflicts: a) The common water sharing and management dispute on the Ganges involving Nepal, India and Bangladesh; b) the Chitagong Hill Tract problem; and c) the Talpatti Dispute over land formation from large scale siltation. Due to environmental and social stress within Bangladesh, a growing number of its population are on the move from areas affected by flooding and desertification, from rural to urban centres, from Bangladesh to West Bengal and Assam and overseas to the Gulf countries, the UK but also to North America, Europe and Australia (Islam 1995: 360). The remittances of the Bangladeshi's working in the Gulf countries paid for one third of Bangladesh's imports (Abella 1995: 421).

\footnotetext{
${ }^{23}$ Saleemul Huq: "Climate Change: A Growing Impediment to Development in Bangladesh", Statement prepared for the Bangladeshi-American Foundation (BAFI), Washington DC, 20 August 2001; see also: Huq/Karim/Asaduzzaman/Mahtab 1999; Huq/Ali/Rahman 1995; Huq/Asaduzzaman 1999.
} 
What may be the impact of the interaction of the six factors of the survival hexagon for security in South Asia and what may be foreseeable consequences for OECD-countries? The natural catastrophes from since 1947 to 2001 killed more than 1 million. Several million Bangladeshis have migrated since 1947 or 1971 to India, West Pakistan, to the Persian Gulf, and to OECD countries. Bangladesh has experienced severe social challenges and natural catastrophes. Domestic social tension repeatedly led to military coups, the murder of key politicians, and violent clashes between internal refugees with tribal people in the CHT region but also with Bangladeshi immigrants in India.

Climate change and its implications on sea-level rise, precipitation, the occurrence of extreme weather events but also high population growth may produce in Bangladesh a humanitarian catastrophe of extreme dimensions. If the population projections and the climate projections should become true by 2050 , the population density may reach more than 2.000 people per $\mathrm{km}^{2}$, if due to climate change some $5-10 \%$ or more of its territory should be inundated due to sea-level rise. Until 2050, all six factors of the survival hexagon foresee severe trends, the complex interaction of both human- and nature induced trends and their socio-economic and political repercussions may lead to situations of political instability and even violent clashes within Bangladesh or at its borders. The effects of both trends will be felt at the level of individual victims. Human insecurity and the fight for survival of the family and community are likely to increase. On the national level these two trends may challenge internal social and political stability and the survival of the country. The water sharing issue of the Ganges river and the migration issue may both contribute to bilateral friction and minor border clashes with India.

There is no military solution to this humanitarian catastrophe in the Bay of Bengal. Only multilateral cooperation with full support of Bangladesh and the willingness of the governments of India and of OECD countries can turn the tide. This requires a mitigation strategy that faces both challenges. An active programme of reproductive health by the UN Populations Fund, but also a readiness of other countries to accept future Bangladeshi labour migrants are needed. As climate change will be caused by the greenhouse gas emissions the best mitigation strategy to reduce the effects of climate change for Bangladesh will be an active climate change policy of the OECD countries with full implementation of the Kyoto Protocol as a first modest step.

\subsection{Projected Climate Change Impacts for Egypt}

\subsubsection{Basic Facts on Egypt}

Egypt regained full sovereignty after World War II. Its territory covers an area of $1,001,450 \mathrm{~km}^{2}$ and its land boundaries total $2,689 \mathrm{~km}$. Its terrain is covered by a vast desert plateau that is interrupted by the Nile valley. Among its natural resources are petroleum, natural gas, iron ore, phosphates, manganese, limestone, gypsum, talc, asbestos, lead, and zinc. Only $2 \%$ of its land is arable of which $32,460 \mathrm{~km}^{2}$ were irrigated.

Egypt has a desert climate with hot, dry summers and moderate winters. The major natural hazards are droughts, earthquakes, flash floods, landslides, and volcanic activity. Hot and driving windstorm occurs in spring and dust and sandstorms. Among the current environmental problems of Egypt are: loss of agricultural land to urbanisation and windblown sands, increasing soil salination; desertification, oil pollution threatening coral reefs, beaches, and marine habitats, water pollution from agricultural pesticides, raw sewage, and industrial effluents, very limited fresh water resources away from the 
Nile the only perennial water source. Egypt is a party to many international environmental agreements, including those on climate change, desertification, environmental modification, hazardous wastes, law of the sea, marine dumping, ozone layer protection, and it signed the Kyoto Protocol to the UNFCCC.

In 2000 Egypt had a population of 67.884 million (UN 2001) of which $94 \%$ are Muslim, and $6 \%$ are Coptic Christian and others. According to 1995 estimates, the literacy rate of the total population was $51.4 \%$. The real growth rate has grown from $3.7 \%$ in $1990 / 91$ to $5 \%$ by end of 1998 . The foreign debt was reduced from $\$ 50$ billion in the late 1980s to $\$ 31$ billion by 1996 and in 1998, the reserves amounted to US\$ 20 billion. The GDP composition by sector was for agriculture: $17 \%$, for industry: $32 \%$, and for the services: $51 \%$. The labour force was 19 million of which $40 \%$ worked in agriculture, $38 \%$ in the services and $22 \%$ in industry. The unemployment rate was $11.8 \%$. The major industries were textiles, food processing, tourism, chemicals, petroleum, construction, cement, and metals. The major agricultural products are cotton, rice, corn, wheat, beans, fruits, vegetables; cattle, water buffalo, sheep, goats, and fish. In 1999, exports amounted to $\$ 4.6$ billion and major export commodities were crude oil and petroleum products, cotton, textiles, metal products, and chemicals. Egypt imported goods for $\$ 15.8$ billion consisting of machinery and equipment, food, chemicals, wood products, and fuels. Major export partners were the EU (47\%), the US (14\%), and Turkey (8\%), and major import partners were the EU (42\%), the US (16\%), and Japan (5\%).

\subsubsection{Environmental Challenges and Climate Change Impacts in Egypt}

Egypt is challenged by processes of desertification and by the projected sea-level rise in the Nile Delta and in its coastal regions. The IPCC (1998: 231-252) analysed Egypt's climate impact in the context of the Middle East and arid Asia and acknowledged "the most pressing need ... is for sound assessment and monitoring programs to establish current baselines and identify rates of change". For Africa, the IPCC (2001a: 489) noted a high vulnerability to six manifestations of climate change: a) water resources; $b$ ) food security, c) productivity of natural resources, d) vector- and water-borne diseases, e) coastal zones vulnerable to sea-level rise, and f) exacerbation of desertification by changes in rainfall and intensified land use, all of which are of importance for Egypt.

A major focus of climate impact studies has been the coastal zone development. Sestini (1992: 535-601) analysed the implications of sea-level rise for the Nile delta in relationship to population growth and coastal economic development until 2010 and 2020. He foresaw that a temperature rise could have severe impacts on agriculture that: "could be negatively affected by increased evapotranspiration and soil salinity and may require more irrigation and fertilizers... The socio-economic structures of the Lower Nile Delta probably will be affected more by population increase and urbanization, than by climatic changes; ... water supply and food production could be altered" (Sestini 1992: 535-536).

Mohammed El-Raey (1991, 1993, 1994) and a team of Egyptian experts produced a Vulnerability Assessment of the Coastal Zone of Egypt to the Impacts of Sea Level Rise which concluded: "that a $0.5 \mathrm{~m}$ sea level rise would cause migration of more than 2.0 million people, loss of more than 214,000 jobs and a value loss of more than $\$ 40.0$ billion, mainly in Alexandria Governorate". The report contained detailed vulnerability assessments for Alexandria (El-Raey/Ahmed/Korany 1997), Roseta and Port Said (ElRaey/Frihy/Nasr/Dewidar 1997). In 2000, El-Raey published a vulnerability assessment 
of Alexandria governorate based on a sea level rise of $0.5 \mathrm{~m}$ and $1.0 \mathrm{~m}$ (figure 4.5) by the end of the $21^{\text {st }}$ century and identified those sectors to be most seriously affected:

Figure 4.5: Sea-Level Rise in the Nile Delta by 50 and 1 m (El-Raey, 2000)
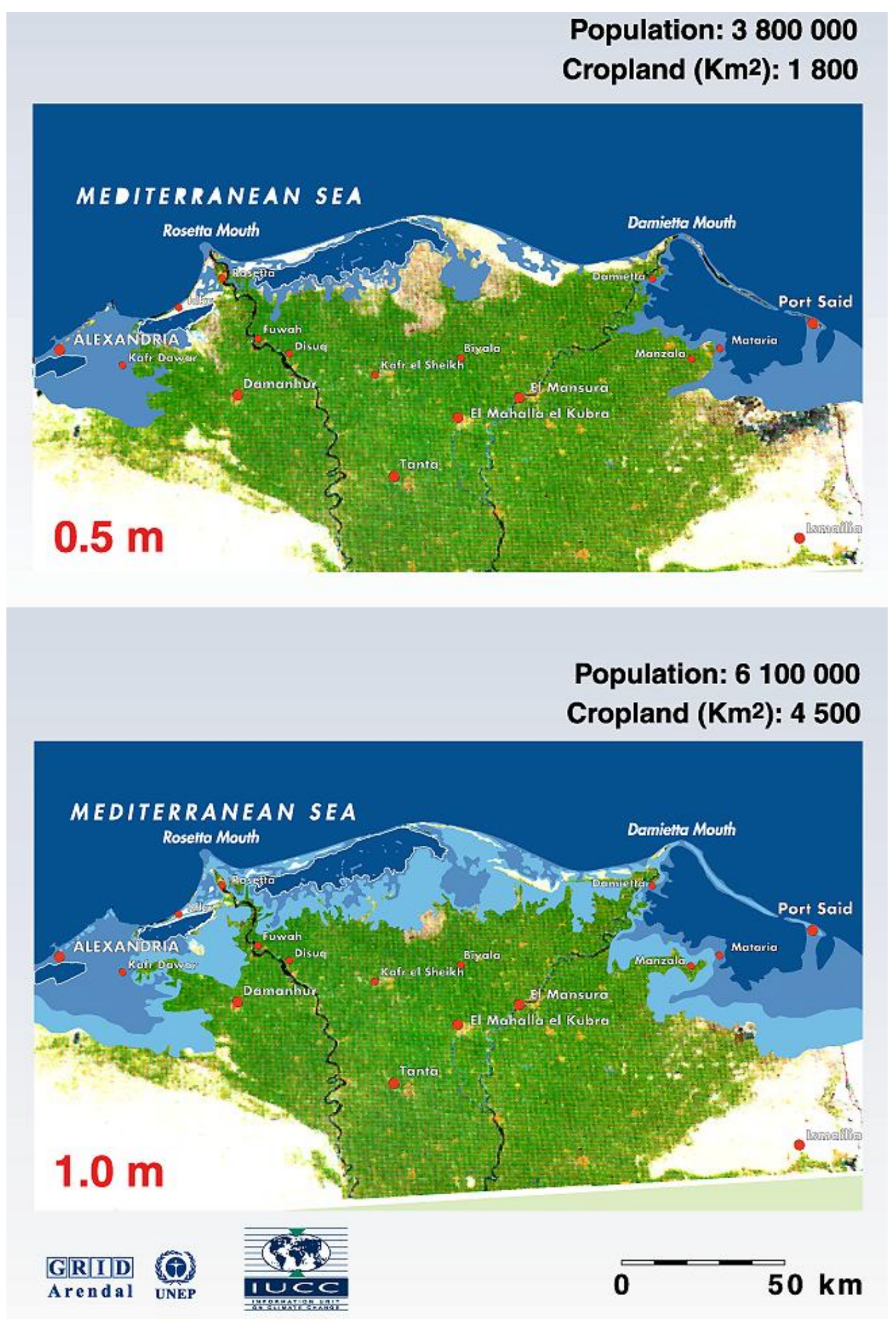

Impacts on the supply side are likely to arise from possible changes of precipitation patterns over the Ethiopian hills (85\% of water flow), and equatorial lakes such as Lake Victoria $(15 \%)$. The effects of predicted climate change on both components are uncertain. The first 
is dependent on two factors, namely variation of the general cycle of the wind, El-Niño and ENSO phenomena. The second component is also uncertain due to increased frequencies of droughts and their intensities over the last two centuries. Rainfall on the upper White Nile catchment, the upper Blue Nile catchment, and the Middle Nile basin ... are all showing a decline in total rainfall. A combination of salt-water intrusion due to Sea Level Rise and increased soil salinity due to increased evaporation are expected to reduce the quality of shallow groundwater supplies in the coastal areas. ${ }^{24}$

Water demand in Egypt is dominated by agricultural irrigation, domestic use and industry. Even without climate change, the population is expected to double by 2050 . Thus, a rapid growth in agricultural and industrial output will be necessary to feed this population. For El-Raey this implies: "that any effects of climate change on water supply and demand will be dwarfed by a much larger increase in demand due to population growth." For Egyptian agriculture El-Raey foresaw these climate change impacts:

1. Increase of temperature and frequency of extreme events will reduce crop yield ....

2. change of average temperature will induce changes of the agricultural distribution of crops.

3. Increase of temperature will negatively affect marginal land and force farmers to abandon marginal land.

4. Shortage of water resources will also force farmers to abandon marginal land, and increase desertification.

5. Socio-economic impacts associated with loss of jobs, such as increase of unemployment, loss of income, and political unrest.

In the view of El-Raey: "The coastal zone of Egypt suffers from a number of serious problems, including a high rate of population growth, land subsidence, excessive erosion rates, water logging, salt water intrusion, soil salination, land use interference ecosystem pollution and degradation, and lack of appropriate ... management systems." El-Raey discussed different scenarios for an assumed sea level rise (SLR) of $0.5 \mathrm{~m}$, $1.0 \mathrm{~m}$, and $2.0 \mathrm{~m}$ during the $21^{\text {st }}$ century. An estimated SLR of $0.5 \mathrm{~m}$ in the governorate of Alexandria alone would cause a displacement of almost 1.5 million people and the loss of about 200000 jobs by 2050 without mitigation measures. El Raey also pointed to the change of precipitation, wind velocity and heat waves that will affect the coastal zone. In his assessment the socio-economic impact on coastal settlements will include:

1. Inundation and salt water intrusion will compel a significant proportion of the coastal zone population to abandon their land and homes.

2. Changes in the ecological system of lakes will reduce fish catches and drive away a large portion of fishermen and their dependants.

3. Loss of beaches will reduce the number of tourists in coastal areas, forcing tourism dependent individuals and communities to abandon their settlements and look for jobs elsewhere.

4. Increased saltwater intrusion will affect the management and access to archaeological sites; reduce tourism, and result in socio-economic impacts on the inhabitants of these areas.

5. Increased unemployment induces political and civil unrest.

6. Increased waterlogging and salinity give rise to insect and pest problems which in turn causes health problems.

7. Increases in temperature lead to increased soil erosion and dust. Increased dust has direct adverse impacts on health, installations and equipment. Increased wind speed encourages sand dune movements and threatens coastal infrastructure.

8. Increased humidity and temperature decrease the human comfort zone, and reduce human productivity.

\footnotetext{
${ }^{24}$ See: M. El-Raey: "Egypt: Coastal Zone Development and Climate Change Impact of Climate Change on Egypt", at: < http://www.ess.co.at/GAIA/CASES/EGY/impact.htm>.
} 
Finally, El Raey pointed to the following secondary regional impacts which also affect the international community that include:

1. Increasing temperature increases soil erosion and wind speed, which in turn increases amount of Saharan dust carried across the Mediterranean to European countries causing health and economic problems.

2. Increased unemployment increases immigration pressure on European countries.

3. Decrease of water resources increases friction among countries sharing the same water resources (e.g. Nile and Euphrates), and leads to political unrest.

4. Increases in temperature and humidity increase rates of deterioration of Egyptian archaeological treasures which are considered among the most important in the world.

Strzepek, Onyeji, Saleh and Yates (1995: 180-200) developed an integrated climate change impact study that projects Egypt's future without climate change and the additional impact of climate change on existing other trends. They assume for 2060 a population of 115 million (UN projection for 2050 is 113.84 million). The study contrasts two opposite economic trends, a pessimist one with a large foreign debt and low investments with low agricultural and other growth rates, while the optimists portray Egypt as the South Korea of the $21^{\text {st }}$ century and project a doubling of the per capita GDP by 2060, "fuelled by a six-fold and three-fold increases in non-agricultural and agricultural GDP, respectively" (Strzepek/Onyeji/Saleh/Yates 1995: 187). They assume an annual temperature increase for Cairo of $4^{\circ} \mathrm{C}$ and for Egypt by $3.1^{\circ} \mathrm{C}$ to $4.7^{\circ} \mathrm{C}$ and precipitation increases from 5 to $31 \%$. Water flows at Aswan would vary from an increase of $30 \%$ to a decrease of $77 \%$.

These changes, as well as the impact of the rising sea-level on the Nile Delta, will have severe implications for the agricultural sector of Egypt and for the whole economy. The decline in water availability and in crop yields on the background of a growing population will require a drastic increase in imports in cereals and especially of rice (120$237 \%$ ). Among the major results of their integrated study is that food self-sufficiency would decline from $60 \%$ in 1990 to $10 \%$ by 2060 and that by 2060 both land and water resources would be extremely scarce (Strzepek/Onyeji/Saleh/Yates 1995: 194). The integrated climate change impact study assumed a sea-level rise of $37 \mathrm{~cm}$ by 2060 , and thus the land loss has a minor economic impact on the agricultural sector. Based on different models, welfare losses are projected until 2050 to range between $-6 \%$ and $-52 \%$. At the end the authors drew the following conclusions on climate change impacts:

Egypt is highly vulnerable to the warming and changes in precipitation and river runoff that are forecast to accompany greenhouse gas-induced climate change. It has been shown that water is an important element in the agricultural economy and must be explicitly included in any analysis of climate change impacts. Finally, this study has shown that in addressing climate change impacts on an economy or nation, the entire economy must be analysed. The linkage of the sectors directly affected by climate change must be analysed in concert with the other sectors of the economy in sufficient detail so that feedback can be part of the analysis (Strzepek/Onyeji/ Saleh/Yates 1995: 199).

\subsubsection{Climate Protection Activities in Egypt}

On 9 June 1992 Egypt signed the UNFCCC and ratified it on 5 December 1994. On 15 March 1999 the Egyptian government signed the Kyoto Protocol and in June 1999 Egypt submitted its Initial National Communication on Climate Change. In this overview the major focus is on climate change impacts, and the Egyptian government foresees: 
Egypt's large and tightly-packed population makes the country highly vulnerable to climate change. ... This expanding population will remain concentrated in a narrow strip along the fertile banks of the Nile river and delta. The increasing population density of this area will reduce Egypt's flexibility and options for responding to climate change impacts (Egypt 1999: 4- 5). ${ }^{25}$

The national communication notes that "the potential social and economic impact of climate change could be devastating for the country's future" (Egypt: 5). Two major present problems that will become more urgent are that Egypt does not grow enough food to feed its current population and that the country's water resources are limited.

The net result is that the annual increase in population (2.8\%) exceeds the annual increase in agricultural production (2.6\%). Egypt's imports of food absorb most of its foreign currency, which is therefore not available for development. If climate change makes Egypt drier or warmer, pressure on agriculture - much of which is dependent on irrigation - would intensify. Egypt relies on the Nile for $90 \%$ of its water needs, but it cannot control the quantity and quality of this water, which depend on activities upstream. ... Egypt consumes 48 billion cubic metres of the Nile annually, but, as with Ethiopia and Sudan ... its demand will increase along with population and development. Competition among these states for water could escalate even without climate change. If climate change results in increased warming, droughts, and evaporation, reduced flow in the Nile would further exacerbate Egypt's problems, and the country could face an explosive situation.

The national communication foresees that climate "may bring about substantial reductions in the national grain production" and "Egypt would have to increase its reliance on costly food imports" (Egypt 1999: 61-62). The report foresees the following changes in yield by 2050 for wheat $(-18 \%)$, for maize $(-19 \%)$; for sorghum $(-19 \%)$, for barley $(-18 \%)$, for rice $(-$ $11 \%)$ and for soybeans (-28\%). Possible mitigation measures could be adapted crops, improved water and land management techniques especially in the northern part of the Nile delta (Egypt 1999: 64-65). Egypt's Mediterranean Coast and the Nile Delta is perceived as especially vulnerable to climate change impacts (Egypt 1999: 66). The report suggested several measures to adapt water supply, by a) improving rain harvesting techniques, b) increased abstraction of groundwater, c) recycling of water, d) desalination of water, e) transportation of water by tankers and f) rationalization of water use. "Improved water management requires minimizing the need for water and optimising the economic return of its unit volume." A precaution against intruding salt water would be to cultivate the largest possible area in the coastal belt with rice (Egypt 1999: 76-77).

Based on present population data, the Egyptian national communication foresees as a result of climate change a likely migration of "at least two million people from the Delta coastal areas due to the inundation and loss of fertile land. This migration will have its impact on the human habitats and settlements" (Egypt 1999: 77). The national communication also mentions adverse effects on the human health in Egypt: "to include physiological disorders, skin cancer, eye cataracts, damage to public health infrastructure, death and injuries, heat strokes and heat related phenomena, etc." (Egypt 1999: 77). While Egypt is highly vulnerable to climate change impacts, it contributes just a fraction of $0,34 \%$ of global greenhouse gas emissions.

National environmental policies are coordinated by the Egyptian Environmental Affairs Agency (EEAA 1995). Since 1995, two major programmes were launched by the

\footnotetext{
${ }^{25}$ The Arab Republic of Egypt: Initial National Communication on Climate Change (Cairo; Egyptian Environmental Affairs Agency, 1999), at: <http://www.unfaccc.de/ resource/country/egypt.html>.
} 
EEAA, the Support for the National Action Plan (SNAP) ${ }^{26}$, and the Building Capacity for Egypt Project. ${ }^{27}$ The communication pointed to remaining research gaps: a) the need to upgrade Egypt's scientific capacity in remote sensing and meteorological sectors, b) research on the likely impacts of climate change in several sectors (water resources, coral reefs) and integrated research, and c) policy oriented research on GHG emissions, the energy sector, the agricultural, the solid waste, and the water resource sector.

\subsubsection{Environmental Stress in Egypt}

In 1989, Norman Myers has pointed to the extreme environmental stress Egypt has already experienced: "Two decades ago Egypt was self-sufficient in food, but today ... it is experiencing quickly mounting difficulties in feeding its population. Urban riots and other domestic upheavals have already resulted from rising food prices and related foodsupply problems. ... Because of rapid population growth, but also because of environmental problems, grain output per person declined by 18 percent from 1971 to 1985." The FAO offered this assessment on Egypt's agricultural resources and prospects:

Amid pronounced fluctuations, food and agricultural output has risen only slowly, particularly between the late 1960s and early 1980 when it actually declined about 10 percent in per caput terms. ... Domestic production has been inadequate to cover the needs of a rapidly expanding population. ... The value of cereal imports ... rose steeply during the 1970s, peaking in 1982 at $\$ 1.7$ billion, but declining since the late 1980s to about $\$ 900$ million in recent years. ... Particularly 1987-90, the value of food imports significantly exceeded the total value of merchandise exports. ... Self-sufficiency rates in wheat have increased from about 20 percent in the mid-1980s to about 45 percent in 1996. Policies aimed at greater investments in extension services, land reclamation, ... and population planning since the $1980 \mathrm{~s}$, combined with the liberalization of prices ... have led to increases in wheat yields and production. Egypt's production ... of fruits and vegetables has also improved (FAO 1997: 189-196).

For Egypt food security will decline and the need for food imports will rise significantly and the self-sufficiency rate, especially in cereals will drop, it may drop as low to $10 \%$ by 2060 , as the integrated climate impact study has projected.

Besides the two root causes of the survival dilemma, population growth and climate change, and the implications for progressing desertification, land loss to sea-level-rise, increased water demand and declining water supply will have a negative impact on agricultural output, self-sufficiency in food and on food security during the $21^{\text {st }}$ century. What have been the consequences of the six structural factors of the survival hexagon and what socio-economic and political consequences may be foreseen for the future?

The population growth rate declined from $2.75 \%$ (1986) to $2.1 \%$ (2000), the fertility rate per woman fell from 4.5 (1986) to 3.4 (1996). Even though urbanisation has grown much slower in Egypt than in North Africa from $31.9 \%$ in 1950 to $46.0 \%$ in to 1995 , the UN growth projection until 2030 are for Egypt 61.8\% and for North Africa $67.2 \%$. However, the population growth in the two major Egyptian urban centres, in Cairo and Alexandria, has been dramatic. According to the UN (2000) World Urbanization Prospects, Cairo has grown from 2.4 million in 1950 to 10.6 million by 2000 and it is projected to grow to 13.8 million by 2015 . The population of Alexandria has grown from 500,000 in 1950 to 3.3 million in 1996 and may grow above 5 million by 2015 in a ter-

\footnotetext{
${ }^{26}$ For details see at: <http://www.highway.idsc.gov.eg/ccinfo/activity/snap.htm>. For the US Country Study Program Activity in Egypt see at: <http://www.highway.idsc.gov.eg/ccinfo/activity/uscscc.htm>.

${ }^{27}$ For details see at: <http://www.highway.idsc.gov.eg/ccinfo/activity/capacity.htm>.
} 
ritory whose survival is challenged by sea-level rise. A major problem has been unemployment. Of $59 \%$ of the population in the workable age only $28 \%$ have a permanent job. Each year about 500,000 young people enter the labour market while the government hopes to create in the next five years a total of 300,000 to 1 million new jobs.

About 1.9 million Egyptians are working abroad most of them in Saudi Arabia (nearly 1,000,000), Libya $(330,000)$ and Jordan $(226,000)$. During the 1980s, about 3 million Egyptian's were working in Iraq but since the second Gulf War in 1991, this number has shrunk to 150,000 people. ${ }^{28}$ Among the OECD countries, in the 1998 review of international migration only Italy listed in 1991 about 10,100 (total: 285,300) and in 1996 9,700 Egyptians (total 332,200) among its foreign labour or $2.9 \%$ in 1996. In 1999, of 268,000 immigrants 6,100 were from Egypt. So far the major Egyptian emigration has been within the Arab world. However, Egypt has already become a country of immigration or transmigration for people from Sub-Saharan African countries.

\subsubsection{Conflict Potentials in the Nile Basin}

What will be possible future security implications of climate change and high population growth for Egypt? The Nile is the key to Egypt's survival. Any plans by the nine other riparian states to use more water of the Nile provoked nervous Egyptian reactions. Since the 1990s the Nile Basin Initiative $(\mathrm{NBI})^{29}$ has become a focal point of regional cooperation on water issues among the 10 Nile countries. In 1996 the NBI published the Nile River Basin Action Plan. The World Bank has supported its implementation since 1997. In June 2001, at a meeting of an international consortium for cooperation on the Nile, a forum of donors was formed that is committed to total investments of up to 3 billion US\$ for infrastructure programmes, for the protection and management of water resources, energy production and environment protection to avoid periods of famine. The World Bank president Wolfensohn noted that the population of these ten Nile countries would grow from 300 million within 20 years to about 500 million. ${ }^{30}$ Until 2050, in the ten Nile countries population has been projected to increase from 280.8 million in 2000 by 575 million to 855.6 million by 2050 (UN 2001). Thus, the competition for water and the struggle for survival for millions of people will increase (table 4.6).

Thus Egypt, will be confronted with severe human catastrophes that may be foreseen in the Nile upstream countries. Whether the severe challenges for distributing the water can be resolved peacefully as the NBI aims at, whether to the existing civil wars along the ethnic divide new types of conflicts, such as environmental conflicts or clashes with migrants fighting for their own survival may be added, cannot be projected. However, these structural factors are distressing and conflict-prone constellations on the NorthSouth axis may not be avoided. Whether the NBI can mitigate these trends will partly depend on the willingness of both donor and recipient countries to implement the needed strategy for survival. Migration from upstream Nile countries in sub-Saharan Africa into Egypt may increase within the next decades. Thus, migration from Egypt to Europe may become a problem in the $21^{\text {st }}$ century, especially due to the efforts of SubSaharan Africans to migrate first to Egypt and then from there to EU countries.

\footnotetext{
28 “Hohes Bevölkerungswachstum in Ägypten. Zu viele Arbeitsfähige, zu wenig Arbeitsplätze“, in: Neue Zürcher Zeitung, 15 May 2001: 4.

${ }^{29}$ For details see its website at: < http://www.nilebasin.org/>.

${ }^{30}$ See: This meeting adopted: Nile Basin Initiative - Shared Vision Program that may be viewed at: $<$ http://www.nilebasin.org/SVP\%20Project\%20Summary.htm>.
} 
Figure 4.6: Nile Basin (NBI at: $<$ http://www. None of these challenges are of a milinilebasin.org/>

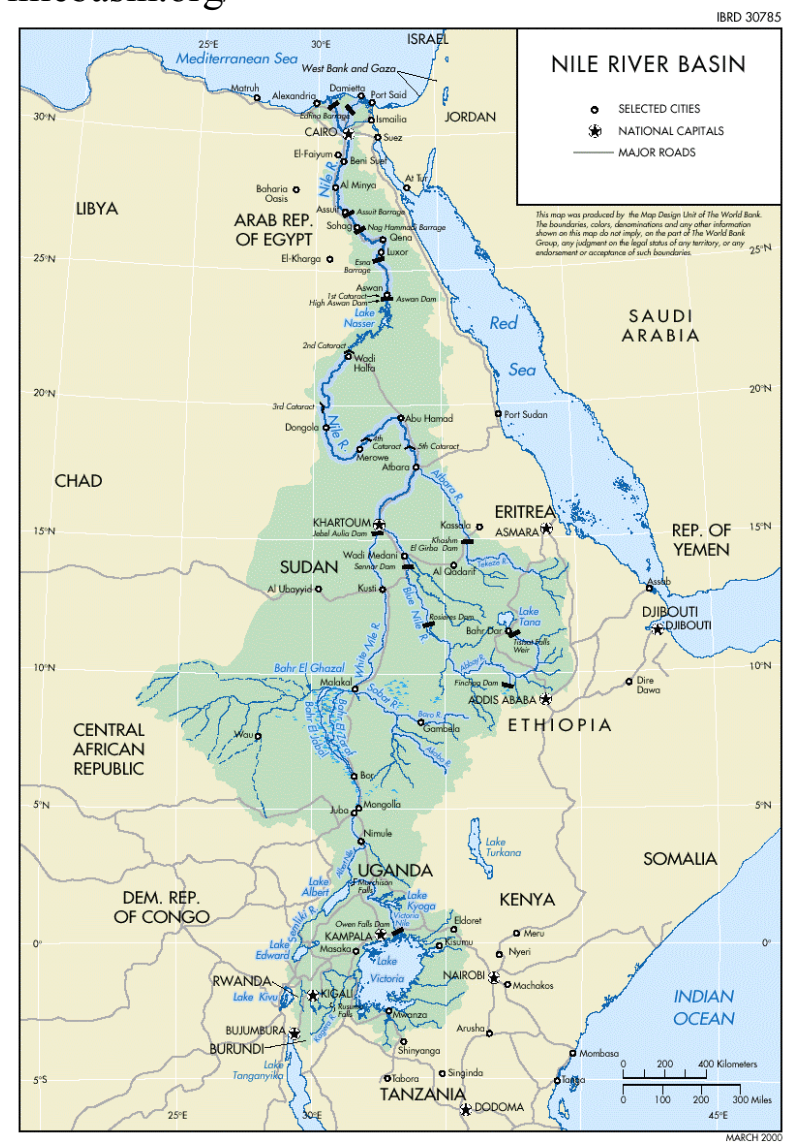
tary nature and none can be solved by military means or military forces. These non-military challenges posed by the struggle for survival of distress migrants at the individual, family or clan level will require short-term catastrophe relief (food aid, water supply etc.) but complex and interrelated counterstrategies of climate change and reproductive health. The best long-term mitigation efforts for all industrialised countries will be effective strategies of reducing GHG emissions, and to assist the countries that will be hit most but that lack the means for mitigating climate change impacts. This requires, development strategies that address the causes that may lead to the catastrophic projections.

O’Neill, MacKellar and Lutz (2001) have called for strategies to reduce population growth through programmes of reproductive health, family planning and better and longer education of

young women will reduce the demand by the projected sea-level rise food, housing etc. but also reduce the emissions and the adverse effects of the poor who in their search for fuel wood contribute to deforestation and soil erosion.

Table 4.6: Population Development of the Ten Nile Basin Countries in million (1950-2050)

\begin{tabular}{|l|r|r|r|r|r|}
\hline Nile Countries & \multicolumn{1}{|c|}{1950} & \multicolumn{1}{c|}{2000} & \multicolumn{2}{|c|}{$2050 \mathrm{MV}$} & \multicolumn{2}{|c|}{ Population Growth } \\
\hline & & & & $1950-2050$ & $\mathbf{2 0 0 0 - 2 0 5 0}$ \\
\hline Egypt & $\mathbf{2 1 , 8 3 4}$ & $\mathbf{6 7 , 8 8 4}$ & $\mathbf{1 1 3 , 8 4 0}$ & $\mathbf{9 2 , 0 0 6}$ & $\mathbf{4 5 , 9 5 6}$ \\
\hline Sudan & 9,190 & 31,095 & 63,530 & 54,340 & 32,435 \\
\hline Ethiopia & 18,434 & 62,908 & 186,452 & 168,018 & 123,544 \\
\hline Uganda & 5,210 & 23,300 & 101,524 & 96,314 & 78,224 \\
\hline Eritrea & 1,140 & 3,659 & 10,028 & 8,888 & 6,369 \\
\hline Kenya & 6,265 & 30,669 & 55,368 & 49,103 & 24,699 \\
\hline Tanzania & 7,886 & 35,119 & 82,740 & 74,854 & 47,621 \\
\hline Rwanda & 2,120 & 7,609 & 18,523 & 16,403 & 10,914 \\
\hline Burundi & 2,456 & 6,356 & 20,218 & 17,762 & 13,862 \\
\hline Congo (Zaire) & 12,184 & 50,948 & 203,527 & 191,343 & 152,579 \\
\hline Total & $\mathbf{8 6 , 7 1 9}$ & $\mathbf{2 8 0 , 7 8 3}$ & $\mathbf{8 5 5 , 7 5 0}$ & $\mathbf{7 6 9 , 0 3 1}$ & $\mathbf{5 7 4 , 9 6 7}$ \\
\hline
\end{tabular}




\subsection{Projected Climate Change Impacts for the Mediterranean}

\subsubsection{The Mediterranean: Common Ecological Space - Divided Region}

There is no generally accepted definition of the Mediterranean nor are there any common criteria of the Mediterranean Sea, its space, region, climate or way of life. It is a 'sea' whose shores combine the three continents: Europe, Africa and Asia. Nevertheless, there is a consensus that it is a 'region' that once has been a centre of the world, that was the cradle of several high civilisations of Egypt, Crete, Greece and Rome and of three monotheistic religions of Jews, Christians and Muslims (Brauch 2001). The 'Mediterranean' is characterised by both unity and diversity, by periods of co-operation and conflict, of tolerance and violent intolerance, by intensive cultural exchange and cultural clashes, of close economic co-operation, interdependence but also by exploitation, unequal exchange and dependence.

Figure 4.7: Countries around the Mediterranean (World Bank/EIB 1990, 1993: 77)

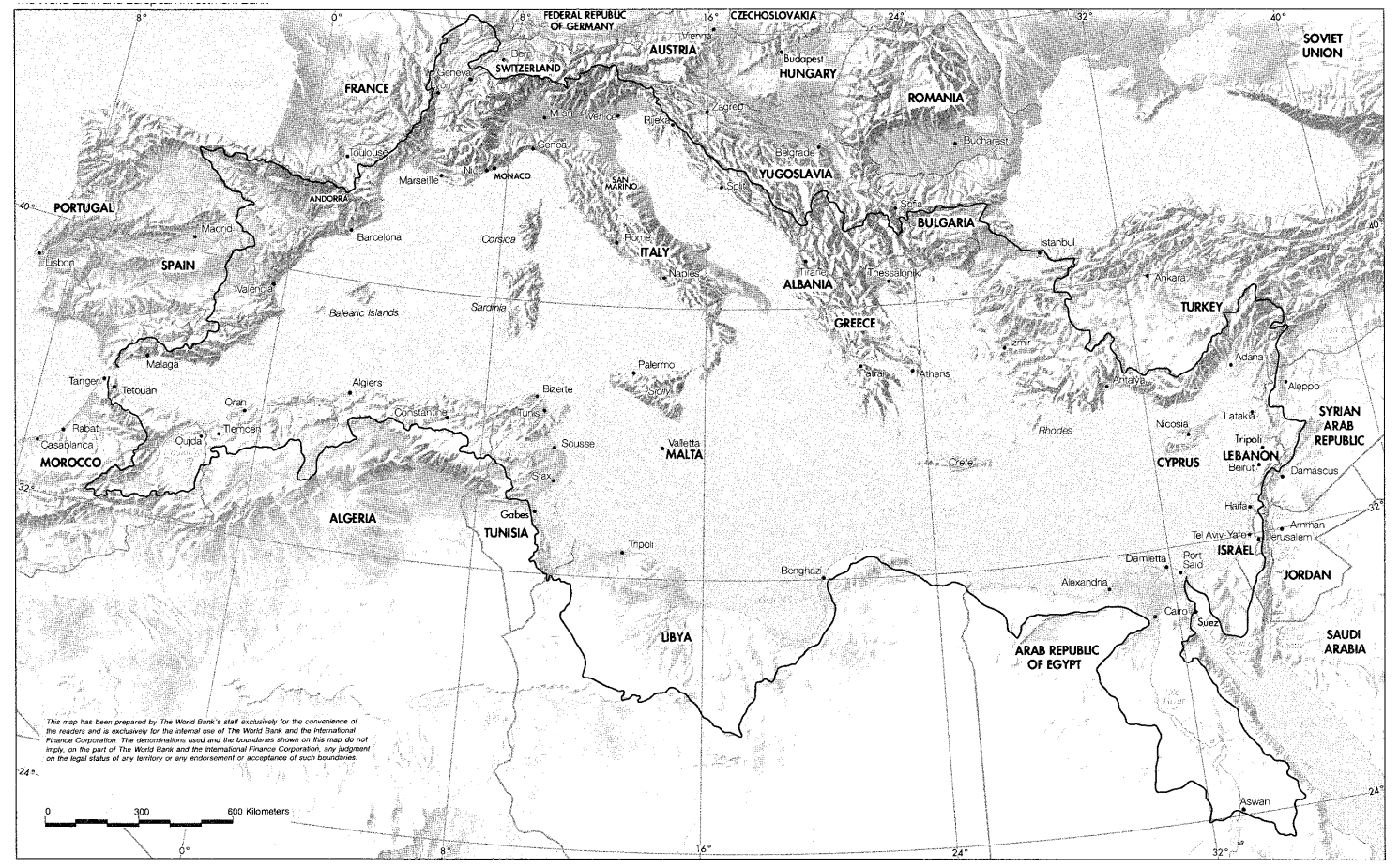

\subsubsection{The Mediterranean: Climate Change Studies and Obligations}

So far the IPCC did not assess the climate change impacts in the Mediterranean, rather there have been only episodic references to the region (or Egypt) in the first assessment of the impacts for agriculture and forestry, natural terrestrial ecosystems, hydrology and water resources, for human settlements and oceans and coastal zone (IPCC 1990). The SAR (IPCC 1996a) dealt in more detail with the impacts, adaptation options and assessment of mitigation options. In the IPCC's (1998) Regional Impacts study, Mediterranean issues are covered under Africa, Europe and the Middle East and arid Asia. This division of the Mediterranean as the periphery of three continents prevents a systematic assessment of climate change impacts. In the TAR (IPCC 2001a), the African chapter deals with climate change impacts on water, food security, natural resource management, human health, settlements, infrastructure and desertification (IPCC 2001a: 525). 
The Asian chapter deals with physical and ecological features, scenarios for future climate change and key variables for sensitivity and adaptability. The European chapter offers an overview of future European climate change scenarios that:

were placed in the context of model estimates of natural variability of European climate. The baseline period selected was 1961-1990; changes in mean 30-year climates were calculated for the periods centred on the 2020s (2010-2039), the 2050s (2040-2069), and the 2080s (2070-2099). ... For each scenario, season, variable, and time-slice, two maps were constructed. One map shows the median change from the sample of eight standardized and scaled GCM responses, the other map shows the absolute range of these eight responses (IPCC 2001a: 653).

With regard to their GHG emissions per capita there is a clear North-South differentiation between the Northern Mediterranean and the Southern Mediterranean countries. Below the contribution of all Mediterranean riparian countries to global warming and their obligations, commitments and efforts will be compared (table 4.7).

Table 4.7: Climate Policy Obligations and Commitments of Mediterranean Countries

\begin{tabular}{|c|c|c|c|c|c|c|c|c|c|c|c|}
\hline & \multicolumn{3}{|c|}{ UNFCCC } & \multicolumn{3}{|c|}{ Kyoto Protocol } & \multicolumn{3}{|c|}{ Communication } & \multicolumn{2}{|c|}{$\begin{array}{l}\text { Reduction } \\
\text { Obligations }\end{array}$} \\
\hline & Signed & Ratified & Status & Signed & Ratified & Status & First & Sec. & Third & $\mathrm{KP}$ & real \\
\hline Albania & & 3.10 .94 & - & - & - & & \multicolumn{3}{|c|}{13.9 .2002} & - & 0 \\
\hline Algeria & 13.6 .92 & 9.6 .93 & - & - & - & & \multicolumn{3}{|c|}{ IC 30.4.2001 } & - & 0 \\
\hline Bosnia & & 7.9.2000 & - & $?$ & $?$ & - & - & - & - & - & 0 \\
\hline Croatia & 11.6 .92 & 8.4 .96 & An. 1 & 11.3 .99 & & An. B & \multicolumn{3}{|c|}{2.7 .2002} & $-6 \%$ & $-6 \%$ \\
\hline Cyprus & 16.6 .92 & 15.10 .97 & - & & 16.7 .99 & & - & - & - & - & 0 \\
\hline Egypt & 9.6 .92 & 5.12 .94 & - & 15.3 .99 & & & \multicolumn{3}{|c|}{ IC 19.7.1999 } & - & 0 \\
\hline France & 13.6 .92 & 25.3 .94 & An. 1 & 29.4 .98 & 31.5 .02 & An. B & \begin{tabular}{l|l}
$x$ \\
\end{tabular} & $\mathrm{x}$ & $\mathrm{x}$ & $-8 \%$ & $0 \%$ \\
\hline Greece & 12.6 .92 & 4.8 .94 & An. 1 & 29.4 .98 & 31.5 .02 & An. B & $\mathrm{x}$ & $\mathrm{x}$ & - & $-8 \%$ & $+25 \%$ \\
\hline Israel & 4.6 .92 & 4.6 .96 & - & 16.12 .98 & - & & \multicolumn{3}{|c|}{ IC 18.11 .2000} & - & 0 \\
\hline Italy & 5.6 .92 & 15.4 .94 & An. 1 & 29.4 .98 & \begin{tabular}{|l|}
31.5 .02 \\
\end{tabular} & An. B & $\mathrm{x}$ & $\mathrm{x}$ & - & $-8 \%$ & $-6.5 \%$ \\
\hline Lebanon & 12.6 .92 & 15.12 .94 & - & & & & \multicolumn{3}{|c|}{ IC 2.11 .1999} & - & 0 \\
\hline Libya & 29.6 .92 & 14.6 .99 & - & & & & \multicolumn{3}{|c|}{ - } & - & 0 \\
\hline Malta & 12.6 .92 & 17.3 .94 & - & 17.4 .98 & 11.11 .01 & & \multicolumn{3}{|c|}{ - } & - & 0 \\
\hline Morocco & 13.6 .92 & 28.12 .95 & - & & 25.1 .02 & & \multicolumn{3}{|c|}{ - } & - & 0 \\
\hline Slovenia & 13.6 .92 & 1.12 .95 & An. 1 & 21.10 .98 & & An. B & - & - & - & $-8 \%$ & $-8 \%$ \\
\hline Spain & 13.6 .92 & 21.12 .93 & An. 1 & 29.4 .98 & 31.5 .02 & An. B & $\mathrm{x}$ & $\mathrm{x}$ & $\mathrm{x}$ & $-8 \%$ & $+15 \%$ \\
\hline Syria & & 4.1 .96 & - & & & & \multicolumn{3}{|c|}{ - } & - & 0 \\
\hline Tunisia & 13.6 .92 & 15.7 .93 & - & & & & \multicolumn{3}{|c|}{ completed 2000} & - & 0 \\
\hline Turkey & \multicolumn{2}{|c|}{ No party } & An. 1 & \multicolumn{3}{|c|}{ No party } & \multirow{2}{*}{\multicolumn{3}{|c|}{$\begin{array}{l}- \\
-\end{array}$}} & - & - \\
\hline FRYugoslavia & 8.6 .92 & 12.3 .2001 & - & & & & & & & - & 0 \\
\hline Portugal & 13.6 .92 & 12.12 .93 & An. 1 & 29.4 .98 & 31.5 .02 & An. B & $\mathrm{x}$ & $\mathrm{x}$ & - & $-8 \%$ & $+27 \%$ \\
\hline Jordan & 11.6 .92 & 12.11 .93 & - & & & & \multicolumn{3}{|c|}{ IC 6.3.1997 } & - & 0 \\
\hline Macedonia & & 28.12 .98 & - & & & & \multicolumn{3}{|c|}{-} & - & 0 \\
\hline
\end{tabular}

Legend: An. 1: Country listed in the Annex 1 to the UN Framework Convention on Climate Change (UNFCCC);

An. B: Country listed in the Annex B to the Kyoto Protocol (KP);

IC: Initial Communication under the UNFCCC to the Climate Secretariat. 
The European chapter foresees that for the Mediterranean due to rising temperature and declining summer precipitation the risk of forest fires may increase further. The risk of severe water shortages in the Mediterranean would also have severe effects on fresh water ecosystems in the region (IPCC 2001a: 666). On migrations the chapter notes:

Migration caused by soil degradation is a very important issue in the Mediterranean region, the southern part of which is mostly arid and vulnerable to climate change. With perhaps $24 \%$ of total drylands in Africa in the process of desertification and $0.3 \%$ of the African population permanently displaced largely as a result of environmental degradation, consequent in-migration pressures on neighboring regions such as southern Europe can be substantial (IPCC 2001a: 672).

Figure 4.8: Summer Scenario Maps for Temperature Changes in 2080s (IPCC 2001a: 651)

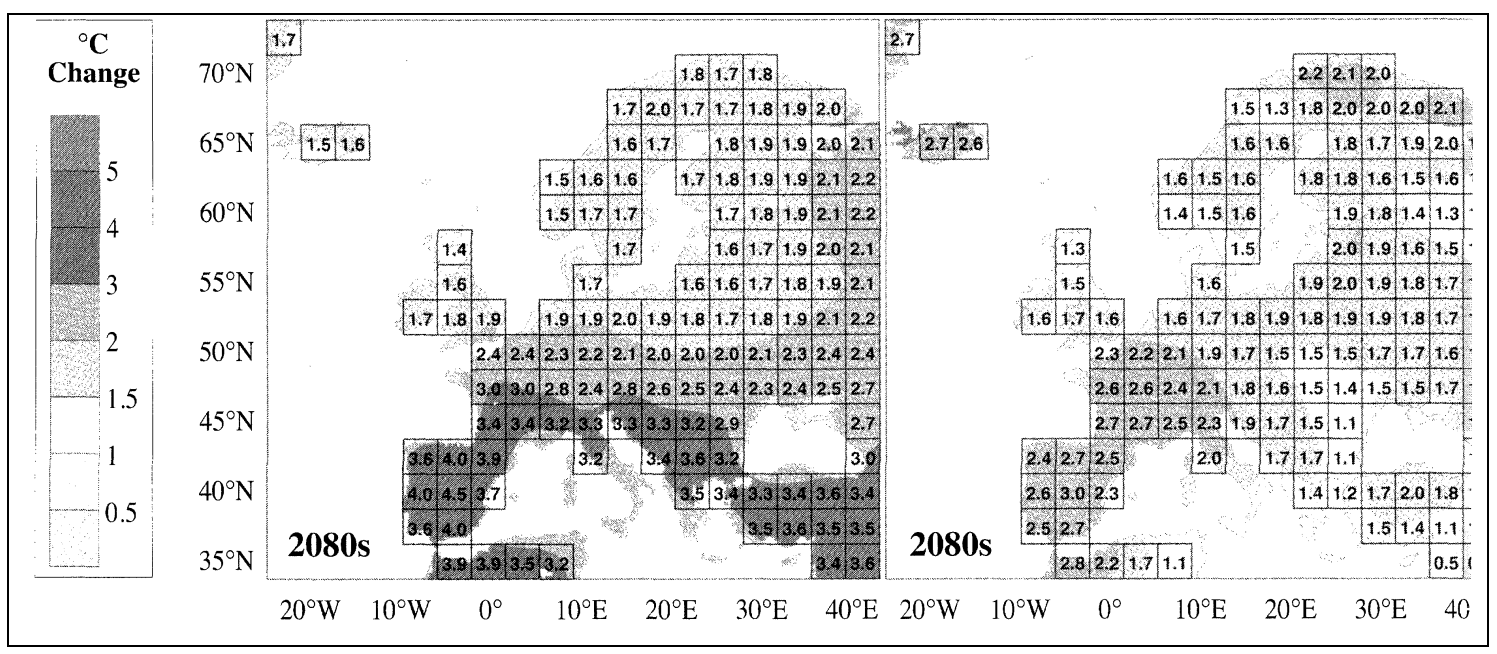

Figure 4.9: Summer Scenario Maps for Precipitation Changes (IPCC 2001a: 652)

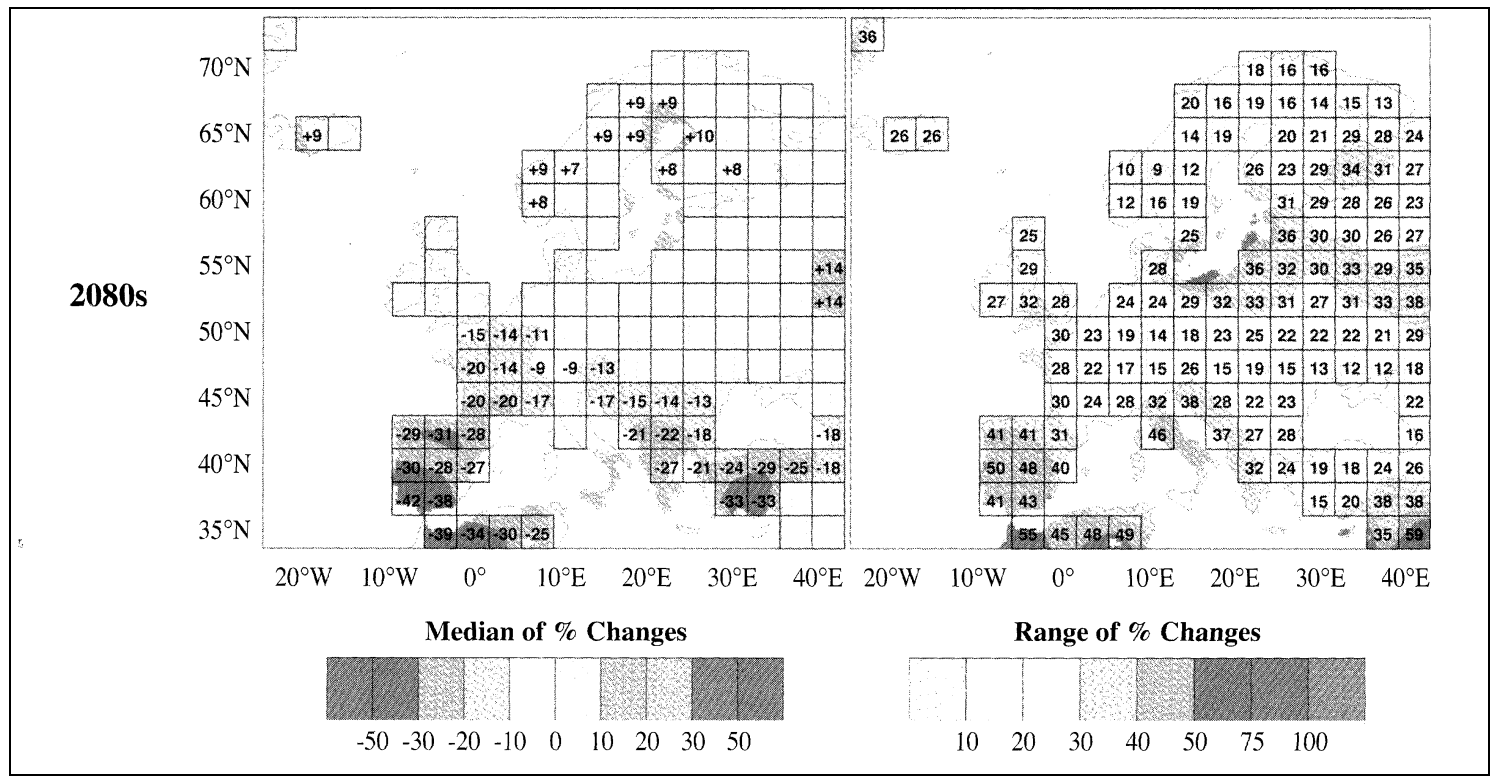

The European chapter foresees losses and gains due to climate change, and for the Mediterranean an increase in the variability of water flows with summer flows reduced and in coastal areas, the risks of flooding and erosion will increase substantially.

Climate observations and the scenarios presented here suggest that southern Europe will be more adversely affected than northern Europe. A shift in climate-related resources from 
south to north may occur in sectors such as tourism, agriculture, and forestry. In particular, the Mediterranean region appears likely to be adversely affected. Among likely adverse effects are increased variability of river flow; increased flood risk; decreased summer runoff and recharge of aquifers; and reduced reliability of public water supply, power generation, and irrigation. Increased fire hazards affecting populated regions and forests and heat stress on humans, crops and livestock may occur. ... There is greater vulnerability, in general, in southern than in northern Europe (IPCC 2001a: 680).

But the IPCC still lacks a systematic assessment of the knowledge on climate change impacts for the Mediterranean. Several EU-sponsored networks have discussed aspects of regional climate models on and socio-economic impacts for the Mediterranean. ${ }^{31}$ In the framework of ECLAT-2, a workshop on: "Applying Climate Scenarios for Regional Studies with particular reference to the Mediterranean"32 reviewed "the construction and application of climate change scenarios in regional-scale impacts assessments". The workshop covered "the use of Regional Climate Models in regional scenario construction, the achievement of consistency between point, local and regional-scale scenarios, and the integration of climate impacts results across regions". Ali Harzallah (2001: 7579) pointed also to several weaknesses in existing scenarios for climate change on the Mediterranean: a) a lack of the analysis of systematic errors, b) poor evaluation of climate variability, c) simulation of short periods, no organised databases for regional model outputs, and d) lack of simulation using ocean-atmosphere coupled regional models on the Mediterranean. To overcome these shortcomings, Harzallah suggested to correctly evaluate the present simulated climate and climate variability from GCMs and RCMs on the region, to use rigorous spatial statistics, to use multi-model ensembles of high resolution scenarios, to define targeted sub-regions of the Mediterranean area for impact studies and to educate the stake holders on deficiencies and uncertainties. In his summary Serge Planton (2001: 84-85) stressed: "The most critical sensitivity of the socioeconomy of the Mediterranean area regarding the impact of climate appears to be linked to the issue of water supply." Planton pointed to "a huge need for regional integrated assessment over the Mediterranean area. A common project involving climate and impact communities, associating stakeholders, should be developed“.

In the framework of the EU-project RICARME (Research on Global Change in the Mediterranean: A regional Network) one study aimed at "improving the management of the fragile Mediterranean ecosystems". Other EU-sponsored research projects focused on Forecasting climatic change impacts on Mediterranean agricultural land use in the $21^{\text {st }}$ century. ${ }^{33}$ But no systematic assessment of these multiple efforts funded by the EU exists. They had no impact on the IPCC's assessments nor did they affect the policy debate in the political Barcelona process for a Euro-Mediterranean partnership.

\subsubsection{Environmental Challenges for the Mediterranean}

Among the regional challenges confronting the Mediterranean in the $21^{\text {st }}$ century, climate change may have significant impacts on precipitation, soil erosion and desertification. These climate related factors will have a significant impact on agricultural pros-

\footnotetext{
${ }^{31}$ On RICARME see at: <http://csd.hss.nthu.edu.tw/RICAMARE.htm>.

32 The results were published by: Climate Research Unit, UEA, Norwich, UK in April 2001. The report may be downloaded at: < http://www.cru.uea.ac.uk/eclat/ >.

${ }^{33}$ See: Stan Openshaw; Andy Tuner, Centre for Computational Geography, School of Geography, University of Leeds, at: <http://www.geog.leeds.ac.uk/people/a.turner/papers/21stC/21stC.html $>$ and at: $<$ http://www.medalus.leeds.ac.uk/SEM/home.htm>.
} 
pects: on the availability of arable land and on yields. In addition three human trends have to be taken into account: population growth, urbanisation and the growing demand for water and food. As many IPCC studies have indicated these six factors of the survival hexagon cannot be separated nor can the impacts of climate change on future security policy be analysed in isolation.

Table 4.8: Population Growth of Germany, five Southern European EU and 12 Mediterranean Dialogue Countries (plus Libya) in million (UN 2001)

\begin{tabular}{|c|c|c|c|c|c|c|c|c|c|}
\hline \multicolumn{7}{|c|}{ Real population development } & \multirow{2}{*}{\begin{tabular}{|c|}
$\begin{array}{c}\text { Projec- } \\
\text { tions } \\
\text { Med. var. }\end{array}$ \\
$\begin{array}{c}2050 \\
(2000 \text { Rev. })\end{array}$ \\
\end{tabular}} & \multicolumn{2}{|c|}{ changes } \\
\hline & 1850 & 1900 & 1950 & 1965 & 1980 & \begin{tabular}{|c|}
2000 \\
$(2000$ \\
Rev. $)$ \\
\end{tabular} & & \begin{tabular}{|c|}
$1950-$ \\
2050 \\
$\mathbf{( 2 0 0 0}$ \\
\end{tabular} & \begin{tabular}{|c}
$2000-$ \\
2050 \\
Rev. $)$ \\
\end{tabular} \\
\hline \multicolumn{10}{|c|}{ Europe (6 of the 15 EU countries) } \\
\hline Germany & 35.0 & 57.0 & 68.376 & 76.031 & 78.304 & 82.017 & 70.850 & 2.474 & -11.167 \\
\hline France & 36.0 & 41.0 & 41.829 & 48.753 & 53.880 & 59.238 & 61.832 & 20.003 & 2.594 \\
\hline Greece & 3.5 & 4.5 & 7.566 & 8.551 & 9.643 & 10.610 & 8.983 & & \\
\hline Italy & 25.0 & 34.0 & 47.104 & 52.112 & 56.434 & 57.530 & 42.962 & -4.142 & -14.568 \\
\hline Portugal & 3.5 & 5.5 & 8.405 & 9.129 & 9.766 & 10.016 & 9.006 & & \\
\hline Spain & 15.0 & 18.5 & 28.009 & 32.065 & 37.542 & 39.910 & 31.282 & 3.273 & -8.628 \\
\hline Total (5) & 83.0 & 103.5 & 132.913 & 150.610 & 167.265 & 177.304 & 154.065 & 21.152 & -23.239 \\
\hline \multicolumn{10}{|c|}{ Two EU candidates } \\
\hline Cyprus & 0.15 & 0.23 & 0.494 & 0.582 & 0.611 & 0.784 & 0.910 & 0.416 & 0.126 \\
\hline Malta & 0.13 & 0.19 & 0.312 & 0.305 & 0.324 & 0.390 & 0.400 & 0.088 & 0.010 \\
\hline Total (Islands) & 0.28 & 0.42 & 0.806 & $\mathbf{0 . 8 8 7}$ & 0.935 & 1.174 & 1.310 & 0.504 & $\mathbf{0 . 1 3 6}$ \\
\hline \multicolumn{10}{|c|}{ Yugoslavia and Albania } \\
\hline Albania & 0.5 & 0.8 & 1.215 & & & 3.134 & 3.905 & 2.690 & 0.771 \\
\hline Yugoslavia & 7.25 & 9.5 & 16.345 & & & 23.205 & 20.088 & 3.743 & -3.117 \\
\hline - Bosnia \& Herz & & & 2.661 & & & 3.977 & 3.458 & & -0.519 \\
\hline - Croatia & & & 3.850 & & & 4.654 & 4.179 & & -0.475 \\
\hline - Macedonia & & & 1.230 & & & 2.034 & 1.894 & & -0.140 \\
\hline - Slovenia & & & 1.473 & & & 1.988 & 1.527 & & -0.461 \\
\hline - FR Yugoslavia & & & 7.131 & & & 10.552 & 9.030 & & -1.522 \\
\hline Total & 7.75 & 10.3 & 17.560 & & & 26.339 & 23.993 & & -2.346 \\
\hline \multicolumn{10}{|c|}{ Ten Non EU-Mediterranean Dialogue Partners (plus Libya) } \\
\hline Algeria & 3.0 & 5.0 & 8.753 & 11.823 & 18.740 & 30.291 & \begin{tabular}{|l|}
51.180 \\
\end{tabular} & 42.427 & 20.889 \\
\hline Morocco & 3.0 & 5.0 & 8.953 & 13.323 & 19.382 & 29.878 & 50.361 & 41.408 & 20.483 \\
\hline Tunisia & 1.0 & 1.5 & 3.530 & 4.630 & 6.448 & 9.459 & 14.076 & \begin{tabular}{|l|}
10.546 \\
\end{tabular} & 4.617 \\
\hline Libya & 0.6 & 0.8 & 1.029 & 1.623 & 3.043 & 5.290 & 9.969 & 8.940 & 4.679 \\
\hline Egypt & 5.5 & 10.0 & 21.834 & 31.563 & 43.749 & 67.884 & 113.840 & 92.006 & 45.956 \\
\hline Only North Africa & 13.1 & 22.3 & 44.099 & 62.962 & 91.362 & 142.802 & 239.426 & 195.327 & 96.624 \\
\hline Jordan & 0.25 & 0.3 & 1.237 & 1.962 & 2.923 & 4.913 & 11.709 & \begin{tabular}{|l|}
10.472 \\
\end{tabular} & \begin{tabular}{|l}
6.796 \\
\end{tabular} \\
\hline Israel & & & 1.258 & 2.563 & 3.879 & 6.040 & 10.065 & 8.807 & 4.025 \\
\hline Palestine Authority & 0.35 & 0.5 & 1.005 & & & 3.191 & 11.821 & 10.816 & 8.630 \\
\hline Lebanon & 0.35 & 0.5 & 1.443 & 2.151 & 2.669 & 3.496 & 5.018 & 3.575 & $\mathbf{1 . 5 2 2}$ \\
\hline Syria & 1.5 & 1.75 & 3.495 & 5.325 & 8.704 & 16.189 & 36.345 & \begin{tabular}{|l|}
32.850 \\
\end{tabular} & 20.156 \\
\hline Turkey & 10.0 & 13.0 & 20.809 & 31.151 & 44.438 & 55.668 & 98,818 & \begin{tabular}{|l|}
78.009 \\
\end{tabular} & 43.150 \\
\hline Eastern Med. & & & 29.247 & & & 89.497 & 173.876 & 144.529 & 84.279 \\
\hline $10+1$ dialogue $c$ & & & & & & & 413.202 & & 180.903 \\
\hline $\begin{array}{l}\text { Total }(12+1) \\
\text { dialogue count. }\end{array}$ & 25.23 & 37.97 & 74.152 & & & 233.473 & 414.512. & 340.036 & 181.039 \\
\hline
\end{tabular}

Sources: McEvedy/Jones for 1850, 1900; for projections to 2050: UN 2001. The data for 1960, 1980 and for 1994 revision are taken from Heilig 1995, 1998, 1998a, 2000. 
Within the Mediterranean there are common features: climate change and weather extremities (droughts, floods), water scarcity and soil erosion and desertification. But there are major differences on demography, food scarcity and surplus and on urbanisation and pollution.

In the MENA water is extremely scarce. Since 1960, the water per person has dropped and population growth will reduce the water available for irrigated agriculture and the amount of food produced. In the $21^{\text {st }}$ century, MENA countries will be confronted with physical, technical and economic constraints. Depending on growth rates, water conservation and efficiency improvements, the water demand in North Africa may fluctuate.

The growing demand for water will require major economic investments. Fakhri Bazzaz (1994: 243-52) claimed that global climate change "could aggravate the problem of assuring adequate supplies of water and water-based food to Arab populations", and could have significant effects on agriculture, natural vegetation and on wildlife. Due to population growth in the $21^{\text {st }}$ century, the need to grow and import food will increase.

In all North African countries the arable land is limited by the Sahara: Egypt: 2.6\%; Libya: $1.2 \%$, Tunisia 10.0\%; Algeria 3\%; Morocco: 20\%. Morocco has about 8.4 million ha of arable land, Algeria 7.5 million ha and Tunisia 4.6 million ha. The overexploitation of land due to specialisation and crop intensification made soil vulnerable to erosion. Salinisation of the soil and water erosion are consequences of deforestation and changes in the use of fertile land resulting in soil loss, carriage of sediments, and discharge in the sea. The Blue Plan model indicated ,that some Mediterranean regions would lose nearly $1 \%$ of their 'agricultural land capital' each year" (Grenon/Batisse, 1989).

Mainguet (1994: 290-1) distinguished between natural causes of recurrent droughts and human causes of land degradation. Uncontrolled population growth ,triggered overcultivation, overgrazing, over-exploitation of marginal lands and shortening of fallow“. Environmental concerns in the Mediterranean have been considered so far primarily in the framework of the Mediterranean Action Plan.

\subsubsection{Environmental Stress and Conflict Potentials in the MENA}

The major human-induced challenge both for the governability of the states and for the survivability of the MENA countries will remain the projected population growth for this region (UN 2001). Table 4.8 focuses on Mediterranean countries for 1850 to 2000 with a projection up to 2050. Since 1950 until 2000, the population of North Africa tripled. While from 1950 to 2050 the population for the southern EU countries is to increase by 21.152 million, the comparable figure for the MENA states has been projected by the UN (2001) to increase by 340.036 million (table 4.8). From 2000 to 2050 the population of the five southern European EU countries may decline by -23.239 million, that of the MENA plus Turkey may increase by 181.039 million people.

The urbanisation trends between Southern Europe and North Africa have differed between 1950 and 2030. While in Southern Europe the relative urban population will still grow and the rural population will decline, in North Africa the rural population will stabilise while nearly all projected population growth will be in the cities.

The different patterns in population growth and in urbanisation pose different demands for water and food. While the North may adapt to declining precipitation more easily with a declining population, for the countries on the southern and eastern shore the declining precipitation will require major efforts that will also affect the water available for irrigation and food production. Self-sufficiency in cereals will drop in MENA coun- 
tries and the need for food imports will rise. In reaction to a region-wide economic crisis in the mid-1980s, Algeria, Morocco and Tunisia launched agricultural reforms to reduce their food imports and food subsidies that contributed to increases in foreign debt.

While the Maghreb region supported its population for millennia, its environment was transformed by human activities, especially by deforestation, land clearance and overgrazing. The rapid population growth in the $20^{\text {th }}$ century put the environment under serious stress. In Morocco between 1987 and 1991, the cropland increased from 4.4 to 5.4 million ha primarily by extending to marginal rangeland (200 $\mathrm{mm}$ rain). This contributed to overgrazing in poorer land and increased the potential for soil erosion. The same development can also be observed in Algeria. Swearingen (1996: 89) concluded that the "agricultural policies implemented during the 1980s have substantially increased the risk of drought in North Africa". The major reason is the strife for self-sufficiency in food. It is difficult to imagine any agricultural technology capable of sustaining such a large population, given the region's limited and deteriorating resource base.

The solution to the Maghreb's shortfall in food production ultimately lies in population control (World Bank 1988). In the $21^{\text {st }}$ century, many Southern and Eastern Mediterranean countries will be affected by two negatively reinforcing trends: the continued high population growth in an area that could not produce enough food. The projected global climate change will make the regional challenges of population growth, urbanisation, pollution, desertification, water and food scarcity more severe. All MENA countries must spend more for importing cereals and for making potable water available to its people, to tourists and for irrigation. Due to oil exports all countries but Morocco gained assets to pay for these imports. However, this source of foreign income is limited.

The Mediterranean is confronted with a major contradiction: The longer-term common environmental challenges are confronted with highly fragmented security, political and economic spaces. In the $21^{\text {st }}$ century two pan-Mediterranean political 'spaces' exist:

- The truly Mediterranean environmental regime of the Barcelona Convention (1976), of the Mediterranean Action Plan and of the Blue Plan that includes all riparians.

- The emerging political regime of the Barcelona Declaration (1995) that includes all 15 EU member countries but excludes the Balkan countries.

While the Barcelona Declaration reflects the different attitudes of North and South, the Barcelona Convention reflects the common Mediterranean space which will be affected most by these environmental factors. The Mediterranean climate implies complex interactions between global climate change and regional implications that will negatively reinforce ongoing processes of desertification. There are common non-military environmental challenges affecting the whole Mediterranean that will have socio-economic and political consequences that may affect the whole Euro-Mediterranean region.

A common long-term scientific agenda is needed to develop an early warning system for common challenges and concerns. Both climate change and desertification may constrain the supply side for water and food. For the analysis of population policy and urbanisation national policies set the framework. While for the analysis of 'environmental security' issues only an environmental spatialisation of the Mediterranean applies, for a policy of avoiding conflicts emerging from medium-term implications of long-term structural causes, early and joint action by the countries participating in the wider EuroMediterranean space of the Barcelona framework is needed. 
The most likely societal, national and international impact of climate change in close interaction with the other five trends of the survival hexagon will be migration: of the young generation from rural areas to the national urban centres (urbanisation), distress, political and economic migration from the Sahel zone and sub-Saharan Africa to North Africa or from South, Central and West Asia to Turkey, and labour migration from MENA countries and the Balkans to the EU that may be pushed by socio-economic and environmental conditions and pulled by the attractiveness of the North and by existing networks. Due to population decline in European countries, labour migrants may be needed to satisfy the future manpower demand in all sectors of the economy.

So far no specific climate impact analyses by the IPCC exist for the Mediterranean. Based on available scientific evidence, the MENA countries will be confronted until 2050 with three structural challenges: population growth, desertification and climate change. The specific short-term interaction of these structural factors with short-term political events and medium-term socio-economic changes cannot be predicted. But based on past evidence it may be concluded that the interaction of these factors could intensify the domestic socio-economic and political crises in these countries.

\subsection{Conclusions: Most Likely Outcomes of Climate Change}

For the Small Island States (4.2), the Mediterranean region (4.6.) and for Mexico (4.3.), Bangladesh (4.4.) and Egypt among the four alternative outcomes (figure 3.1): a) hazards and disasters, b) migration, c) severe environmentally-induced domestic crises and d) violent conflicts, a significant increase in severe hazards and natural disasters due to an increasing number of extreme weather events could be observed (Brauch 2003).

Among the countries reviewed above for the years 1980 to 2000, Bangladesh has become the primary target of natural disasters with 175,656 dead victims and with 319 million people that were affected during the last two decades, many persons were affected several times to the impacts of floods and cyclones. Due to the projected impact of climate change, the number of dead and affected victims may further increase if no adaptation and mitigation measures are launched now.

There is less evidence on the causal linkage between environmental stress and domestic crises that escalate to violent outcomes. This is partly due to the definitions of those research teams that analyse violent conflicts. All major research groups that are systematically analysing conflicts did not include hunger revolts in their data bases in reaction to drought (e.g. in North Africa during the 1980s and 1990s) which were repressed by police and the military (with hundreds of casualties). Individual cases, e.g. the clashes between Bangladeshi and the tribal people in Assam, have been analysed as case studies. But at this stage it is empirically impossible to draw generalised conclusions from these case studies of the second and third phase of environmental security studies.

With regard to the peaceful resolution, prevention and avoidance of domestic crises and domestic and international conflicts induced by environmental stress even less empirical evidence exists. The Transboundary Freshwater Dispute Database ${ }^{34}$ on the resolution of water disputes among riparian countries developed systematic evidence of one aspect that is related to climate change impacts (water scarcity). It includes i.a., primary and secondary sources for 14 cases of international water conflict resolution, bibliographic sources on acute water conflicts, and on freshwater dispute resolution.

\footnotetext{
${ }^{34}$ For details at: $<$ http://www.transboundarywaters.orst.edu/>; Contact address: Department of Geosciences Oregon State University, 104 Wilkinson Hall, Corvallis, OR 97331-5506, USA, Fax: 1-541-737-1200.
} 


\section{From Conflict Prevention to Conflict Avoidance: Conceptual Suggestions}

In this assessment, no militarily relevant security threat presently exists resulting from environmental stress but there are severe short- and long-term non-military challenges confronting many countries that have been victims of natural disasters that may put at risk both the governability of several states and the survivability of regions.

\subsection{Need for Problem Recognition and Anticipatory Learning}

While the major task of the scientific dialogue must be knowledge, learning, and truth, the goal of the political dialogue should be co-operation to contain the implications of long-term non-military challenges. Thus, the first step is to recognise and respect the different perceptions of the future challenges for our own societies and that of dialogue partners. This intellectual effort should contribute to a process of political learning and co-operation that revises the prophecies by jointly defined counter actions.

In foreign and international politics learning of key decision makers has often been in response to severe political, economic and military crises. Thus, learning was an instrument of domestic crisis management responding to complex challenges in an innovative way beyond traditional patterns. Anticipatory learning and forward looking foreign policy strategies are more ambitious. They require that foreign policy analysts and decision makers foresee challenges that may have an impact on future governments and generations and that may require unpopular decisions today to avoid highly costly crises events in the future. Anticipatory learning on the six structural causes of the survival hexagon requires the formulation and implementation of sustainable policies for industry, water management, soil preservation, agriculture and tourism. Anticipatory learning as a tool of crisis prevention, however, is far more ambitious and difficult than the requirements of crisis management as a centrepiece of national emergency planning.

With regard to developing countries, e.g. in the MENA region, anticipatory learning requires that both analysts and policy makers foresee the negative impacts and the socio-economic consequences of the six structural determinants of the survival hexagon that can pose a survival dilemma in the future. Anticipatory learning remains the domain of long-range and interdisciplinary discourses of academics and to a more limited extent of foreign policy planning staffs on the level of national governments and of units in international organisations. As these long-term structural challenges do not require urgent responses, sufficient time exists for the formation of conceptually focused and policy oriented epistemic communities.

Joint North-South anticipatory learning requires as a first step a debate on longer-term challenges and a mutual understanding of their relevance, and as a second step a multidisciplinary search for complex strategies to cope both with the root causes and the socio-economic implications of the six factors of the survival hexagon. The task of anticipatory learning must be on three different levels: a) across the boundaries of scientific disciplines; b) across the North-South cultural and political divide and c) between conceptually oriented academics and action oriented decision-makers. 


\subsection{Partnership Building to Counter Climate Change Impacts}

Partnership requires mutual trust and confidence. It implies equal rights and benefits, and it requires a symmetric and mutually benefiting relationship of individuals, groups or nations. Partnership building measures (PBMs, Brauch 1994, 2000) are political measures primarily in the economic and ecological realm that may have a positive impact on the societal and cultural level. They are to perform different functions as economic and environmental tools for the Mediterranean region as a whole and its subregions. After World War II, the Marshall Plan was a unique instrument of US policy but also a partnership building project (PBP) that helped to stabilise the fragile democracies in Western Europe economically and politically. In Europe the Marshall Plan (1947) and the Schuman Plan (1950) contributed to a stable partnership and lasting peace order. Such Economic PBPs must reflect the political, economic, and environmental interests of both sides and be mutually benefiting. Functional PBMs should aim at:

- creating awareness on these challenges among decision makers and in the public;

- analysing in detail the complex interrelationship among the factors of the hexagon;

- initiating regional climate impact studies and specific mitigation strategies;

- supporting scientific exchanges among soil, desertitification and climate experts.

These global and regional challenges should also lead to more active policies of cooperation on sustainable development in agriculture, industry, tourism and transport. What can PBMs contribute conceptually as a new political tool to a complex anticipatory learning process? In the medium-term, PBMs and PBPs could become important instruments of preventive diplomacy and of a post-conflict peace-building (United Nations, 1992: 5-6) in other areas of the globe with violent conflicts.

\subsection{Conflict Avoidance with Adaptation and Mitigation}

One example for a partnership building project to mitigate several impacts of climate change for MENA countries could be the development of a Survival Pact that links "virtual water" (food exports) with "virtual sun" (renewable energy exports) based on a longer-term interdependence. Anthony Allan (2001, 2003) has introduced the concept of "virtual water" by pointing to the fact that it takes about 1,000 tons of water to produce a ton of wheat. In analogy, this author used the concept of "virtual sun" that exploits the solar resources where they are the strongest, e.g. in the Sahara and in the desert in Mexico.

A "survival pact" implies a new international division of labour that links two commodities that are indispensable for human survival: food and energy. In cereal production parts of Europe may benefit from higher temperature and more precipitation in the summer what may produce higher yields for those commodities that have been projected to decline in the South, e.g. in Egypt. Increases in temperature and solar intensity may contribute to a higher output of solar energy in solar thermal farms in the deserts of the Sahara, in the Middle East and in Mexico. Solar generated electricity could be transported by long-distance cable to Europe or to the US or as hydrogen as the new fuel for the transportation systems of the $21^{\text {st }}$ century (Knies/Czisch/Brauch 1999). But there are two major conceptual impediments both in the North and in the South: the notion of self-sufficiency in food and energy due to a deep distrust (Brauch 2002a).

The notion of a "survival pact" tries to combine "virtual water" and "virtual sun". It requires to overcome the deeply ingrained notions of self-sufficiency that has already 
been overcome in many areas of a globalising world. Linking mutual dependence on commodities that are of crucial importance for life (cereals) and work, transport and leisure (energy) a high degree of trust and predictability is needed based on mutual respect and partnership. Such a trans-Mediterranean of a US-Mexican "survival pact" could start now with the training of experts form the respective countries in the area of renewable energy (solar and wind power) who may be in the important positions by 2020 when some of these projections will become more severe and the market for these energies will exist. The components could be produced locally in plants by workers from the MENA countries, in Mexico or in India with local resources. Such a huge project may create many jobs in the region, from manual workers to engineers.

Such a survival pact between European and MENA countries - but also across the Rio Grande between the USA and Mexico - will increase their export income from electricity and hydrogen. The flexible Kyoto mechanisms could be used, e.g. the clean development mechanism, to contribute to financing the build-up of renewable energy industries in the Sahara or in the deserts of Mexico.

\subsection{Conflict Avoidance and the Survival Hexagon}

A declining birth rate will reduce the demand for water, food and housing but also the emissions of global warming gases. In Mexico, Bangladesh, Egypt and in most MENA countries the birth rate is already declining but the life expectancy is still rising. The UN Population Fund with its reproductive health programme is very well accepted as an international actor promoting family planning.

Better water management and the fight against desertification have also become major programmes of UNEP, of the desertification secretariat and of development programmes of many EU countries. Sustainable agriculture and food security are a major concern of FAO, of the World Bank and of many national development agencies. Urbanisation and urban pollution are an object covered by UNEP and at HABITAT conferences. Both climate change and pollution related health problems will gain in urgency in Mexico, Bangladesh and Egypt and in many MENA countries. The WHO has addressed many of these health challenges and tries in cooperation with national health ministries and officials to contain these challenges to human well-being and survival. Many of these concerns are reflected in the Secretary General's Report (Annan 2000) and in the Declaration by the Millennium Summit (2000) that stated on environmental protection:

21. We must spare no effort to free all of humanity, and above all our children and grandchildren, from the threat of living on a planet irredeemably spoilt by human activities, and whose resources would no longer be sufficient for their needs.

22. We reaffirm our support for the principles of sustainable development, including those set out in Agenda 21. ...

23. We resolve, therefore, to adopt in all our environmental actions a new ethic of conservation and stewardship, and, as first steps we resolve:

- To make every effort to ensure the entry into force of the Kyoto Protocol, preferably by the tenth anniversary of the United Nations Conference on Environment and Development in 2002, and to embark on the required reduction in emissions of greenhouse gases.

- To intensify our collective efforts for the management, conservation and sustainable development of all types of forests.

- To press for the full implementation of the Convention on Biological Diversity and the Convention to Combat Desertification in Countries Experiencing Serious Drought and/or Desertification, Particularly in Africa. 
- To stop the unsustainable exploitation of water resources, by developing water management strategies at the regional, national and local levels, which promote both equitable access and adequate supplies.

- To intensify cooperation to reduce the number and effects of natural and man-made disasters.

The Secretary General's Millennium Report is a clear statement that relies on a wide security concept, including environmental challenges, and that stresses multilateral cooperation in the common search for effective countermeasures.

These declared goals require an effective and longer-term strategy of implementation in a multilateral cooperative framework based on partnership. This study analysed based on the best available scientific knowledge the projected impacts of climate change for Mexico, Bangladesh, Egypt, for the Mediterranean region and for the Small Island States. The societal impacts of climate change may trigger conflicts that may be solved peacefully but they may also escalate into violent clashes, But they are unlikely to produce militarily relevant "threats" that can be deterred or countered by military means. None of the countries analysed above has the power to threaten the North militarily but the consequences for not acting proactively now may nevertheless pose human catastrophes for the victims of climate change and environmental stress (Williams 1998).

The consequences of distress migrants from Central America will impact first on Mexico, and these environmental migrants will certainly have implications for the USA and Canada. Human catastrophes as a consequence of extreme weather events in Bangladesh will affect India first, droughts in the Sahel countries will impact on the North African countries first and at a later stage also on Europe.

The film "The March" (Nicholson 1990) may have projected a nightmare that could become true if policy makers fail to recognise the causes of environmental stress and climate change and if they do not develop strategies for timely and effective implementation of their obligations under the UNFCCC and the Kyoto Protocol. Thus, active and efficient implementation of climate policies could become the best security strategy to prevent environmental conflicts from occurring and to contribute to a "sustainable peace" that combines non-violent conflict resolution, equitable economic relationships and sustainable policies in the North and in the South. ${ }^{35}$

Thus, long-term oriented and proactive policies of sustainable development - in our case active policies of climate protection, emission reduction, active reproductive health programmes and family planning but also functional cooperation to enhance the fight against soil erosion and desertification, to increase water management and pollution control techniques, to offer employment in rural areas and in rural towns and sustainable agricultural policies - may become the most effective policy of conflict prevention that will enhance both human and societal security in the affected regions but it may also reduce the costs for coping with the consequences of the missed opportunities that exist for multilateral cooperative policies in the early $21^{\text {st }}$ century.

\footnotetext{
${ }^{35}$ See the project website: see also our project websites: <http://www.sustainable-peace.org $>$.
} 


\section{References}

Abella, Manolo.I., 1995: "Asian Migrant Workers in the Middle East”, in: Cohen, Robin (Ed.): The Cambridge Survey of World Migration (Cambridge: Cambridge University Press): 418-423.

Abramovitz, Janet N., 2001: Unnatural Disasters. Worldwatch Paper 158 (Washington: Worldwatch Institute)

Ahmad, Q.R.; Warrick, R.A.; Ericksen, N.J.; Mirza, M.Q., 1996: "The Implications of Climate Change for Bangladesh: A Synthesis", in: Warrick, R.A.; Ahmad, Q.K. (Eds.): The Implications of Climate and SeaLevel Change for Bangladesh (Dordrecht - Boston - London: Kluwer Academic Publishers): 1-34.

Ahmed, Ahsan Uddin; Rahman, Atiq, 2001: „Reviews of Activities Towards the National Communication of Bangladesh to the UNFCC", at: < http://www.whrc.org/pubaffair/ asiaset.htm>.

Alexandratos, Nikos (Ed.), 1995: World Agriculture Towards 2010. An FAO Study (Chichester - New York: Brisbane - Toronto - Singapore: John Wiley).

Alexandratos, Nikos, 2003: "Mediterranean Countries and World Markets: Basic Foods and Mediterranean Products", in: Brauch, Hans Günter; Selim, Mohammed; Liotta, Peter H.; Chourou, Bechir; Rogers, Paul (Eds.): Security and Environment in the Mediterranean. Conceptualising Security and Environmental Conflicts (Berlin-Heidelberg: Springer).

Allan, Tony, 2001: The Middle East Water Question. Hydropolitics and the Global Economy (London - New York: I.B. Tauris).

Allan, Tony, 2003: "Water Security in the Mediterranean and Middle East”, in: Brauch, Hans Günter; Selim, Mohammed; Liotta, Peter H.; Chourou, Bechir; Rogers, Paul (Eds.): Security and Environment in the Mediterranean. Conceptualising Security and Environmental Conflicts (Berlin-Heidelberg: Springer).

Annan, Kofi A., 2000: Millenium Report: We the Peoples. The Role of the United Nations in the $21^{\text {st }}$ Century (New York: United Nations), also at: <http://www.un.org/millennium/sg/report/>.

Aptekar, Lewis, 1994: Environmental Disasters in Global Perspective (New York: G.K. Hall).

Asher, William; Mirovitskaya, Natalia (Eds.), 2000: The Caspian Sea: A Quest for Environmental Security. NATO ASI Series (Dordrecht: Kluwer Academic Publishers).

Babaev, Agajan G (Ed.), 1999: Desert Problems and Desertification in Central Asia. The Researches of the Desert Institute (Berlin - Heidelberg: Springer).

Bächler, Günther, 1990: Ökologische Sicherheit und Konflikt. Arbeitspapiere der Schweizerischen Friedensstiftung, Nr, 5 (Bern: Schweizerischen Friedensstiftung).

Bächler, Günther, 1994: Umweltflüchtlinge. Das Konfliktpotential von morgen (Münster: agenda).

Bächler, Günther, 1994a: Desertification and Conflict. The Marginalization of Poverty and of Environmental Conflict. ENCOP Occasional Paper No. 10 (Zürich: ETH Zürich - Berne: Swiss Peace Foundation).

Bächler, Günther, 1995: „Desertification and conflict. The marginalization of poverty and of environmental conflicts“, in: Puigdefábregas, Juan; Mendizabal, Teresa (Eds.): Desertification and Migrations - Desertificacion y Migraciones. International Symposium on Desertification and Migrations (Madrid: Ministerio de Asuntos Exteriores - Logroño: Geoforma Ediciones): 185-224.

Bächler, Günther, 1999: "Environmental Degradation in the South as a Cause of Armed Conflict", in: Carius, Alexander; Lietzmann, Kurt M. (Eds.), 1999: Environmental Change and Security: A European Perspective. (Berlin: Springer-Verlag).

Bächler, Günther, 1999a: Violence Through Environmental Discrimination. Causes, Rwanda Arena, and Conflict Model (Dordrecht/Boston/London: Kluwer).

Bächler, Günther, 1999b: „Umwelt und Konflikte“, in: Stiftung Entwicklung und Frieden(Eds.): Globale Trends 2000. Fakten, Analysen, Prognosen (Frankfurt am Main: Fischer): 319-344.

Bächler, Günther, 1999c: Initiativgutachten im Auftrag des Bundesministeriums für Bildung und Forschung zur Friedens. Und Konfliktforschung (Bern: Schweizerischen Friedensstiftung).

Bächler, Günther; Spillmann, Kurt R. (Eds.), 1996a: Environmental Degradation as a Cause of War. Regional and Country Studies of Research Fellows (Chur-Zürich: Rüegger).

Bächler, Günther; Spillmann, Kurt R. (Eds.), 1996b: Environmental Degradation as a Cause of War. Country Studies of External Experts (Chur-Zürich: Rüegger).

Bächles, Günther; Böge, Volker; Klötzli, S.; Libiszewski, S.; Spillmann, K. (Eds.), 1996: Kriegsursache Umweltzerstörung. Ökologische Konflikte in der Dritten Welt und Wege ihrer friedlichen Bearbeitung (ChurZürich: Rüegger).

Bangladesh Government, 1993: Assessment of Vulnerability of Coastal Areas to Climate Change and Sea Level Rise: A Pilot Study of Bangladesh (Dhaka: Bangladesh Government).

Barandat, Jörg; Kaplan, Aytül, 1998: „International Water Law: Regulations for Cooperation and the Discussion of the International Water Convention“, in: Scheumann, Waltina; Schiffler, Manuel (Eds.): Water in the Middle East. Potentials for Conflict and Prospects for Cooperation (Berlin - Heidelberg: Springer): 11-30.

Bass, Brad, 2002: "Downscaling”, in: MacCracken, Michael C.; Perry, John S., (Eds.): Encyclopedia of Global Environmental Change, vol. 1: The Earth System. Physical and chemical dimensions of global environmental change (Chichester: John Wiley): 346-347. 
Bazzaz, Fakhri, 1994: "Global Climate Change and Its Consequences for Water Availability in the Arab World", in: Rogers, Peter; Lydon, Peter (Eds.): Water in the Arab World (Cambridge: Harvard University Press): 243-52.

Bazzaz, Fakhri; Sombroek, Wim, 1996: Global Climate Change and Agricultural Production (Chichester New York: Wiley).

Beach, Heather L.; Hamner. Jesse; Hewitt, J. Joseph; Kaufman, Edy; Kurki, Anja; Oppenheimer, Joe A.; Wolf, Aaron T., 2000: Transboundary Freshwater Dispute Resolution. Theory, Practice, and Annotated References (Tokyo - New York - Paris: United Nations University Press).

Beaumont, Peter, 1997: "Water and Armed Conflict in the Middle East - Fantasy or Reality", in: Gleditsch, Nils-Petter (Ed.), 1997: Conflict and the Environment (Dordrecht - Boston - London): 355-374.

Beck, Ulrich, 1999: World Risk Society (Cambridge: Polity).

Black, Richard, 1993: "Geography and refugees: current issues”, in: Black, Richard; Robinson, V. (Eds.): Geography and Refugees: Patterns and Processes of Change (London: Halsted Press - New York: Belhaven Press): $3-14$.

Black, Richard, 1998: Refugees, Environment and Development (Harlow: Longman).

Black, Richard, 2001: Environmental refugees: myth or reality? New Issues in Refugee Research, Working Paper No. 34 (Falmer: University of Sussex, CDE).

Blaikie, P, Cannon, T, Davis, I and Wisner, B , 1994: At Risk: Natural Hazards, People's Vulnerability and Disasters (London: Routledge).

Brauch, Hans Günter, 1994: „Partnership Building Measures for Conflict Prevention in the Western Mediterranean“, in: Marquina, Antonio; Brauch, Hans Günter (Eds.): Confidence Building and Partnership in the Western Mediterranean: Tasks for Preventive Diplomacy and Conflict Avoidance (Madrid: UNISCI - Mosbach: AFES-PRESS): 257-324.

Brauch, Hans Günter, 1997b: "La emigración como desafio para las relaciones internacionales y como área de cooperación Norte-Sur en el proceso de Barcelonal", in: Marquina, Antonio (Ed.): Flujos Migratorios Norteafricanos Hacia La Union Europea. Asociacion y Diplomacia Preventiva (Madrid: Agencia Española de Cooperación Internacional): 17-90.

Brauch, Hans Günter, 1997c: "Causas a largo plazo de las migraciones desde el Norte de Africa a los países de la Unión Europea. El Factor Demográfico", in: Marquina, Antonio (Ed.): Flujos Migratorios Norteafricanos Hacia La Union Europea. Asociacion y Diplomacia Preventiva (Madrid: Agencia Española de Cooperación Internacional): 241-333.

Brauch, Hans Günter, 2000/2001: „Environmental Degradation as Root Causes of Migration: Desertification and Climate Change. Long-Term Causes of Migration from North Africa to Europe“, in: Peter Friedrich, Sakari Jutila (Eds.): Policies of Regional Competition. Schriften zur öffentlichen Verwaltung und öffentlichen Wirtschaft, Vol. 161 (Baden-Baden: Nomos, 2000/2001): 102-138.

Brauch, Hans Günter, 2000: "Euro-Mediterrane Partnerschaft im 21. Jahrhundert. Langfristige Herausforderungen an die Mittelmeerpolitik der EU”, in: Reiter, Erich (Ed.): Jahrbuch für internationale Sicherheitspolitik 2000 (Hamburg - Berlin - Bonn: Mittler): 417-455.

Brauch, Hans Günter, 2000a: "Partnership Building Measures to Deal with Long-term Non-military Challenges Affecting North-South Security Relations ”, in: Brauch, Hans Günter; Marquina, Antonio; Biad, Abdelwahab (Eds.), 2000: Euro-Mediterranean Partnership for the $21^{\text {st }}$ Century (London: Macmillan - New York: St. Martin's Press): 281-318.

Brauch, Hans Günter, 2001: “The Mediterranean 'Space’ Beyond Geopolitique and Globalization. Common Space - Divided Region”. in: Marquina, Antonio; Brauch, Hans Günter (Eds.): The Mediterranean Space ant its Borders. Geography, Politics, Economics and Environment. Collection Strademed 14 (Madrid: UNISCI Mosbach: AFES-PRESS, 2001): 109-144.

Brauch, Hans Günter, 2002: „Umwelt und Sicherheit im Mittelmeerraum - Vierte Phase der Forschung zu Umweltsicherheit“ in: Erich Reiter (Hrsg.): Jahrbuch für internationale Sicherheitspolitik 2002 (Hamburg Berlin - Bonn: E.S. Mittler): 337-374.

Brauch, Hans Günter, 2002a: “A Survival Pact for the Mediterranean: Linking 'virtual water' and 'virtual sun"”, in: TERI (Eds..): Global Partnerships for Sustainable Development: Harnessing Action for the $21^{\text {st }}$ Century (New Delhi: TERI, 2002): forthcoming.

Brauch, Hans Günter, 2003: "Security and Environment Linkages in the Mediterranean: Fourth Phase of Research on Human and Environmental Security and Peace”, in: Brauch, Hans Günter; Selim, Mohammed; Liotta, Peter H.; Chourou, Bechir; Rogers, Paul (Eds.): Security and Environment in the Mediterranean. Conceptualising Security and Environmental Conflicts (Berlin-Heidelberg: Springer 2003).

Brauch, Hans Günter, 2003a: "Natural Disasters in the Mediterranean (1900-2001): From Disaster Response to Disaster Preparedness", in: Brauch, Hans Günter; Selim, Mohammed; Liotta, Peter H.; Chourou, Bechir; Rogers, Paul (Eds.): Security and Environment in the Mediterranean. Conceptualising Security and Environmental Conflicts (Berlin-Heidelberg: Springer). 
Brauch, Hans Günter; Selim, Mohammed; Liotta, Peter H.; Chourou, Bechir; Rogers, Paul (Eds.), 2003: Security and Environment in the Mediterranean. Conceptualising Security and Environmental Conflicts (BerlinHeidelberg: Springer).

Broadhus, J.M. 1993: "Possible Impacts, and adjustments to sea level rise: the cases of Bangladesh and Egypt", in: Warrick, R.A.; Barrow, E.M.; Wigley, T.M.L. (Eds.): Climate and Sea Level Change: Observations, Projections and Implications (Cambridge: Cambridge University Press): 263-275.

Brown, L.R.; Gardner, G.; Halweil, B., 1999: Beyond Malthus. Nineteen Dimensions of the Population Challenge. Worldwath Environmental Alert Aeries (New York - London: Norton).

Brundtland Commission, 1987: Our Common Future. The World Commission on Environment and Development (Oxford - New York: Oxford University Press).

Buckland, Roger; Eele, Graham; Mugwara, Reggie, 2000: "Humanitarian Crises and Natural Disasters: A SADC Perspective“, in: Clay, Edward; Stokke, Olav (Eds.): Food and Human Security (London - Portland, OR: Frank Cass): 181-195.

Carius, Alexander; Imbusch, Karin, 1999: "Environment and Security in International Politics - an Introduction", in: Carius, Alexander; Lietzmann, Kurt M. (Eds.), 1999: Environmental Change and Security. A European Perspective (Berlin-Heidelberg: Springer): 7-30.

De Soysa, Indra; Gleditsch, Nils-Petter, 1999: To Cultivate Peace: Agriculture in a World of Conflict, PRIO Report 1/99 (Oslo: International Peace Research Institute - Washington, DC: Future Harvest/ CGIAR).

Diehl, Paul F.; Gleditsch, Nils Petter (Eds.), 2001: Environmental Conflict (Boulder - Oxford: Westview).

Diehl, Paul F.; Gleditsch, Nils Petter, 2001: in: Diehl, Paul F.; Gleditsch, Nils Petter (Eds.), 2001: Environmental Conflict (Boulder - Oxford: Westview): 1-9.

DFID, 2000: Linkages between Environmental Stress and Conflict (London: ERM/DFID).

Dombrowsky, Ines, 1998: "The Jordan River Basin: Prospects for Cooperation Within the Middle east Peace Process?", in: Scheumann, Waltina; Schiffler, Manuel (Eds.): Water in the Middle East. Potentials for Conflict and Prospects for Cooperation (Berlin - Heidelberg: Springer): 91-112.

Dombrowsky, Ines, 2003: "Water Accords in the Middle East Peace Process: Moving towards Cooperation?", in: Brauch, Hans Günter; Selim, Mohammed; Liotta, Peter H.; Chourou, Bechir; Rogers, Paul (Eds.): Security and Environment in the Mediterranean. Conceptualising Security and Environmental Conflicts (BerlinHeidelberg: Springer).

ECOMAN, 1999: "Environmental Change, Consensus Building and Resource Management in the Horn of Africa (ECOMAN)", at: <http://www.fsk.ethz.ch/research>.

ECONILE, 2001: "Environment and Cooperation in the Nile Basin (ECONILE)", at: <http://www.fsk.ethz.ch/ research/project.cfm? ID $=11$ \&area $=$ cr $>$.

EEAA, 1995: Framework for the National Action Plan for Climate Change; Egyptian Environmental Affairs Agency (Cairo: EEAA).

Egypt [The Arab Republic of Egypt], 1999:: Initial National Communication on Climate Change Prepared for the United Nations Framework Convention on Climate Change UNFCCC (Cairo: Egyptian Environmental Affairs Agency, June), at: <http://www.unfaccc.de/ resource/country/ egypt.html $>$.

Ehrlich, P.; Holdren, John, 1971: “The impact of population growth", in: Science, 171: 1212-1217.

El-Hinnawi, E., 1985: Environmental Refugees (Nairobi. UNEP).

El-Raey, M., 1991: "Responses to the Impacts of Greenhouse-Induced Sea-Level Rise on Egypt", in: Titus, J.G. (Ed.): Changing Climate and the Coast, vol. 2: West Africa, the Americas, the Mediterranean Basin, and the Rest of Europe (Washington, DC: UNEP \& USEPA).

El-Raey, M., 1993: "Vulnerability of the coastal zones", in: World Coast Conference (Noordwjik, Netherlands, November).

El-Raey, M., 1994: Environmental Refugees Case Study: Egypt (Alexandria: University of Alexandria, Department of Environmental Studies).

El-Raey, M., 2000: "Egypt: Coastal Zone Development and Climate Change Impact of Climate Change on Egypt”, at: < http://www.ess.co.at/GAIA/CASES/EGY/impact.htm>.

El-Raey, M.; Ahmed, S.; Korany, E., 1997: "Remote Sensing and GIS for Vulnerability Assessment of the Impact of Sea Level Rise over Alexandria City and Vicinity" (Alexandria, Egypt: Alexandria University, Department of Environmental Studies, Institute of Graduate Studies and Research).

El-Raey, M.; Frihy, O.; Nasr, S. M.; Dewidar, Kh., 1997: "Vulnerability Assessment of Sea level Rise over Port-Said Governorate, Egypt”, Submitted to: Journal of Environmental Monitoring.

El-Raey, M.; Nasr, S.; Frihy, O.; Desouki, S.; Dewidar, Kh., 1995: "Potential impacts of Accelerated sea level rise on Alexandria governorate" in: Egyptian Journal of Coast. Research, special issue \# 14.

Enquete Commission, ["Protecting the Earth's Atmosphere" of the Bundestag], 1992: Climate Change - A Threat to Global Development. Acting Now to Safeguard the Future (Bonn: Economica - Karlsruhe: C.F. Müller). 
Ericksen, N.J.; Ahmad, Q.K.; Chowdhury, A.R., 1996: "Socio-Economic Implications of Climate Change for Bangladesh”, in: Warrick, R.A.; Ahmad, Q.K. (Eds.), 1996: The Implications of Climate and Sea-Level Change for Bangladesh (Dordrecht - Boston - London: Kluwer Academic Publishers): 205-288.

Esty, Daniel C.; Goldstone, Jack A.; Gurr, Ted Robert; Harff, Barbara; Levy, Marc; Dabelko, Geoffrey D.; Surko, Pamela T.; Unger, Alan N., 1998: State Failure Task Force Report: Phase II Findings (McLean, VA: Science Applications International Corporation, 31 July).

Esty, Daniel C.; Goldstone, Jack A.; Gurr, Ted Robert; Surko, Pamela T.; Unger, Alan N.; Chen, Robert, 1998a: "The State Failure Project: Early Warning Research for US Foreign Policy Planning”, in: Davies, John L.; Gurr, Ted Robert (Eds.), Preventive Measures: Building Risk Assessment and Crisis Early Warning Systems (Boulder, CO - Totowa, NJ: Rowman and Littlefield, 1998).

FAO, 1997: The State of Food and Agriculture (Rome: FAO).

FAO, 1999: The State of Food and Agriculture (Rome: FAO).

Feitelson, Eran; Haddad, Marwan (Eds.), 2001: Management of Shared Groundwater Resources: The IsraeliPalestinian Case with an International Perspective (Boston - Dordrecht - London: Kluwer Academic Publishers).

Gleditsch, Nils Petter (Ed.), 1997: Conflicts and the Environment (Dordrecht - Boston - London: Kluwer Academic Publishers);

Gleditsch, Nils-Petter 1998: "Armed Conflict and the Environment: A Critique of the Literature”, in: Journal of Peace Research, 35: 3 (May): 381-400.

Gleditsch, Nils-Petter, 2001: „Armed Conflict and the Environment”, in: Diehl, Paul F.; Gleditsch, Nils Petter (Eds.): Environmental Conflict (Boulder - Oxford: West-view): 251-272.

Gleditsch, Nils-Petter, 2002: „Resource and Environmental Conflict“, in: Petzold-Bradley, Eileen; Carius, Alexander; Vincze, Arpad (Eds.), 2002: Responding to Environmental Conflicts: Implications for Theory and Practice (Dordrecht - Boston - London: Kluwer Academic Publishers): 53-66.

Gleditsch, Nils-Petter; Sverdrup, Björn Otto, 1995: „Democracy and the Environment“, Paper presented at the 36th Annual Convention of the International Studies Association“, Chicago, Il., 21-16 February.

Gleick, Peter H., 1989: "Climate change and international politics: Problems facing developing countries", in: Ambio, 18,6: 333-339.

Gleick, Peter H., 1989a: "The implications of global climate changes for international security", in: Climate Change, 15: 303-325.

Gleick, Peter H., 1993: "Water and conflict: Fresh water resources and international security", in: International Security, 18,1: 79-112.

Gleick, Peter H., 1993: Water in crisis: A guide to the world's fresh water resources (New York: Oxford University Press).

Gleick, Peter H., 1994: "Water, war and peace in the Middle East", in: Environment, 36,3. 6-15.

Gleick, Peter H., 1998: The World's Water: The Biannual Report on Fresh Water Resources (Washington, DC - Covelo, CA: Island Press).

Grenon, Michel; Batisse, Michel (Eds.), 1989: Futures for the Mediterranean Basin. The Blue Plan (Oxford: Oxford University Press).

Gurr, Ted R., 1995: "Minorities, nationalists, and ethnopolitical conflict”, in: Crocker, Chester A. ; Hampson, Feb Osler; Aall, Pamela (Eds.): Managing Global Chaos: Sources of and Responses to International Conflict (Washington, D.C.: United States Institute of Peace Press): 53-77.

Gurr, Ted, 1993: Minorities at Risk: A Global View of Ethnopolitical Conflicts (Washington, D.C.: US Institute of Peace).

Haavisto, Pekka, 2003: "Environmental consequences of the wars in the Balkans", in: Brauch, Hans Günter; Selim, Mohammed; Liotta, Peter H.; Chourou, Bechir; Rogers, Paul (Eds.): Security and Environment in the Mediterranean. Conceptualising Security and Environmental Conflicts (Berlin-Heidelberg: Springer).

Hafiz, Abdul; Islam, Nahid, 1996: "Environmental Degradation and Intra/intrestate Conflicts in Bangladesh", in: Bächler, Günther; Spillmann, Kurt R. (Eds.): Environmental Degradation as a Cause of War: Regional and Country Studies of Research Fellows (Chur-Zürich: Rüegger): 1-108.

Harzallah, Ali, 2001: "What is Special to the Mediterranean Area", in: Planton, Serge; Hanson, Clair; Viner, David; Hoepffner, Michel (Eds.): Applying Climate Scenarios for Regional Studies With Particular Reference to the Mediterranean (Norwich: Climate Research Unit, April): 75-79.

Hauge, Wenche; Ellingsen, Tanja, 1998: "Beyond environmental scarcity: Causal pathways to conflict", in: Journal of Peace Research, 35,3: 299-317.

Heilig, Gerhard A., 1995: DemoGraphics '94 (Laxenburg: IIASA).

Heilig, Gerhard A., 1998: DemoGraphics '96. A population education software developed for the United Nations Population Fund (Vienna: Heilig).

Heilig, Gerhard A., 1998a: DemoTables '96 (Vienna: Heilig).

Heilig, Gerhard A., 2000: Demo Tools. Tool \# 1:Populations Projections (Vienna: Heilig). 
Hermann, Charles, 1993: "Crisis", in: Krieger, Joel (Ed.): The Oxford Companion to Politics of the World (New York - Oxford: Oxford University Press): 205-206.

Hewitt, Kenneth, 2002: "Hazards in Global Environment Change", in: Timmerman, Peter (Ed.): Encyclopedia of Global Environmental Change, vol. 5: Social and Economic Dimensions of Global Environmental Change (Chichester: John Wiley): 297-303.

Homer-Dixon, Thomas F., 1994: "Environmental scarcities and violent conflict: evidence from cases", in: International Security , 19, 1: 5-40.

Homer-Dixon, Thomas, 1991: "On the Threshold: Environmental Changes as Causes of acute Conflict", in: International Security, 16:2 (Fall): 76-116.

Homer-Dixon, Thomas, 1996: „Strategies for Studying Causation in Complex Ecological-Political Systems“, in: The Journal of Environment and Development, 5,2 (June): 132-48.

Homer-Dixon, Thomas, 1999: Environment, Scarcity and Violence (Princeton: Princeton University Press).

Homer-Dixon, Thomas, 2000: The Ingenuity Gap (New York -Toronto: Alfred A. Knopf).

Homer-Dixon, Thomas; Blitt, Jessica (Eds.), 1999: Ecoviolence. Links Among Environment, Population, and Security (Lanham - Boulder - New York - Oxford: Rowman and Littlefield).

Huq, S.; Karim, Z.; Asaduzzaman, M.; Mahtab, F. (Es.), 1999: Vulnerability and Adaptation to Climate Change for Bangladesh (Dordrecht - Boston - London: Kluwer Academic Publishers),

Huq, Saleemul, 2001: "Climate Change: A Growing Impediment to Development in Bangladesh", Statement prepared for the Bangladeshi-American Foundation (BAFI), Washington DC, 20 August.

Huq, Saleemul; Ali, S.I.; Rahman, A.A., 1995: "Sea-level rise and Bangladesh: a preliminary analysis", in: Journal of Coastal Research, Special Issue, 14: 44-53.

Huq, Saleemul; Asaduzzaman, M., 1999: “Overview”, in: Huq, S.; Karim, Z.; Asaduzzaman, M.; Mahtab, F. (Es.): Vulnerability and Adaptation to Climate Change for Bangladesh (Dordrecht - Boston - London: Kluwer Academic Publishers): 1-13.

IFRC [International Federation of Red Cross and Red Crescent Societies], 2001: World Disasters Report. Focus on recovery. 2001 (Bloomfield, CT: Kumarian Press - London: Eurospan).

IFRC [International Federation of Red Cross and Red Crescent Societies], 2002: World Disasters Report. Focus on reducing risk. 2002 (Bloomfield, CT: Kumarian Press - London: Eurospan).

IMF 2000: World Economic Outlook 2000 (Washington, D.C.: IMF).

IOM, 1996: Environmentally-Induced Population Displacements and Environmental Impacts Resulting from Mass Migration. International Symposium, Geneva, 21-14 April 1996 (Geneva: International Organisation for Migration with United Nations High Commissioner for Refugees and Refugee Policy Group).

IPCC [Intergovernmental Panel on Climate Change], 1990: Climate Change. The IPCC Impacts Assessment (Geneva: WMO; UNEP; IPCC).

IPCC [Intergovernmental Panel on Climate Change], 1995: IPCC Second Assessment Climate Change 1995. A Report of the International Panel on Climate Change (Geneva: WMO, UNEP).

IPCC [Intergovernmental Panel on Climate Change], 1996: Climate Change 1995. The Science of Climate Change. Contributions of Working Group I to the Second Assessment Report of the Intergovernmental Panel on Climate Change (Cambridge: Cambridge University Press).

IPCC [Intergovernmental Panel on Climate Change], 1996a: Climate Change 1995. Impacts, Adaptations and Mitigation of Climate Change. Contributions of Working Group II to the Second Assessment Report of the Intergovernmental Panel on Climate Change (Cambridge: Cambridge University Press).

IPCC [Intergovernmental Panel on Climate Change], 1996b: Climate Change 1995. Economic and Social Dimensions of Climate Change. Contributions of Working Group III to the Second Assessment Report of the Intergovernmental Panel on Climate Change (Cambridge: Cambridge University Press).

IPCC [Intergovernmental Panel on Climate Change], 1998: The Regional Impacts of Climate Change. An Assessment of Vulnerability (Cambridge - New York: Cambridge University Press).

IPPC [Intergovernmental Panel on Climate Change], 2001: Climate Change 2001. The Scientific Basis (Cambridge - New York: Cambridge University Press).

IPPC [Intergovernmental Panel on Climate Change], 2001a: Climate Change 2001. Impacts, Adaptation and Vulnerability. Mitigation (Cambridge - New York: Cambridge University Press).

IPPC [Intergovernmental Panel on Climate Change], 2001b: Climate Change 2001. Mitigation (Cambridge New York: Cambridge University Press).

Islam, Muinul, 1995: "Bangladeshi Migration: an impact study", in: Cohen, Robin (Ed.): The Cambridge Survey of World Migration (Cambridge: Cambridge University Press): 360-366.

Islam, S.M. Rakibul; Huq, A'Saleemul; Ali, Anwar, 1999: "Beach Erosion in the Eastern Coastline of Bangladesh", in: Huq, S.; Karim, Z.; Asaduzzaman, M.; Mahtab, F. (Eds.): Vulnerability and Adaptation to Climate Change for Bangladesh (Dordrecht - Boston - London: Kluwer Academic Publishers).

Jacobsen, J.L., 1988: Environmental Refugees: A Yardstick of Habitability (Washington, D.C.: Worldwatch Institute). 
Karim, Zahurul; Hussain, Sk. Ghulam; Ahmed, Ahsan Uddin, 1999: "Climate Change Vulnerability of Crop Agriculture", in: Huq, S.; Karim, Z.; Asaduzzaman, M.; Mahtab, F. (Es.): Vulnerability and Adaptation to Climate Change for Bangladesh (Dordrecht - Boston - London: Kluwer Academic Publishers).

Kasperson, Jeanne X.; Kasperson, Roger E. (Eds.), 2001: Global Environmental Risk (Tokyo - New York Paris: United Nations University Press, London: Earthscan).

Kasperson, Jeanne X.; Kasperson, Roger E.; Dow, Kirstin, 2001: "Introduction: Global environmental risk and society”, in: Kasperson, Jeanne X.; Kasperson, Roger E. (Eds.), 2001: Global Environmental Risk (Tokyo New York - Paris: United Nations University Press, London: Earthscan): 1-48.

King, Russell, 1997: "Introduction: An Essay on Mediterraneanism”, in: King, Russell; Proudfoot, Lindsay; Smith, Bernard (Eds.), 1997: The Mediterranean. Environment and Society (London - New York: Arnold): 1-11.

Knies, Gerhard; Czisch, Gregor; Brauch, Hans Günter (Eds.), 1999: Regenerativer Strom für Europa durch Fernübertragung elektrischer Energie. Energiestudien 1 (Mosbach: AFES-PRESS).

Kracht, Uwe, 2000: "Humanitarian Crises, Food Security and Conflict Prevention", in: Clay, Edward; Stokke, Olav (Eds.): Food and Human Security (London - Portland, OR: Frank Cass): 133-148.

Leatherman, Stephen P. (Ed.), 1997: Island States at Risk: global Climate Change, Development and Population. Special Issue 24: Journal of Coastal Research (Charlottesville, Va.: Coastal Education and Research Foundation).

Libiszewski, Stephan, 1992: What is an Environmental Conflict? Environment and Conflicts Project (ENCOP), Occasional Paper No. 6 (Zurich: Center for Security Studies and Conflict Research).

Libiszewski, Stephan, 1995: Water Disputes in the Jordan Basin Region and their Role in the Resolution of the Arab-Israeli Conflict. ENCOP Occasional Paper No. 13 (Zürich: ETH Zürich - Berne: Swiss Peace Foundation).

Libiszewski, Stephan, 1997: 'Integrating Political and Technical Approaches: Lessons from the Israeli - Jordanian Water Negotiations", in: Gleditsch, Nils-Petter (Ed.): Conflict and the Environment (Dordrecht - Boston - London): 385-402.

Lipschutz, Ronnie D., 1995: On Security (New York, NY: Columbia University Press).

Lipschutz, Ronnie D., Holdren, John P., 1990: „Crossing Borders: Resource Flows, The Global Environment, and International Security”, in: Bulletin of Peace Proposals, 21,2: 121-133.

Lonergan, Steve, 1997: "Water Resources and Conflict: Examples from the Middle East", in: Gleditsch, NilsPetter (Ed.): Conflict and the Environment (Dordrecht - Boston - London): 375-384.

Lonergan, Steve, 1999: Global Environmental Change and Human Security. GECHS Science Plan. IHDP Report No. 11 (Bonn: IHDP).

Lonergan, Steve; Gustavson, Kent;Carter, Brian, 2000: "The Index of Human Insecurity", in: AVISO No.6 (Victoria, BC, Canada, University of Victoria, Department of Geography, January).

Lonergan, Steve, 2002: "Environmental Security", in: Munn, Ted (Ed.): Encyclopedia of Global Environmental Change, vol. 5: Timmerman, Peter (Ed.): Social and Economic Dimensions of Global Environmental Change (Chichester: John Wiley): 269-278.

Lowi, Miriam R., 1993: Water and Power. The Politics of a Scarce Resource in the Jordan River Basin (Cambridge: Cambridge University Press).

Lund, Michael, 2003 : "Conflict Prevention: A New Task of Security Policy in the 1990s: Lessons learned from successes and failures with relevance to the Mediterranean region", in: Brauch, Hans Günter; Selim, Mohammed; Liotta, Peter H.; Chourou, Bechir; Rogers, Paul (Eds.): Security and Environment in the Mediterranean. Conceptualising Security and Environmental Conflicts (Berlin-Heidelberg: Springer).

Mainguet, Monique, 1994: Desertification. Natural Background and Human Mismanagement, 2nd edition (Berlin - Heidelberg: Springer Verlag).

Marland, G., et al., 1999: Global, Regional, and National CO Emission (Oak Ridge, Tennessee : US Department of Energy, Oak Ridge National Laboratory, Carbon Dioxide Information Analysis Center).

Mathews, Jessica Tuchman, 1989: "Redefining Security", in: Foreign Affairs, 68: 2 (Spring): 162-177.

Mathews, Jessica Tuchman, 1993: "Nations and nature: A new view of security", in: Prins, Gwyn (Ed.): Threats without enemies: Facing environmental security (London: Earthscan): 25-37.

McEvedy, Colin; Jones, Richard, 1978: Atlas of World Population History (London: Allen Lane).

McMichael, A.J.; Haines, A.; Sloof, R.; Kovats, S. (Eds.), 1996: Climate Change and Human Health. An assessment prepared by a Task Group on behalf of the World Health Organization, the World Meteorological Organization and the United Nations Environment Programme (Geneva: WHO - WMO - UNEP).

Meadows, Donella H., et. al., 1972: The Limits of Growth (New York: Universe Books).

MÉXICO [Estados Unidos Mexicanos], 1997: México. Primera Comunicación ante la Convención Marco de las Naciones Unidas sobre el Cambio Climático (Mexico: Secretaría de Medio Ambien-te, Recursos Naturales y Pesca, November). For the Spanish original: $<$ http://www.unfccc.de/ resource/docs/ natc/mexnc1.pdf $>$; for an English translation: <http://www.unfccc.de/resource/ docs/natc/mexncle.pdf.

Midlarsky, Manus I., 1998: "Democracy and the Environment: An empirical Assessment", in: Journal of Peace Research, 35: 3 (May): 341-362.

Myers, Norman, 1989: “Environment and Security”, in: Foreign Policy, No. 74: 23-41. 
Myers, Norman, 1993: „Environmental Refugees in a Globally Warmed World“, in: BioScience, 43,11: 75261.

Myers, Norman, 1994: Ultimate Security. The Environmental Basis of Political Stability (New York: W.W. Norton).

Myers, Norman, 1995: Environmental Exodus. An Emergent Crisis in the Global Arena (Washington, DC: Climate Institute).

Myers, Norman, 1996: Ultimate Security. The Environmental Basis of Political Stability (Washington, D.C. Covelo: Island Press).

Myers, Norman, 2002: "Environmental Refugees", in: Tolba, Mostafa K. (Ed.): Encyclopedia of Global Environmental Change, vol. 4: Responding to Global Environmental Change (Chichester, UK: John Wiley): 214218.

National Academy of Science, 1991: Policy Implications of Global Warming (Washington D.C.: NAS Press).

Nicholson, William, 1990: Der Marsch. Aufbruch der Massen nach Europa. Das Drama des Nord-Süd-Konflikts (Rosenheim: Horizonte).

O’Neill, Brian C.; MacKellar, F. Landis; Lutz, Wolfgang (Eds.), 2001: Population and Climate Change (Cambridge: Cambridge University Press).

O’Riordan, Timothy, 1986: "Coping with Environmental Hazards", in: Kates, R.W.; Burton, I., (Eds.): Geography. Resources and Environment: Theses from the Work of Gilbert F. White II (Chicago: University of Chicago Press): 212-309.

O’Riordan, Timothy, 2002: "Precautionary Principle", in: Tolba, Mostafa K. (Ed.): Encyclopedia of Global Environmental Change, vol. 4: Responding to Global Environmental Chan ge (Chichester, UK: John Wiley): 369.

Oberthür, Sebastian, 1999: "Preventing Environmentally-Induced Conflicts Through Development Policy and International Environmental Policy”, in: Carius, Alexander; Lietzmann, Kurt M. (Eds.), 1999: Environmental Change and Security: A European Perspective. (Berlin: Springer-Verlag): 249-268.

Oberthür, Sebastian, 2002: "Preventing Environmentally-Induced Conflicts Through International Environmental Policy”, in: Petzold-Bradley, Eileen; Carius, Alexander; Vinvze Arpád (Eds.): Responding to Environmental Conflicts - Implications for Theory and Practice. NATO ASI Series (Dordrecht: Kluwer Academic Publishers)::239-251.

OECD, 1995: Trends in International Migration. Annual Report 1994 (Paris: OECD).

OECD, 1997: Conflict, Peace and Development Cooperation on the Threshold of the $21^{\text {st }}$ Century (Paris: OECD).

OECD, 1997a: $\mathrm{CO}_{2}$ Emissions from Fuel Combustion. A New Basis for Comparing Emissions of a Major Greenhouse Gas 1972 - 1995. 1997 Edition (Paris: OECD).

OECD, 1997b: Economic Surveys. Mexico 1997 (Paris: OECD).

OECD, 1998: Trends in International Migration. Annual Report 1998 (Paris: OECD).

OECD, 1998b: Environmental Performance Reviews Mexico (Paris: OECD).

OECD, 2001: Trends in International Migration. Annual Report 2001 (Paris: OECD).

OECD, 2001a: The DAC Guidelines: Helping Prevent Violent Conflict (Paris: OECD).

Pachauri, R.K., 1994: Climate Change in Asia: India (Manila: Asian Development Bank).

Pachauri, R.K., 2000: "Environmental Security: A Developing Country Perspective", Wilson Center, Environmental Change and Security Project, Current Events, 17 October 2000, at: <http://ecsp.si.edu/ archive/rkpauchari.htm>.

Parry, Martin, 1990: Climate Change and World Agriculture (London: Earthscan).

Paterson, Matthew, 1996: Global Warming and Global Politics (London: Routledge).

Pearson, John A., 2003: "Climate Change: The Implications for International Peace and Security", M.A. thesis in International Peace and Security (London: University of London, King's College, September 2002).

Petzold-Bradley, Eileen; Carius, Alexander; Vincze, Arpad (Eds.), 2002: Responding to Environmental Conflicts: Implications for Theory and Practice (Dordrecht - Boston - London: Kluwer Academic Publishers).

Planton, Serge, 2001: „Applying Climate Scenarios for Regional Studies: With Particular Reference to the Mediterranean. Workshop Summary", in: Planton, Serge; Hanson, Clair; Viner, David; Hoepffner, Michel (Eds.): Applying Climate Scenarios for Regional Studies With Particular Reference to the Mediterranean (Norwich: Climate Research Unit, April): 84-85.

Peichert, Heinrike, 2003: "The Nile Basin Initiative: A Catalyst for Cooperation”, in: Brauch, Hans Günter; Selim, Mohammed; Liotta, Peter H.; Chourou, Bechir; Rogers, Paul (Eds.): Security and Environment in the Mediterranean. Conceptualising Security and Environmental Conflicts (Berlin-Heidelberg: Springer 2003).

Portnov, Boris A.; Hare, A. Paul (Eds.), 1999: Desert Regions. Population. Migration and Environment (Berlin: Springer).

Puigdefábregas, Juan; Mendizabal, Teresa (Eds.), 1995: Desertification and Migrations - Desertificacion y Migraciones. International Symposium on Desertification and Migrations (Madrid: Ministerio de Asuntos Exteriores - Logroño: Geoforma Ediciones). 
Rahman, A Atiq, 1999: “Climate Change and Violent Conflicts”, in: Suliman, Mohamed (Ed.), Ecology, Politics and Violent Conflict (London: Zed Books).

Saad, Somaya, 1995: "For Whose Benefit? Redefining Security", in: Conca, Ken; Alberty, Michael; Dabelko, Geoffrey D. (Eds.): Green Planet Blues:Environmental Politics from Stockholm to Rio (Boulder, CO.: Westview Press): 273-275.

Scheumann,Waltina, 2003: "The Euphrates Issue in Turkish-Syrian Relations”, in: Brauch, Hans Günter; Selim, Mohammed; Liotta, Peter H.; Chourou, Bechir; Rogers, Paul (Eds.): Security and Environment in the Mediterranean. Conceptualising Security and Environmental Conflicts (Berlin-Heidelberg: Springer).

Schiffler, Manuel, 1998: "Conflicts over the Nile or Conflicts on the Nile", in: Scheumann, Waltina; Schiffler, Manuel (Eds.): Water in the Middle East. Potentials for Conflict and Prospects for Cooperation (Berlin Heidelberg: Springer): 137-150.

Schwartz, Daniel M., 2002: “The Environment and Violent Conflict”, in: Munn, Ted (Ed.): Encyclopedia of Global Environmental Change, vol. 5, Timmerman, Peter (Ed.):: Social and Economic Dimensions of Global Environmental Change (Chichester: John Wiley): 137-149.

Schwartz, Daniel M.; Delingiannis, Tom; Homer-Dixon, Thomas, 2001: “The Environment and Violent Conflict", in: Diehl, Paul F.; Gleditsch, Nils Petter (Eds.): Environmental Conflict (Boulder - Oxford: Westview): 273-294.

Schwartz, Daniel; Singh, Ashbindu, 1999: Environmental Conditions. Resources, and Conflicts : An Introductory Overview and Data Collection (Nairobi: UNEP).

Selim, Mohammad El Sayed, 2003: "Conceptualising Security by Arab Mashreq Countries”, in: Brauch, Hans Günter; Selim, Mohammed; Liotta, Peter H.; Chourou, Bechir; Rogers, Paul (Eds.): Security and Environment in the Mediterranean. Conceptualising Security and Environmental Conflicts (Berlin-Heidelberg: Springer).

Sestini, G., 1992: "Implications of Climatic Changes for the Nile Delta", in: Jeftic, Lubomir; Milliman, J.D.., Sestini, G. (Eds.): Climatic Change and the Mediterranean. Environmental and Societal Impacts of climate Change and sea-level Rise in the Mediterranean Region (London - New York - Melbourne - Auckland: Edward Arnold): 535-601.

Smith J.B.; Rahman, A.; Haq, S.; Mirza, M. Q., 1998: Considering Adaptation to Climate Change in the Sustainable Development of Bangladesh. World Bank Report (Washington. D.C.: World Bank).

Smith, Keith, 2001: Environmental Hazards. Assessing Risk and Reducing Disaster, $3^{\text {rd }}$ ed. (London - New York: Routledge).

Starr, Joyce, 1991: "Water Wars", in: Foreign Policy, 82 (Spring).

Statistisches Bundesamt, 1995: Länderbericht Mexiko (Stuttgart: Metzler-Poeschel, September).

Stock, Manfred, 1996: "Klimawirkungsforschung: Mögliche Folgen des Klimawandels für Europa!, in: Brauch, Hans Günter (Ed.): Klimapolitik (Berlin-Heidelberg: Springer, 1996): 33-46.

Stripple, Johannes, 2002: "Climate Change as a Security Issue", in. Redclift, M.; Page, E. (Eds.): Human Security and the Environment: International Comparisons (Cheltenham: Edward Elgar, forthcoming)

Strzepek, Kenneth; Onyeji, S. Chibo; Saleh, Magda; Yates, David N., 1995: „An Assessment of Integrated Climate Change Impacts on Egypt“, in: Strzepek, Kenneth; Smith, Joel B. (Eds.): As Climate Changes. International Impacts and Implications (Cambridge - New York: Cambridge University Press): 180-200.

Suhrke, Astri, 1993: Pressure Points: Environmental degradation, Migration and Conflict. Occasional Paper Series of the Project on Environmental Change and Acute Conflict, no. 3 ( Cambridge, MA: American Academy of Arts and Science; Toronto: Peace and Conflict Studies Program, University College, University of Toronto).

Suhrke, Astri, 1996: "Environmental Degradation, Migration, and Conflict: A Lethal Feedback Dynamic", in: Crocker, Chester et al. (eds.): Managing Global Chaos (Washington, DC: United States Institute of Peace): 113-128.

Suhrke, Astri, 1997: "Environmental Degradation, Migration, and the Potential for Violent Conflict", in: Gleditsch, Nils-Petter (Ed.): Conflict and the Environment (Dordrecht - Boston - London): 255-273.

Swart, Rob, 1996: "Security risks of global environmental changes", in: Global Environmental Change, 6,3: 187-192.

Swearingen, Will D., 1996: „Agricultural Reform in North Africa: Economic Necessity and Environmental Dilemmas", in: Vandewalle, Dirk (Ed.): North Africa, Development and Reform in a Changing Global Economy (Basingstoke-London: Macmillan): 60-70.

Szelinski, Bert-Axel, 2001: „Enhancing the Effective Co-operation Among International Organisations: An Overview", speech at OSCE Seminar: Strengthening the OSCE's Role in the Realm of Environment and Security, Berlin 3-4 July.

Turner, B.L.; Kasperson, Jeanne X.; Kasperson, Roger E.; Dow, Kirstin; Meyer, William B., 1995: “Comparisons and Conclusions", in: Kasperson, Jeanne X.; Kasperson, Roger E.; Turner, B.L. (Eds.): Regions at Risk. Comparisons of Threatened Environments (Tokyo - New York - Paris: United Nations University Press): 519-586. 
UN, 1997: World Population Prospects. The 1996 Revision. Highlights (New York: UN Population Division, Department of Economic and Social Affairs, United Nations Secretariat).

UN, 2000: World Urbanization Prospects. The 1999 Revision. Data Tables and Highlights (New York: UN Population Division, Department of Economic and Social Affairs, United Nations Secretariat).

UN, 2001: World Population Prospects. The 2000 Revision. Highlights (New York, Population Division, Department of Economic and Social Affairs, UN Secretariat, 28 February 2001).

UN, 2001a: World Population Monitoring 2000. Population, environment and development. ESA/P/WP. 164 (New York: UN Secretariat, Department of Economic and Social Affairs, Populations Division, 10 January)

UNEP, 1999: Global Environment Outlook 2000 (London: Earthscan)..

United Nations [UN], 1992: An Agenda of Peace: Preventive diplomacy, peacemaking and peace-keeping: Report of the Secretary-General pursuant to the statement adopted by the Summit Meeting of the Security Council on 31 January 1992, Security Council, S/24111, 47th year (New York: UN, 17 June).

Waterbury, John, 2002: The Nile Basin. National Determinants of Collective Action (New York - London: Yale UP).

WBGU [Wissenschaftlicher Beirat der Bundesregierung Globale Umweltzerstörung] 1996: Welt im Wandel. Herausforderungen für die deutsche Wissenschaft. Jahresgutachten 1996 (Berlin: Springer).

Westing, Arthur H., 1976: Ecological Consequences of the Second Indochina War (Stockholm: Almquist \& Wiksell).

Westing, Arthur H., 1980: Warfare in a Fragile World. Military Impact on the Human Environment London Philadelphia: Taylor \& Francis).

Westing, Arthur H., 1984: Environmental Warfare. A Technical, Legal and Policy Appraisal London - Philadelphia: Taylor \& Francis).

Westing, Arthur H., 1985: Explosive Remnants of War. Mitigating the Environmental Effects (London - Philadelphia: Taylor \& Francis).

Westing, Arthur H., 1986: Global Resources and International Conflict: Environmental Factors in Strategic Policy and Action (Oxford: Oxford University Press).

Westing, Arthur H., 1988: "The Military Sector vis-à-vis the Environment”, in: Journal for Peace Research, 25,3: 257-264.

Westing, Arthur H., 1988a: Cultural Norms, War and the Environment. Military Activities and the Human Environment 5 (Oxford: Oxford University Press): 129-134.

Westing, Arthur H., 1989: "The Environmental Component of Comprehensive Security", in: Bulletin of Peace Proposals, 20,2: 129-134.

Westing, Arthur H., 1997: Armed Conflict and Environmental Security. Special issue of Environment and Security 1,2 .

Westing, Arthur H., 2003: "Environmental Dimension of the Gulf War of 1991”, in: Brauch, Hans Günter; Selim, Mohammed; Liotta, Peter H.; Chourou, Bechir; Rogers, Paul (Eds.): Security and Environment in the Mediterranean. Conceptualising Security and Environmental Conflicts (Berlin-Heidelberg: Springer).

Westing, Arthur, 1994: "Population, desertification, and migration", in: Environmental Conservation [Cambridge, UK], 21,2 (summer): 110-114,109.

Westing, Arthur, 1994a: "International Symposium on 'Desertification and Migration”, held in Almeria, Spain, 9-11 February 1994, in: Environmental Conservation [Cambridge, UK], 21,1 (spring): 85-86

Williams, Christopher (Eds.), 1998: Environmental Victims (London: Earthscan).

Williams, Martin A.J.; Balling Jr, Robert C. , 1996: Interactions of Desertification and Climate (London-New York-Sydney-Auckland: Arnold).

Wilson, M. Jeffrey; Maliszewska-Kordybach, Barbara (Eds.), 2000: Soil Quality, Sustainable Agriculture and Environmental Security in Central and Eastern Europe (Dordrecht - Boston - London: Kluwer Academic Publishers).

Wolf, Aaron T., 1995: Hydropolitics long the Jordan River. Scarce water and its impact on the Arab-Israeli conflict (Tokyo - New York - Paris: United Nations University Press).

World Bank, 1988: World Development Report 1988 (New York: Oxford University Press).

World Bank; European Investment Bank, 1990, ${ }^{2}$ 1993: The Environmental Program for the Mediterranean. Preserving a Shared Heritage and Managing a Common Resource (Washington, DC: World Bank; Luxembourg: European Investment Bank).

Zürn, Michael, 1995: „Globale Gefährdungen und internationale Kooperation“, in: Der Bürger im Staat, 45,1: 49-56.

Zürn, Michael, 1997: „Vom Nutzen internationaler Regime für die Friedensordnung“, in: Senghaas, Dieter (Ed.): Frieden machen (Frankfurt/M.: Suhrkamp). 


\title{
Climate Change and Conflict Prevention: The Relevance for the International Process on Climate Change
}

\author{
Background Paper \\ by Dr. Sebastian Oberthür (Ecologic), \\ Dennis Tänzler (Adelphi Research) \\ and Alexander Carius (Adelphi Research)
}

for the Special Event

"Climate Change and Conflict Prevention",

Bonn, 10 June 2002,

16th meeting of the Subsidiaries Bodies UNFCCC

commissioned by the

Federal Ministry for the Environment,

Nature Conservation and Nuclear Safety 


\section{Executive Summary}

Since the 1980s, a growing body of literature has dealt with the relationship of environmental problems and conflict prevention. More specifically, evidence is mounting that the adverse effects of climate change can, particularly by interacting with a number of other factors such as scarcity of natural resources, contribute to an increasing potential for conflict. On the other side, effective climate and environmental policies hold the promise to lessen such potential. Despite the significance of the issue, however, conflict prevention has not yet been established as a topic in the international process on climate change.

The role of climate change in increasing the potential for conflict, and the role of effective climate policy in lessening it, is particularly relevant to two major strains of discussion in international climate policy. First, the rationale for taking preventive action to mitigate climate change appears to be strengthened, as such climate change mitigation also represents a contribution to reducing conflict potential in general. As it generally leads to a decrease in energy demand, it reduces dependence on foreign energy supplies and enhances the security of energy supply. Second, the need to take appropriate adaptation measures in order to respond to any increased conflict potential diligently is highlighted. Furthermore, careful analysis of the impacts of climate change on the potential for conflict may allow identifying and determining regional and substantive priority areas of action so as to reduce the potential for conflict, by implementing adaptation measures as appropriate.

Related to the issue of adaptation is the question of vulnerability of our human system. Vulnerability to climate change refers to the degree to which a system is susceptible to or unable to cope with its adverse effects. The adaptive capacity depends on very different context variables, for example on the access to resources, the skill and knowledge to use them, or the stability and effectiveness of economic, social and cultural institutions. Accordingly, in addition to the analysis of the impacts of climate change on the potential for conflict, the degree of capacity of livelihoods or regions to adapt to respective impacts appears to be relevant for the identification of regional and substantive priority areas of action in the context of conflict prevention.

While the relevance of the issue of climate change and conflict prevention for pertinent international political discussions on the future development of climate policy - such as the further strengthening of international commitments to reduce greenhouse gas emissions and the appropriate priorities in financing adaptation activities - is evident, no authoritative international scientific assessment of the issue exists yet. Snce the interna- 
tional process on climate change is science-based, an obvious possibility for linking the aspect of climate change and conflict prevention to the UNFCCC process would appear to be through scientific channels.

Set up by WMO and UNEP in 1988, the Intergovernmental Panel on Climate Change (IPCC) produces the most authoritative international scientific assessments that are regularly fed into the UNFCCC process and constitute its major scientific basis. The IPCC is an intergovernmental body organised in three working groups dealing with the science of climate change, impacts and adaptation, and mitigation options. It is headed by a Chairman and a Bureau. The IPCC generally produces full Assessment Reports covering the causes, effects and mitigation options regarding climate change, Technical Papers on particular issues based on already existing assessment reports, and Special Reports as assessments on special issues.

The options to introduce the issue of climate change and conflict prevention to the IPCC process are as follows. A Technical Paper on the issue of climate change and conflict prevention hardly appears to be possible, since the issue has not yet been addressed in the main assessment reports of the IPCC. Initiating a Special Report requires careful preparation since the IPCC has limited resources to produce them (i.e. only issues considered to be of first priority are usually selected). The issue could also be dealt with in two envisaged Special Reports on the relationship between Climate Change and Sustainable Development as well as on Climate Change and Water. Another option consists in taking the issue of conflict prevention up in the IPCC's regular Assessment Reports. The work of the IPCC Working Group II on the impacts of climate change appears to be most appropriate for addressing the topic since it has already dealt with social impacts in the past. The contents of the Fourth Assessment Report of the IPCC are currently under discussion and the IPCC plenary is scheduled to decide thereon in early 2003. Furthermore, specialised expert workshops co-sponsored by the IPCC have in the past explored particular items of scientific discussion.

In any event, considerable knowledge about the link between climate change and conflict prevention already exists. Sound climate policies can already contribute to conflict prevention. As a result, interested Parties can use this knowledge to define priorities both in international discussions on mitigation and adaptation within the UNFCCC and its Kyoto Protocol and in their domestic implementation. 


\section{Introduction}

Since the 1980s, the debate on the relationship between environmental degradation and resource scarcity on the one hand and security on the other hand has intensified steadily. Since its early days, this debate has seen diverse concepts of environmental security being put forward by various policy-makers and institutions (for an overview see Gleditsch 1997; Carius and Lietzmann 1999; see also the annual reports of the Environmental Change and Security Project of the Woodrow Wilson International Centre for Scholars). In the wake of this debate and following the end of the Cold War in the late 1980s, environmental stress has become established as an important non-traditional security concern. As a result, environmental stress has been found to trigger or catalyse acute or latent conflicts rather than being a root cause of such conflicts. It can contribute to or result in mass migration and refugee movement. Environmental degradation has so far generally increased conflict potential in domestic contexts, in particular in developing countries. Whether environmental stress actually leads to conflict or even violence depends on socio-economic framework conditions, demographic pressure and conflict history (Carius/Imbusch 1999). Global environmental change as a long-term pressure is also likely to intensify already existing local and regional conflicts over renewable resources (shared water or agricultural land) that are often coupled with poverty, migration and the marginalization of arable land.

However, impacts of global environmental change do not necessarily lead to violence and have not yet posed concrete threats to national security. In this context it is noteworthy that since the mid-1990s the debate on environment and security has broadened by exploring the "human security" dimension of environmental change (Lonergan 1999; Pachauri 2000). This integrative and interdisciplinary concept, developed by the United Nations Development Programme (UNDP 1994) is understood to include economic, health, and environmental concerns and is also a result of the redefinition of the overall concept of national security (Spector/Wolf 2000; Evans et al. 2000). Human security is achieved "when and where individuals and communities have options necessary to end, mitigate or adapt to threats to their human, environmental and social rights" (Lonergan 1999). The main components of the human dimension of security are the assurance of fundamental needs such as food, health, basic income, a healthy physical environment or a personal feeling of safety (Spector/Wolf 2000: 415). This broader approach encompasses the problem area of poverty, inequity and global environmental change and has been addressed earlier by the Brundtland Report in 1987 (World Commission on Environment and Development 1998). 
Since the end of the 1980s, the issue of climate change has increased in importance on the agenda of international environmental politics. The early milestones of the international process on climate change comprise the establishment of the Intergovernmental Panel on Climate Change (IPCC) in 1988, the Second World Climate Conference in 1990, and the adoption of the UN Framework Convention on Climate Change (UNFCCC) in 1992. In recent years, climate change has even become one of the major topics of international affairs due to the negotiations of the Kyoto Protocol which only recently was finalised through the so-called Marrakesh Accords (see Oberthür/Ott 1999; Ott 2001; Bail et al. 2002)

Relevant research results on the nexus of climate change and the conflict dimension already exist (see for example Gleick 1989; van lerland et al. 1996; Barnett 2002) and are confirmed and specified by a recent review on climate change impact research (Brauch 2002). The results suggest that there is no mono-causal linkage between climate change and conflicts. Climate change impacts do not pose a military threat nor can they be solved by traditional military means. However, climate change impacts can - in combination with other factors - contribute to environmental stress and may pose a challenge to human security (Pachauri 2000). For example, the number of environmental refugees is likely to increase as a result of rising sea-levels in the delta areas. For the same reasons the security of people in Tuvalu and Kiribati is threatened since their long-term ability to remain on their island is at risk. Given that people are going to be displaced as a consequence of climate change impacts, the UNFCCC has been referred to as "an important security treaty, making certain negotiating groups such as the Alliance of Small Island States security coalitions" (Barnett 2002: 2). Thus, climate change impacts might contribute, in combination with disputes on scarce resources, to increasing instability and potential for conflict in some regions.

Seen in this light, climate protection policies represent a means of conflict prevention (see generally Oberthür 1999). The ultimate objective of the UNFCCC is to stabilise atmospheric concentrations of greenhouse gases (GHGs) "at a level that would prevent dangerous anthropogenic interference with the climate system" (Article 2 FCCC). Accordingly, taking preventive action to mitigate climate change is at the core of the international regime, and this approach is to be further developed in the future. As such, climate change mitigation also represents a contribution to reducing the potential for conflicts, for example, through enhancing the security of energy supply (MacKenzie 1997; European Commission 2000a). In addition, the need to take appropriate adaptation measures is emphasised in the UNFCCC Framework Convention and the issue of adaptation has gained importance in the context of climate change during the last years. The identification and implementation of adequate adaptation measures can contribute significantly to responding 
to any increased conflict potential. Careful analysis of the impacts of climate change on the potential for conflict may allow identifying and determining regional and substantive priority areas of action so as to reduce conflict potential, in particular by implementing adaptation measures as appropriate. Both of these two basic options for responding to the problem of climate change and its implications for conflict prevention are further dealt with in section 3 of this paper.

In addition to the international climate change regime, there are a number of international and regional institutions and fora dealing with either climate change policies or prevention or mitigation of crisis and conflicts. Several approaches have tackled the issue of climate change and global warming and their potential security implications so far, mainly referring to monitoring issues. The United Nations Environment Programme's (UNEP) Executive Director Klaus Töpfer attempted to include crisis prevention and early warning into UNEP's mandate to monitor global environmental change (United Nations Task Force on Environment and Human Settlement 1998; UNEP 1999). Moreover, the issue has been dealt with in several ways within the OECD context. First, the Development Assistance Committee (DAC) of the OECD is about to extent the environment and resource chapter in the OECD's Guidelines for Conflict Prevention (OECD 2001). Second, the DAC work on good governance, capacity development and conflict and peace is undertaken by the Network on Good Governance and Capacity Development (GOVNET) and the Network on Conflict, Peace and Development Co-operation (CPDC Net), respectively. The DAC Network on Conflict, Peace and Development Co-operation is the only international forum where conflict and peace-building experts from bilateral and multilateral development cooperation agencies meet to define common approaches in support of peace. Third, there are also ongoing discussions in the OECD Annex I expert group. Fourth, the OECD's Working Party Global and Structural Policy (WP GSP) is currently pursuing a Climate/Development Project in coperation with DAC where climate change and conflict prevention should be discussed with strong participation of developing countries.

At the European level, the European Commission will establish until 2008 a global monitoring system for environment and security (European Commission 2001) as part of the European Strategy for Space (European Commission 2000). As part of a comprehensive monitoring system, earth observation technology and remote sensing data are to be systematically applied to monitor the implementation of the Kyoto Protocol. In addition, several institutions are dealing with the issue of conflict prevention, such as the Conflict Prevention and Reconstruction Unit of the World Bank, which is dedicated to easing the transition to sustainable peace and supporting socio-economic development in conflictaffected countries. The respective activities might also strengthen regional capacities to cope with potential negative effects of climate change. 
These examples illustrate that the link between global environmental change/climate change and security is dealt with in a variety of institutions worldwide. However, this paper deals exclusively with the relevance of conflict prevention in the context of the focused international process on climate change. Given that the scientific discussion on the role of environmental problems in the emergence of conflict and the international political process on climate change have so far hardly been linked, this paper aims at contributing to filling this gap by discussing the options for combining both strands of the discussion. In particular, it will explore which options exist for integrating and making the broader scientific discussion on environmental policy and conflict prevention fruitful for the international process on climate change.

To this end, this paper will proceed in three steps. First, it will investigate how the results of this discussion may be made to bear fruit for the international scientific process on climate change led by the Intergovernmental Panel on Climate Change (IPCC). Second, the potential relevance of the topic for the activities and discussions within the context of the UNFCCC and its Kyoto Protocol will be assessed. Finally, the paper's main findings are summarised in the conclusions.

\section{Conflict Prevention and Avoidance as a Potential Topic for the IPCC}

This section investigates to what extent the issue of climate change and conflict prevention is relevant to the IPCC which assesses the consensual scientific knowledge in the area of climate change, and how it may be introduced in the IPCC's work. To provide the background, first the role, organisational structure and scientific outputs of the IPCC are described. Second, this section examines to what extent the IPCC has already dealt with issues related to climate change and conflict prevention, including vulnerability to the adverse effects of climate change. Finally, how the IPCC might take up the issue of climate change and conflict prevention as a topic of its work in the future is explored.

\subsection{The IPCC: Objective, Organisation and Output}

The Intergovernmental Panel on Climate Change (IPCC) produces the most authoritative international scientific assessments that are regularly fed into the UNFCCC process and constitute its major scientific bases. The IPCC is an intergovernmental body organised in three working groups dealing with the science of climate change, impacts and adaptation, and mitigation options. It is headed by a Chairman and a Bureau. The IPCC was set up in 1988 by the United Nations Environment Programme (UNEP) and the World Meteorological Organization (WMO) with the mandate to regularly review the state of scientific knowl- 
edge on climate change (for an analysis see Alfsen/Skodvin 1998; Agrawala 1998; Depledge 2002).

\section{Organisation and objective}

All the member states of the United Nations and the WMO can participate as full members in the IPCC and its working groups. Apart from the structuring and the endorsement of IPCC products (see below for more details), the plenary of the Panel decides on the IPCC Principles and Procedures as well as on the budget, it elects the IPCC Chairman and the

\section{IPCC Organisation}

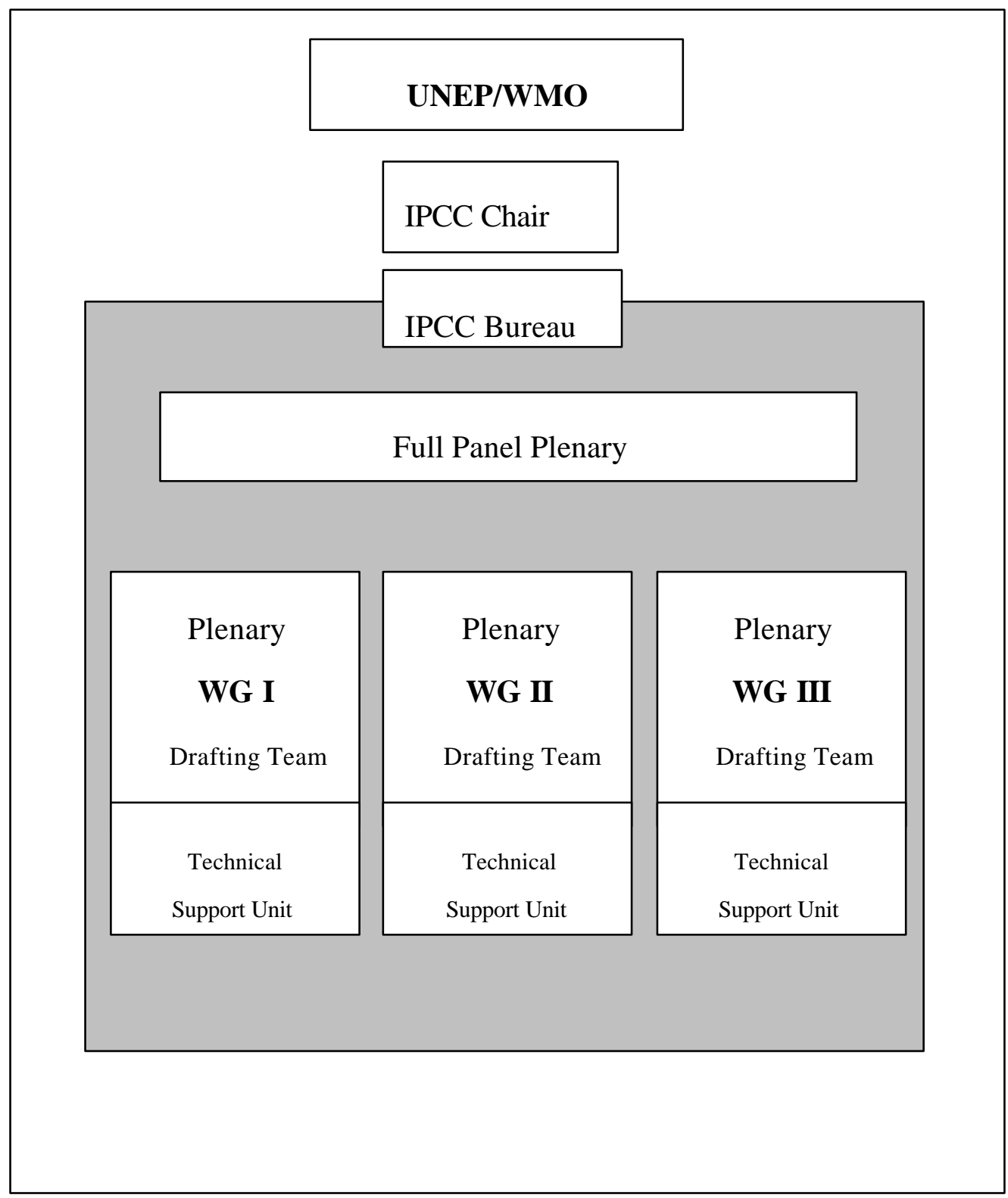


rest of its Bureau. The Chairman invites members of governments and other bodies as well as experts from WMO/UNEP member countries or international, or non-governmental organisations to participate in the plenary sessions of the Panel which meets about once a year. It is worth noting that scientists may be invited in their own right to contribute to the work of the IPCC. The IPCC Bureau, the IPCC Working Group Bureaux and any Task Force shall reflect balanced geographic representations with due consideration for scientific and technical requirements (IPCC 1998). The IPCC Bureau comprises thirty members: the IPCC Chairman, the three Vice-Chairs, the members of the three Working Group Bureaux (two Co-Chairs and six Vice-Chairs each) and the two Co-Chairs of the Task Force to oversee National Greenhouse Gas Inventories Programmes (IPCC-NGGIP; see below). ${ }^{1}$

The IPCC defines its role as follows:

"The role of the IPCC is to assess on a comprehensive, objective, open and transparent basis the scientific, technical and socio-economic information relevant to understanding the scientific basis of risk of human-induced climate change, its potential impacts and options for adaptation and mitigation. IPCC reports should be neutral with respect to policy, although they may need to deal objectively with scientific, technical and socio-economic factors relevant to the application of particular policies" (IPCC 1998: Section 2).

Accordingly, the IPCC does not conduct research nor does it monitor climate related data or other relevant parameters. It bases its assessment mainly on peer reviewed and published scientific and technical literature. ${ }^{2}$ To attain this objective, three Working Groups (WGs) were set up in 1988. Their respective tasks have been subject to slight variations over the years. ${ }^{3}$ For the Third Assessment Report (TAR), the scope was decided as follows:

I) Working Group I (WG I) assessed the scientific aspects of the climate system and climate change.

The Task Force was established at the 14th session of the IPCC in October 1998.

According to the latest revision of the IPCC rules of procedure, the following material can also be relevant for the work of the IPCC: industry journals, internal org anizational publications, non-peer reviewed reports or working papers of research institutions, proceedings of workshops (IPCC 1999: Annex 2; see critically Skodvin 2000: 414-415).

For the Second Assessment Report, WG II dealt with impacts, adaptation and mitigation, whereas WG III addressed the cross-cutting economic and social dimensions (Depledge 2002: 2). 
II) Working Group II (WG II) addressed the vulnerability (sensitivity and adaptability) of socio-economic and natural systems to climate change, and options for adapting to it. It also focused on human health, with an emphasis on regional, sectoral and cross-sectoral issues.

III) Working Group III (WG III) assessed options for limiting greenhouse gas emissions and otherwise mitigating climate change.

\section{Assessment Procedures}

In order to start the assessment process, the WGs have clearly defined and approved mandates and work plans as es tablished by the Panel which, however, are subject to ongoing improvements concerning the scope and structure of the output (for an analysis of the assessment process see Agrawala 1998: 623-628; focusing on the last revisions of the TAR in particular Moss 2000 and Skodvin 2000). For instance, suggestions to advance an integrated assessment of climate change resulted in increased attention to coordination across the Working Groups on so-called 'cross-cutting' issues such as the relationship of climate change to development, sustainability, and equity (Moss 2000; Depledge 2002).

The preparation of the TAR exemplifies the complexity of the internationally co-ordinated assessment process (see Moss 2000). The starting point was a workshop of members of the research community where background preparations started and ideas on the structure of the report were developed. In a second step, then IPCC Chair Robert Watson included these suggestions in a White Paper that was circulated for review by both experts and government representatives. This paper served as the basis for the plan and procedures finally adopted by the Panel in 1997 (see IPCC 1997). After the agreement on the proposed scope of each of the WGs (see IPCC-XIII/Doc. 4) the IPCC Secretary requested governments and IPCC focal points, as well as experts and organisations, to propose lead authors for the TAR.

The lead authors that are identified by the Working Group Bureaux on the basis of the proposals, are responsible for the production of designated sections. ${ }^{4}$ As outlined in the IPCC procedures (IPCC 1998: Annex 1), lead authors typically work in small groups which ensure that the various components of a section are assembled and integrated (for more detail see Alfsen/Skodvin 1998: 10-12). With the collaboration of the members of the ap-

For instance, in addition to a small core of dedicated staff in the Technical Support Unit, more than 100 lead authors and several hundreds of contributing authors participated in the work of Working Group I on the TAR (Karoly 2000: 469). 
propriate Working Group Bureau, lead authors develop at a scoping meeting the concrete chapter structure, which is subsequently approved by the Working Group plenary. The essence of the lead authors' task is the synthesis of material drawn from the expert contributions, mainly material from the peer-reviewed and internationally available literature. They also have, in conjunction with review editors, to take into account expert and government review comments when revising the text. Co-ordinating lead authors are in charge of co-ordinating major sections of a report, while contributing authors prepare technical information in the form of text, graphs or data for assimilation by the lead authors into the draft section.

The reports of the WGs are drafted and reviewed by hundreds of experts from all over the world. The experts who act in their personal capacity are nominated by governments, by a Working Group Bureau, by lead and contributing authors as well as by intergovernmental and non-governmental organisations. The comprehensive review process is organised in two phases, an expert and a government review.

The IPCC produces several types of reports that are finalised following different procedures (accepting, approving or adopting ${ }^{5}$ ) in the respective bodies (WG drafting team, WG plenary, and full (IPCC) Plenary ${ }^{6}$ ):

- The periodic Assessment Reports by the three WGs are accepted as a whole by the appropriate WG plenary. Until today, three Assessment Reports have been published, in 1990/1992, in 1995/1996 and the most recent one in 2001. In contrast to the full Assessment Reports, the Executive Summaries and the Summaries for Policy-makers, that form part of the overall reports, are subject to line-by-line approval by the appropriate WG plenary and they must be accepted by the full Panel plenary. The Synthesis of the Reports of all WGs are subject to line-by-line approval by the full Panel plenary. session of the Working Group or Panel signifies that the material has not been subject to line by line discussion and agreement. The "adoption" of IPCC reports is a process of endorsement section by section and "approval" signifies that the material has been subject to detailed line by line discussion and agreement (see IPCC 1999).

6 The WG Drafting Team mainly comprises the Lead and Contributing Authors (in a way as the "Scientific Core" as Alfsen/Skodvin (1998: 11) put it), the WG plenaries are composed of national delegations (government officials, policy-maker, scientist with governmental affiliations as well as partly independent scientist). 
- Special Reports are assessments on special issues that are subject to the same review, acceptance and approval procedures as the assessment reports in general.

- Technical Papers are reports on specific issues; they based on already existing assessment reports and are therefore not subject to the same acceptance and approval procedures as the assessment reports.

In addition, supporting material is prepared for consideration by the IPCC which is not subject to formal IPCC review processes. This material results from workshops and expert meetings (including the respective proceedings) which are useful or necessary for the completion of a WG's working plan or a task of the IPCC. An IPCC co-sponsorship of events such as expert workshops is possible if it has been determined in advance that it will be a useful contribution to the IPCC work.

\subsection{The Relevance of Conflict Prevention for the Work of the IPCC}

The IPCC has not yet taken up the issue of conflict or conflict potentials explicitly although relevant research results exist and are already published in peer-reviewed scientific journals (see for example Gleick 1989; van lerland et al. 1996). According to this research, future climatic changes will have widespread societal impacts that can also increase conflict potentials. It is worth noting that it depends on varying context variables whether an increased environmental stress indeed leads to conflict (Carius/Imbusch 1999: 20-22). The impacts of climate change could contribute to and reinforce already existing socioeconomic and environmental pressures (Brauch 2002: Chap. 2.5). Whether heightened pressure induced by climate change impacts indeed result in growing conflict potential depends on their future development and on a number of socio-economic context variables. Both relevant climate change impacts and socio-economic context variables have already been dealt with in the existing IPCC assessments. As outlined above, the TAR of the IPCC addressed its impacts (WG II) and the response options to mitigate the problem (WG III) or to adapt to the changing conditions (WG II).

\section{Impacts}

In the TAR, WG II addressed on the one hand the vulnerability of both natural and socioeconomic systems to climate change. On the other hand, it dealt with options for adapting to climate change. As WG II took into account the social dimension of impacts, a linkage to the issue of climate change and conflict potential becomes obvious. Conflict potentials clearly are social impacts, therefore this issue would fit into the mandate of WG II of the IPCC. 
More specifically, regarding the special character of impacts WG II distinguishes between three relevant concepts (IPCC 2001a: 6):

1. Sensitivity (as "the degree to which a system is affected, either adversely or beneficially, by climate-related stimuli"),

2. Adaptive Capacity (as "the ability of a system to adjust to climate change[..] to moderate potential damages [....] or to cope with the consequences"), and

3. Vulnerability (as "the degree to which a system is susceptible to, or unable to cope with, adverse effects of climate change").

The adaptive capacity refers to the above mentioned socio-economic context variables and therefore it is the area where either conflict potential or conflict prevention capacity might be part of the assessment of a society's vulnerability. Climate change impacts could contribute to increasing environmental stress or sensitivity and this might subsequently in relation with other forces increase regional conflict potentials. At the same time, it follows that the adaptive capacity influences the ability to reduce vulnerability and to increase the potential for conflict prevention.

To a certain degree, the assessment of WG II already recognizes the specific importance of this kind of impact dimension through the finding that developing countries will be hardest affected by climate change, as they are more vulnerable to its adverse impacts and have less adaptive capacity. By assessing the potential impacts of future climate change across sectors and regions, key concerns are identified and it is emphasized that the ability of human systems to adapt to and cope with climate change depends on different factors. The TAR recognises that "many communities and regions that are vulnerable to climate change are also under pressure from forces such as population growth, resource depletion, and poverty" (IPCC 2001a, 8). Moreover, the potential occurrence of socioeconomic disruptions or migration as a consequence of climate change is mentioned (IPCC 2001a: 12; on the issue of climate change and environmental refugees, see, for example, Myers/Kent 1995). However, the linkage to existing or latent conflict constellation is not made explicit and the analysis of the interaction of climate change with other pressures remains vague or limited due to, inter alia, methodological problems regarding the assessment of future developments of the different pressures. Accordingly, further research is required to strengthen future assessments, in particular with respect to integrated assessments of interactions between climate change impacts and other stressfactors such as pre-existing water shortages, desertification, population growth, etc. that may reinforce certain potentials for conflict. The need for an improved assessment of $1 \mathrm{~m}$ pacts, Vulnerabilities, and Adaptation is also formulated by Working Group II of the IPCC in its TAR (IPCC 2001a, 17). 


\section{Adaptation}

The IPCC has explicitly included the topic "Adaptation" in the Second and Third Assessment Reports of Working Group II (IPCC 1996; 2001a) and also dealt with adaptation strategies in its 1994 Technical Guidelines (IPCC 1994). Adaptation is considered an important response strategy, keeping in mind that even with reductions in greenhouse gas emissions, changes in climate are likely to occur. Policy responses like the implementation of effective water resource management techniques therefore cannot only be applied to adapt to hydrologic effects of climate change but also to lessen vulnerability of a region in general (IPCC 2001a, 9). With respect to adaptation options for coastal and marine management, the TAR of WG II highlights the effectiveness of solutions that integrate several policy sectors, such as climate change, disaster mitigation, and land planning (IPCC 2001a: 12). In this respect, the relevance of the existing research on unifying effects of co-operative arrangements for transboundary water resources (e.g. Wolf 2001) are obvious. This research has revealed that the establishment of co-operative institutions for the joint management of natural resources can contribute to enhancing cooperation between different countries. If the IPCC were to deal with the issue of climate change and conflict prevention, such findings could represent important and valuable contributions.

Hence, the work of WG II on adaptation measures offers important links to the issue of climate change and conflict prevention. This issue could play a prominent role especially when priorities for adaptation activities are defined. In order to develop strategies to cope with future climate change impacts, a full understanding of vulnerability is necessary (see Klein/Downing 2002). Accordingly, an integrated assessment of vulnerability should take into systematic account the potential for both conflicts and conflict prevention measures. In addition, further research is needed concerning the question of what kind of adaptation activities may be prioritised to minimise conflict potential.

\section{Mitigation}

In this context, the expertise of Working Group III on mitigation measures is also relevant. It is worth noting that the issue of mitigation received its own report during the third assessment cycle whereas the issues of climate change impacts and adaptation measures are integrated in one assessment. Actions of mitigation - defined by WG III as "an anthropogenic intervention to reduce the sources of greenhouse gases or enhance their sinks" (IPCC 2001b: 3) - may yield extensive benefits in areas outside of climate change, for example with respect to resource use or degradation, but also reductions in other pollutants jointly produced with greenhouse gases. Hence, the benefits of limiting greenhouse gas emissions are not only that climate change damages will be avoided but also that secondary benefits associated with the relevant policies could be achieved. However, as 
of yet, the IPCC assessments do not mention the reduction of conflict potentials as a secondary benefit of climate change mitigation.

\subsection{Options for Integrating the Topic into the IPCC Work}

As outlined above, the IPCC produces different types of reports that may be used to take up the issue of conflict prevention and climate change. In the following, the feasibility of the different options is assessed:

- A Technical Paper on the issue of climate change and conflict prevention hardly appears to be possible, since the issue has not yet been addressed in the main assessment reports of the IPCC.

- The preparation of a Special Report. A special report on climate change and conflict prevention might have the aim to examine the implications of climate change and response options for existing or latent conflict constellations. The next IPCC Bureau meeting at the beginning of August 2002 in Geneva will provide the first opportunity for such an initiative. To this end, the existing but indirect links in the current assessment reports on the issue of conflict prevention and avoidance can be built upon.

A related option might be to attempt to deal with the issue of climate change and conflict prevention in the context of the proposed Special Report on "Climate change and Sustainable Development" (SRCCSD). An expert meeting to prepare the groundwork for such a report is planned (see Dec. 9 of IPCC 2002). The fact that the issue of conflict prevention is part of the sustainable development debate (see for example World Commission on Environment and Development 1987: ch. 11; Carnegie Commission on Preventing Deadly Conflict 1997: 86; UN Secretary General 1998: sec. IV, B; WWF 2002: 15) provides a rationale for integrating the issue in the envisaged SRCCSD. A decision on the SRCCSD may be taken at the next plenary scheduled for February 2003.

In addition, the issue of conflict prevention could be included in the Special Report on Climate Change and Water. At the XIX session the Panel decided to entrust the Bureaux of WG I and II, in consultation with WG III, with the preparation of a scoping paper for a possible Special Report (see Dec. 8 of IPCC 2002). Since the potential for conflict over scarce water resources is well-known, there is good reason to include the theme of climate change and conflict prevention in this special report. At the same time, it represents only one aspect of the much broader theme so that a demand to address the issue in another context would persist. 
- Another option is to deal with this issue as part of the regular Assessment Report. A growing body of literature exists that could be reviewed by the lead and contributing authors. The IPCC is currently in the process of considering the overall programme for the Fourth Assessment Report (FoAR). Apart from discussions about the general outline of this report (shortening underlying reports, switch of focus to new findings, making the reports more comprehensible to policy-makers) the IPCC Bureau was to consult the UNFCCC SBSTA on its requirements as an input for the FoAR (according to Decision 2 of the XVIII Session of the IPCC). As the above discussion has shown, the closest links between the existing work of the IPCC and the issue of climate change and conflict prevention exist in the area of IPCC WG II. If a fourth report on cross-cutting issues such as sustainable development, uncertainty or equity was agreed upon (see Depledge 2002: 8), the issue of climate change and conflict prevention could feature therein.

- The issue could also be advanced within the IPCC context by means of an expert workshop including experts with different disciplinary backgrounds, members of governments, NGOs and business representatives. This might constitute a first step towards including conflict prevention as a topic in an Assessment Report or producing an IPCC Special Report on the issue.

\section{Links to the UNFCCC and its Kyoto Protocol}

In the following section, the major links between the debate about climate change and conflict prevention on the one side and the international regime on climate change on the other are identified and investigated. To this end, first the major provisions and the institutional structure of the international climate change regime constituted by the UNFCCC and its Kyoto Protocol are introduced briefly. Subsequently, the major threads of discussion under the UNFCCC and its Kyoto Protocol are analysed as to their relevance for the debate on climate change and conflict prevention. The emphasis will be on mitigation of climate change and adaptation to its impacts as the major themes of the international climate change regime.

\subsection{The International Climate Change Regime: A Brief Overview}

The international regime on climate change is built upon two international treaties, the UN Framework Convention on Climate Change (UNFCCC) of 1992 and its Kyoto Protocol that was adopted in 1997. Since the Kyoto Protocol represented "unfinished business" (Ott 1998), Parties agreed in 1998 to clarify and elaborate the rules under the Kyoto Protocol 
by the year 2000. Eventually, agreement was only reached in 2001 through the so-called "Bonn Agreement" and the "Marrakesh Accords" (see Sach/Reese 2002; Bail et al. 2002).

The UNFCCC was adopted after intense negotiations that started in early 1991 on the basis of the first report of the IPCC of 1990 (on the UNFCCC see Sands 1992; Bodansky 1993; Ott 1996). It established the very foundation of the regime by defining the principles which guide its development (Article 3 FCCC) and its ultimate objective which is to stabilise atmospheric concentrations of greenhouse gases (GHGs) "at a level that would prevent dangerous anthropogenic interference with the climate system" (Article 2 FCCC).

Moreover, the UNFCCC provides the institutional framework for the further development of the regime. The Conference of the Parties (COP), that usually meets once a year, is the supreme decision-making body assisted by two standing subsidiary bodies, the Subsidiary Body for Scientific and Technological Advice (SBSTA) and the Subsidiary Body for $\mathrm{m}$ plementation (SBI). The COP serves as the meeting of the Parties to the Kyoto Protocol (becoming the COP/MOP) and the subsidiary bodies also serve in their respective functions under the Protocol. Since it has so far been impossible to adopt rules of procedure, all decisions under the Convention need to be made by consensus. The Convention also acknowledges the role of the IPCC in providing scientific advice to the Parties. Scientific and technological advice provided by the IPCC is fed into the international regime through the SBSTA.

The Convention did not contain any concrete obligations to limit or reduce the emissions of GHGs or to implement specific policies and measures to combat climate change. The Kyoto Protocol (KP) for the first time establishes legally binding emission reduction commitments for industrialised countries. These differentiated commitments shall amount to an overall reduction of at least 5\% from 1990 levels by 2008-2012 (the 'commitment period'). The commitments cover six GHGs and groups of GHGs: carbon dioxide $\left(\mathrm{CO}_{2}\right)$, methane $\left(\mathrm{CH}_{4}\right)$, nitrous oxide $\left(\mathrm{N}_{2} \mathrm{O}\right)$, hydrofluorocarbons (HFCs), perfluorocarbons (PFCs), and sulphur hexafluoride $\left(\mathrm{SF}_{6}\right)$. The Protocol follows the approach of the UNFCCC by including "sinks" into the equation: Removals and emissions of GHGs from afforestation, reforestation and deforestation are to be accounted for (Art. 3.3 KP). According to Article $3.4 \mathrm{KP}$, additional sink categories can be included in the accounting later by decisions of the Conference of the Parties serving as the meeting of the Parties (COP/MOP), the supreme decision-making body under the Protocol. The agreements reached in 2001 take into account forest management and agricultural activities (cropland management, grazing land management, and revegetation) as further sink categories (Bail et al. 2002; on the Kyoto Protocol in general see Oberthür/Ott 1999; Grubb et al. 1999). 
The Protocol furthermore establishes three innovative "flexible mechanisms" that allow countries to meet their emission obligations by acquiring emission credits from abroad. An emissions trading system may be used by industrialised countries with excess emission allowances to transfer them to other industrialised countries in need of such allowances (Article 17 of the Protocol). Under the so-called 'project-based mechanisms' - 'Joint mplementation' ( $\mathrm{JI}$ ) according to Article 6 and the Clean Development Mechanism (CDM) according to Article 12 of the Protocol - an investor and a host country can generate additional emission reductions by implementing a suitable joint project, with the investor receiving (part of) the resulting emission credits. The investor in both $\mathrm{JI}$ and CDM projects would be from an industrialised country. Other industrialised countries would act as hosts of $\mathrm{Jl}$ projects, whereas CDM projects would be implemented in developing countries. More detailed rules and guidelines on the operation of the Kyoto Mechanisms were passed as part of the further agreements reached in 2001 (Bail et al. 2002).

The Kyoto Protocol also provides for the elaboration of detailed rules on reporting, monitoring and review of information (Articles 5, 7, and $8 \mathrm{KP}$ ) and mandates the development of a compliance system to determine and address cases of non-compliance (Article 18). Decisions on both areas were part of the agreement reached in 2002 (Bail et al. 2002). The Convention and the Protocol make use of the same financial mechanism that is operated by the Global Environment Facility (GEF). The provision of additional financial assistance for developing countries has been a central part of the post-Kyoto negotiations. As part of the agreement reached in 2001, three particular funds for assisting developing countries to mitigate and adapt to climate change were established (see FCCC/CP/2001/13/Add.1; Sach/Reese 2002; Bail et al. 2002; see also section 3.3 below).

\subsection{Climate Change Mitigation}

Mitigation is at the core of the international regime on climate change, as is evident from the objective of the UNFCCC to achieve stabilisation of greenhouse gas concentrations in the atmosphere. Many discussions on the development of international climate policy have therefore been concerned with mitigation. Most prominently, this is exemplified by the negotiations on the legally binding reduction commitments under the Kyoto Protocol. Other cases in point are provided by the discussions on whether and to what extent human-induced sequestration of amospheric carbon could be credited against the Kyoto targets and to what extent industrialised countries can employ the flexible mechanisms to achieve their targets instead of taking domestic action (see Oberthür/Ott 1999: ch. 11 and 15). 
Climate change mitigation is also set to remain a major focus of the international debate in the framework of the climate change regime in the future. The next major milestone in this debate is provided by the start of discussions on targets for a second commitment period post-2012. According to Art. 3.9 of the Kyoto Protocol, the COP/MOP has to initiate consideration of such targets in 2005. Intimately linked to these negotiations on the second commitment period targets are two crucial strategic issues of the development of international climate policy:

- First, the re-integration of the US into global efforts to combat climate change after President Bush in March 2001 decided not to ratify the Kyoto Protocol, declaring that it was "fatally flawed" (see Ott 2001).

- Second, the further development of commitments of developing countries under the Kyoto Protocol. While it has been acknowledged by industrialised country Parties to the international climate change regime that they have to take the lead, it has also been part of the international understanding reached that developing countries will have to step up their efforts once this lead has been firmly established.

The issue of an increased conflict potential resulting from anthropogenic climate change impacts is relevant for these international discussions because it enhances the rationale for taking strengthened action by both industrialised and developing countries to mitigate climate change. Such strengthened action could thus provide a means of preventing increases in conflict potential and actual future conflicts by mitigating against a number of relevant impacts (e.g. migration, water scarcity caused by climate change). Furthermore, it supports the further development and implementation of international and domestic climate policies that possess a particular potential to reduce existing conflict potential. Most importantly, policies that help expand the use of domestic renewable energy sources and promote energy efficiency are set to result in greater independence from foreign energy sources and enhance security of energy supply (for the nexus of climate change and energy supply security, see MacKenzie 1997; European Commission 2000a, part 2).

\subsection{Adaptation and Transfer of Resources}

Adaptation to the adverse effects of man-made climate change is another cornerstone of international efforts to deal with global warming. Although adaptation has received less attention than climate change mitigation, its importance has been acknowledged in both the UNFCCC and the Kyoto Protocol and is firmly established as a major element of the international climate change regime (see also Müller 2002). For example, Article 4 of the UNFCCC commits: 
- All Parties to formulate and implement "measures to facilitate adequate adaptation to climate change" and to co-operate "in preparing for adaptation to the impacts of climate change" (Article 4.1 UNFCCC);

- All Parties to consider what actions are necessary (including actions related to funding or transfer of technology) in order "to meet the specific needs and concerns of developing country Parties arising from the adverse effects of climate change" (Article 4.8 UNFCCC).

- Industrialised country Parties other than countries in transition to "assist the developing country Parties that are particularly vulnerable to the adverse effects of climate change in meeting costs of adaptation to these adverse effects" (Article 4.4 UNFCCC);

- All Parties to "take full account of the specific needs and special situations of the least developed countries in their actions with regard to funding and transfer of technology" (Article 4.9 UNFCCC).

In addition, Article 4.8 of UNFCCC lists a number of categories of countries that are particularly vulnerable to the adverse effects of climate change. On this basis, specific adaptation activities have been initiated under the UNFCCC following the so-called three-stage approach, as laid down in Decision 11/CP.1. In particular, preparatory adaptation activities in developing countries have received assistance under the financial mechanism of the Convention operated by the GEF. The scope of eligible activities has been extended slowly over the years (Oberthür/Ott 1999: 41-42; 290; UN doc. FCCC/2001/13/Add.1).

Article 10 of the Kyoto Protocol also commits Parties to promote and facilitate adaptation to climate change. The system of providing assistance to developing countries for adaptation was further developed with the adoption of the "Marrakesh Accords" in 2001. In particular, three new relevant funds were established (Bail et al. 2002; Sach/Reese 2002; UN doc. FCCC/2001/13/Add.1):

- An Adaptation Fund was established under the Kyoto Protocol to finance concrete adaptation projects and programmes in developing countries. This is to be financed from $2 \%$ of the share of proceeds from Clean Development Mechanism (CDM) projects.

- Annex I Party contributions will feed a Special Climate Change Fund under the Convention to finance activities that are complementary to those funded by the GEF. In addition to adaptation activities, this fund will also support technology transfer, programmes and measures in GHG emitting sectors, and diversification of economies that would be adversely affected by GHG mitigation. 
- A Least Developed Countries (LDCs) Fund was introduced under the Convention to support a work programme for LDCs to implement the Convention, ncluding the preparation of National Adaptation Programmes of Action (NAPAs).

These three funds will be operated by the GEF and are to complement each other as well as the relevant activities under the normal financial mechanism of the regime operated by the GEF (see Decision 5/CP.7 in UN doc. FCCC/2001/13/Add.1). The GEF was invited by the Parties to the UNFCCC to make the necessary arrangements. The system of funding for adaptation will have to be further elaborated within the GEF, and further guidance may have to be provided by the Parties to the international climate change regime, in the years to come. In general, there is a need to elaborate further guidelines and methodologies for assessing vulnerability and developing adaptation strategies, building on previous efforts (see for example UNFCCC 1999; 2000; STAP 2002; Klein/Downing 2002). A number of relevant activities have been identified and are underway (Pazstor/Pilifosova 2002).

While the issue of adaptation is closely related to funding, the issue of resource transfer also covers general capacity building and assistance for climate change mitigation. The Marrakesh Accords call upon industrialised country Parties in general to provide funding to developing countries for all these purposes through the aforementioned funds, ncreased GEF replenishment, and bilateral and multilateral channels. Some countries (Canada, EU, Iceland, New Zealand, Norway, and Switzerland) have passed a political declaration, undertaking to provide an annual contribution of 450 million Euros/410 million US dollars by 2005 to developing countries (Sach/Reese 2002). In addition, COP 7 established an Expert Group on Technology Transfer that will provide advice to SBSTA on relevant issues (Decision 4/CP.7 in UN doc. FCCC/2001/13/Add.1).

The debate about climate change and conflict prevention is relevant to the issues of adaptation and transfer of resources under the international climate change regime in several ways. First of all, it provides an additional rationale for supporting action to mitigate climate change in developing countries to help prevent an increase of conflict potential and may indeed lower such conflict potential, in particular by contributing to greater security of energy supply (see above on mitigation). Second, the fact that climate change may lead to a heightened conflict potential lends general support for strengthened efforts to adapt to the impacts of climate change so as to counter this trend as quickly and efficiently as possible.

Furthermore, it may also be possible to define certain priority adaptation (and mitigation) measures that would be particularly promising regarding the prevention of conflicts where climate change impacts are expected to contribute to an increased conflict potential. For example, it might be worth supporting the co-operative management of shared fresh water 
resources where climate change is predicted to result in these fresh water resources being diminished. On other occasions, general capacity building measures may represent a valuable contribution to conflict prevention as it enhances the ability of a society to deal effectively with climate change and its impacts without destabilising existing governance and management systems. To enable drawing such conclusions it may be necessary to develop relevant methodologies, definitions and indicators in the ongoing preparatory work regarding vulnerability and adaptation (for the latter see Pazstor/Pilifosova 2002 and OECD 2002: 11). In this respect, the assessment of best practicable adaptation measures and strategies raises new methodological challenges (Klein/Downing 2002). In particular, a stronger emphasis on social factors might be required when elaborating assessments and reporting on vulnerability. Subsequently the elaboration and implementation of adaptation strategies must recognise the specific regional context regarding both immediate and long-term sectoral needs. In general, the debate about climate change and conflict prevention can add a new dimension of consideration when it comes to evaluating, assessing and prioritising available options for GHG mitigation and adaptation.

\subsection{Other Areas of Discussion}

The above sections on climate change mitigation and adaptation and resources transfer have demonstrated the general relevance of the link between climate change and conflict prevention for the international political process on climate change within the UNFCCC context. However, these section only covered two major threads of the international debate. The UNFCCC process has become increasingly diversified with many parallel discourses being developed simultaneously. It is hardly possible in the context of this paper to explore each and every strain in the discussion. A few references may suffice to indicate that the relevance of the debate about climate change and conflict prevention may well extend beyond the broader issues raised so far.

The discussion about co-ordination of policies and measures has a long history within the UNFCCC and its Kyoto Protocol (see Oberthür/Ott 1999: ch. 10). The discussion about an increased conflict potential resulting from climate change could again bolster the rationale for strengthened co-ordination in this area to increase the effectiveness of international climate policy and possibly any cleavages in the implementation of specific policies. In addition, it could direct our attention to the demand for co-ordination in the area of adaptation policies. Overall, the contribution to a general confidence building resulting from coordination of policies and measures could acquire a value of its own.

With respect to the project-based flexible mechanisms (i.e. Jl and CDM), rules and guidelines have been agreed upon in 2001. These rules include a preferential treatment of par- 
ticular CDM projects in particular (small-scale projects, projects in LDCs; see Sach/Reese 2002; Bail et al. 2002). Similarly, a preferential treatment could in principle be provided for projects that were shown to result in considerable additional benefits regarding conflict prevention. Such "secondary" benefits could for example consist of an enhanced energy supply security or the build-up of significant domestic capacity to mitigate and adapt to climate change (beyond the particular project in question). Relevant projects may increase relevant adaptive capacity in recipient countries (enabling them to deal better with environmental and social impacts of climate change) and thus reduce the conflict potential.

In the area of implementation review, a compliance system under the Kyoto Protocol was agreed upon in 2001. This comprises of an enforcement branch that is responsible for determining compliance with the Kyoto targets in particular, and a facilitative branch that is generally mandated to assist Parties in the implementation of the Protocol (Oberthür/Marr 2002). Thus, the facilitative branch may in principle also become an instrument for addressing issues of implementation related to a growing conflict potential resulting from climate change. For example, it could recommend and thus initiate strengthened adaptation efforts in countries and regions experiencing a worsening scarcity of fresh-water resources as a result of climate change and an increasing conflict potential regarding these resources.

Some of these links between the international process on climate change and the debate about climate change and conflict prevention may appear to be remote as long as no official scientific assessment has been fed into the political process and can provide a firm basis for any such deliberations. In essence, discussions within the international regime on climate change are science-based. The weight which the aforementioned considerations regarding climate change and conflict prevention will acquire in the international political deliberations is therefore heavily dependent upon its scientific foundation. The main source of authoritative scientific knowledge fed into he UNFCCC process is the IPCC (see section 2).

\section{Conclusion}

The relationship of environmental problems and conflict prevention has been increasingly dealt with in the social science literature. More specifically, evidence is mounting that the adverse effects of climate change can, particularly by interacting with a number of other factors such as scarcity of natural resources, contribute to an increasing potential for conflict. On the other side, effective climate and environmental policies hold the promise to lessen such potential. 
As shown above, the issue of conflict prevention has not yet been established as a topic in the international process on climate change. However, the role of climate change in increasing the potential for conflict, and the role of effective climate policy in lessening it, is particularly relevant to two major strains of discussion in international climate policy. First, the rationale for taking preventive action to mitigate climate change appears to be strengthened, as such climate change mitigation also represents a contribution to reducing conflict potential in general. As it generally leads to a decrease in energy demand, it reduces dependence on foreign energy supplies and enhances the security of energy supply. Second, the need to take appropriate adaptation measures in order to respond to any increased conflict potential diligently is highlighted. Furthermore, careful analysis of the impacts of climate change on the potential for conflict may allow identifying and determining regional and substantive priority areas of action so as to reduce the potential for conflict, by implementing adaptation measures as appropriate.

The issue of adaptation is also related to the question of vulnerability of our human system. Vulnerability to climate change refers to the degree to which a system is susceptible to or unable to cope with its adverse effects. The adaptive capacity depends on very different context variables, for example on the access to resources, the skill and knowledge to use them, or the stability and effectiveness of economic, social and cultural institutions. Accordingly, in addition to the analysis of the impacts of climate change on the potential for conflict, the degree of capacity of livelihoods or regions to adapt to respective impacts appears to be relevant for the identification of regional and substantive priority areas of action in the context of conflict prevention.

Both strains of the discussion - mitigation and adaptation - illustrate the relevance of the issue of climate change and conflict prevention for pertinent international political discussions on the future development of climate policy - such as the further strengthening of international commitments to reduce greenhouse gas emissions and the appropriate priorities in financing adaptation activities. Though this relevance is evident, no authoritative international scientific assessment of the issue exists yet. Since the international process on climate change is science-based, an obvious possibility for linking the aspect of climate change and conflict prevention to the UNFCCC process would appear to be through scientific channels. As pointed out above, the Intergovernmental Panel on Climate Change (IPCC) produces the most authoritative international scientific assessments that are regularly fed into the UNFCCC process and constitute its major scientific basis. The IPCC organised in three working groups dealing with the science of climate change, impacts and adaptation, and mitigation options - generally produces full Assessment Reports covering the causes, effects and mitigation options regarding climate change, Technical Pa- 
pers on particular issues based on already existing assessment reports, and Special Reports as assessments on special issues.

The options to introduce the issue of climate change and conflict prevention to the IPCC are as follows: A Technical Paper on the issue of climate change and conflict prevention hardly appears to be possible, since the issue has not yet been addressed in the main assessment reports of the IPCC. Initiating a Special Report requires careful preparation since the IPCC has limited resources to produce them (i.e. only issues considered to be of first priority are usually selected). The issue could also be dealt with in two envisaged Special Reports on the relationship between Climate Change and Sustainable Development as well as on Climate Change and Water. Another option consists in taking the issue of conflict prevention up in the IPCC's regular Assessment Reports. The work of the IPCC Working Group II on the impacts of climate change appears to be most appropriate for addressing the topic since it has already dealt with social impacts in the past. The contents of the Fourth Assessment Report of the IPCC are currently under discussion and the IPCC plenary is scheduled to decide thereon in early 2003. Furthermore, specialised expert workshops co-sponsored by the IPCC have in the past explored particular items of scientific discussion.

In any event, considerable knowledge about the link between climate change and conflict prevention already exists. Sound climate policies can already contribute to conflict prevention. As a result, interested Parties can use this knowledge to define priorities both in international discussions on mitigation and adaptation within the UNFCCC and its Kyoto Protocol and in their domestic implementation. 


\section{References}

Agrawala, Shardul 1998: Structural and Process History of the Intergovernmental Panel on Climate Change. In: Climatic Change, Vol. 39, No.4, 621-642.

Alfsen, Knut H. and Tora Skodvin 1998: The Intergovernmental Panel on Climate Change (IPCC) and scientific consensus. How scientists come to say what the say about climate change. CICERO Policy Note 1998:3. Oslo: Center for International Climate and Environmental Research.

Bail, Christoph, Simon Marr and Sebastian Oberthür 2002: Klimaschutz und Recht. In: Rengeling, Hans-Werner (Hrsg.): Handbuch zum europäischen und deutschen Umweltrecht, Band I. Köln et al.: Carl Heymanns Verlag. (forthcoming)

Barnett, Jon 2001: Security and Climate Change. Tyndall Centre Working Paper No. 7. Norwich: Tyndall Centre for Climate Change Research.

Bodansky, David 1993: The United Nations Framework Convention on Climate Change: A Commentary. Yale Journal of International Law, Vol. 18, 451-558.

Brauch, Hans Günther 2002: Climate Change, Environmental Stress and Conflict. Background Paper for the Special Event "Climate Change and Conflict Prevention", Bonn, 10 June 2002, 16th meeting of the Subsidiaries Bodies UNFCCC, Bonn (05 - 14 June 2002).

Carius, Alexander and Kurt M. Lietzmann (eds.) 1999: Environmental Change and Security. A European Perspective. Berlin, Heidelberg: Springer.

Carius, Alexander and Kerstin Imbusch 1999: Environment and Security in International Politics - An Introduction. In: Alexander Carius and Kurt M. Lietzmann (eds.): Environmental Change and Security. A European Perspective. Berlin, Heidelberg: Springer, 7-30.

Carius, Alexander, Eileen Petzold-Bradley and Stefanie Pfahl 2001: Umweltpolitik und nachhaltige Friedenspolitik. Eine neues Thema auf der internationalen Agenda. Aus Politik und Zeitgeschichte, Band Vol. 12, 16. März 2001.

Carnegie Commission on Preventing Deadly Conflict 1997: Preventing Deadly Conflict. Final Report. Washington, D.C.: Carnegie Commission on Preventing Deadly Conflict.

Depledge, Joanna 2002: Climate Change in Focus. The IPCC Third Assessment Report. RIIA Briefing Paper, new Series No. 29. London: Royal Institute of International Affairs.

European Commission 2000: Communication from the Commission to the Council and the European Parliament. Europe and Space: Turning to a new chapter $\operatorname{COM}(2000) 597$ final. Brussels. 
European Commission: 2000a: Green paper. Towards a European Strategy for the Security of energy supply (COM (2000) 769final). Brussels.

European Commission 2001: Commission Staff Working Paper. Joint document from Commission services and the European Space Agency. A European Approach in Global Monitoring for Environment and Security (GMES): Towards Meeting User's Needs SEC(2001) 993. Brussels.

Evans, Mary Margaret, John W. Mentz, Robert W. Chandler and Stephanie L. Eubanks 2000: The Changing Definition of National Security. In: Miriam R. Lowi and Brian R. Shaw (eds.): Environment and Security. Discourses and Practices. New York: St. Martin's Press, 11-32.

Gleditsch, Nils Peter (ed.) 1997: Conflict and the Environment. NATO ASI Series 2: Environment. Dordrecht, Boston, London: Kluwer.

Gleick, Peter H. 1989: The Implications of Global Climatic Changes for International Security. In: Climatic Change, Vol. 15, Nos. 1-2, 309-325.

Grubb, Michael, Christiaan Vrolijk and Duncan Brack 1999: The Kyoto Protocol. A Guide and Assessment. London: The Royal Institute of International Affairs. Earthscan.

lerland van, Ekko C., Marcel G. Klaassen, Tom Nierop and Herman v.d. Wusten 1996: Climate Change: Socio-Economic Impacts and Violent Conflict. Dutch National research Programme on Global air Pollution and Climate Change.

IPCC 1994: Technical Guidelines for Assessing Climate Change Impacts and Adaptation (prepared by Carter, T.P., Parry, M.L., Harasawa, H., and Nishioka, N.). London: University College London.

IPCC 1997: The IPCC Third Assessment Report. Decision paper. Approved by the Panel at its $13^{\text {th }}$ Plenary Session, The Maledives, September 1997. Available at http://www.ipcc.ch/activity/tardpaper.html [as of May 2002].

IPCC 1997a:The Regional Impacts of Climate Change: An Assessment of Vulnerability. Summary for Policymakers. A Special Report of IPCC Working Group II (edited by R.T. Watson, M.C. Zinyowera, R.H. Moss and D. J. Dokken). Available at http://www.ipcc.ch/pub/regional(E).pdf [as of May 2002].

IPCC 1998: Principles Governing IPCC Work. Approved at the Fourteenth Session (Vienna, 1-3 October 1998) on 1 October 1998. Available at http://www. ipcc.ch/about/princ.pdf [as of May 2002].

IPCC 1999: Procedures for the Preparation, Review, Acceptance, Adoption, Approval and Publication of IPCC Reports: Adopted at the Fifteenth Session (San Jose, 15-13 April 1999). Available at http://www.ipcc.ch/about/app-a.pdf [as of May 2002].

IPCC 2001a: Climate Change 2001: Impacts, Adaptation, and Vulnerability. Summary for Policymakers. A Report of Working Group II of the Intergovernmental Panel on Climate Change. Available at http://www.ipcc.ch/pub/wg2SPMfinal.pdf [as of May 2002]. 
IPCC 2001: Draft Report of the Nineteenth Session of the IPCC, Geneva, 17-20 April 2002. Available at http://www.ipcc.ch/meet/session19/draftreport19.pdf [as of 3 . June 2002].

IPCC 2001b: Climate Change 2001: Mitigation. Summary for Policymakers. A Report of Working Group II of the Intergovernmental Panel on Climate Change. Available at http://www.ipcc.ch/pub/wg3spm.pdf [as of May 2002].

Karoly, David J. 2000: Ready for IPCC-2001: A Practical Approach to a daunting Task. An Editorial Comment. In: Climatic Change, Vol. 45, Nos. 3-4, 469-470.

Kelly, P. M. and W. N. Adger 2000: Theory and Practice in Assessing Vulnerability to Climate Change and Facilitating Adaptation. In: Climatic Change, Vol. 47, No. 4, 325352.

Klein, Richard J.T. and Thomas E. Downing 2002: Towards an International Funding Strategy for Climate Adaptation - A Contribution from Adaptation Science. A Background Paper to the Scientific and Technical Advisory Panel of the Global Environment Facility, presented at STAP Expert Workshop on Adaptation and Vulnerability, 18-20 February 2002, Nairobi, Kenya.

Lonergan, Steve 1999: Global Environmental Change and Human Security. Science Plan. Bonn: International Human Dimensions Programme on Global Environmental Change.

MacKenzie, James J. 1997: Climate Protection and the National Interest: The Links Among Climate Change, Air Pollution, and Energy Security. Washington, D.C.: World Resources Institute.

Moss, Richard H. 2000: Ready for IPCC-2001: Innovation and Change in plans for the IPCC Third Assessment Report. An Editorial Comment. In: Climatic Change, Vol. 45, Nos. 3-4, 459-468.

Müller, Benito 2002: An FCCC Impact Response Instrument as part of a Balanced Global Climate Change Regime. Paper presented at the Tata Energy Research Institute, New Delhi, 16 May 2002.

Myers, Norman and Jennifer Kent 1995: Environmental Exodus. An Emergent Crisis in the Global Arena. Washington, D.C.: Climate Institute.

Oberthür, Sebastian 1999: Preventing Environmentally-Induced Conflicts Through Development Policy and International Environmental Policy. In: In: Alexander Carius and Kurt M. Lietzmann (eds.): Environmental Change and Security. A European Perspective. Berlin, Heidelberg: Springer, 249-268.

Oberthür, Sebastian and Hermann E. Ott 1999: The Kyoto Protocol. International Climate Policy for the 21st century. Springer: Berlin.

Oberthür, Sebastian and Simon Marr 2002: "Das System der Erfüllungskontrolle des Kyoto-Protokolls: Ein Schritt zur wirksamen Durchsetzung im Umweltvölkerrecht." Zeitschrift für Umweltrecht, Vol. 13, No. 2, 81-89. 
OECD 2001: Helping Prevent Violent Conflict. Paris: Organisation for Economic Development and Cooperation.

OECD 2002: Working Party on Global and Structural Policies. Results of Expert Meeting and Next Steps (ENV/EPOC/GSP(2002)5 ), 22-23. April 2002. Paris: OECD, Environment Directorate/ Environment Policy Committee.

Ott, Hermann 1996: "Völkerrechtliche Aspekte der Klimarahmenkonvention", in: Hans Günter Brauch (ed.): Klimapolitik. Berlin/Heidelberg: Springer, 61-74.

Ott, Hermann E. 1998: The Kyoto Protocol. Unfinished Business. In: Environment, Vol. 40, No.6, 16-20, 41-45.

Ott, Hermann E. 2001: Climate Change: an important foreign policy issue. In: International Affairs, Vol. 77, No. 2, 277-296.

Pachauri, Rajendra 2000: Environmental Security: A Developing Country Perspective. ECSP (Meeting report). In: PECS News of the Wilson Center, Environmental Change and Security Project, Winter 2000, 2, 8.

Pazstor, Jnos and Olga Pilifosova 2002: Outcomes of COP 7 related to adaptation. Presentation prepared for the STAP Expert Group Workshop on Adaptation and Vulnerability, UNEP Headquarters, Nairobi, 18-20 February, 2002.

Sach, Karsten and Moritz Reese 2002: Das Kyoto Protokoll nach Bonn und Marrakesch. In Zeitschrift für Umweltrecht, Vol. 13, No. 2, 65-73.

Sands, Phillippe 1992: The United Nations Framework Convention on Climate Change. Review of European Community \& International Law, No. 1/1992, 270-277.

Schwartz, Daniel and Ashbindu Singh 1999: Environmental Conditions, Resources, and Conflicts: An introductory overview and data collection. Nairobi: United Nations Environment Programme.

Skodvin, Tora 2000: Revised Rules of Procedure for the IPCC Process. An Editorial Essay. In: Climatic Change, Vol. 46, No. 4, 409-415.

Spector, Bertram I. and Amanda Wolf 2000: Negotiating Security: New Goals, Changed Process. International Negotiation, Vol. 5, 411-426.

STAP 2002: STAP Expert Group Workshop on Adaptation and Vulnerability, UNEP Headquarters, Nairobi, 18-20 February, 2002.

Wolf, Aaron T. 2001: Transboundary Waters: Sharing Benefits, Lessons Learned. (Paper prepared for the International Conference on Freshwater in Bonn, 3.-7.12. 2001). Bonn: Secretariat of the International Conference on Freshwater.

Woodrow Wilson International Centre for Scholars, Environmental Change and Security Project (ECSP): Environmental Change and Security Project Report, Vol.1-7 (periodically 1995-2001).

World Commission on Environment and Devleopment 1987: Our Common Future. Oxford, New York: Oxford University Press. 
WWF 2002: Shaping the EU's International Sustainable Development Strategy. WWF's contribution to the European Commission's Communication. Brussels: WWF European Policy Office.

UNDP 1994: The Human Development Report. Oxford: Oxford University Press.

UNEP 1998: Handbook on Methods for Impact Assessment and Adaptation Strategies (prepared by Feenstra, J.F., Burton, I., Smith, J.B., and Tol, R. S.J.). Nairobi and Amsterdam: UNEP and Institute for Environmental Studies/Vrije University.

UNFCCC 1999: Compendium of Decision Tools to Evaluate Strategies for and Adaptation to Climate Change. Bonn: UNFCCC.

UNFCCC 2000: Methods and Tools to Evaluate Impacts and Adaptation: Information on Impacts and Adaptation Assessment Methods (Progress Report, Note by the Secretariat). Subsidiary Body for Scientific and Technological Advice, Twelfth Session, Bonn, 12-16 June (FCCC/SBSTA/2000/INF.4).

UN Secretary General 1998: The causes of conflict and the promotion of durable peace and sustainable development in Africa. Report of the Secretary-General. A/52/871S/1998/318.

United Nations Task Force on Environment and Human Settlement 1998: Report of the Secretary General. A/53/463. UN reform measures and proposals (section $22 \mathrm{~g}$ ) as of June 15, 1998. 


\section{About the Authors:}

Hans Günter Brauch is Senior lecturer at the Free University of Berlin and chairman of AFES-PRESS. He was guest professor at the universities of Frankfurt am Main, Leipzig and Greifswald. He has published more than thirty books and numerous research reports in English and German on security, climate, energy and Mediterranean issues. He is a consultant to national government agencies and to international organisations. He currently works on issues of crisis prevention, climate change impacts, disaster reduction, human and environmental security and weapons 2020. See (CV and activities): http://www.afes-press.de/html/brauch en.html; Email: brauch@onlinehome.de

Alexander Carius is co-founder and managing director of Adelphi Research. As an internationally recognized expert in the areas of environment, development and foreign policy, he is an advisor to numerous national and international institutions. The main fields of his research and consulting include „Sustainable Transport Policy and Mobility“, „Environment, Development and Crisis Prevention“ „Environmental Policy in Central and Eastern Europe“ as well as governance and institutions in national and international environment policy. Email: carius@adelphi-research.de

Dr. Sebastian Oberthür is Senior Associate at Ecologic, Institute for International and European Environmental Policy, and Assistant Professor at the Otto-Friedrich University of Bamberg (International Relations). His work focuses on international institutions with special emphasis on international environmental and climate policy. Sebastian Oberthür has followed the negotiating processes on international cooperation for ozone layer as well as climate protection for several years as a scientific observer and a government adviser. Email: oberthuer@ecologic.de

Dennis Tänzler is Research Fellow at Adelphi Research. His main areas of research are international environmental and developmental policy with a special focus on transatlantic climate and energy policy as well as crises and conflict prevention strategies. Email: taenzler@adelphi-research.de 
About the Institutes:

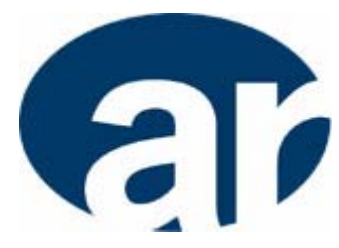

Adelphi Research

Adelphi Research is a Berlin-based non-profit organisation active in the area of sustainability science, policy analysis and public policy consulting. Adelphi Research conducts research, provides public policy consulting, initiates and moderates policy dialogues, develops research programmes and projects and fosters transboundary cooperation on sustainable resource management and environmental policy. Adelphi Research analyses and regularly reports on multilateral environmental agreements, implementation and enforcement in signatory states to various government and non-government institutions as well as on developments in European environmental policy and related policy areas. Researchers and consultants at Adelphi Research have conducted and managed almost 100 national, European and international research projects on environmental policy and related issues and have published numerous articles, study reports and books on sustainable development issues. Adelphi Research builds on a worldwide network of individual and institutional partners, experts and policy-makers dealing with environment, development, finance and foreign policy.

$\square$ http://www.adelphi-research.de

\section{A F E S S R R E S S $A G$ Friedensforschung und Europäische Sicherheitspolitik Peace Research and European Security Studies (AFES-PRESS) e.V.

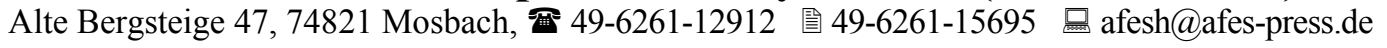

AFES-PRESS is a non-profit scientific society under German law. AFES-PRESS board members teach at universities in Berlin, Amsterdam, and Cracow. Since 1987 AFES-PRESS has conducted scientific research projects on international relations, security policy and peace research, technology assessment, on environment, energy and climate policies. AFES-PRESS has organised scientific conferences and workshops on space weapons, SDI, European security; weapons technologies, military doctrine, verification and arms control, military research and development and disarmament, confidence building and partnership, and on security and environment in the Mediterranean. AFES-PRESS published books and its AFES-PRESS Reports. Its members support international scientific cooperation and promote young scientists. Its activities have been funded by UNESCO, World Bank, UNEP, European Commission, European Parliament, German Research Society (DFG), Berghof Foundation on Conflict Research, TAB (German Parliament), Federal Environmental Agency and Federal Ministry for the Environment, Nature Conservation and Nuclear Safety. $\square$ http://www.afes-press.de

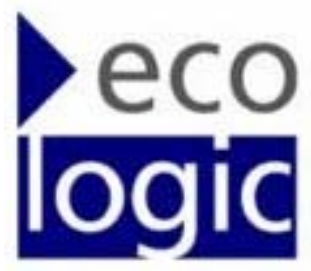

\section{Ecologic}

Ecologic is a not-for-profit institution for applied environmental research and policy consultancy, seated in Berlin. Ecologic conducts implementation-focused research projects and prepares expert opinions on a range of issues relating to nature conservation and environmental protection. These include new approaches in environmental policy, ecologically sustainable resource policy, international environmental agreements and institutions, environmental planning and the integration of environmental concerns into other policy realms. Ecologic's work focuses in particular on analyzing the environmental policy of the European Union and its member states and enhancing the effectiveness of international environmental regimes. Ecologic is part of the network of Institutes for European Environmental Policy with offices in a number of principal European cities, and is part of numerous other issue-focused and project-related international networks. Ecologic works primarily for international and supranational organizations, parliaments, governments, national agencies and local authorities, industry federations, trade unions, and environmental or conservation NGOs. Ecologic pursues exclusively academic and non-profit aims. It is an economically and academically independent, non-partisan institute. $\square$ http://www.ecologic.de 

Published by:

The Federal Ministry for the Environment, Nature Conservation and Nuclear Safety

Public Relations Division

Alexanderplatz 6

10178 Berlin

Germany

www.bmu.de

Email: service@bmu.bund.de

This publication forms part of the information activities of Germany's Federal Government.

It is available free of change and is not to be sold. Printed on paper composed entirely of recycled materials.

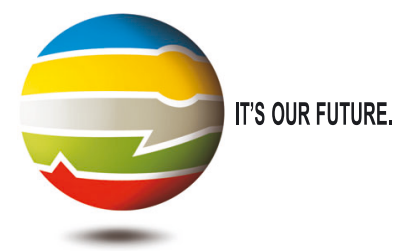

